Tatiana de Cássia Coutinho Silva da Fonseca

\title{
REFORÇO DE LIGAÇÕES VIGA-PILAR DE ESTRUTURAS DE CONCRETO PRÉ-MOLDADO PELA COLAGEM DE LAMINADOS DE POLÍMERO REFORÇADO COM FIBRA DE CARBONO (PRFC) EM ENTALHES NO CONCRETO DE COBRIMENTO
}

Tese apresentada à Escola de Engenharia de São Carlos da Universidade de São Paulo como parte dos requisitos para obtenção do Título de Doutora em Engenharia Civil (Engenharia de Estruturas).

Orientador: Prof. João Bento de Hanai

\author{
VERSÃO CORRIGIDA \\ A versão original encontra-se na Escola de Engenharia de São Carlos \\ São Carlos \\ 2012
}


AUTORIZO A REPRODUÇÃO TOTAL OU PARCIAL DESTE TRABALHO, POR QUALQUER MEIO CONVENCIONAL OU ELETRÔNICO, PARA FINS DE ESTUDO E PESQUISA, DESDE QUE CITADA A FONTE.

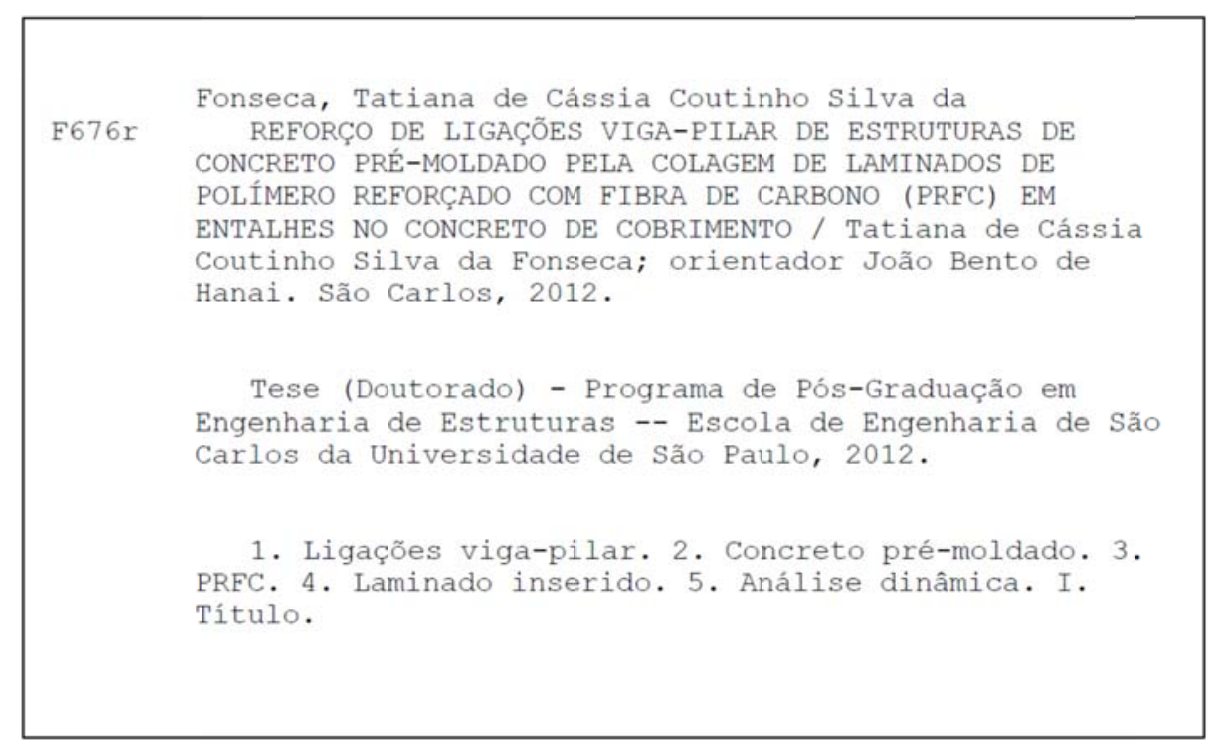


Candidata:

Engenheira TATIANA DE CÁSSIA COUTINHO SILVA DA FONSECA.

Título da tese: "Reforço de ligações viga-pilar de estruturas de concreto prémoldado pela colagem de laminados de polímeros reforçado com fibra de carbono (PRFC) em entalhes no concreto de cobrimento".

Data da defesa: 07/02/2013

Comissão Julgadora:

Prof. Titular João Bento de Hanai (Orientador)

(Escola de Engenharia de São Carlos/EESC)

Prof. Titular Mounir Khalil El Debs

(Escola de Engenharia de São Carlos/EESC)

Prof. Dr. Ricardo Carrazedo

(Escola de Engenharia de São Carlos/EESC)

Prof. Dr. Marcelo de Araújo Ferreira

(Universidade Federal de São Carlos/UFSCar)

Prof. Dr. João Carlos Della Bella

(Escola Politécnica/USP)
Resultado:

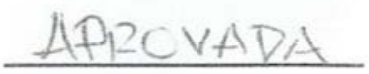

APnoVADA

APROVADA

ATROVAOA

APROVADA

Coordenador do Programa de Pós-Graduação em Engenharia Civil (Engenharia de Estruturas):

Profa. Associada Ana Lucia Homce de Cresce El Debs

Presidente da Comissão de Pós-Graduação:

Prof. Titular Denis Vinicius Coury 

A meu tio (incentivador) Dariel que tão logo ingressei na pós-graduação me chamava "Mestre" e quando nem existia uma linha deste texto antecipava:

"Doutora". Gostaria imensamente de te ouvir me chamar "Doutora Tatiana" com propriedade ... muito embora o mais certo é que, se estivesse aqui, inventaria logo um título mais alto e me faria crer que eu era digna dele. Saudades! 



\section{AGRADECIMENTO}

A Deus, que sempre torna mais leve e fácil mesmo o que acreditamos estar acima das nossas forças.

Aos meus pais Ronaldo e Olívia, que respeito, amo e a quem devo toda e qualquer conquista. Aos meus irmãos Priscila, Tamara, Eduardo e Ana Fábia que sempre me apoiam de forma irrestrita e de que tanto me orgulho. Um dia vou ser grande como eles. Aos meus tios e tias que, primos e primas cujo auxílio esteve sempre a meu dispor. Aos pequenos que me inspiram Mary, Thiago, Dudu, Chiquinho, Vitória e Dariel. A meu marido, amigo, companheiro e revisor nas horas vagas, Rodrigo, que compartilhou comigo tantos fins de semana ensolarados, trancado em um apartamento, solidário em um dever que era só meu.

Ao meu Orientador, João Bento de Hanai. Foi uma grande honra ter um pedaço da minha história ligada à dele e foi uma sorte poder contar com sua paciência e sabedoria.

Aos professores do Departamento de Engenharia de Estruturas, em especial aos professores Mounir Khalil El Debs, Vladimir Haach e Ricardo Carrazedo.

Aos professores da Universidade Federal da Bahia Mário Mendonça, Mônica da Guarda, Inês Rezende e Tatiana Dumet.

Aos funcionários do SET, especialmente ao Fagá, ao $\mathrm{Eng}^{\circ}$ Dr. Luiz Vareda e demais colaboradores do Laboratório de Estruturas: Amaury, Fabiano, Mário, Mauri, Romeu e Valdir.

Às amigas queridas e companheiras do início da jornada Fernanda Calmon e Marta Paes.

À Sandra Almeida colega e amiga que dividiu comigo o peso do programa experimental e também bons momentos nessa nossa jornada em São Carlos e agora em São Paulo.

Aos amigos do departamento que vão ficar guardados nas minhas lembranças, em especial a Hidelbrando Diógenes, Jeferson Lins, Jesus Daniel, Jesus Garcia, Luis Álvaro e Saulo Almeida.

Aos amigos da R4h e R2B com quem vivi os momentos mais divertidos da minha vida.

Aos colegas de trabalho e à minha coordenadora Audrey sempre compreensiva quando precisei de tempo para dedicar à tese.

Ao CNPq que me concedeu bolsa no início do doutorado.

À FAPESP que disponibilizou recursos importantes para a execução deste trabalho, tanto por meio da bolsa de doutorado quanto pelo financiamento do projeto temático "Nucleação $e$ incremento da pesquisa, inovação e difusão em concreto pré-moldado e estruturas mistas para a modernização da Construção Civil”. 



\section{RESUMO}

FONSECA, T. C. C. S. Reforço de ligações viga-pilar de estruturas de concreto prémoldado pela colagem de laminados de polímero reforçado com fibra de carbono (PRFC) em entalhes no concreto de cobrimento. 2012. Tese (Doutorado) - Escola de Engenharia de São Carlos, Universidade de São Paulo, São Carlos, 2012.

Buscou-se por meio desta pesquisa avaliar a eficiência do reforço de ligações viga-pilar em estruturas de concreto pré-moldado. A técnica de reforço utilizada consiste na colagem de laminados de Polímero Reforçado com Fibra de Carbono (PRFC) em entalhes no concreto de cobrimento. Trata-se de uma técnica desenvolvida há cerca de dez anos, que apresentou, em pesquisas, desempenho superior às alternativas de colagem externa de mantas e laminados no tocante a reforço à flexão. Nenhuma referência ao uso desta ou de qualquer outra técnica para o reforço de ligações viga-pilar de estruturas pré-moldadas foi encontrada na pesquisa bibliográfica realizada. Entretanto, considera-se importante que esta opção seja apreciada ao se verificar comportamento insatisfatório de uma estrutura, haja vista a importância das ligações em seu desempenho global. Dado o caráter da pesquisa e o ineditismo da proposta, realizou-se um estudo experimental diversificado. Um ensaio piloto em modelo reduzido de pórtico com elementos de pilar e viga pré-moldados foi realizado. Por meio deste ensaio, verificou-se que o reforço promoveu significativa redução no deslocamento vertical da viga. Embora os resultados tenham sido promissores, destaca-se que o modelo reduzido impôs limitações, em relação ao comprimento para colagem do laminado e à distância do laminado ao canto da viga, que contribuíram para o seu arrancamento prematuro em uma das ligações. Realizou-se um ensaio em um modelo de ligação em escala real reforçado a momento fletor negativo e positivo. Em relação ao momento negativo, se alcançou um aumento de cerca de $100 \%$ na rigidez do modelo. Realizaram-se ensaios experimentais estáticos e dinâmicos em três modelos de pórtico cuja viga tinha escala real. Os resultados destes ensaios comprovaram a eficiência do reforço das ligações no aumento da sua rigidez, da frequência natural do pórtico e da resistência da estrutura. Observou-se também que o reforço promoveu redução da solicitação das armaduras principais da ligação. A simulação numérica dos ensaios dinâmicos permitiu a determinação indireta da rigidez das ligações de modo satisfatório e subsidiou a adoção de apoios elásticos na simulação dos ensaios estáticos que permitiram expandir a análise dos resultados experimentais em relação à fissuração e à distribuição de tensões. Por meio desta pesquisa comprovou-se a possibilidade de emprego da técnica de reforço proposta para a reabilitação de estruturas com deficiência relacionadas ao estado limite ultimo, já que o aumento de resistência foi alcançado, e também relacionadas aos estados limites de serviço, uma vez que as estruturas reforçadas apresentaram menores deslocamentos verticais e maiores frequências naturais. Destaca-se ainda uso eficiente da experimentação dinâmica que se prestou não somente à obtenção dos parâmetros modais da estrutura, mas também a uma avaliação realista das condições de contorno dos ensaios estáticos.

Palavras-chave: Ligações viga-pilar. Concreto pré-moldado. Polímero reforçado com fibra de carbono. PRFC. Reforço estrutural. Laminado inserido.Diana. Análise dinâmica. 

ABSTRACT

\section{FONSECA, T. C. C. S. Strengthening of beam-to-column connections in precast concrete structures by NSM CFRP strips. 2012.}

In this research, the strengthening of beam-to-column connections in precast concrete structures is evaluated. The strengthening technique used is internationally known as NearSurface-Mounted and involves the bonding of CFRP (Carbon Fiber Reinforced Polymer) strips into slits made in concrete cover. There are no references about the use of this or any else technique in the strengthening of connections in precast structures however it could be an option when the structure presents an unsatisfactory behavior. Because of the innovative characteristic of the purpose, experimental tests are required. A pilot test was performed in a frame with reduced dimensions. The frame had initially pinned connections that were strengthened. The strengthening provided a reduction in the beam deflection and the recovery of the initial stiffness of the frame. Although the promising results, the frame dimensions imposed limitations in relation to the strips bonding length and to the distance to the beam edge that contributed to the premature failure by splitting of strips and concrete. It was also performed a test in a strengthened semi-rigid connection. An increase in the connection stiffness was observed. Experimental static and dynamic tests were performed on three real scaled frame models. The results of these tests demonstrated the effectiveness of the strengthening in the increasing of stiffness, natural frequency and strength of the frame. It was also observed that the strengthening reduced the reinforcement strain. The numerical simulation of the dynamic tests allowed the indirect determination of the connections stiffness and supported the definition of boundary conditions in the simulation of the static tests that allowed a better understanding in relation to cracking and stress distribution. Through this research it was confirmed that the strengthening technique proposed is useful for rehabilitation of structures with disabilities related to ultimate limit state, since the increase in resistance was achieved, and also related to the serviceability limit states, since strengthened structures presented lower vertical displacements and higher natural frequencies. It is highlighted that the dynamic tests were important not only to obtain the modal parameters of the structure, but also to evaluate the real boundary conditions of the static tests.

Key-words: Beam-to-column connection. Precast structures. NSM. CFRP. Connection strengthening. DIANA. Dynamic analysis. 



\section{SUMÁRIO}

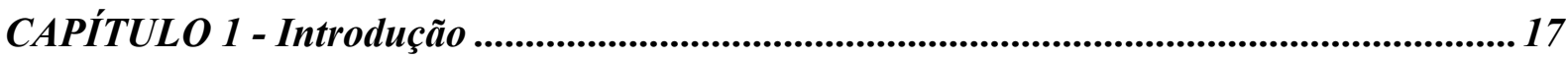

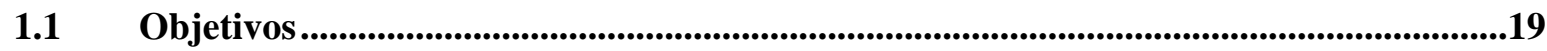

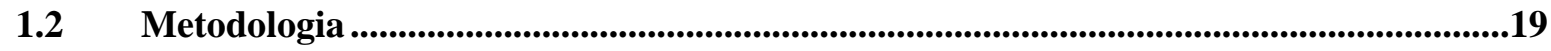

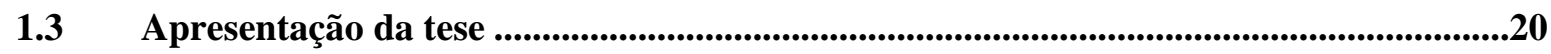

CAPÍTULO 2 - Reforço por colagem de barras e laminados de PRF em entalhes............... 23

CAPÍTULO 3 - Estruturas de concreto pré-moldado ..........................................................35

CAPÍTULO 4 - Ensaios de aderência.........................................................................45

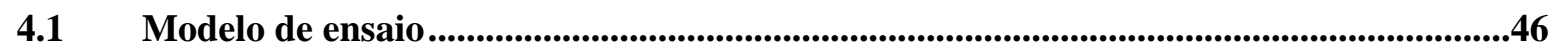

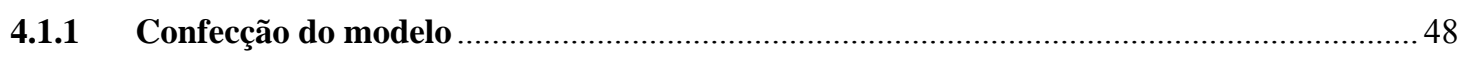

$4.2 \quad$ Propriedades dos materiais....................................................................................................50

4.3 Configuração e instrumentação dos ensaios.......................................................................51

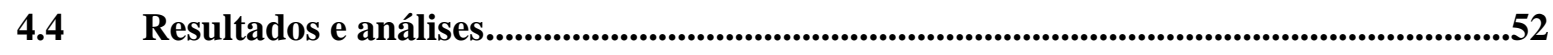

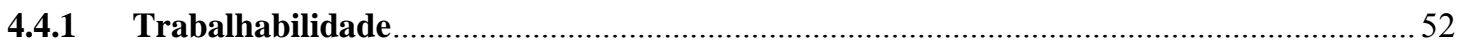

4.4.2 Ruptura

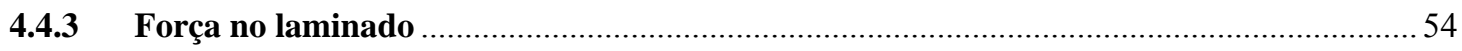

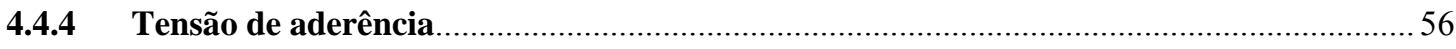

4.4.5 Variações com o comprimento aderido e comparações …………………………………....57

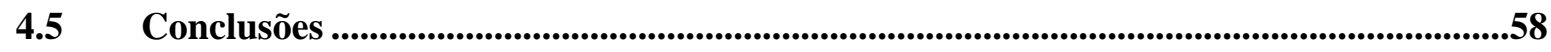

CAPÍTULO 5 - Ensaio em modelos de ligação semirrígida reforçada .............................. 61

Características dos modelos .....................................................................................................61

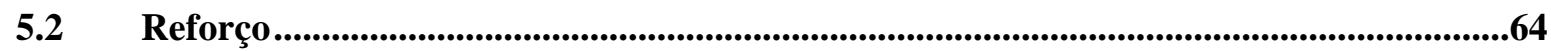




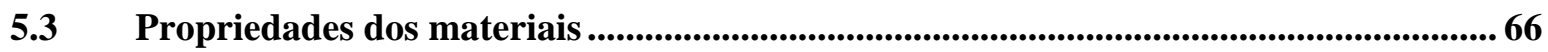

5.4 Instrumentação e configuração do ensaio estático ............................................................... 67

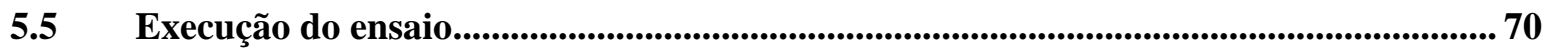

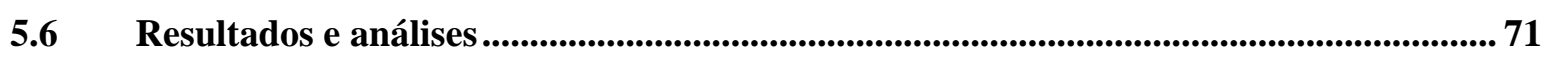

5.6.1 Ruptura

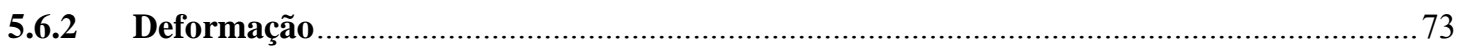

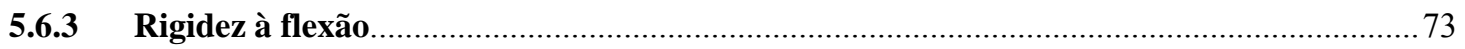

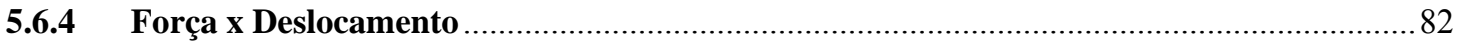

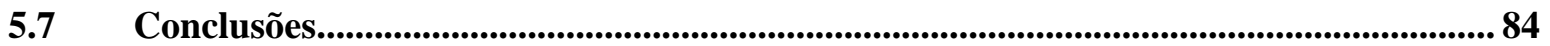

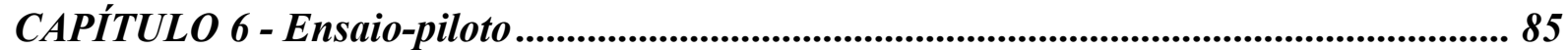

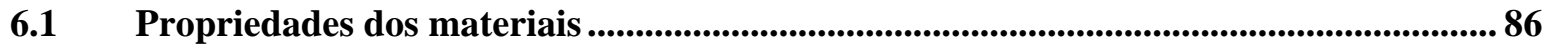

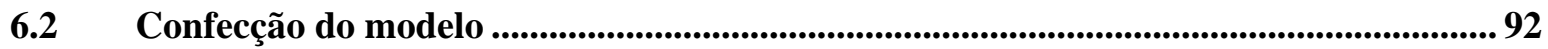

6.3 Instrumentação e configuração do ensaio estático ................................................................ 94

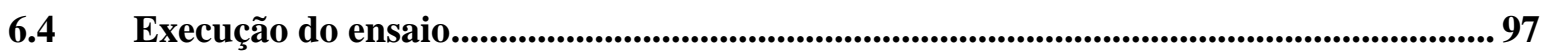

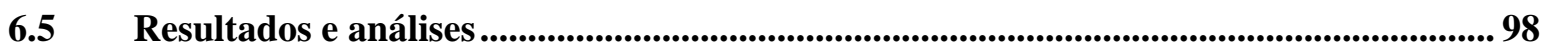

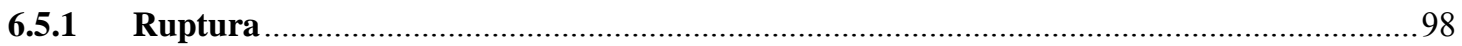

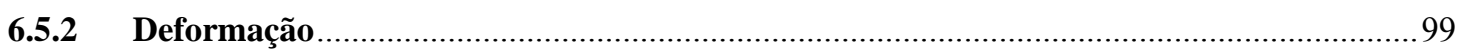

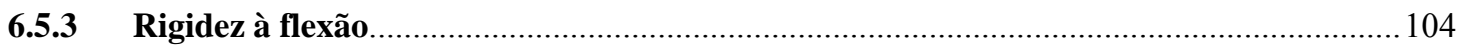

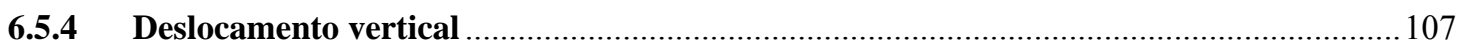

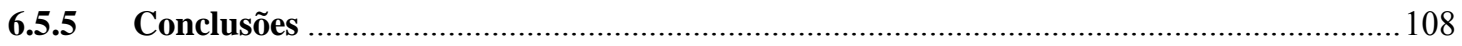

6.6 Simulação numérica com base nos resultados do Ensaio-Piloto ....................................... 109

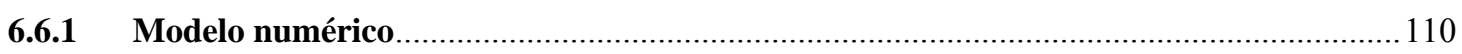

6.6.2 Elementos finitos …………………………………………………………………111

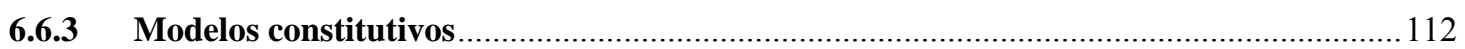

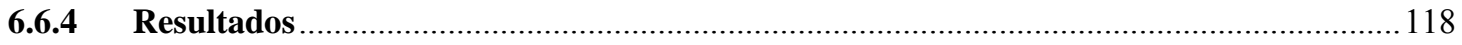

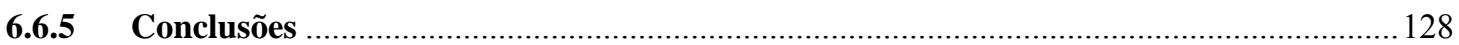

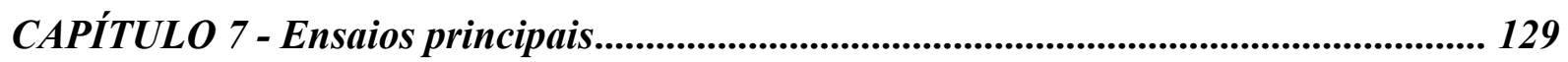

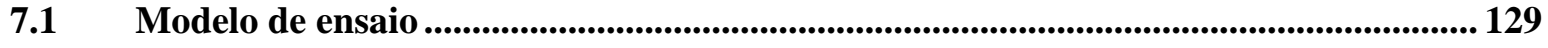


$7.2 \quad$ Propriedades dos materiais...............................................................................................133

Confecção do modelo ...............................................................................................................138

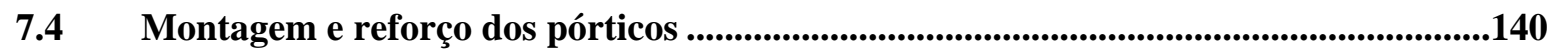

7.5 Instrumentação e configuração do ensaio estático.....................................................142

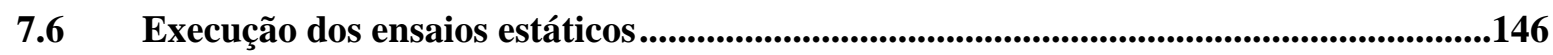

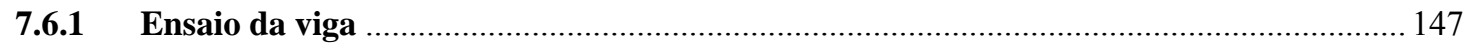

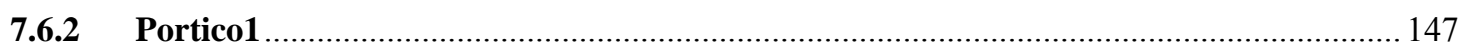

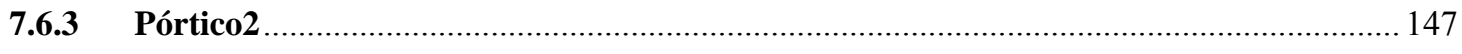

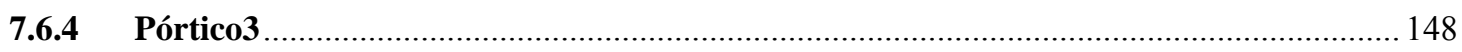

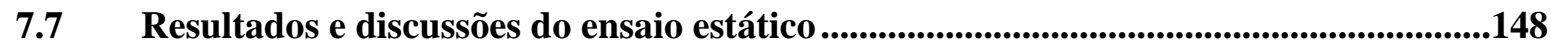

7.7.1 Fissuração e ruptura .................................................................................................. 148

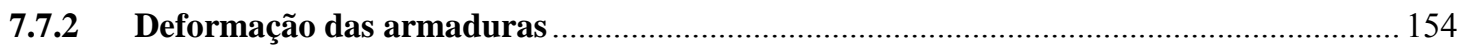

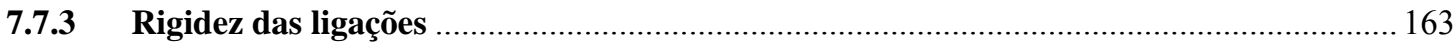

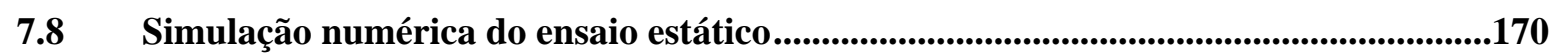

7.9 Execução do ensaio dinâmico....................................................................................................193

7.10 Resultados e discussões do ensaio dinâmico ....................................................................196

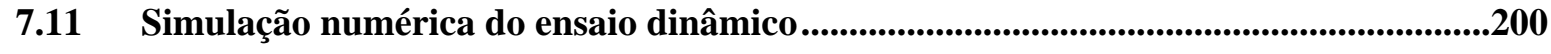

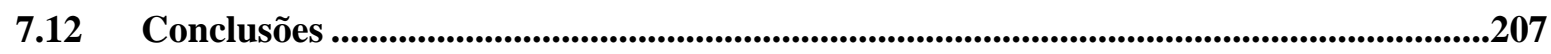

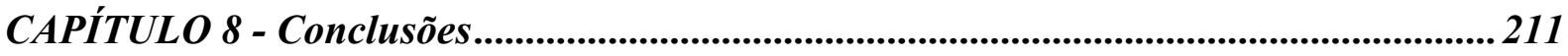

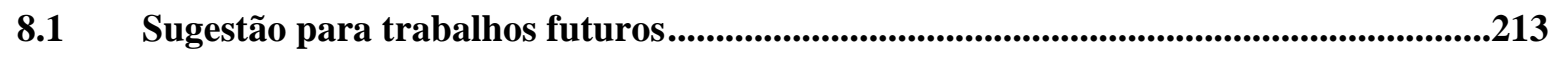

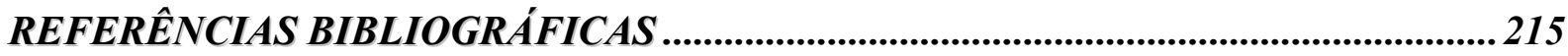





\section{CAPÍTULO 1}

\section{INTRODUÇÃO}

Erros de projeto ou execução, danos acidentais, utilização indevida dentre outros fatores podem resultar em comportamento estrutural inadequado e conduzir à necessidade de intervenções para reabilitação ou reforço estrutural. Estruturas de concreto pré-moldado estão, em geral, menos sujeitas a erros de execução, como mau posicionamento de armaduras, inobservância de cobrimento e resistência do concreto inferior à especificada, devido ao maior controle de qualidade na produção das peças. Restam, contudo, vários fatores que podem suscitar patologias como vibração, flechas e deslocamentos laterais excessivos.

Em estruturas de concreto armado, monolíticas ou pré-moldadas, a reabilitação, quando necessária, é geralmente empregada nos elementos de viga e pilar que a compõem. Certamente, para a maioria dos casos é o procedimento mais prático a adotar. Entretanto, se a questão a ser corrigida está relacionada ao comportamento global da estrutura, o reforço das ligações entre vigas e pilares deve ser considerado, sobretudo, para estrutura de concreto prémoldado em que o desempenho das ligações tem extrema importância.

Marin e El Debs (2009) afirmam que "a estabilidade global de estruturas de concreto pré-moldado de múltiplos pavimentos pode ser obtida pelo enrijecimento das ligações vigapilar ou pela utilização de elementos ou sistemas de contraventamento.”. 
As ligações são responsáveis pela transferência de esforços e pela estabilidade na fase de montagem e de utilização da estrutura. Conforme destaca o CEB-FIP (1990), a ligação deve ser capaz de acomodar deslocamentos relativos necessários à mobilização de resistência da ligação, resistir a todas as ações resultantes da análise da estrutura como um todo, bem como da análise dos membros individualmente, ter resistência e deformabilidade que assegurem a estabilidade da estrutura como um todo.

$\mathrm{Na}$ presente pesquisa, avalia-se uma alternativa de reabilitação das ligações que apresentem deficiência em alguma dessas funções ou uma opção para melhorar o desempenho global da estrutura. O trabalho desenvolvido por esta pesquisadora no seu programa de mestrado (FONSECA, 2007) representou apenas um primeiro passo em direção à validação de uma nova técnica de reforço. Nenhuma outra investigação sobre o reforço de ligações vigapilar é encontrada na bibliografia técnica e são raras as referências sobre o reforço de outros tipos de ligações de estruturas pré-moldadas. Obviamente, diante do ineditismo da proposta, muitas questões a ela correlatas requerem maior aprofundamento e várias outras, que sequer foram abordadas, necessitam de respostas antes que se possa apontar a técnica de reforço como solução segura e eficiente para eventuais problemas em estruturas reais. O avanço na compreensão dos efeitos do reforço no comportamento da ligação bem como no comportamento global da estrutura é o objetivo geral que se pretende alcançar.

O SET conta com um histórico de desenvolvimento de pesquisas no tema de estruturas pré-moldadas, iniciado por Ballarin (1993) e Ferreira (1993). Seguiram-se a estes trabalhos Soares (1998), Ferreira (1999), Barboza (2001), Miotto (2002), Canha (2004), Ebeling (2006), Baldissera (2006), Siqueira (2007), David (2007), Fonseca (2007), Silva (2008) e Farias (2008). O estudo das ligações de estruturas de concreto pré-moldado foi um dos enfoques do Projeto Temático apoiado pela FAPESP intitulado "Nucleação e incremento da pesquisa, inovação e difusão em concreto pré-moldado e estruturas mistas para a 
modernização da Construção Civil”, no qual se insere o presente trabalho, bem como os sete últimos listados. Além do perfeito enquadramento da pesquisa no Projeto Temático destaca-se a sua relação com uma importante linha de pesquisa que vem se desenvolvendo no Departamento de Estruturas que é a Análise Dinâmica Experimental. O emprego das técnicas de detecção da rigidez da ligação por meio da análise modal faz parte da metodologia empregada na pesquisa.

\subsection{Objetivos}

O objetivo geral é avançar na compreensão dos efeitos da técnica de reforço com laminado de PRFC inserido no comportamento da ligação bem como no comportamento global da estrutura. Os objetivos específicos são:

- Avaliar a adequação de determinadas resinas na colagem dos laminados em entalhes no concreto de cobrimento;

- Compreender os mecanismos de ruptura das ligações reforçadas;

- Aplicar as técnicas de detecção da rigidez da ligação por meio de ensaios experimentais dinâmicos;

- Desenvolver um modelo numérico representativo da ligação estudada.

\subsection{Metodologia}

A metodologia da pesquisa prevê análises experimentais e simulações numéricas fundamentadas na bibliografia existente.

A seguir descreve-se de modo sucinto a metodologia a ser empregada:

- Elaboração de síntese bibliográfica sobre os assuntos relacionados ao tema;

- Realização de ensaio experimental em modelo-piloto;

- Modelagem numérica alimentada pelos resultados do ensaio em modelo-piloto; 
- Idealização e confecção dos modelos de ensaio definitivos;

- Realização de ensaios em elementos isolados (viga e pilar) usados como referência para a análise dos modelos definitivos;

- Realização de ensaios experimentais dinâmicos e estáticos nos modelos definitivos;

- Modelagem numérica alimentada pelos resultados dos ensaios nos modelos definitivos;

- Analise dos resultados e elaboração de conclusões.

\subsection{Apresentação da tese}

O conteúdo deste documento está organizado nos Capítulos de 1 a 8 . O Capítulo 1 é introdutório. Os Capítulos 2 e 3 se dedicam apresentação da revisão bibliográfica. Nos Capítulos 4, 5 e 6 são descritos os ensaios de aderência, ensaio em um modelo de ligação semirrígida e Ensaio-Piloto, respectivamente. O sétimo capítulo é dedicado aos ensaios dos modelos principais. No oitavo capítulo sintetizam-se as conclusões da pesquisa. A finalidade de cada capítulo é apresentada com mais detalhes a seguir.

Capítulo 1 - Introdução: apresenta os aspectos gerais do trabalho, justificativa da pesquisa, delimitação dos objetivos e metodologia resumida.

Capítulo 2 - Reforço por inserção de barras e laminados de PRF em entalhes: apresenta revisão bibliográfica sobre a técnica de reforço por colagem de barras e laminados de PRF em entalhes.

Capítulo 3 - Estruturas de concreto pré-moldado: apresenta aspectos gerais a respeito das ligações de estruturas de concreto pré-moldado. Enfoca os limites classificatórios quanto à rigidez e à resistência. Detalha pesquisas experimentais que serviram de base para elaboração dos ensaios realizados por esta pesquisadora. 
Capítulo 4 - Ensaios de aderência: descrição dos ensaios de aderência. Apresentação dos resultados, análises e conclusões parciais.

Capítulo 5 - Ensaio em modelo de ligação semirrígida reforçada: descrição do ensaio em modelo cruciforme de ligação. Apresentação dos resultados, análises e conclusões parciais.

Capítulo 6 - Ensaio-piloto: descrição do ensaio experimental de um modelo de pórtico em escala reduzida e da sua simulação numérica. Apresentação dos resultados, análises e conclusões parciais.

Capítulo 7 - Ensaios Principais: descrição do estudo experimental e numérico computacional de pórticos com ligações articuladas e reforçadas. Apresentação dos resultados, análises e conclusões parciais.

Capítulo 8 - Conclusões: síntese das principais conclusões que foram alcançadas na pesquisa. 


\section{CAPÍTULO 2}

\section{REFORÇO POR COLAGEM DE BARRAS E LAMINADOS DE PRF EM ENTALHES}

Em Blaschko e Zilch (1999) apresenta-se uma das primeiras investigações acerca da colagem de laminados de Polímeros Reforçados com Fibras (PRF) em entalhes no concreto de cobrimento que é atualmente conhecida por NSM (Near Surface Mounted). Blaschko e Zilch (1999) concluem, por meio da análise de ensaios experimentais de arrancamento e de flexão em vigas reforçadas pelo método de colagem externa e em entalhes, que a técnica NSM apresenta maior eficiência em relação à capacidade de ancoragem, ao aproveitamento da resistência do reforço e à ductilidade do elemento reforçado. A técnica tem ainda por vantagens: execução mais simples, maior facilidade de ancoragem em membros adjacentes ao elemento reforçado, maior facilidade de pré-tensionamento, proteção pelo concreto de cobrimento e consequentemente menor exposição a danos mecânicos, impactos acidentais, fogo e vandalismo e a não interferência em aspectos estéticos das estruturas (DE LORENZIS; TENG, 2007).

A execução do reforço pode ser resumida nas seguintes etapas:

- Realização de entalhe na face a ser reforçada com uso de serra de corte;

- Limpeza do entalhe com jato de ar;

- Limpeza do laminado com solvente apropriado; 
- Aplicação de adesivo no laminado;

- Aplicação de adesivo no entalhe;

- Introdução do laminado no entalhe.

O ACI 440.2R-08 (2008) apresenta prescrições específicas para o reforço por colagem de barras e laminados de PRF em entalhes.

Os modos de ruptura de vigas reforçadas por colagem de laminados em entalhes podem divididos em:

- Clássicos, nos quais a ação conjunta entre reforço e viga é mantida praticamente até a ruptura. Podem se caracterizar por: esmagamento do concreto; deformação excessiva da armadura de tração; ruptura do reforço; ruptura por cisalhamento.

- Prematuros, nos quais ocorre a perda da ação conjunta entre reforço e viga.

De Lorenzis e Teng (2006) classificam os modos de ruptura prematura em:

1. Ruptura na interface barra-epóxi: envolve o descolamento do reforço na interface barra-epóxi (Figura 2.1-a);

2. Destacamento do concreto de cobrimento: fissuras de aderência se propagam a $45^{\circ}$ da face da viga até atingir o nível da armadura longitudinal e passa a se propagar horizontalmente. A ruptura pode apresentar as seguintes configurações:

- Destacamento do cobrimento na seção da extremidade da barra: quando a extremidade final do reforço se encontra distante do apoio (Figura 2.1-b);

- Destacamento local do cobrimento: fissuras de aderência juntamente com fissuras de flexão e de flexão e cisalhamento combinados podem isolar cunhas de concreto triangulares ou trapezoidais, que são eventualmente destacadas da viga (Figura 2.1-c); 
- Destacamento do cobrimento induzido por fissuras de flexão: fissuras de flexão induzem o destacamento da camada de concreto de cobrimento. Esse destacamento se dá ao longo de grande porção da região reforçada da viga (Figura 2.1-d);

- Destacamento do cobrimento ao longo do canto da viga: relacionado ao posicionamento do reforço próximo ao canto da viga (Figura 2.1-e).

3. Ruptura na interface concreto-epóxi: para vigas reforçadas com limitado comprimento de reforço, observa-se a ocorrência de ruptura coesiva por cisalhamento na interface concreto-epóxi, iniciada na extremidade do reforço;

4. Mecanismos secundários de descolamento: outros mecanismos que relacionados ao descolamento prematuro do reforço não se enquadram nas descrições anteriores (Figura 2.1-f e Figura 2.1-g).

A ruptura do reforço foi observada nos ensaios cíclicos em pilares reforçados à flexão descritos em Barros; Ferreira e Lourenço (2000) e em Barros et al (2001). Nos trabalhos de Barros; Ferreira e Lourenço (2000) e Barros et al (2001), comprovou-se o aumento na capacidade resistente do pilar à flexão em cerca de $100 \%$ e que este aumento é mais significativo para pilares com menores taxas de armadura longitudinal.

O acréscimo na resistência original da ordem de 100\% foi também obtido por Fortes (2004) no reforço de vigas à flexão mobilizando uma deformação no laminado de $91 \%$ da deformação na ruptura do material. Houve acréscimo de rigidez de aproximadamente 39\% para a carga de serviço e de $47 \%$ para uma carga de $90 \%$ da carga última da viga de referência. 


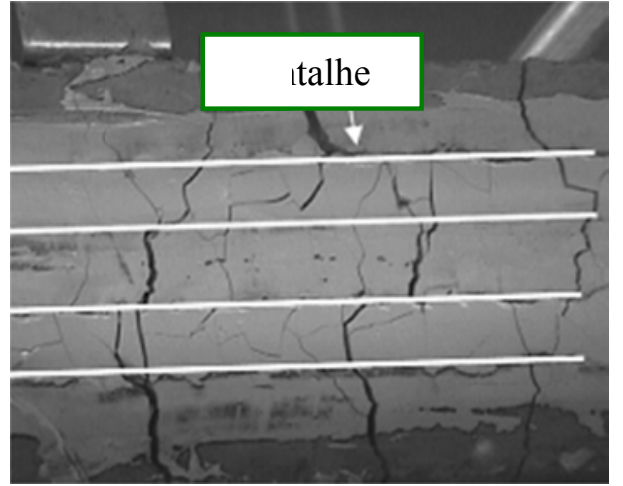

(a)

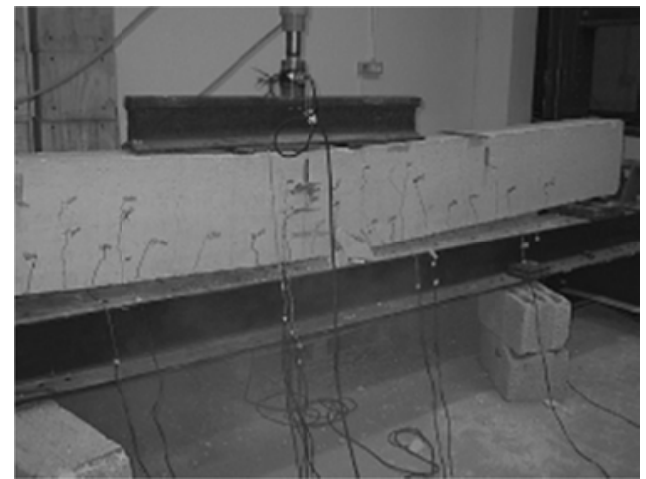

(c)

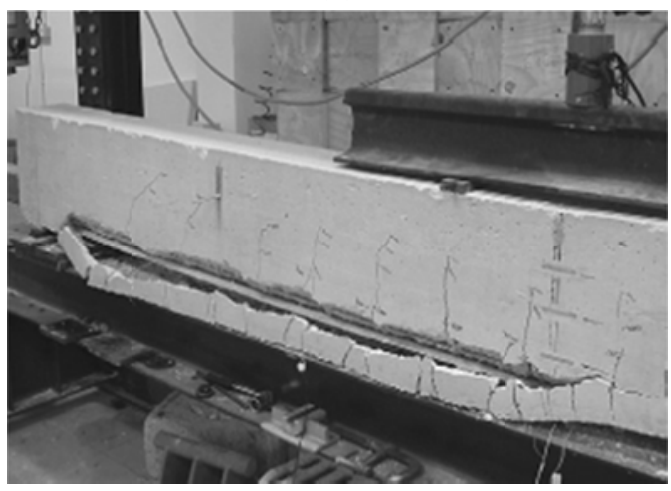

(e)

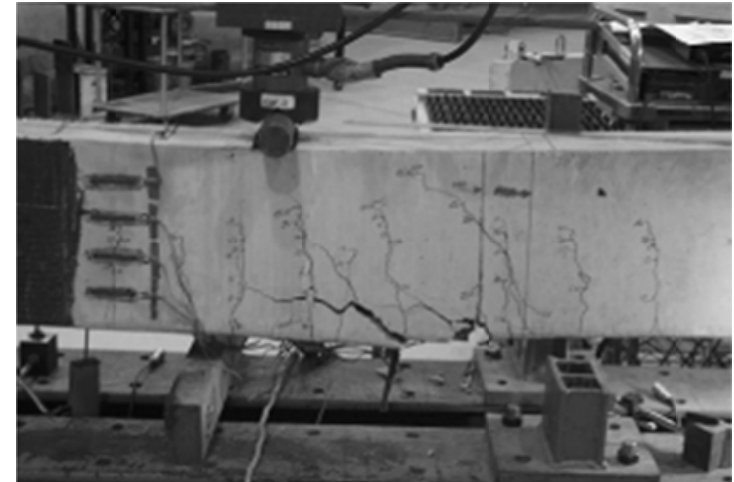

(b)

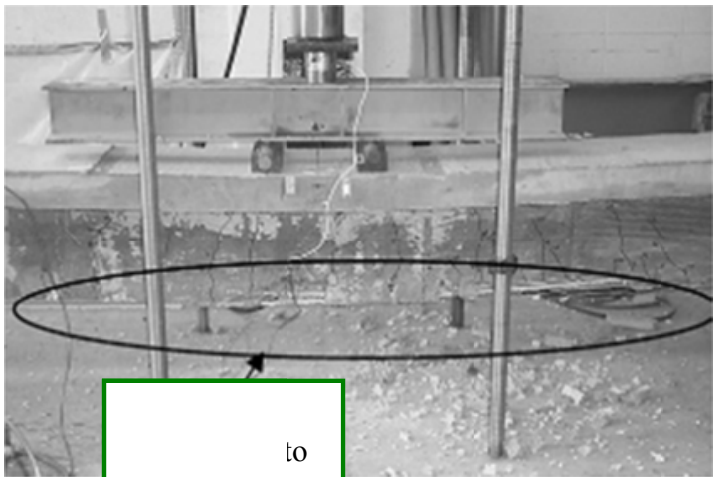

(d)

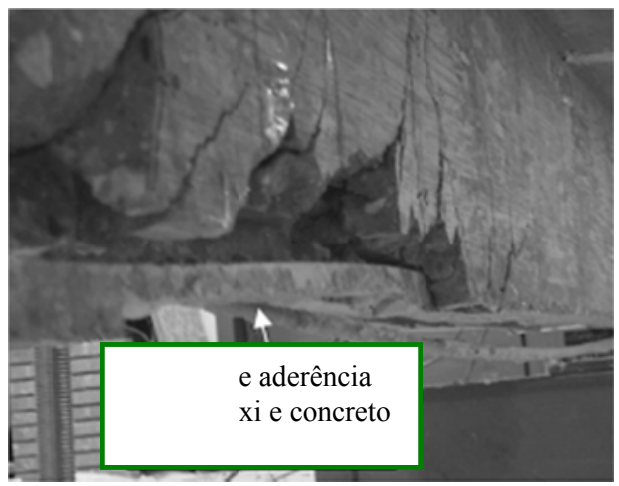

(f)

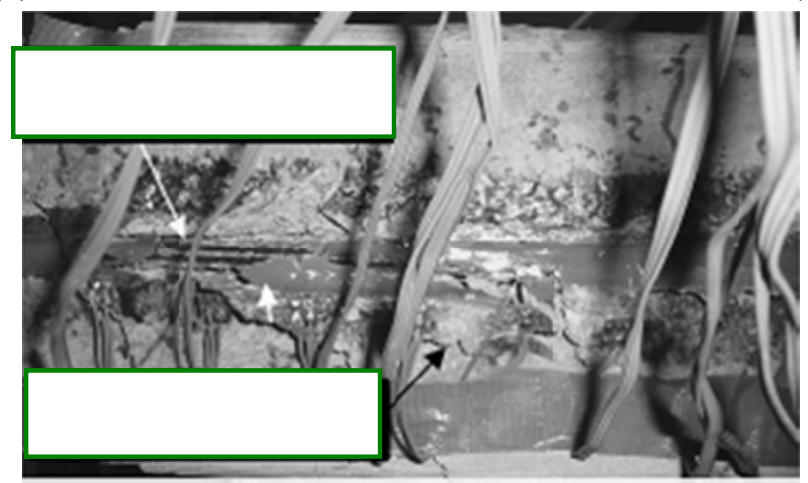

(g)

Figura 2.1 - (a) Perda de aderência na interface barra-epóxi; (b), (c) e (d) destacamento do concreto de cobrimento iniciado na extremidade do reforço, entre duas fissuras na região de momento máximo e ao longo de uma grande parte do comprimento da viga, respectivamente; (e) Destacamento de concreto ao longo do canto da viga; (f) e (g) mecanismos secundários de descolamento (figuras adaptadas de De Lorenzis e Teng (2006) ). 
Castro (2005) apresenta um estudo comparativo entre o reforço de vigas pela colagem externa de mantas de PRFC e o reforço pela colagem de tipos diversos de barras (laminados de PRFC e barras com seção circular de aço, PRFC e polímero reforçado com fibra de vidro). A taxa de armadura também foi um parâmetro avaliado. Castro (2005) conclui que a colagem do reforço em entalhe no concreto é mais eficiente que a colagem externa para as menores taxas de armadura convencional e que a inserção de barras de aço é menos eficiente que a de outros materiais.

Kang et al. (2005) avaliam a eficiência da técnica NSM no reforço à flexão de vigas por meio de um estudo paramétrico, tendo como variáveis a profundidade do entalhe e a disposição dos laminados de PRFC. O estudo foi realizado com utilização de modelo numérico baseado no Método dos Elementos Finitos. Para calibração do modelo, foram realizados ensaios experimentais de flexão a quatro pontos em vigas com quatro diferentes configurações de reforço (variação da quantidade e do posicionamento dos laminados) e em uma viga não reforçada.

Observou-se acréscimo de $40 \%$ a $95 \%$ na carga de ruptura para as vigas reforçadas. O percentual de acréscimo foi diferente para modelos com mesma área de reforço. Fundamentados nisso, Kang et al. (2005) concluem que a eficiência do reforço varia com a disposição dos laminados.

Atestada a precisão do modelo numérico, Kang et al. (2005) procederam análise paramétrica dividida em dois casos: reforço com um laminado e reforço com dois laminados. Para o primeiro caso, variou-se a profundidade do entalhe de $5 \mathrm{~mm}$ a $35 \mathrm{~mm}$ com incremento de $5 \mathrm{~mm}$. Para o segundo caso, variações na profundidade do entalhe e na disposição dos laminados foram consideradas simultaneamente. Para entalhes de profundidade de $15 \mathrm{~mm}$ e $25 \mathrm{~mm}$, variou-se o espaçamento entre os laminados de $20 \mathrm{~mm}$ a $180 \mathrm{~mm}$. 
Os resultados do primeiro caso em estudo revelam que a eficiência do reforço não é diretamente proporcional à profundidade do entalhe ou à área de PRFC. Existe uma profundidade ótima de entalhe que maximiza a eficiência do reforço.

Com base nos resultados do segundo caso da análise, Kang et al. (2005) afirmam que, na definição de uma disposição ótima, deve-se garantir uma distância mínima entre os laminados de forma que eles trabalhem independentemente (Figura 2.2). Deve-se, ao mesmo tempo, garantir um espaçamento mínimo do reforço em relação às faces laterais da viga, uma vez que, nas proximidades dos cantos de concreto, o laminado não desenvolve capacidade aderente, além de essa situação favorecer ao arrancamento do canto de concreto. Kang et al. (2005) recomendam que o espaçamento entre laminados e a distância do reforço ao canto da viga sejam sempre superiores a $40 \mathrm{~mm}$. A prescrição de Kang et al. (2005) para distância do reforço ao canto é superior á sugestão de Blaschko (2003) que é de uma distância mínima de $30 \mathrm{~mm}$ ou igual à maior dimensão do agregado, o que for maior.

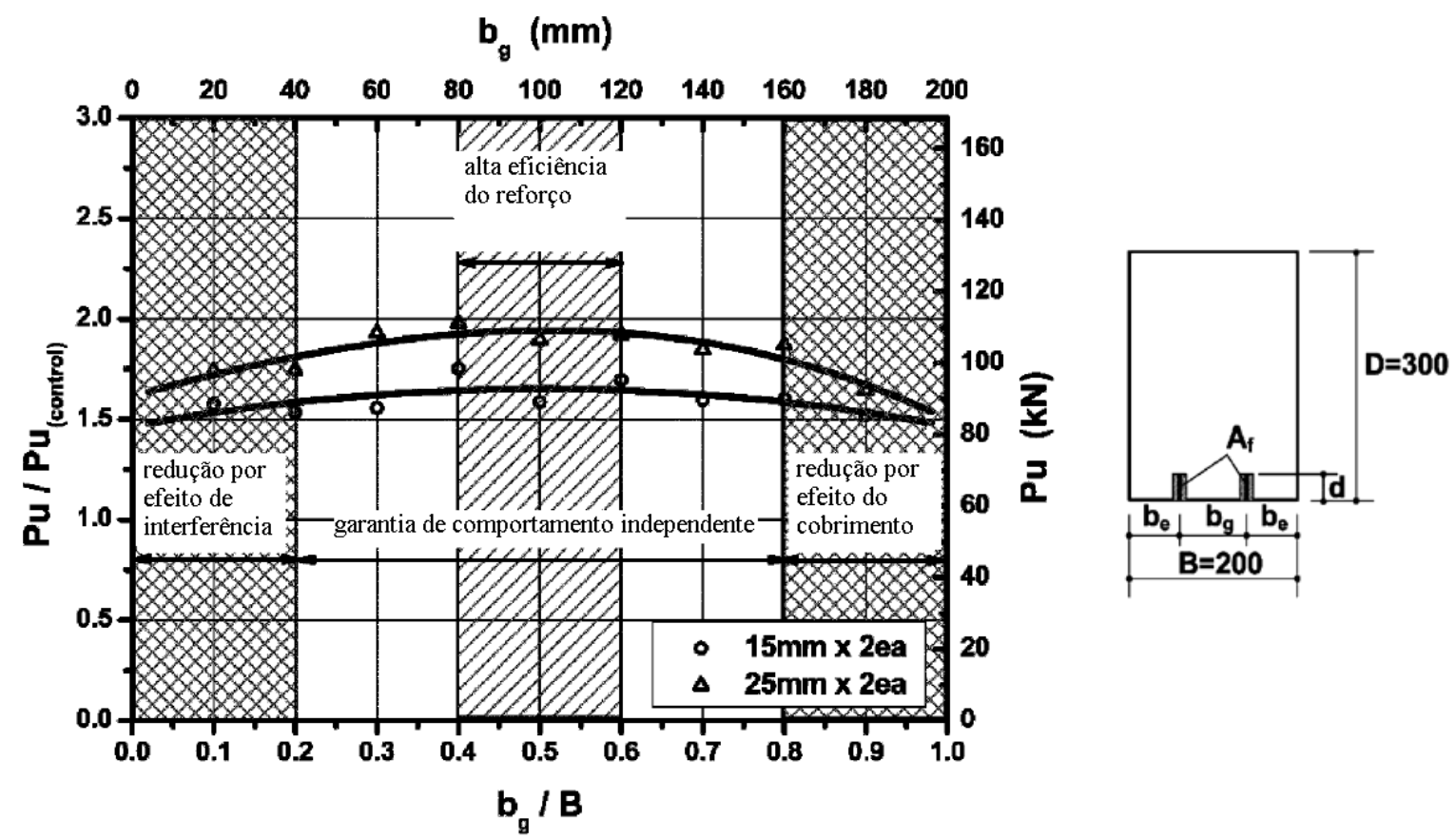

Figura 2.2 - Influência da disposição dos laminados na eficiência do reforço para duas profundidades de entalhe: $15 \mathrm{~mm}$ e $25 \mathrm{~mm}$ (Fonte: adaptado de Kang et al. (2005)). 
Pantelides et al. (2003) apresentam uma proposta para reabilitação sísmica (seismic retrofit) de estruturas de painéis portante em concreto pré-moldado em que mantas de PRF são usadas como conectores entre painéis permitindo a transferência de esforço cortante entre eles. A Figura 2.3 ilustra o modelo de ensaio e uma das configurações de reforço testada.

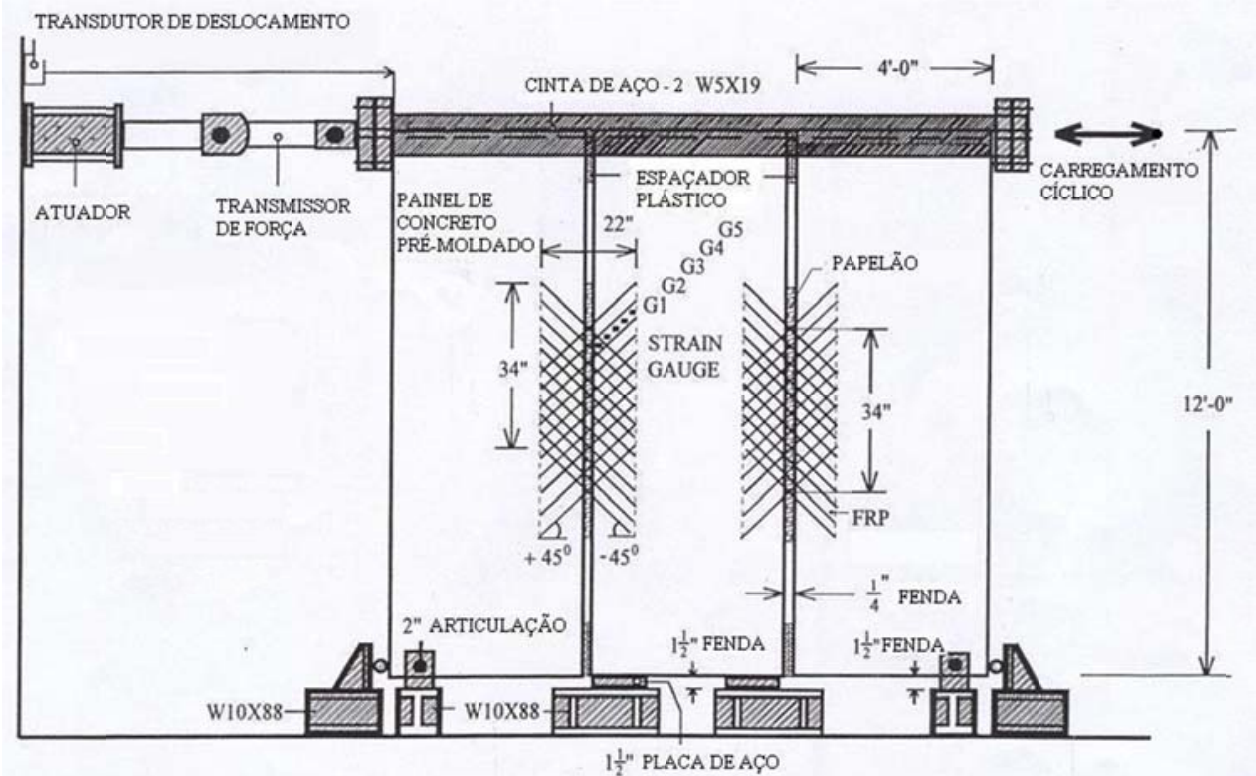

Figura 2.3 - Configuração esquemática do ensaio (Fonte: adaptado de Pantelides et al. (2003)).

Modelos com ligações em chapa de aço foram utilizados como referenciais. Pantelides et al. (2003) concluem que a capacidade de transmissão de esforço cortante original, correspondente à ligação com chapa de aço, foi acrescida de 17 a 40\%.

Fonseca (2007) apresenta investigação acerca do reforço de ligações viga-pilar de estruturas de concreto pré-moldado. Fonseca (2007) utilizou em seu programa experimental modelos em escala reduzida de uma ligação viga-pilar composta por encaixe de dente Gerber e consolo, com uso de chumbador, almofada de apoio e graute. Esse tipo de ligação é muito utilizado na construção de galpões e tem, na sua concepção original, comportamento essencialmente de articulação. Foram também utilizados modelos de referência para o estudo da influência da almofada de apoio e do grauteamento no comportamento resistente e da deformabilidade da ligação. Nesses modelos, as juntas eram perfeitamente conjugadas, isto é, os trechos de viga foram concretados com um elemento pré-moldado de pilar-consolo 
posicionado dentro da fôrma, sem disposição de almofadas. Os modelos foram reforçados conforme descrito na Tabela 2.1. Na Figura 2.4, ilustram-se as características geométricas do modelo-piloto e, na Figura 2.5, apresenta-se o modo como o reforço a momento fletor positivo seria empregado em uma estrutura, representado espacialmente.

Vista frontal
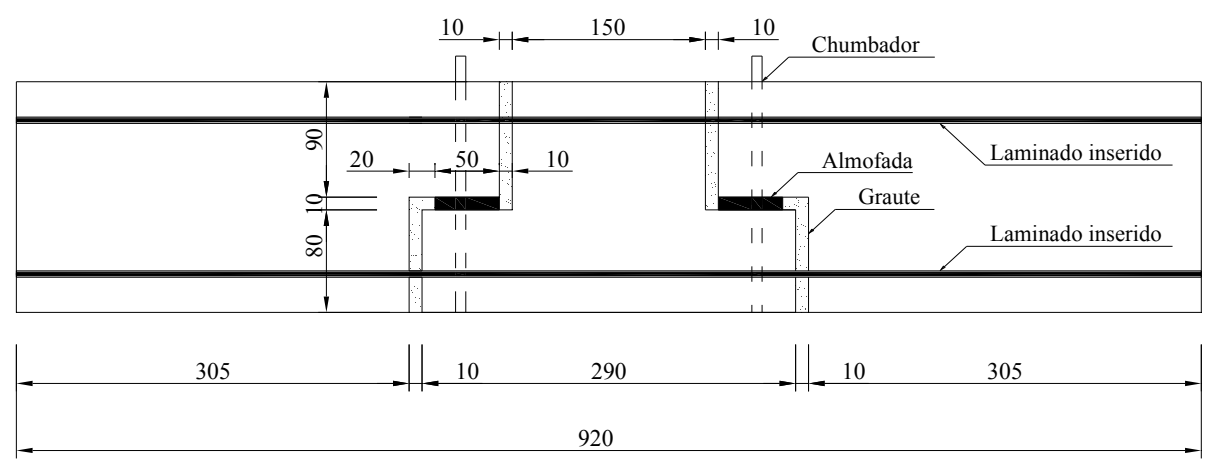

Medidas em milímetros
Vista lateral

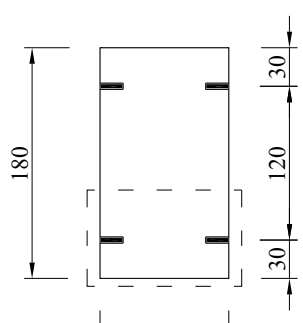

$100 \rightarrow$

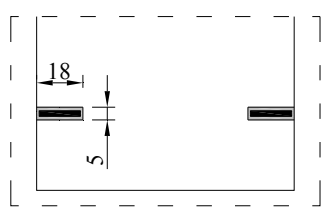

Figura 2.4 - Características geométricas do modelo-piloto (Fonte: Fonseca (2007)).

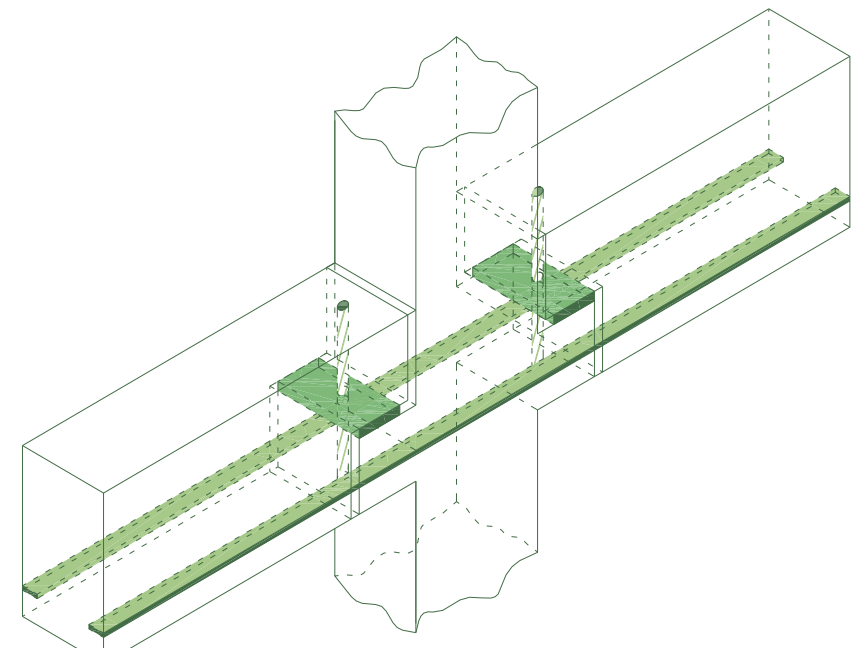

Figura 2.5 - Representação espacial do reforço a momento positivo em um trecho de estrutura. 
Tabela 2.1 - Características dos modelos de ensaio de Fonseca (2207).

\begin{tabular}{|c|c|c|c|c|c|}
\hline 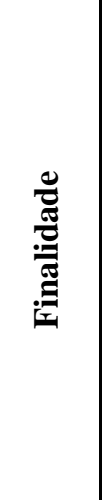 & 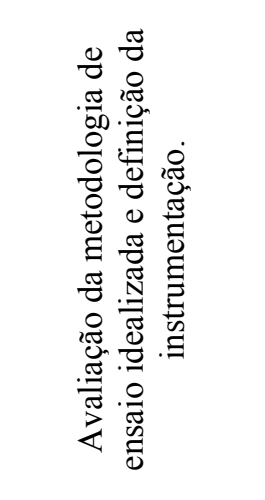 & 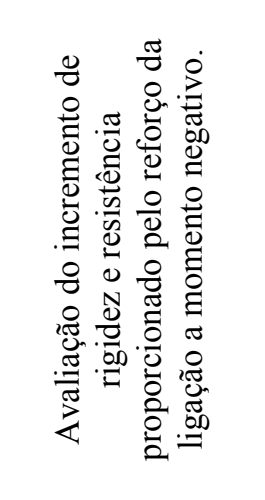 & 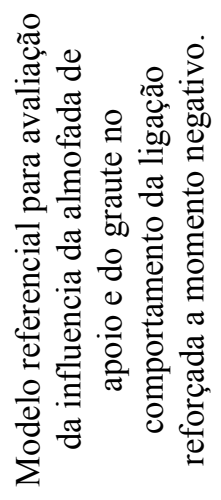 & 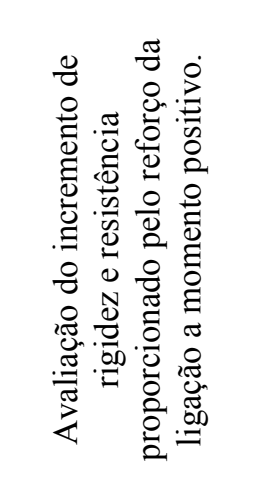 & 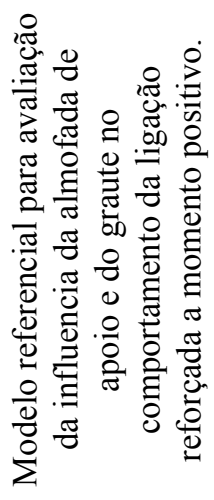 \\
\hline 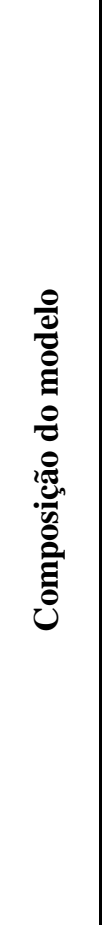 & 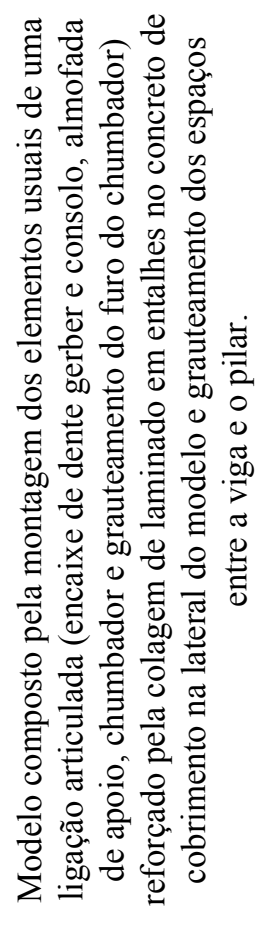 & 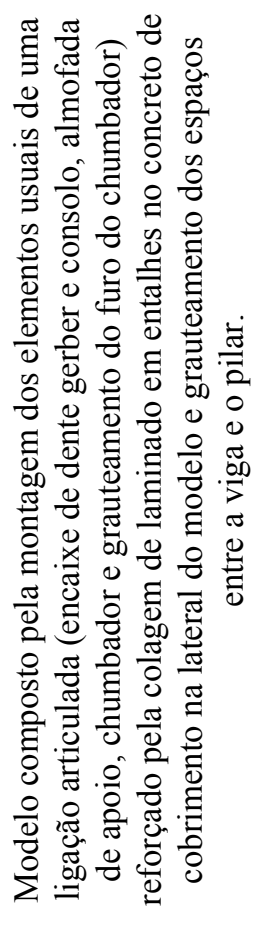 & 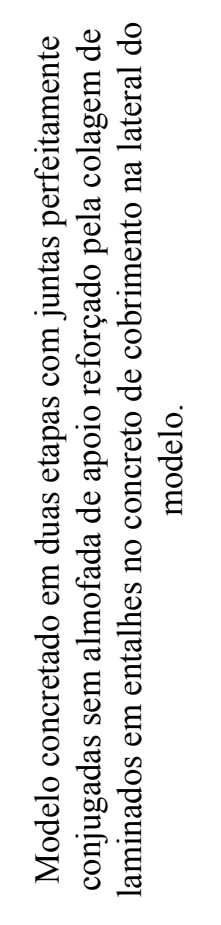 & 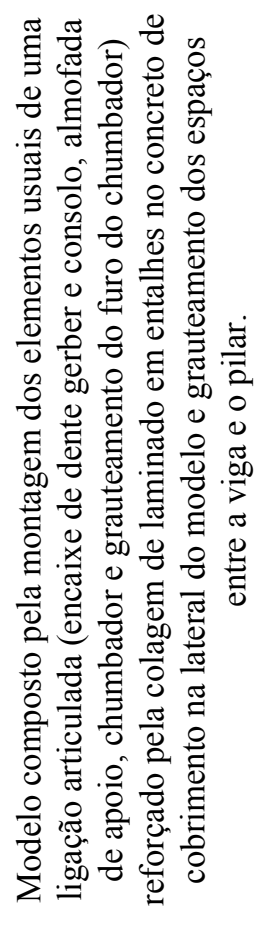 & 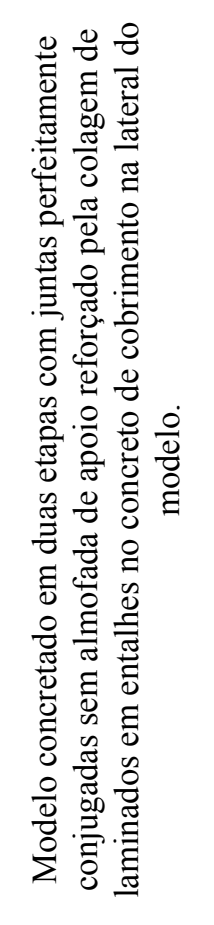 \\
\hline 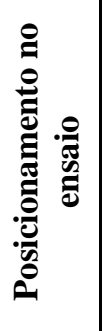 & 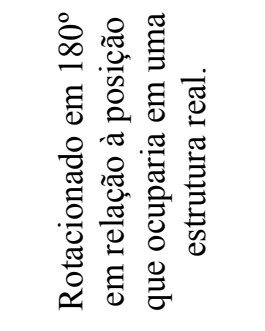 & 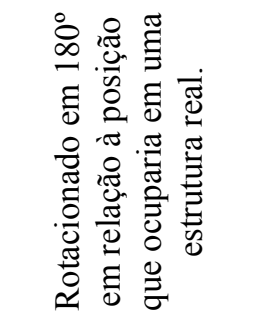 & 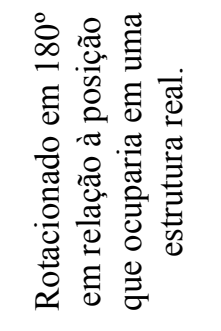 & 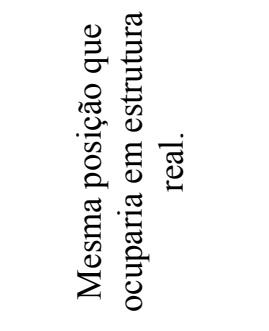 & 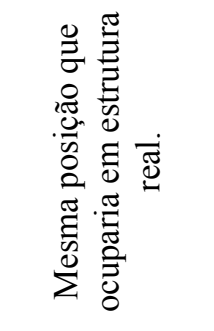 \\
\hline 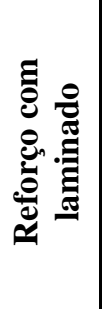 & 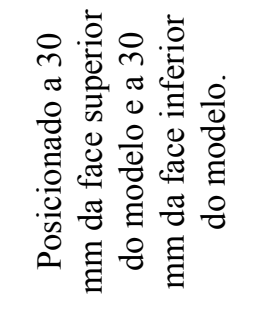 & 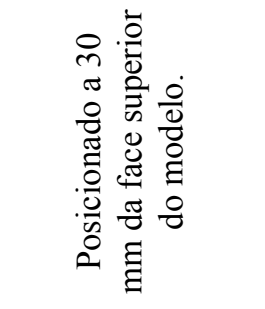 & 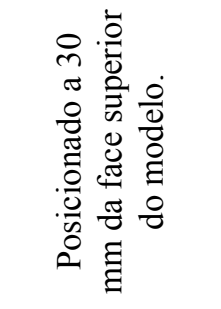 & 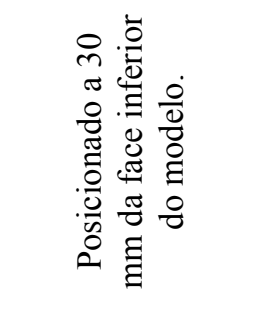 & 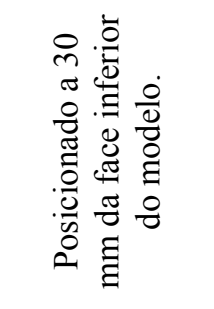 \\
\hline 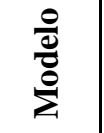 & $\frac{\stackrel{0}{0}}{\frac{0}{a}}$ & $\begin{array}{l}\tilde{U}, \\
\bar{z} \tilde{z}\end{array}$ & $\begin{array}{l}\overrightarrow{0} \\
\vec{z}\end{array}$ & $\vec{U}$ & $\vec{\omega}$ \\
\hline
\end{tabular}


Os modelos de ligação foram submetidos a ensaios com aplicação de carregamento cíclico alternado de curta duração, solicitando-se os modelos a momento fletor positivo ou negativo (Figura 2.6). A análise da rigidez da ligação foi baseada nas relações "momento $\mathrm{x}$ rotação" (Figura 2.7-a) e "força x deslocamento" (Figura 2.7-b). Ambas tiveram seu comportamento aproximado a diagramas bi-lineares em que o primeiro trecho é caracterizado pela rigidez inicial $\left(\mathrm{K}_{\mathrm{i}}\right.$ na Figura $2.7-\mathrm{a}$ e $\mathrm{K}_{\mathrm{i}}$ ' na Figura 2.7-b) e o segundo pela rigidez final $\left(\mathrm{K}_{\mathrm{f}}\right.$ na Figura 2.7-a e $\mathrm{K}_{\mathrm{f}}$ ' na Figura 2.7-b). Em função das rigidezes apresentadas pelas ligações reforçadas elas foram classificadas como semirrígidas, arbitrando-se para o cálculo dos limites classificatórios propostos por Ferreira, El Debs e Elliot (2002) e pelo Eurocode 3 (2002) um comprimento de viga de 1,80 m, compatível com a seção do modelo.

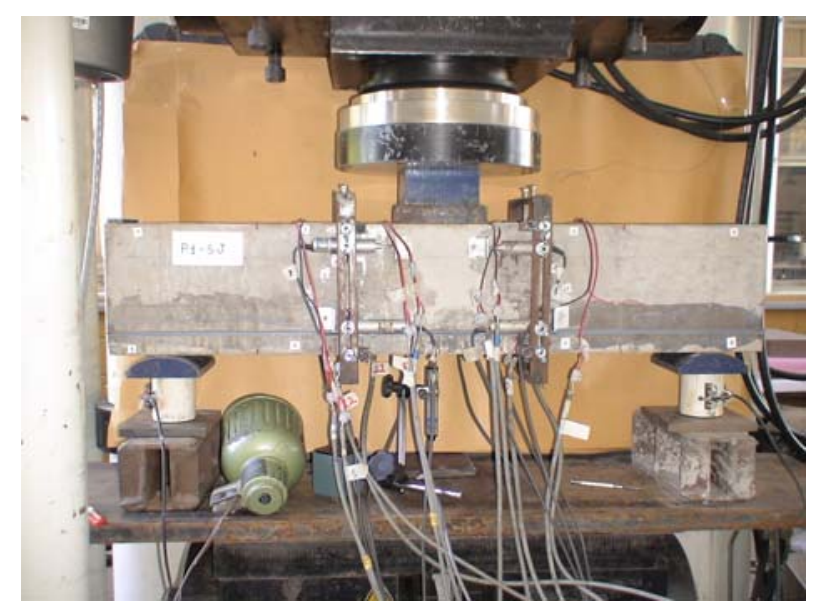

Figura 2.6 - Configuração do ensaio do modelo P1SJ.

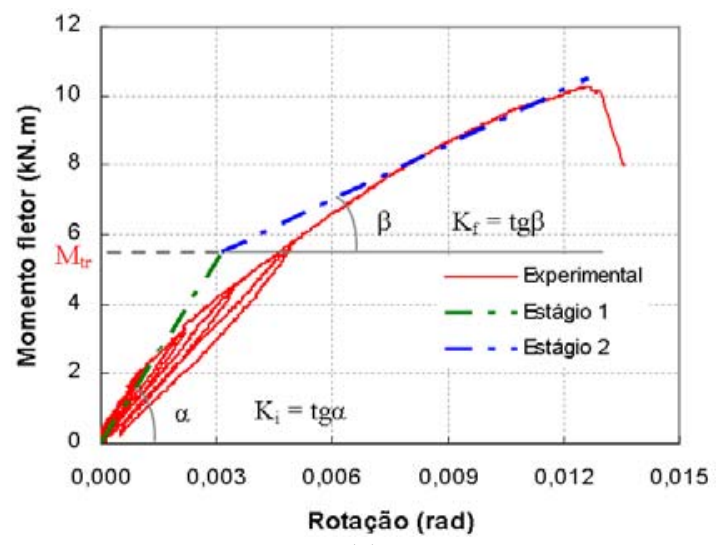

(a)

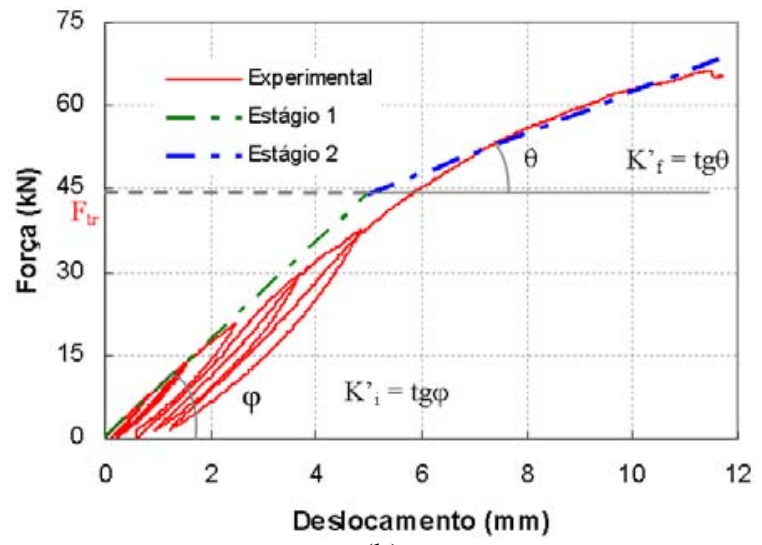

(b)

Figura 2.7 - (a) Curva "momento x rotação" e aproximação bi-linear; (b) Curva "momento x rotação" e aproximação bi-linear (Fonte: Fonseca (2007)). 
Algumas das principais conclusões de Fonseca (2007) foram:

- O estudo realizado demonstrou que a técnica NSM é aplicável ao incremento da rigidez e da resistência de ligações de estruturas de concreto pré-moldado, com rapidez e eficiência compatíveis com o processo industrializado;

- O processo de execução inerente à técnica de reforço foi testado, concluindo-se que ele tem condições de ser assimilado sem grandes dificuldades pelos agentes executores;

- No tipo de ligação e configuração particularmente analisada, a aplicação do graute mostrou-se satisfatória, praticamente reconstituindo a condição de ligação monolítica, em relação aos esforços de compressão. A existência da almofada não teve influência significativa no comportamento da ligação reforçada. 


\section{CAPÍTULO 3}

\section{ESTRUTURAS DE CONCRETO PRÉ-MOLDADO}

A pré-moldagem é um caminho para a racionalização e industrialização da construção de estruturas em concreto armado inserindo um maior controle de qualidade nessa atividade que é ainda excessivamente artesanal. É inegável que com a pré-moldagem quer de canteiro (em que as peças são produzidas no canteiro fora de sua posição definitiva) quer industrial (em que os elementos são pré-fabricados em indústrias e transportados para a obra) se ganha em produtividade, no atendimento às especificações e na velocidade de execução.

Uma questão chave para as estruturas pré-moldadas são as ligações. Do ponto de vista construtivo são mais interessantes as ligações mais simples que, em geral, não apresentam resistência à flexão. Um exemplo é a ligação viga-pilar por encaixe de dente Gerber e consolo, muito utilizada em estruturas de galpão e em edifícios de pequena altura com estrutura tipo esqueleto. Entretanto, essas ligações resultam em elementos de viga e pilar mais solicitados e consequentemente com maiores seções e taxas de armadura, em oposição à economia. Sua utilização é desaconselhável em estruturas com altura superior a $12 \mathrm{~m}$. O uso de ligações resistentes à flexão pode sanar essas limitações, porém sua execução mais trabalhosa contrasta com uma das vantagens da pré-moldagem que é a velocidade. 
Por muito tempo, os projetistas ignoraram questão do real comportamento das ligações, assumindo, na fase de projeto, que elas funcionariam como articulações ou como perfeitamente rígidas. Contudo, mesmo as ligações mais simples por encaixe de dente gerber e consolo podem, em determinadas circunstâncias, apresentar alguma rigidez e resistência à flexão e por outro lado mesmo as mais elaboradas não representam engaste. Enfim, em função da deformabilidade dos elementos que a compõem, o comportamento real de uma ligação em estruturas pré-moldadas se situa no intermédio das articulações e ligações rígidas, podendo tender a algum dos extremos, reproduzindo suas características. As ligações com características intermediárias são definidas como semirrígidas.

O termo "semirrigidez" tem origem no vocabulário empregado no estudo de estruturas metálicas, refletindo a capacidade parcial de transferência de momento fletor. As ligações semirrígidas podem também ser classificadas como deformáveis, sendo a deformabilidade “[...] definida como a relação dos deslocamentos relativos entre os elementos que compõem a ligação com o esforço solicitante na direção desse deslocamento.” (El DEBS, 2000, p. 222). Além da deformabilidade à flexão, as ligações de estruturas de concreto pré-moldado podem apresentar deformabilidade ao esforço normal, ao cisalhamento e à torção (SOARES, 1998). Na Figura 3.1, observa-se as curvas "momento x rotação" para três tipos de ligação: perfeitamente rígida, semirrígida e perfeitamente articulada. A Figura 3.1 ilustra também a relação inversa existente entre os conceitos de rigidez $\left(K_{m}\right)$ e deformabilidade $\left(D_{m}\right)$. 


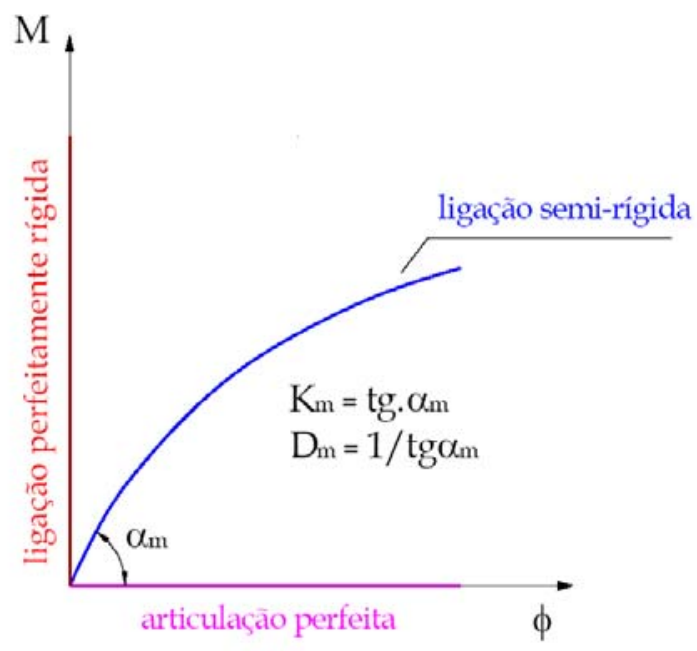

Figura 3.1 - Curvas "momento x rotação" ideais para ligações articuladas semirrígidas e rígidas (Fonte: Miotto (2002)).

O Eurocode 3 (2002) delimita, para as ligações, três zonas de classificação quanto à rigidez, conforme Quadro 1.

\begin{tabular}{|c|c|c|}
\hline \multirow{5}{*}{$\mathrm{M}_{\mathrm{j}} \Lambda$} & Classificação & Limites \\
\hline & Zona 1: Rígida & $K_{m} \geq \frac{k_{b} \cdot E . I}{L}$ \\
\hline & Zona 2: Semi-rígida & $\frac{0,5 \cdot E . I}{L}<K_{m}<\frac{k_{b} \cdot E \cdot I}{L}$ \\
\hline & Zona 3: Articulada & $K_{m} \leq \frac{0,5 \cdot E \cdot I}{L}$ \\
\hline & \multicolumn{2}{|c|}{$k_{b}=\left\{\begin{array}{l}8(\text { estrutura contraventada }) \\
25(\text { estrutura não contraventada })\end{array}\right.$} \\
\hline
\end{tabular}

Quadro 3.1 - Limites de classificação da ligação quanto à rigidez (Fonte: adaptado de EUROCODE 3 (2002)).

Quanto à resistência a momento fletor, as ligações são classificadas como articuladas de resistência total e de resistência parcial (EUROCODE 3, 2002). As ligações articuladas devem apresentar resistência de cálculo a momento fletor $\left(\mathrm{M}_{\mathrm{j}, \mathrm{Rd}}\right)$ inferior a $25 \%$ da resistência requerida para a ligação de resistência total. Os critérios para a classificação da ligação como de resistência total estão definidos na Figura 3.2. As ligações de resistência parcial são aquelas que não se encaixam nos critérios dos dois outros tipos de ligação. Ressalta-se que Eurocode 3 (2002) está direcionado à análise de estruturas metálicas. 
a) Topo do pilar

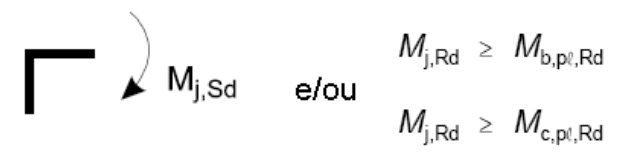

b) Intermediária ao pilar

$$
\text { 丩 } \quad \text { elou } \begin{aligned}
M_{\mathrm{j}, \mathrm{Sd}, \mathrm{Rd}} & \geq M_{\mathrm{b}, \mathrm{p} \ell, \mathrm{Rd}} \\
M_{\mathrm{j}, \mathrm{Rd}} & \geq 2 M_{\mathrm{c}, \mathrm{pl}, \mathrm{Rd}}
\end{aligned}
$$

$M_{\mathrm{j}, \mathrm{Rd}} \quad$ - momento resistente de projeto da ligação

$M_{\mathrm{b}, \mathrm{pl}, \mathrm{Rd}}$ - momento de plastificação de projeto da viga

$M_{\mathrm{c}, \mathrm{p}, \mathrm{Rd}}$ - momento de plastificação de projeto do pilar

Figura 3.2 - Ligação de resistência total (Fonte: adaptado do Eurocode 3 (2002)).

Ferreira, El Debs e Elliot (2002) ponderam que “... apenas a informação de que uma ligação é semirrígida é algo genérico e não fornece critérios objetivos de desempenho para serem utilizados quer na análise ou no projeto de ligações semirrígidas." Ferreira, El Debs e Elliot (2002) propõem uma classificação para ligações semirrígidas em estruturas prémoldadas em função do fator de rigidez $\gamma$, que relaciona a rigidez da ligação $\mathrm{K} \phi$ com a rigidez da viga. Esse fator é determinado pela Equação 1 e varia de 0 a 1 correspondendo às condições ideais de articulação e engastamento, respectivamente.

$$
\gamma=\left[1 \frac{3 E I}{k_{\phi}^{L}}\right]^{-1}
$$

Algumas relações entre momentos, rotações e deslocamentos (Equações 2, 3, 4 e 5) são expressas em função do fator de rigidez e se constituem em parâmetros para a classificação das ligações. A forma de classificação proposta por Ferreira, El Debs e Elliot (2002) está sintetizada na Figura 3.3.

$$
\begin{aligned}
& \frac{M_{E}}{M_{R}}=\left[\frac{3 \gamma}{2+\gamma}\right] \\
& \frac{M_{M S}}{M_{R}}=\left[\frac{3-1,5 \gamma}{2+\gamma}\right] \\
& \frac{\phi_{E}}{\theta_{R}}=1-\left[\frac{3 \gamma}{2+\gamma}\right] \\
& \frac{\delta_{M S}}{\delta_{R}}=\left[\frac{2-1,4 \gamma}{2+\gamma}\right]
\end{aligned}
$$

$M_{E}$ : momento modificado na extremidade da viga devido à ligação semirrígida 
$M_{R}:$ momento de engastamento no apoio

$M_{M S}$ : momento modificado no meio do vão

$\phi_{E}:$ rotação efetiva na extremidade da viga

$\theta_{R}:$ rotação livre na extremidade de uma viga bi-apoiada

$\delta_{M S}:$ flecha efetiva no meio do vão

$\delta_{R}$ : flecha para a condição de uma viga simplesmente apoiada

$\mathrm{Na}$ Figura 3.3, as zonas de classificação especificam:

Zona I: ligação articulada

Zona II: ligação semirrígida com baixa resistência à flexão

Zona III: ligação semirrígida com resistência média à flexão

Zona IV: ligação semirrígida com alta resistência à flexão

Zona V: ligação rígida.

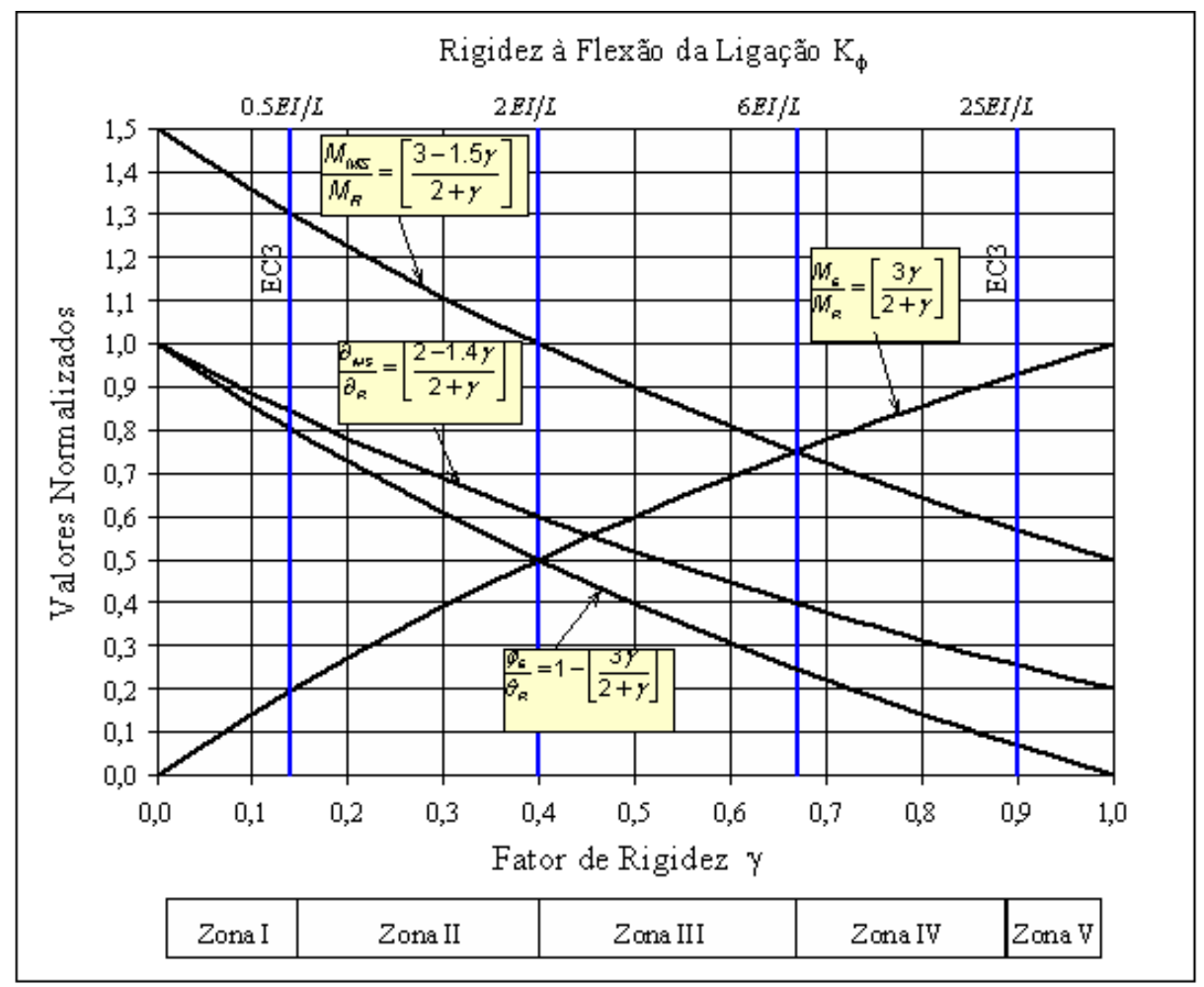

Figura 3.3 - Proposta de classificação para ligações semirrígidas (Fonte: Ferreira, El Debs e Elliot (2002)).

A adoção da rigidez real da ligação é obviamente um procedimento que levaria a um dimensionamento mais coerente das estruturas. A consideração da semirrigidez ao invés de articulação poderia diminuir as seções de elementos como vigas e pilares e ser um fator 
favorável na estabilidade global da estrutura. Embora existam hoje programas computacionais que permitem que a semirrigidez seja implementada na análise da estrutura, ainda persiste um entrave para isso: a dificuldade de se predizer o comportamento da ligação. A determinação do comportamento das ligações por meio de ensaios experimentais é atualmente o meio mais utilizado, mas apresenta alguns inconvenientes. Ensaios experimentais são muito caros e seus resultados se aplicam somente a ligações com as mesmas características dos modelos experimentais. Uma alternativa é a modelagem numérica. Em geral, essas análises consomem bastante tempo e para que tenham confiabilidade devem estar associadas a resultados experimentais. Pode-se dizer que a modelagem numérica amplia a validade dos dados experimentais, pois se pode através dela inferir o comportamento de ligações com alguns parâmetros diferentes do modelo físico ensaiado. Por fim, há os modelos matemáticos para o comportamento das ligações como o Método dos Elementos, contudo são poucos os disponíveis.

Muitas pesquisas têm focado as ligações em estruturas pré-moldadas. Ferreira (1999) desenvolveu uma metodologia analítica para o cálculo de deformabilidades de ligações típicas de concreto pré-moldado, levando-se em conta os mecanismos básicos de deformação na ligação. Foram estudadas duas ligações típicas viga-pilar de concreto pré-moldado. A primeira é uma ligação com almofada de elastômero e chumbador. Na Figura 3.4, ilustra-se o modelo esquemático utilizado. A segunda é uma ligação resistente à flexão com chapas soldadas. A partir da boa correlação entre os valores de rigidez calculados com valores obtidos experimentalmente, demonstrou-se que utilização de procedimentos analíticos para a determinação das deformabilidades é alternativa viável e uma ferramenta de grande potencial a ser explorado para o projeto das ligações de concreto pré-moldado. 


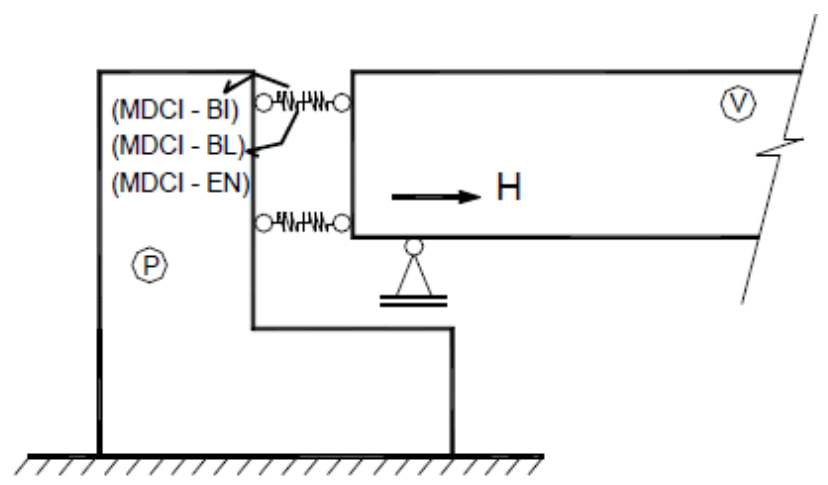

Figura 3.4 - Esquematização por meio de molas para o mecanismo de deformação ao cisalhamento em ligação viga-pilar articulada (FERREIRA, 1999).

Miotto (2002) estudou duas ligações viga-pilar de estruturas de concreto pré-moldado com ênfase na deformabilidade ao momento fletor. A primeira utilizada em galpões com sistema estrutural de pórticos para telhado com duas águas (Figura 3.5) e a segunda utilizada em estruturas de edifícios com múltiplos pavimentos (Figura 3.6). Foram realizados ensaios físicos em dois modelos de cada tipo de ligação. Com base nos resultados experimentais, foram propostos modelos analíticos, baseados no Método dos Componentes, e realizadas simulações numéricas, baseadas no Método dos Elementos Finitos. Houve boa correlação entre a simulação numérica e os ensaios experimentais. A primeira ligação transmitiu mais de $90 \%$ do momento equivalente ao de uma estrutura monolítica, comportamento próximo ao de uma ligação perfeitamente rígida. A segunda ligação também garantiu uma boa transferência de momento fletor.
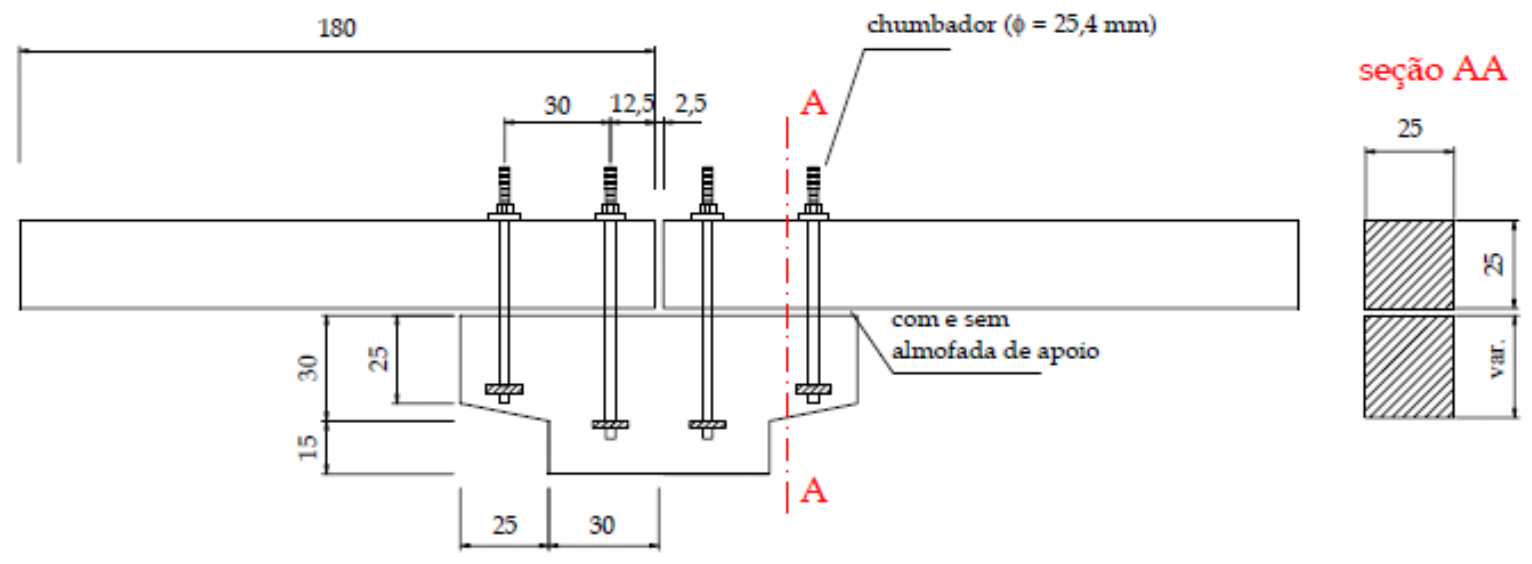

Figura 3.5 - Modelo de ligação utilizada em estruturas de galpão (MIOTTO, 2002). 

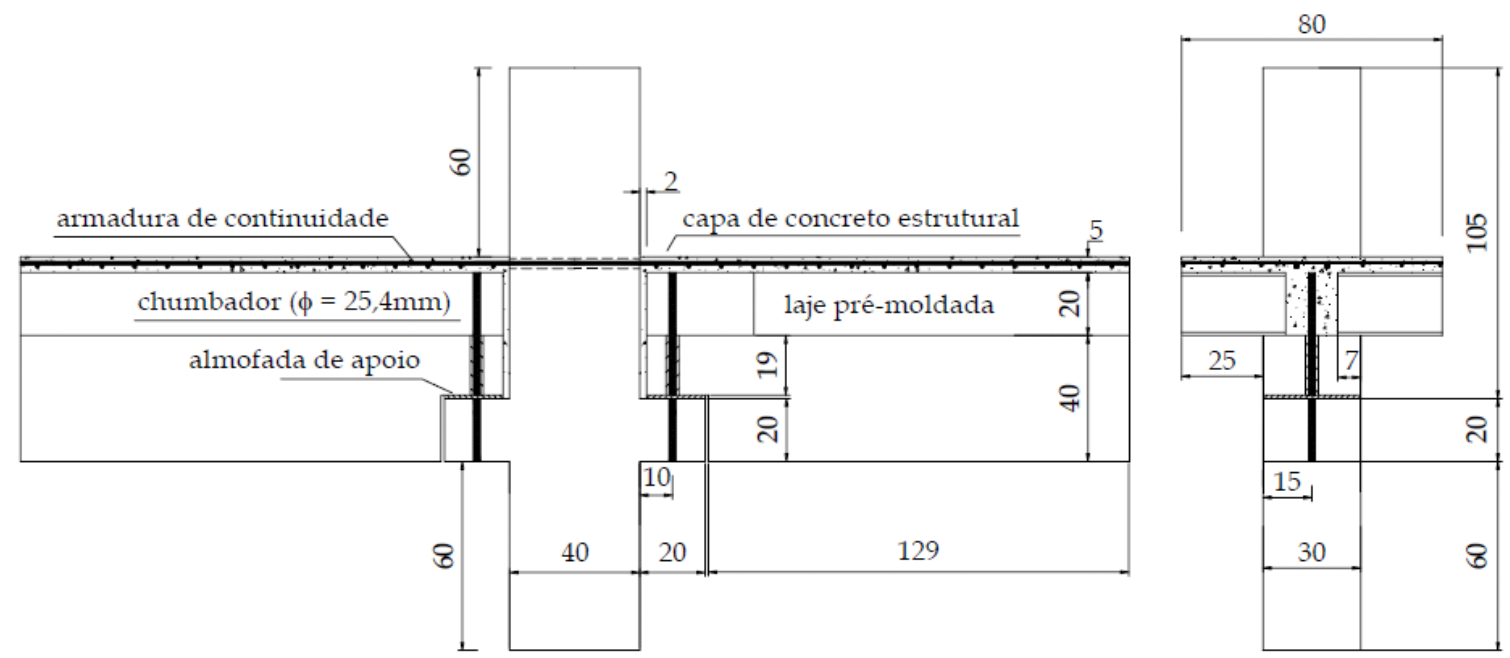

Figura 3.6 - Modelo de ligação utilizada em estruturas de edifícios de múltiplos pavimentos (MIOTTO, 2002).

Baldissera (2006) realizou ensaios em dois modelos de ligação usados em estruturas de múltiplos pavimentos semelhantes ao estudado por Miotto (2002). A principal modificação destas ligações foi a utilização de chumbador inclinado (Figura 3.7 e Figura 3.8). Baldissera (2006) desenvolveu uma metodologia analítica para estimativa da rigidez. A utilização de chumbador inclinado promoveu um aumento de 2,5 vezes nos valores de momento de plastificação e de 2 vezes na rigidez, quando comparados aos modelos com chumbadores retilíneos.

CORTE A-A
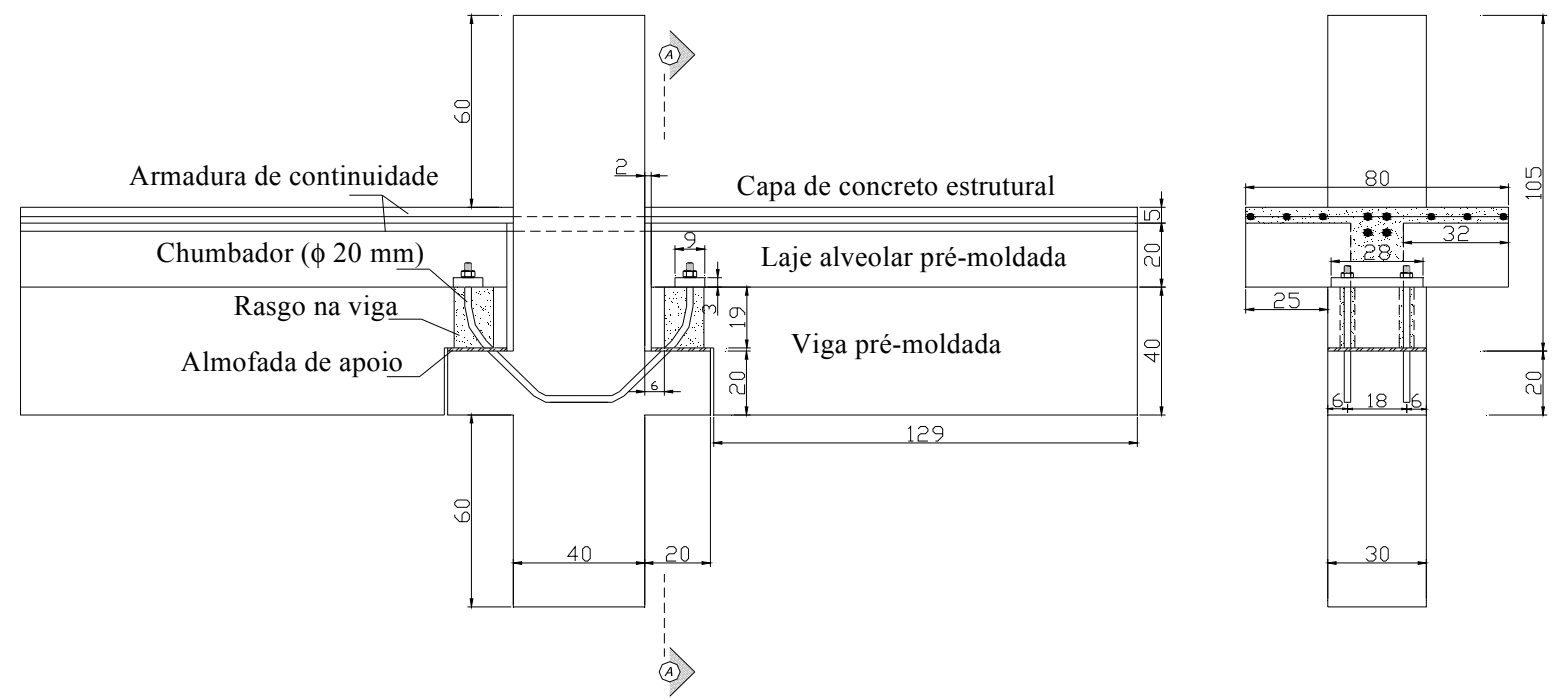

Figura 3.7 - Modelo de ligações viga-pilar intermediário (BALDISSERA, 2006). 

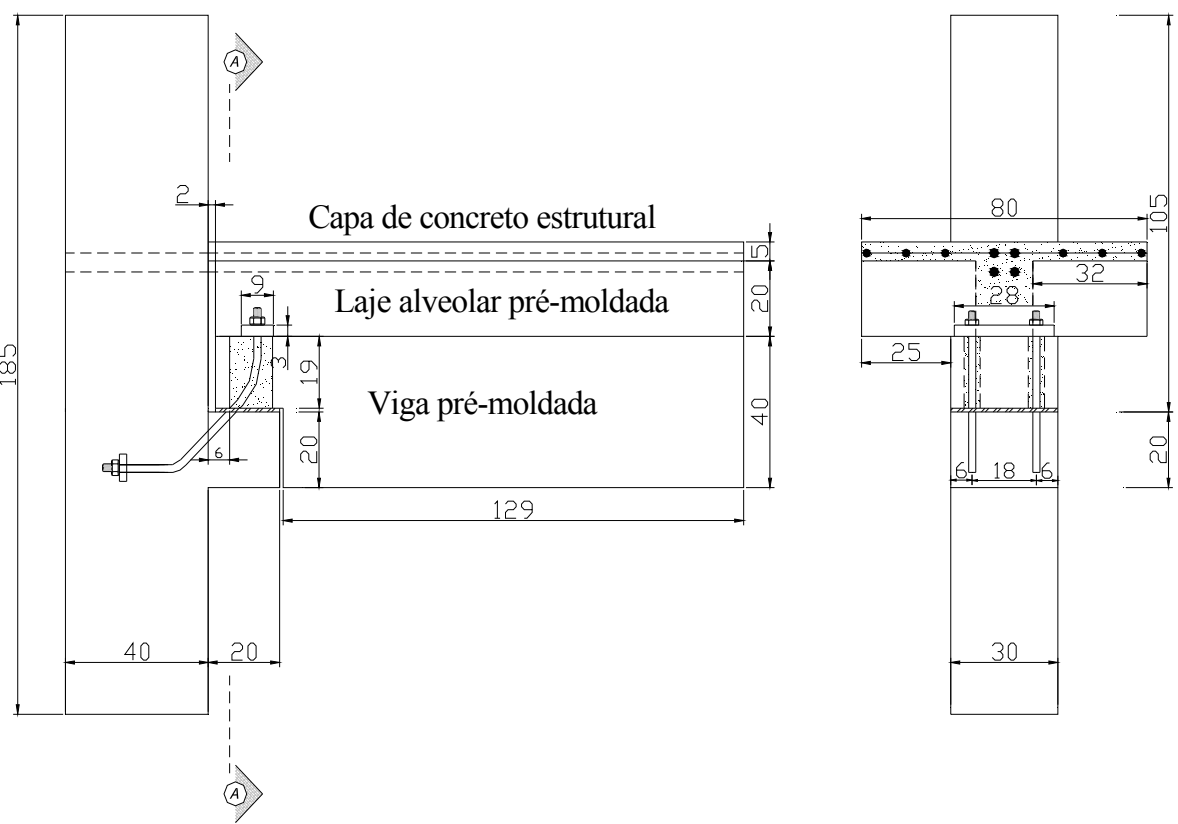

Figura 3.8 - Modelo de ligações viga-pilar de extremidade (BALDISSERA, 2006).

Catoia (2007) avaliou o comportamento de vigas pré-moldadas protendidas, considerando a influência das ligações entre a viga e os pilares. Assim como Nobrega (2004), não utilizou modelo de ensaio cruciforme geralmente adotado nas pesquisas envolvendo ensaios em ligações isoladas, adotando como modelo de ensaio um pórtico (Figura 3.9). Catoia (2007) desenvolveu um procedimento experimental que permitiu integrar diversos equacionamentos teóricos que levam em consideração diferentes parâmetros na análise dos resultados.

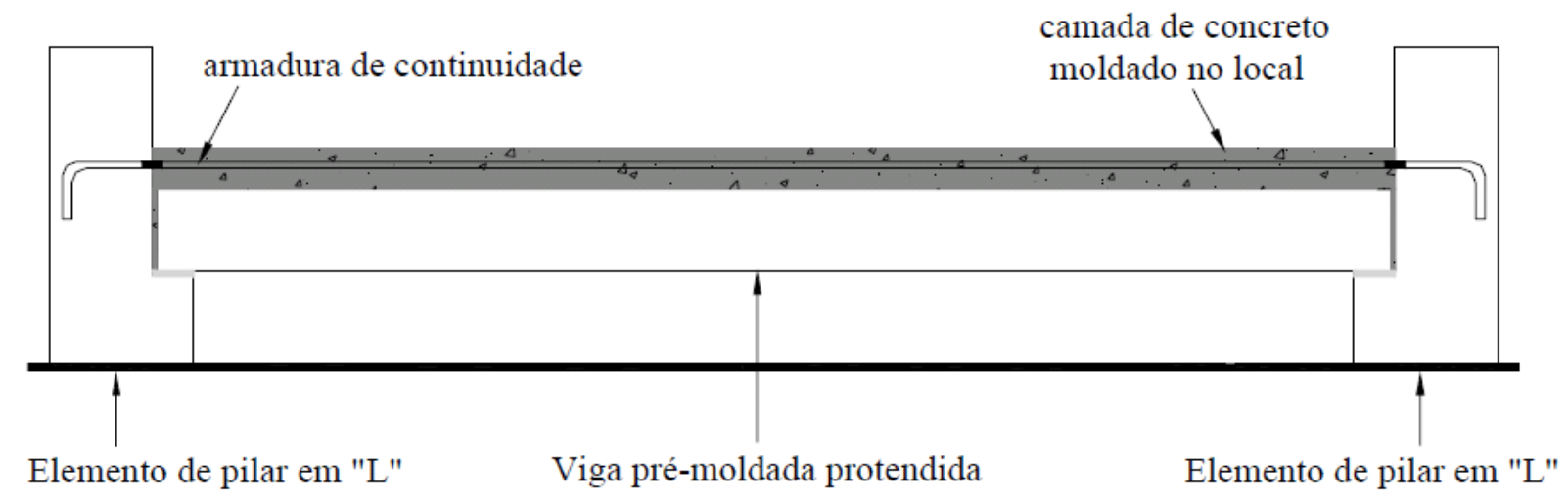

Figura 3.9 - Modelo de ensaio com ligações semirrígidas (CATOIA, 2007). 


\section{CAPÍTULO 4}

\section{ENSAIOS DE ADERÊNCIA}

A aderência tem papel fundamental na eficiência do reforço por colagem de polímeros reforçados com fibras (PRF), pois é quem permite que os esforços sejam transferidos entre concreto e o PRF. Desde que a técnica de reforço por colagem de laminado em entalhes no cobrimento (conhecida por NSM do inglês Near Surface Mounted) foi desenvolvida, muitas investigações acerca da aderência foram realizadas. Conquanto exista uma grande quantidade de trabalhos dedicados ao tema, ainda não se tem um conhecimento consolidado em relação à aderência. Uma forte razão para isso é a dificuldade de comparação entre os resultados das pesquisas existentes. Observa-se uma variação de métodos de ensaio experimental entre arrancamento em viga (HASSAN E HIZKALLA, 2003; CRUZ, 2004; DE LORENZIS E NANNI, 2002) e arrancamento direto (DE LORENZIS ET AL, 2002; SHIELD ET AL 2005). Mesmo quando o método coincide, a comparação é dificultada pela variedade das dimensões dos modelos. Observa-se também uma grande variação quanto aos materiais utilizados nas pesquisas, tanto do compósito quanto do material para colagem do compósito. O compósito pode ser de fibras de vidro, aramida, carbono e se apresentar sob a forma de barras de seção circular com diferentes tratamentos superficiais ou seção retangular com espessura e largura diversas. As resinas são o material mais usado para colagem do compósito, contudo há pesquisas em que se relata o uso de argamassa (DE LORENZIS ET AL, 2002). 
Esta pesquisadora já havia realizado em seu mestrado (FONSECA, 2007) um estudo da aderência do laminado colado dois tipos de resina: Epóxi Estruturante FC e Sikadur ${ }^{\circledR} 330$. Esta última foi utilizada no ensaio-piloto descrito no Capítulo 6. Era um material disponível no laboratório e teve seu bom desempenho constatado em pesquisas anteriores (FONSECA, 2007 e ARQUEZ, 2010). Quando se necessitou obter um novo lote de resina, o fornecedor (Sika) informou que a resina mais apropriada para a colagem de laminados inseridos era a Sikadur ${ }^{\circledR}$ 30. Adquiriu-se então esse outro tipo de resina e realizaram-se novos ensaios de aderência com o intuito de avaliar principalmente a mobilização da capacidade resistente do laminado com a resina. Os resultados deste ensaio são apresentados aqui juntamente com os resultados dos ensaios realizados no mestrado desta pesquisadora e de Arquez (2010), dado o interesse da análise comparativa. Salienta-se, contudo, que apenas a avaliação da resina Sikadur ${ }^{\circledR} 30$ é objeto de estudo exclusivo desta pesquisa.

Além da influência da resina, pode-se avaliar a influência da utilização do concreto com e sem fibras na aderência. As quatro séries de ensaios experimentais foram realizadas sob configuração baseada na RILEM-CEB-FIB (1973). Como as séries de ensaio não foram objeto de uma mesma pesquisa, observam-se diferenças nas propriedades do concreto e no posicionamento do laminado no modelo de ensaio.

\subsection{Modelo de ensaio}

As configurações do ensaios foram baseadas nas recomendações da RILEM-CEB-FIB (1973) que originalmente se aplicam à caracterização da aderência de barras de aço, utilizadas como armadura em concreto. Foram feitas adaptações para que o ensaio melhor se adequasse ao material estudado fundamentadas em Cruz (2004).

O modelo de ensaio consiste em dois blocos de concreto, A e B, unidos na parte superior por uma rótula e na parte inferior por laminados inseridos em entalhes no concreto de cobrimento. Para as séries S1 e S2, utilizaram-se dois laminados colados no cobrimento 
lateral, a uma altura de $50 \mathrm{~mm}$ a partir do fundo do modelo, conforme se observa na Figura 4.1. Para as séries S3 e S4, utilizou-se um laminado inserido na base do modelo (Figura 4.2). Os entalhes foram executados com dimensões aproximadas de $18 \mathrm{~mm}$ de profundidade e 5 mm de largura. A região de teste se restringiu ao bloco A no qual se variou o comprimento de ancoragem $\left(\ell_{\mathrm{a}}\right)$. No bloco $\mathrm{B}$, foi mantido comprimento de ancoragem fixo igual a $325 \mathrm{~mm}$, suficiente para impedir o deslizamento do laminado em relação ao concreto neste bloco.

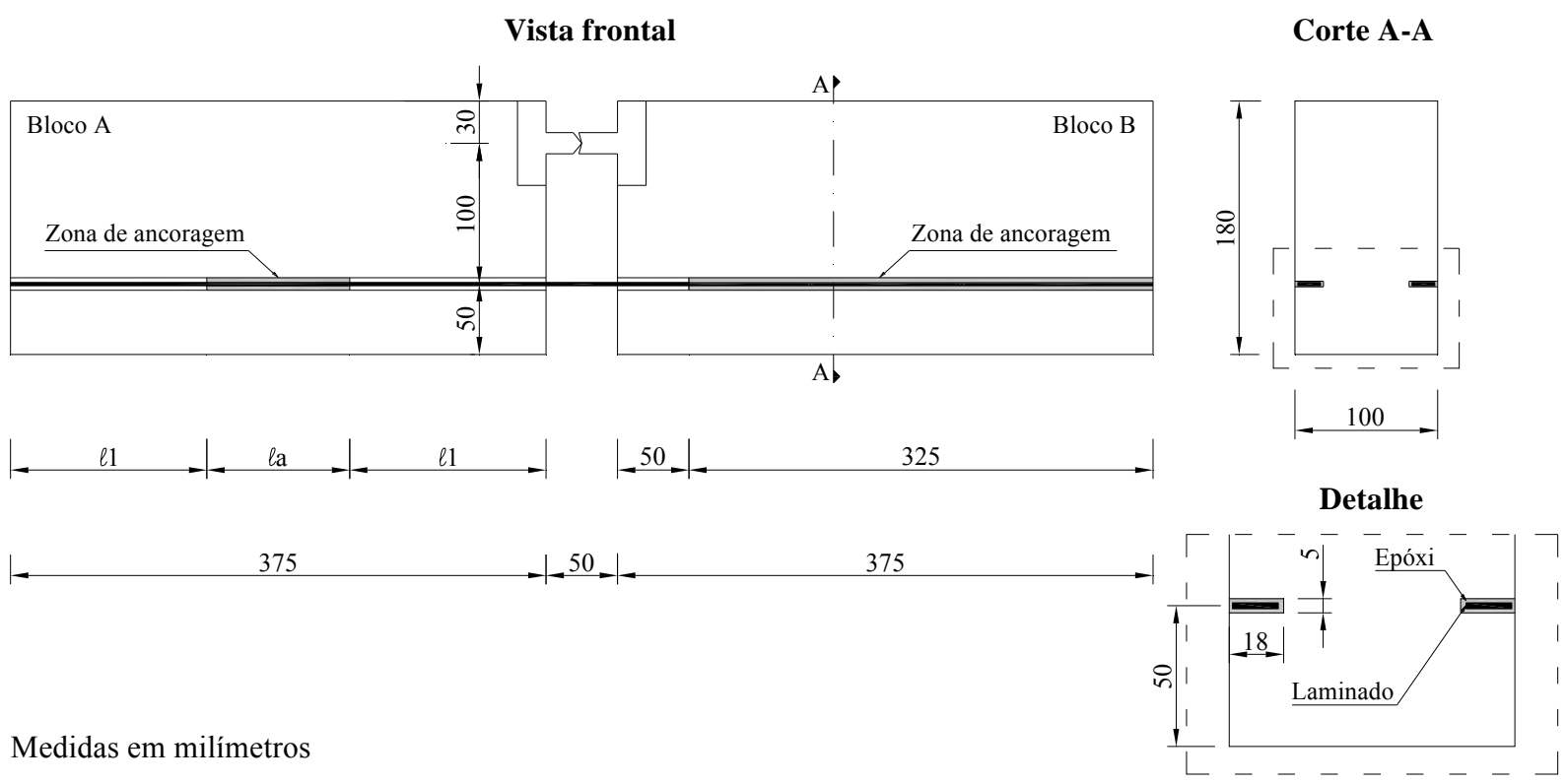

Figura 4.1 - Modelo de ensaio utilizado nas séries S1 e S2

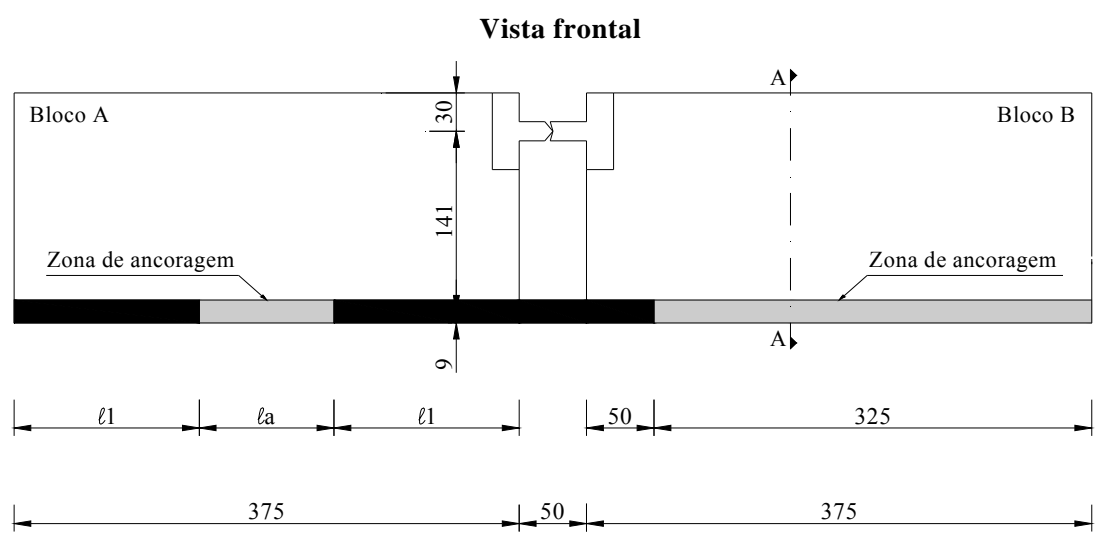

Medidas em milímetros

Corte A-A

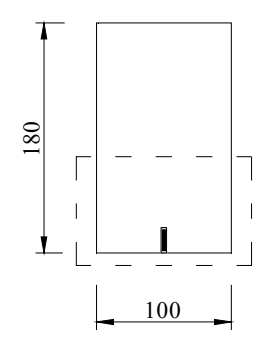

Detalhe

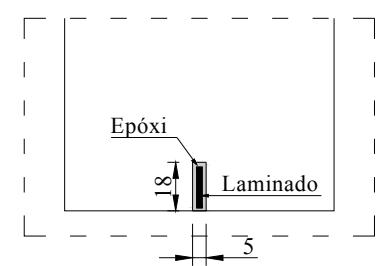

Figura 4.2 - Modelo de ensaio utilizado nas séries S3 e S4 
Foram estudados, nos ensaios da série S1, os comprimentos de 90, 120 e $150 \mathrm{~mm}$. Nas demais séries, os comprimentos foram de 70, 140 e $210 \mathrm{~mm}$. Para todas as séries, avaliaramse dois modelos para cada comprimento de ancoragem fixado. Para as séries S3 e S4, em que se utilizou concreto com fibras, não se empregou armadura metálica como prescreve a RILEM-CEB-FIB (1973). O Quadro 4.1 sintetiza as características dos modelos de ensaio.

Quadro 4.1 - Características dos modelos de ensaio.

\begin{tabular}{|c|c|c|c|c|}
\hline Série & Resina & Concreto & Comprimento de ancoragem (mm) & Modelo \\
\hline \multirow{6}{*}{$\mathrm{S} 1$} & \multirow{6}{*}{$\begin{array}{l}\text { Epóxi Estruturante } \\
\text { FC }\end{array}$} & \multirow{6}{*}{ Convencional } & \multirow{2}{*}{90} & M1L90S1 \\
\hline & & & & M2L90S1 \\
\hline & & & \multirow{2}{*}{120} & M1L120S1 \\
\hline & & & & M2L120S1 \\
\hline & & & \multirow{2}{*}{150} & M1L150S1 \\
\hline & & & & M2L150S1 \\
\hline \multirow{6}{*}{$\mathrm{S} 2$} & \multirow{6}{*}{ Sikadur ${ }^{\circledR} 330$} & \multirow{6}{*}{ Convencional } & \multirow{2}{*}{70} & M1L70S2 \\
\hline & & & & M2L70S2 \\
\hline & & & \multirow{2}{*}{140} & M1L140S2 \\
\hline & & & & M2L140S2 \\
\hline & & & \multirow{2}{*}{210} & M1L210S2 \\
\hline & & & & M2L210S2 \\
\hline \multirow{6}{*}{ S3 } & \multirow{6}{*}{ Sikadur ${ }^{\circledR} 330$} & \multirow{6}{*}{ Com fibras } & \multirow{2}{*}{70} & M1L70S3 \\
\hline & & & & M2L70S3 \\
\hline & & & \multirow{2}{*}{140} & M1L140S3 \\
\hline & & & & M2L140S3 \\
\hline & & & \multirow{2}{*}{210} & M1L210S3 \\
\hline & & & & M2L210S3 \\
\hline \multirow{6}{*}{$\mathrm{S} 3$} & \multirow{6}{*}{ Sikadur ${ }^{\circledR} 30$} & \multirow{6}{*}{ Com fibras } & \multirow{2}{*}{70} & M1L70S4 \\
\hline & & & & M2L70S4 \\
\hline & & & \multirow{2}{*}{140} & M1L140S4 \\
\hline & & & & M2L140S4 \\
\hline & & & \multirow{2}{*}{210} & M1L210S4 \\
\hline & & & & M2L210S4 \\
\hline
\end{tabular}

\subsubsection{Confecção do modelo}

Os blocos que compõem o modelo foram elaborados em concreto com e sem fibras em fôrmas de madeira compensada laminada. Após a desforma, executaram-se os entalhes nos 
blocos com uso de ferramenta elétrica com disco de corte (Figura 4.3-a). Optou-se pela utilização de dois discos de corte justapostos, o que proporcionou uma largura do entalhe de aproximadamente $5 \mathrm{~mm}$ e profundidade de aproximadamente $18 \mathrm{~mm}$. O corte foi feito por via úmida em todas as peças, que foram posteriormente lavadas com água e deixadas secar ao ar.

Mesmo com a lavagem, as peças de concreto apresentavam muito pó depositado em sua superfície e no interior dos entalhes. Na ocasião da colagem do laminado, foi realizada limpeza dos modelos com uso de jato de ar comprimido (Figura 4.3-b). Os laminados utilizados na confecção dos modelos foram cortados com comprimento de $80 \mathrm{~cm}$. As zonas a serem ancoradas foram delimitadas por fita adesiva. Devido à natureza excessivamente fluida do adesivo utilizado na série $\mathrm{S} 1$, foram coladas sobre as fitas placas finas de poliestireno expandido, para prevenir que o adesivo escorresse da zona de ancoragem, ocasionando a existência de vazios entre o laminado e o concreto, ou mesmo a colagem do laminado em zonas indesejadas. No início e fim da zona ancorada, foram coladas chapas metálicas com espessura de aproximadamente $1 \mathrm{~mm}$, comprimento de aproximadamente $5 \mathrm{~cm}$ e largura de 2 $\mathrm{cm}$, nas quais foram fixadas cantoneiras para medição do deslocamento relativo entre o concreto e o laminado. Extensômetros foram colados no laminado em posição correspondente à metade do vão da viga.

O laminado foi limpo com acetona. Colocaram-se as duas partes da rótula nos blocos que foram posicionados de forma a apresentar a configuração definitiva do modelo. Procedeuse a mistura dos dois componentes do adesivo conforme orientações do fabricante. Aplicou-se o adesivo no entalhe (Figura 4.3-c) ao longo do comprimento de ancoragem e nos laminados, com auxílio de uma espátula (Figura 4.3-d). Introduziram-se os laminados nos entalhes (Figura 4.3-e), retirou-se o excesso de adesivo com a espátula (Figura 4.3-f). Na preparação dos modelos da série R1, foi necessária a colagem de fita adesiva ao longo da zona ancorada para que o adesivo não escorresse. 


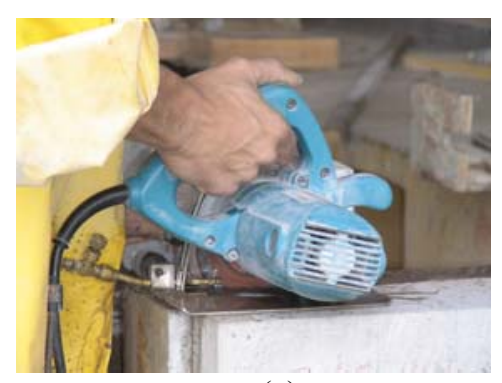

(a)

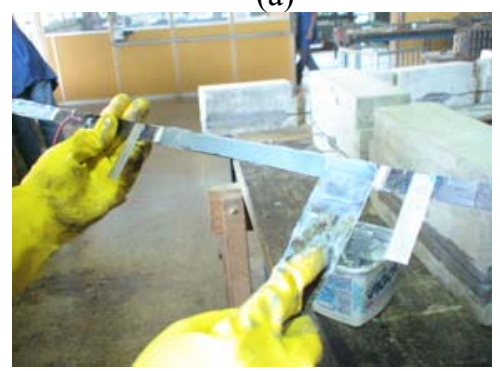

(d)

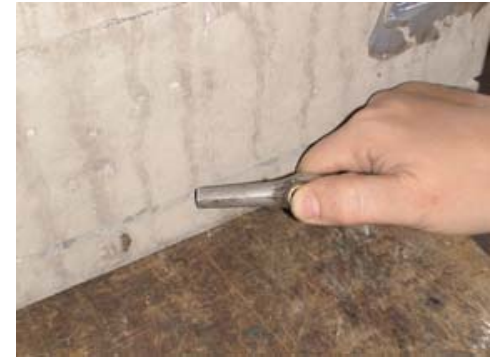

(b)

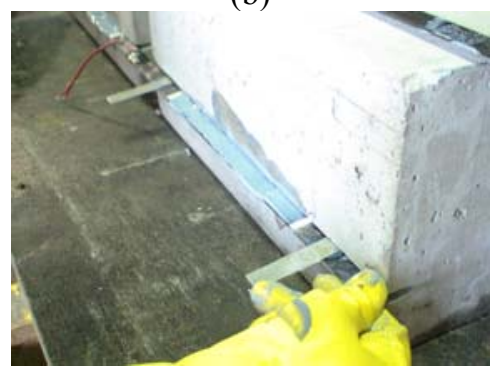

(e)

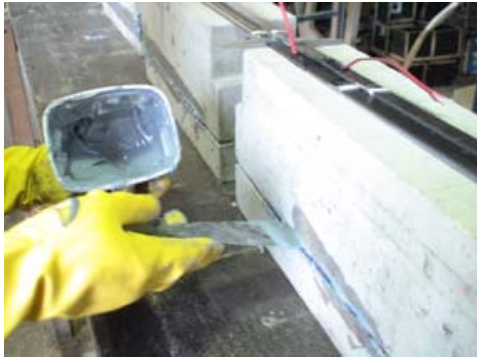

(c)

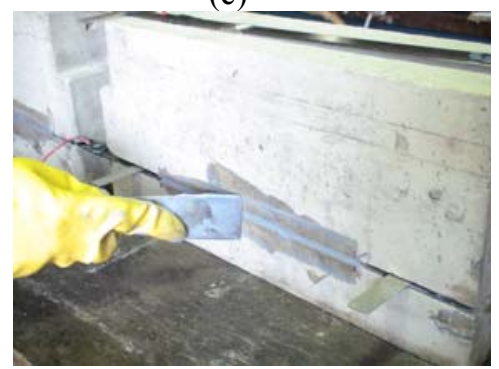

(f)

Figura 4.3 - Etapas da confecção dos modelos de ensaio de aderência.

\subsection{Propriedades dos materiais}

\section{- Concreto}

As determinações das resistências à compressão e à tração do concreto foram realizadas em corpos-de-prova cilíndricos com base na NBR 5739 (1994) e na NBR 7222 (1994), respectivamente. As resistências dos concretos bem como seus módulos de elasticidade encontram-se reunidas na Tabela 4.1.

Tabela 4.1 - Propriedades dos concretos.

\begin{tabular}{cccc}
\hline Série & $\boldsymbol{f}_{\boldsymbol{c}}(\boldsymbol{M P a})$ & $\boldsymbol{f}_{\boldsymbol{t}}(\boldsymbol{M P a})$ & $\boldsymbol{E}_{\boldsymbol{c}}(\boldsymbol{G P a})$ \\
\hline S1 & 45,2 & 3,00 & - \\
S2 & 50,0 & 3,81 & 30,0 \\
S3 & 32,0 & 3,36 & - \\
S4 & 63,6 & 5,21 & 41,5 \\
\hline
\end{tabular}

\section{- Resinas}

As propriedades das resinas fornecidas pelos fabricantes e encontram-se nas Tabelas de 11 a 13.

Tabela 4.2 - Propriedades físicas do adesivo utilizado nos modelos da série S1.

\begin{tabular}{|c|c|c|c|c|c|c|}
\hline $\begin{array}{c}\text { Resistência à } \\
\text { traçãoo } \\
\text { (MPa) }\end{array}$ & $\begin{array}{c}\text { Deformação } \\
\text { na traçâao } \\
\text { (\%) }\end{array}$ & $\begin{array}{c}\text { Módulo } \\
\text { à tração } \\
(\text { MPa) }\end{array}$ & $\begin{array}{l}\text { Resistência à } \\
\text { flexão } \\
\text { (MPa) }\end{array}$ & $\begin{array}{c}\text { Módulo à } \\
\text { flexão } \\
\text { (MPa) }\end{array}$ & $\begin{array}{c}\text { Resistência à } \\
\text { Compressãa } \\
\text { (MPa) }\end{array}$ & $\begin{array}{c}\text { Módulo à } \\
\text { compressão } \\
(\text { (MPa) }\end{array}$ \\
\hline 57 & 2,4 & 2998 & 131 & 3684 & 81 & 2560 \\
\hline
\end{tabular}


Tabela 4.3 - Propriedades físicas do adesivo utilizado nos modelos das séries S2 e S3.

\begin{tabular}{cccc}
\hline $\begin{array}{c}\text { Resistência à tração } \\
(\mathbf{M P a})\end{array}$ & $\begin{array}{c}\text { Deformação na ruptura } \\
(\%)\end{array}$ & $\begin{array}{c}\text { Módulo à tração } \\
(\mathbf{M P a})\end{array}$ & $\begin{array}{c}\text { Módulo à flexão } \\
(\boldsymbol{M P a})\end{array}$ \\
\hline 30 & 0,9 & 4500 & 3800 \\
\hline
\end{tabular}

Tabela 4.4 - Propriedades físicas do adesivo utilizado nos modelos da série S4.

\begin{tabular}{cccc}
\hline $\begin{array}{c}\text { Resistência ao cisalhamento } \\
(\mathbf{M P a})\end{array}$ & $\begin{array}{c}\text { Módulo de } \\
\text { elasticidade (MPa) }\end{array}$ & $\begin{array}{c}\text { Resistência à } \\
\text { flexotração (MPa) }\end{array}$ & $\begin{array}{c}\text { Resistência à } \\
\text { Compressão (MPa) }\end{array}$ \\
\hline 15 & 12800 & 28 & 95 \\
\hline
\end{tabular}

\section{- Laminado}

O laminado utilizado em todas as séries de ensaios bem como no ensaio-piloto tem denominação comercial "Fita de Fibra de Carbono" e foi adquirido junto à empresa "Rogertec". Embora se tenham realizado ensaios para caracterização de seu módulo de elasticidade e resistência à tração tanto em Fonseca (2007) quanto em Arquez (2010), preferiu-se, por uma questão de uniformidade, utilizar os dados informados pelo fornecedor (Tabela 4.5) na análise dos dados.

Tabela 4.5 - Propriedades físicas do laminado (dados do fornecedor).

\begin{tabular}{ccccccc}
\hline $\begin{array}{c}\text { Largura } \\
(\mathbf{m m})\end{array}$ & $\begin{array}{c}\text { Espessura } \\
(\mathbf{m m})\end{array}$ & $\begin{array}{c}\text { Resistência } \\
\dot{a} \text { tração } \\
(\mathbf{M P a})\end{array}$ & $\begin{array}{c}\text { Módulo de } \\
\text { elasticidade } \\
(\mathbf{G P a})\end{array}$ & $\begin{array}{c}\boldsymbol{\varepsilon}_{\boldsymbol{u}} \\
(\%)\end{array}$ & $\begin{array}{c}\text { Coeficiente de dilatação } \\
\text { térmica } \\
\text { Transversal } \\
\left(\mathbf{x 1 0} /^{\circ} \mathbf{C}\right)\end{array}$ & $\begin{array}{c}\text { Longitudinal } \\
\left(\mathbf{x 1 0} /^{\circ} \mathbf{C}\right)\end{array}$ \\
\hline 16 & 2 & 2068 & 131 & 1,7 & 74 a 104 & 9 a 0,0 \\
\hline
\end{tabular}

\subsection{Configuração e instrumentação dos ensaios}

A configuração do carregamento apresentou simetria em relação ao plano perpendicular que continha o eixo longitudinal da peça. O modelo foi bi-apoiado. Em cada apoio, foram posicionadas células de carga com capacidade de medida de $100 \mathrm{kN}$ que permitiram a determinação da reação. Sobre as células, semicilindros simularam a condição de articulação nos apoios. Dois cilindros metálicos foram utilizados para aplicação da carga em dois pontos distantes $75 \mathrm{~mm}$ do centro. Foram posicionados transdutores de deslocamento 
(LVDT) no laminado, no início da zona de ancoragem (laminado tracionado) e fim da zona de ancoragem (laminado livre de esforços) do bloco A, para medir o deslizamento do laminado em relação ao concreto. Um extensômetro foi colado em cada laminado posicionado a meio vão. A configuração esquemática do ensaio para as séries S1 e S2 e a instrumentação podem ser visualizadas na Figura 4.4. Para as séries S3 e S4, utilizou-se a mesma configuração do ensaio com a diferença apenas na posição do laminado e de se ter utilizado apenas um laminado por modelo. Os ensaios foram realizados na máquina universal de ensaios servohidráulica INSTRON, sob controle de deslocamento do pistão a uma taxa de $0,005 \mathrm{~mm} / \mathrm{s}$ e interrompidos com o deslizamento dos laminados.

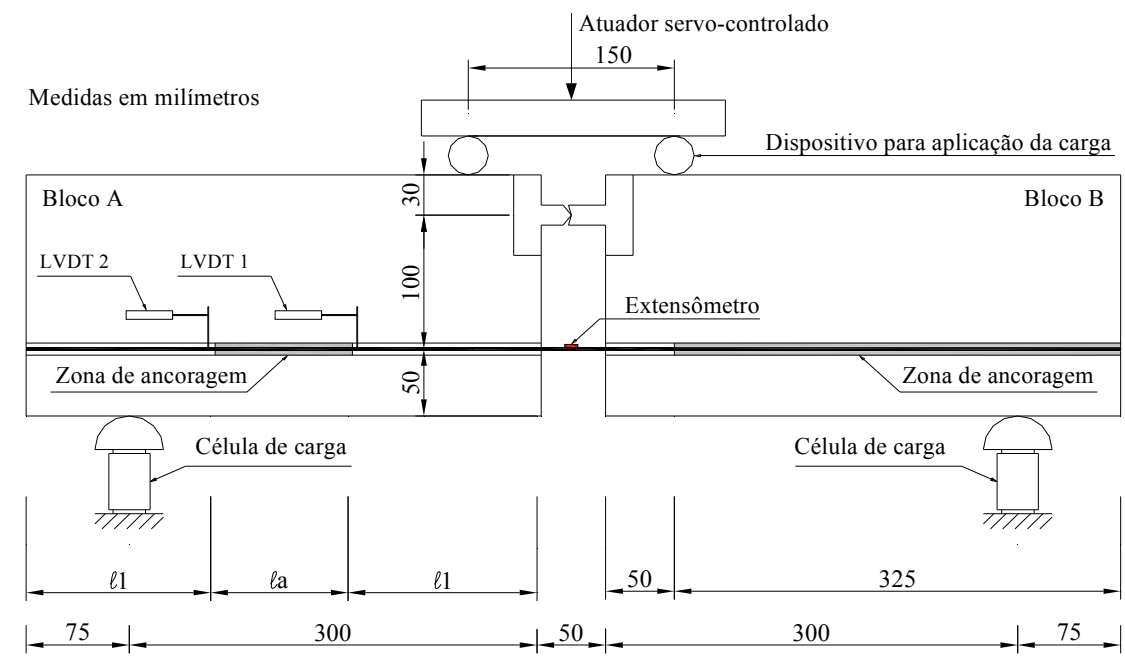

Figura 4.4 - Configuração esquemática dos ensaios.

\subsection{Resultados e análises}

\subsubsection{Trabalhabilidade}

Refere-se aqui a trabalhabilidade como a propriedade relacionada à maior ou menor facilidade de utilização das resinas de acordo com a técnica NSM. Essa avaliação foi feita apenas qualitativamente baseada na experiência da pesquisadora que pessoalmente efetuou a colagem dos laminados utilizando todas as resinas avaliadas. Quanto à consistência, apenas a resina utilizada na série $\mathrm{S} 1$ pareceu inadequada, pelo menos à colagem dos laminados lateralmente como foi utilizada. A resina, que é vendida conjuntamente ao laminado utilizado 
na pesquisa, se apresentou excessivamente fluida para a finalidade em questão, escorrendo facilmente do laminado na medida em que era aplicada e também do entalhe. Mesmo tendo-se o cuidado de colar uma fita adesiva sobre o entalhe preenchido, é perceptível na Figura 4.5-a que a resina escorreu do entalhe o que gerou vazios e um mau acabamento superficial. Imagina-se que esta resina seja mais apropriada para o reforço de lajes ou vigas a momento negativo, no banzo superior da peça. A resina utilizada nas séries S2 e S3 apresentou excelente trabalhabilidade embora ela seja indicada pelo fabricante para a colagem de mantas. O entalhe era facilmente preenchido e a resina não escorreu, sem a necessidade de utilização da fita adesiva para sua contenção. O reforço com essa resina apresentou um excelente acabamento superficial Figura 4.5-b. A resina utilizada na série S4, cuja finalidade especificada no catálogo do fabricante é a colagem de laminados pré-fabricados, foi a mais consistente de todas gerando certa dificuldade no preenchimento do entalhe e exigindo um maior esforço para introdução do laminado, contudo julga-se que o preenchimento foi eficiente e também com está resina se obteve um bom acabamento superficial (Figura 4.5-c).

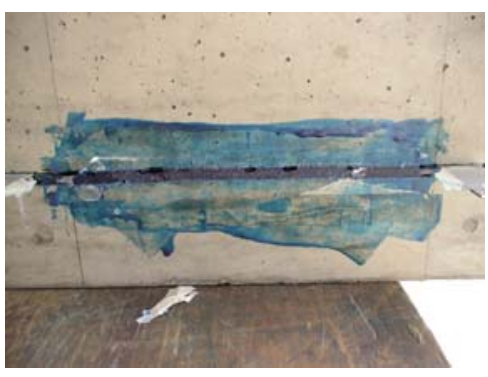

(a)

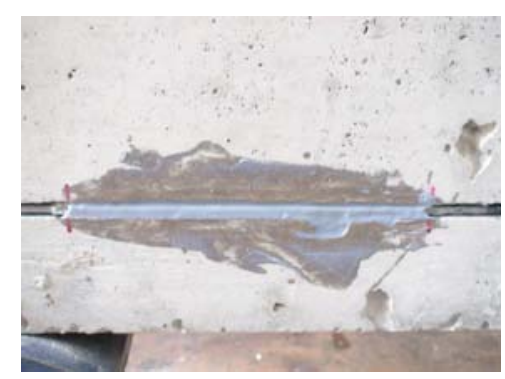

(b)

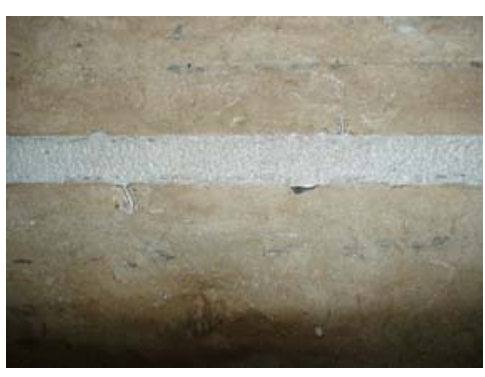

(c)

Figura 4.5 - Acabamento superficial da zona aderida para as três resinas utilizadas.

\subsubsection{Ruptura}

Para os ensaios da série S1 a ruptura ocorreu sempre por deslizamento na interface entre o adesivo e o concreto em direção paralela à do reforço e sem apresentar fissuras (Figura 4.6-a). Nos ensaios da série S2 e S3, a forma de ruptura variou com o comprimento de 
ancoragem. Para os modelos com comprimento de ancoragem de 70 e $140 \mathrm{~mm}$, a ruptura se deu puramente na interface adesivo/laminado. Para os modelos com maior comprimento de ancoragem estudado (210 mm), ocorreu fissuração diagonal no adesivo (Figura 4.6-b). Para a maioria dos modelos da série S4 foi impossível determinar o tipo de ruptura por inspeção visual. Naqueles em que foi possível identificou-se a ruptura na interface adesivo laminado (Figura 4.6-c).

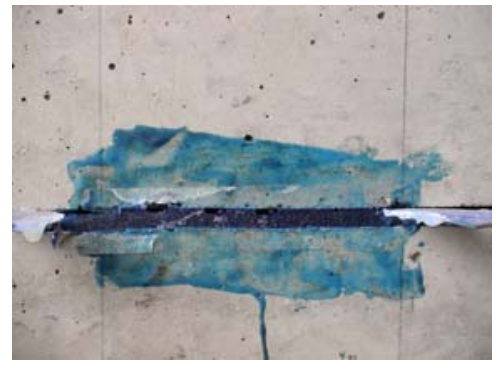

(a)

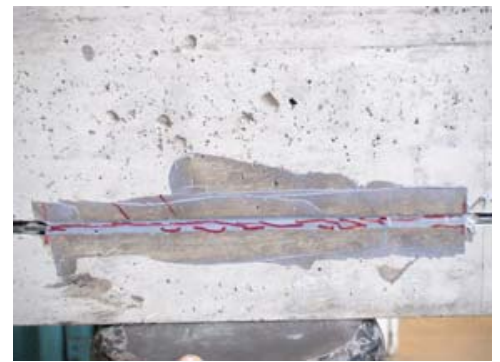

(b)

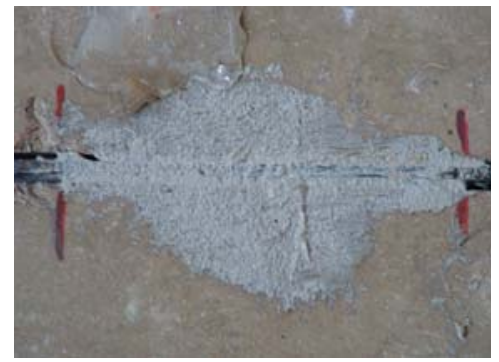

(c)

Figura 4.6 - Padrões de ruptura por deslizamento observados nos ensaios de aderência.

\subsubsection{Força no laminado}

A configuração do ensaio (Figura 4.7) permitiu o cálculo da força (força média por modelo de ensaio no caso das séries S1 e S2) no laminado por meio de duas formas: pela aplicação das condições de equilíbrio (Equação 6 para as séries S1 e S2 e Equação 7 para as séries S3 e S4) e pelo produto da deformação lida nos extensômetros fixados no laminado pelo módulo de elasticidade e pela área do compósito (Equação 8 para as séries S1 e S2 e Equação 9 para as séries S3 e S4).

$$
\begin{aligned}
& F_{\text {medl }}=\left(\frac{c 1+c 2}{2} \cdot \frac{B}{b}\right) \cdot \frac{1}{2} \\
& F_{1}=\frac{c 1+c 2}{2} \cdot \frac{B}{b} \\
& F_{\text {medl }}=\left(\frac{\varepsilon_{l 1}+\varepsilon_{l 1}}{2} \cdot \frac{B}{b}\right) \cdot E_{1} \cdot e \cdot L \\
& F_{1}=\varepsilon_{1} \cdot E_{1} \cdot e \cdot L
\end{aligned}
$$

Os símbolos nas Equações de 10 a 13 têm os seguintes significados: 
$F_{\text {med }}$ - Força média por laminado, por modelo (séries S1 e S2);

$F_{l}$ - Força no laminado (séries S3 e S4);

$C 1$ - Leitura da célula de carga C1;

C 2 - Leitura da célula de carga C2;

$B$ - Distância entre o apoio e o ponto de aplicação da força (Figura 4.7);

$b$ - Braço de alavanca interno igual a $100 \mathrm{~mm}$ para as séries $\mathrm{S} 1$ e $\mathrm{S} 2$ e a $141 \mathrm{~mm}$ para as séries S3 e S4 (graficamente definido na Figura 4.7);

$\mathcal{E}_{l 1}$ - Deformação lida no extensômetro colado ao laminado 1 (séries S1 e S2);

$\mathcal{E}_{l 2}$ - Deformação lida no extensômetro colado ao laminado 2 (séries S1 e S2);

$\varepsilon_{l}$ - Deformação lida no extensômetro colado ao laminado (séries S3 e S4);

$E_{l}$ - Módulo de elasticidade do laminado;

$e$ - Espessura do laminado (graficamente definida na Figura 4.7);

$L$ - Largura do laminado (graficamente definida na Figura 4.7).

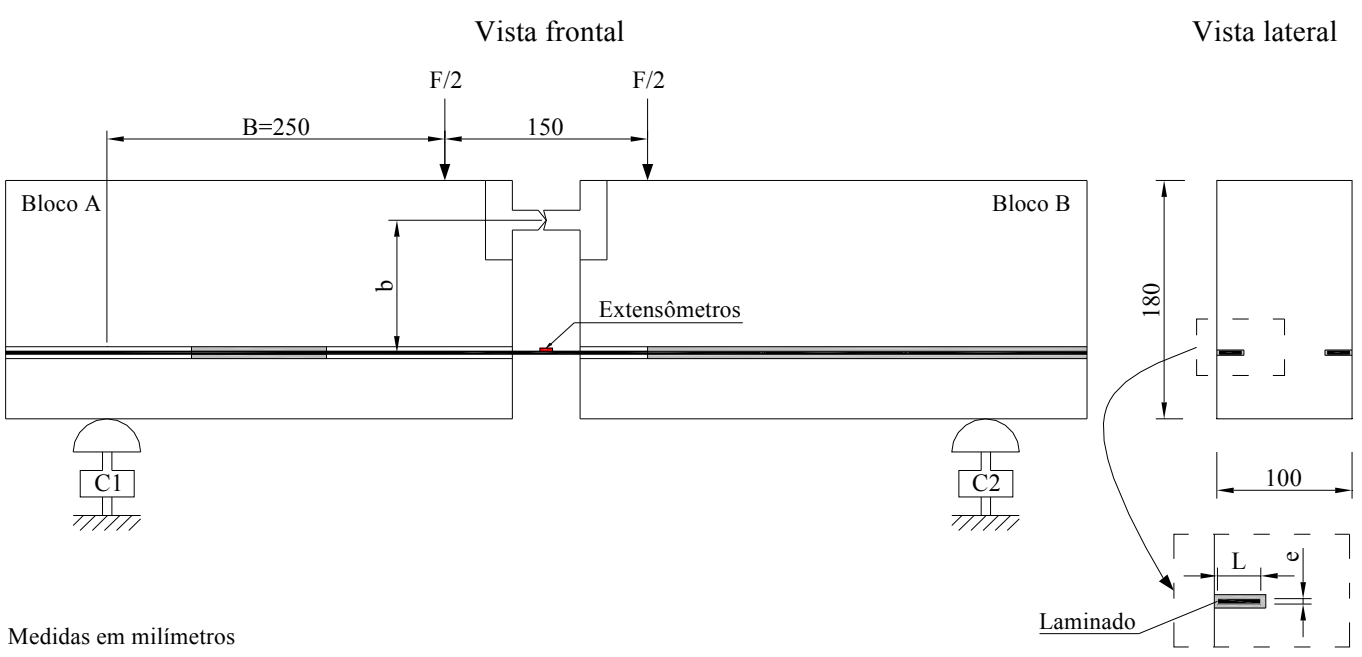

Figura 4.7 - Configuração esquemática do ensaio.

O grau de concordância entre as duas formas de cálculo variou nos modelos, entretanto, de modo geral, pode-se dizer que houve semelhança satisfatória nos resultados para todos os modelos. Na Figura 4.8-a, destaca-se o resultado do ensaio em que as duas 
formas de cálculo mais se aproximaram e na Figura 4.8-b, um resultado em que houve distanciamento entre elas.

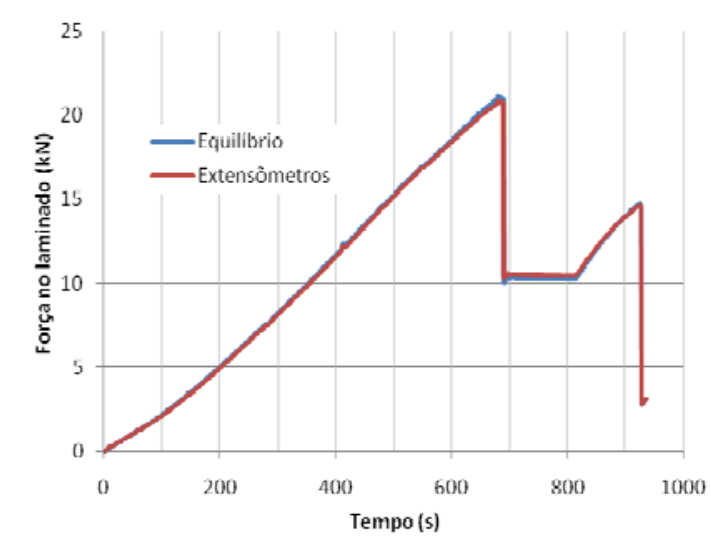

(a)

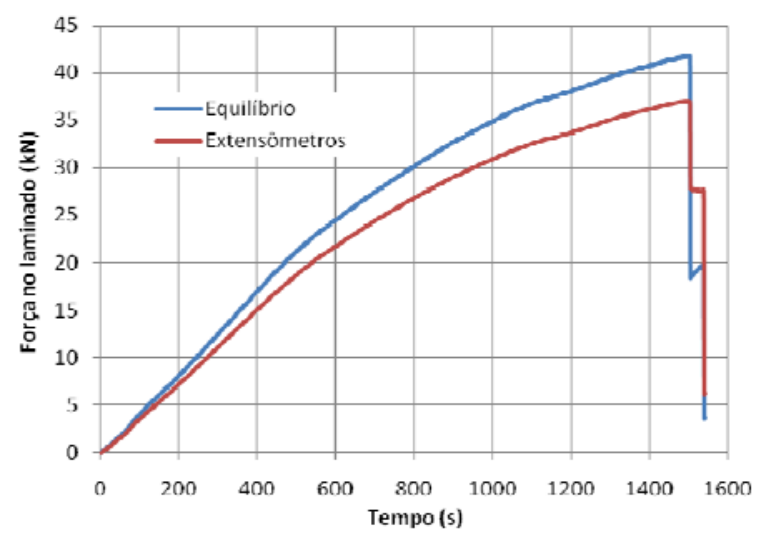

(b)

Figura 4.8 - Gráfico "força x tempo" definido por meio do equilíbrio de forças e dos dados obtidos nos extensômetros: (a) modelo M1L70S2; (b) modelo M1L210S2.

As análises subsequentes se fundamentam na determinação da força em cada laminado individualmente calculadas, para os ensaios das séries S1 e S2, pela Equação 10.

$F_{l i}=\varepsilon_{l i} \cdot E_{1} \cdot e \cdot L$

Em que:

$F_{l i}$ - Força no laminado determinada individualmente ( $i=1$ ou 2$)$

$\mathcal{E}_{l i}$ - Deformação lida no extensômetro colado ao laminado $(i=1$ ou 2$)$

Houve problemas nos extensômetros do modelo M1L140S3, assim as análises para este modelo foram baseadas no equilíbrio das forças. Os resultados do modelo M1L210S3 foram descartados, pois o entalhe deste modelo apresentou profundidade inferior a $18 \mathrm{~mm}$ e o laminado não pôde ser totalmente introduzido nele.

\subsubsection{Tensão de aderência}

A tensão de aderência foi calculada como a razão entre a força no laminado e a área superficial ao longo do comprimento de ancoragem, por meio da Equação 11. 


$$
\tau_{l i}=\frac{F_{l i}}{2 \cdot(e+L) \cdot l_{a}}
$$

A curva "tensão x deslizamento", no início da zona de ancoragem para o laminado 2 do modelo M2L150S1 (Figura 4.9) tem a forma típica, observada em ensaio de laminados ou barras de PRF. Apresenta um trecho ascendente até um pico de tensão (resistência de aderência). Após o pico observa-se um trecho descendente até que se alcança um patamar para determinada tensão residual. Para a maioria dos laminados, como para o laminado 1 do modelo M2L150S1, foi possível a obtenção apenas do trecho ascendente da curva "tensão x deslizamento", no início da zona ancorada. Na maior parte dos casos, a interrupção prematura ocorreu em função da perda de leitura do deslizamento pelo desprendimento do dispositivo de referência colado ao laminado. A realização do ensaio sob controle de deslocamento do transdutor fixado no inicio da zona ancorada permitiria provavelmente a obtenção do ramo descendente como se observou em Cruz (2004).

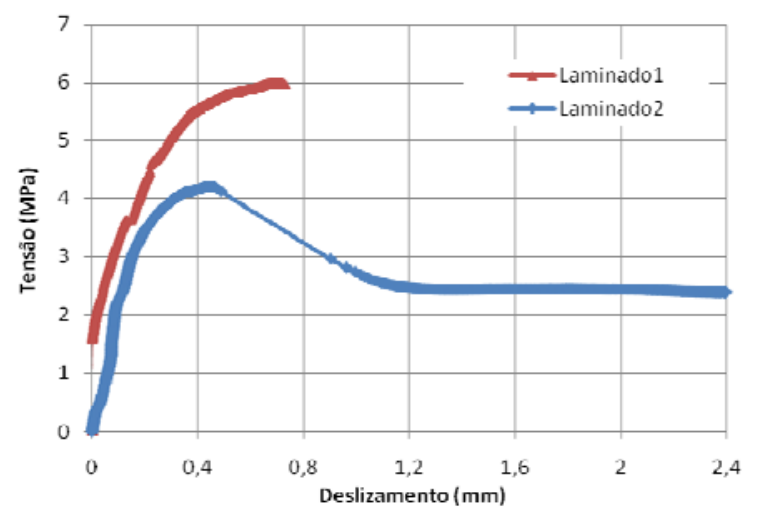

Figura 4.9 - Curva “tensão x deslizamento", no início da zona de ancoragem - M2L150S1.

\subsubsection{Variações com o comprimento aderido e comparações}

O gráfico da Figura 4.10 ilustra a variação da força no laminado com o comprimento aderido. Como se previa, a força no laminado aumenta conforme se aumenta o comprimento aderido. Esta relação não é, contudo, linear, pois a distribuição de tensões de aderência na interface não é linear. Dentre todas as resinas utilizadas, a da série S4 foi a que apresentou o melhor desempenho que foi bastante semelhante ao da resina utilizada nas series S2 e S3. 
Ainda assim, a força máxima alcançada foi muito inferior a força que levaria à ruptura do laminado (em torno de 60\%). Uma maior variabilidade dos resultados por laminado foi observada para a série $\mathrm{S} 1$, justificável pela má trabalhabilidade da resina utilizada nesta serie.

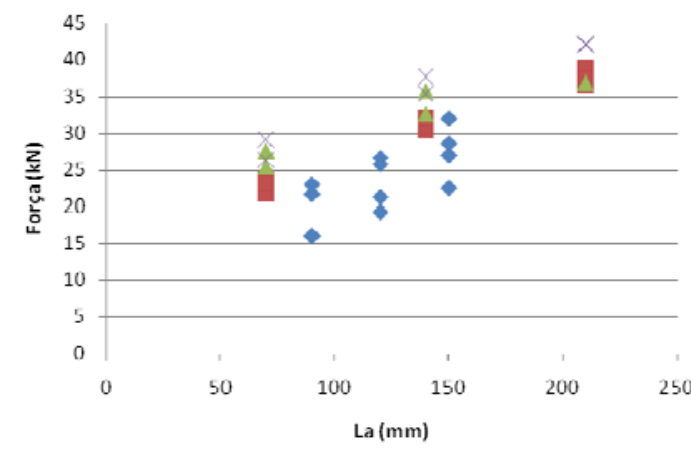

(a)

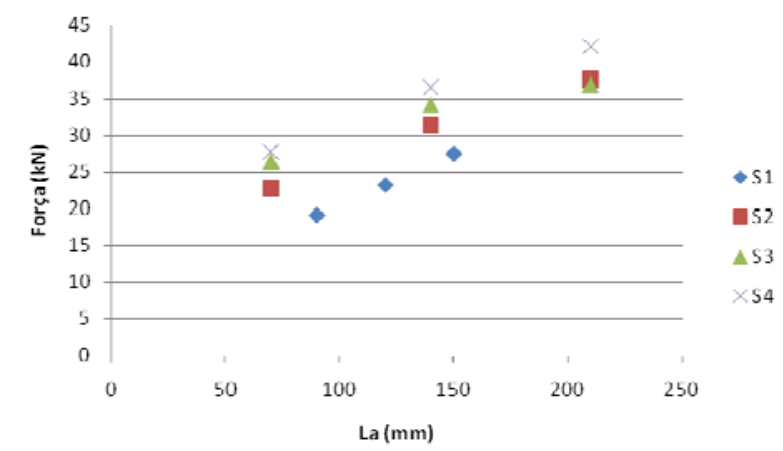

(b)

Figura 4.10 - Variação da força máxima no laminado com comprimento de ancoragem.

A tensão máxima de aderência $\left(\tau_{\text {máx }}\right)$ apresenta decréscimo com o aumento do comprimento de ancoragem, como se pode observar nos gráficos da Figura 4.11.

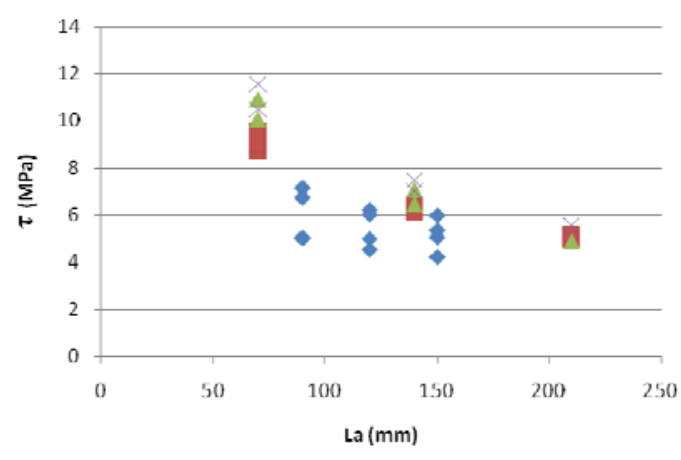

(a)

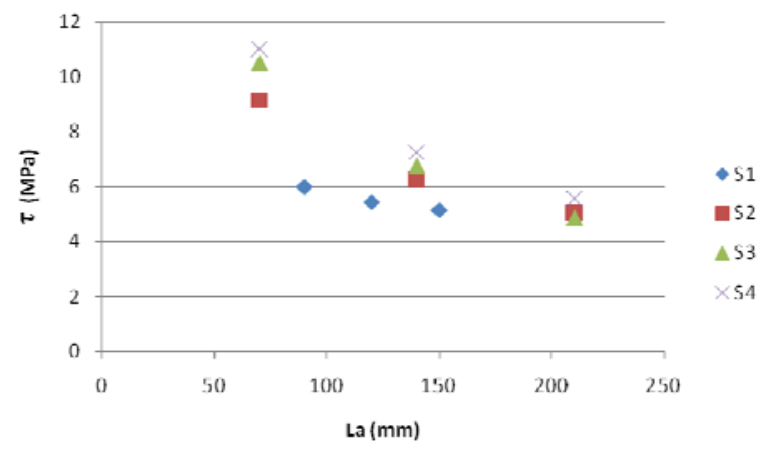

(b)

Figura 4.11 - Variação da tensão máxima de aderência com o comprimento de ancoragem.

\subsection{Conclusões}

As resinas aplicadas neste estudo apresentaram diferenças na trabalhabilidade, no modo de ruptura, na mobilização da capacidade resistente do laminado, no acabamento superficial e na homogeneidade do reforço. 
Nos testes realizados, particularmente, uma das resinas se mostrou imprópria para utilização no reforço por colagem de laminados em entalhes realizados nas laterais ou fundo de elementos estruturais. Sua consistência excessivamente fluida acarretou grande dificuldade no preenchimento dos entalhes, mesmo nas condições de laboratório, mais favoráveis que as condições de obra.

Considerando-se o gráfico "tensão máxima de aderência $\mathrm{x}$ comprimento de ancoragem", verificou-se que uma diferença considerável na resistência de aderência foi observada apenas para os menores comprimentos aderidos. Para maiores comprimentos aderidos pode-se inferir um desempenho semelhante para os três tipos de resina utilizados.

Com base na comparação dos resultados das séries S2 e S3, percebe-se que adição de fibras ao concreto não tem influência significativa na aderência do reforço.

A resina Sikadur ® 330, embora não seja específica para colagem de laminados, apresentou desempenho quase tão bom quanto a Sikadur ${ }^{\circledR}$ 30. Para aplicação na colagem de entalhes no concreto de cobrimento lateral ou no banzo superior de peças estruturais, como utilizado nessa pesquisa, apresentou uma maior facilidade de emprego em função da sua consistência. A resina Sikadur ${ }^{\circledR} 30$ é a mais consistente e, portanto a mais apropriada dentre as estudadas no caso da utilização para reforço no fundo de peças estruturais por uma menor propensão ao desprendimento do laminado antes da cura da resina. 


\section{CAPÍTULO 5}

\section{ENSAIO EM MODELO DE LIGAÇÃO SEMIRRÍGIDA REFORÇADA A FLEXÃO}

\subsection{Características dos modelos}

Trata-se de um estudo de caso da aplicação do reforço na reabilitação de uma ligação viga-pilar previamente submetida à ruptura. $\mathrm{O}$ modelo de ensaio (Figura 5.1) foi utilizado na pesquisa de Baldissera (2006), já citada no Capítulo 3, e permaneceu, após isto, no laboratório de estruturas a fim de ser utilizado em outras investigações.

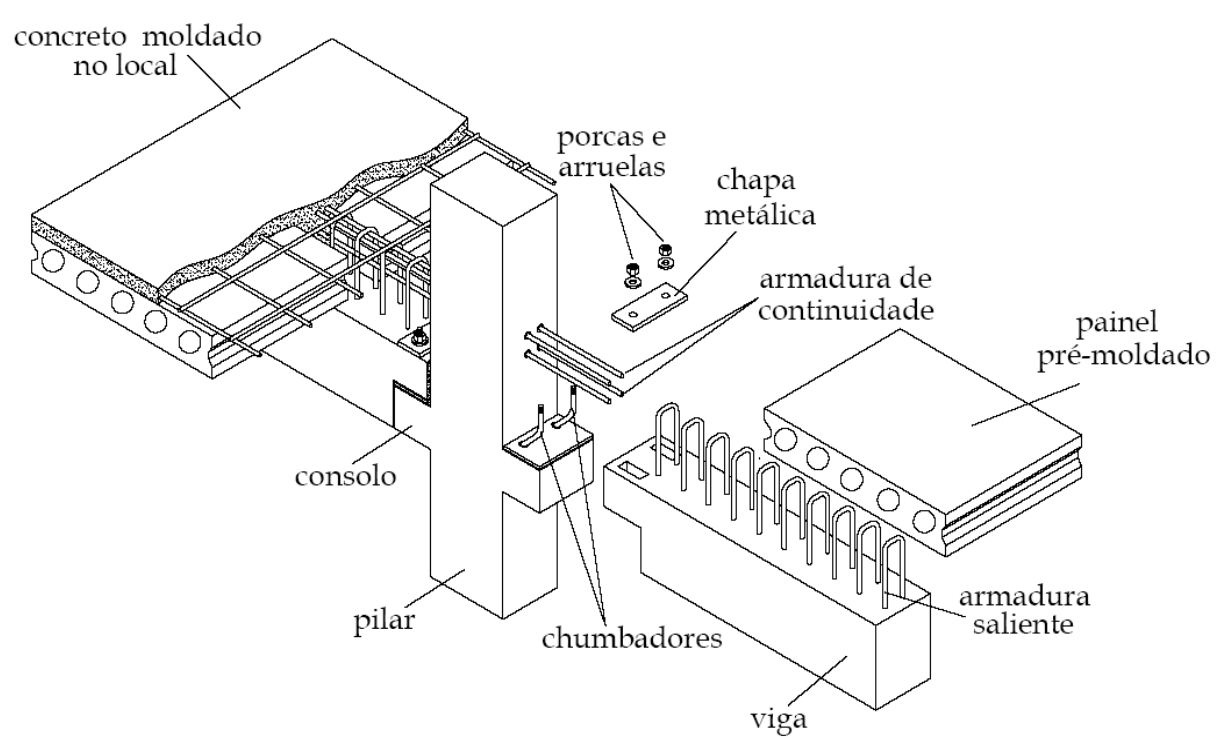

Figura 5.1 - Componentes da ligação estudada por Baldissera (2006) 
O modelo I (denominação proposta por Baldissera, (2006)) representa uma ligação viga-pilar intermediária. A resistência a momento negativo da ligação é resultante da armadura passante no pilar e capa da laje. A ligação apresenta também resistência a momento positivo obtida por meio da utilização de chumbador inclinado. Os componentes da ligação e suas características geométricas são apresentados na Figura 5.1 e na Figura 5.2.

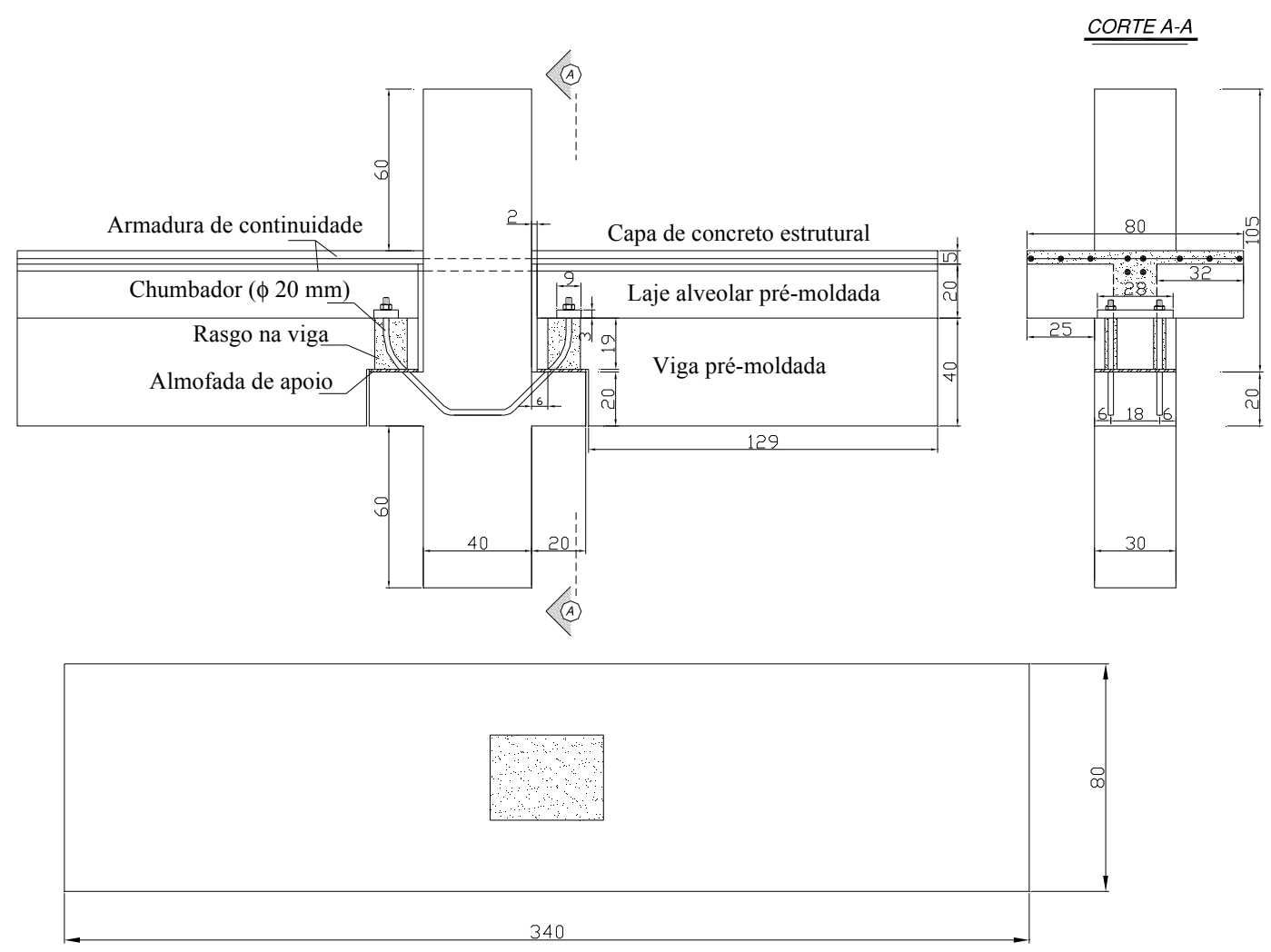

Figura 5.2 - Características geométricas do modelo estudado por Baldissera (2006)

Em seu ensaio, Baldissera (2006) submeteu o modelo à força cíclica alternada solicitando a ligação a momento positivo e negativo, conforme esquema apresentado na Figura 5.3. Na Figura 5.4, pode-se observar o modelo fixado à estrutura de reação e ao atuador antes da realização do ensaio. O carregamento foi aplicado em vinte e um ciclos. Nos vinte primeiros, aplicou-se uma força correspondente a $60 \%$ da força de ruptura prevista. No vigésimo primeiro, o modelo foi levado à ruptura a momento negativo pelo escoamento da armadura passante na capa e a momento positivo pelo escoamento do chumbador. Maiores 
detalhes sobre o ensaio podem ser consultados em Baldissera (2006). Um resumo das principais características do modelo é apresentado no Quadro 5.1.

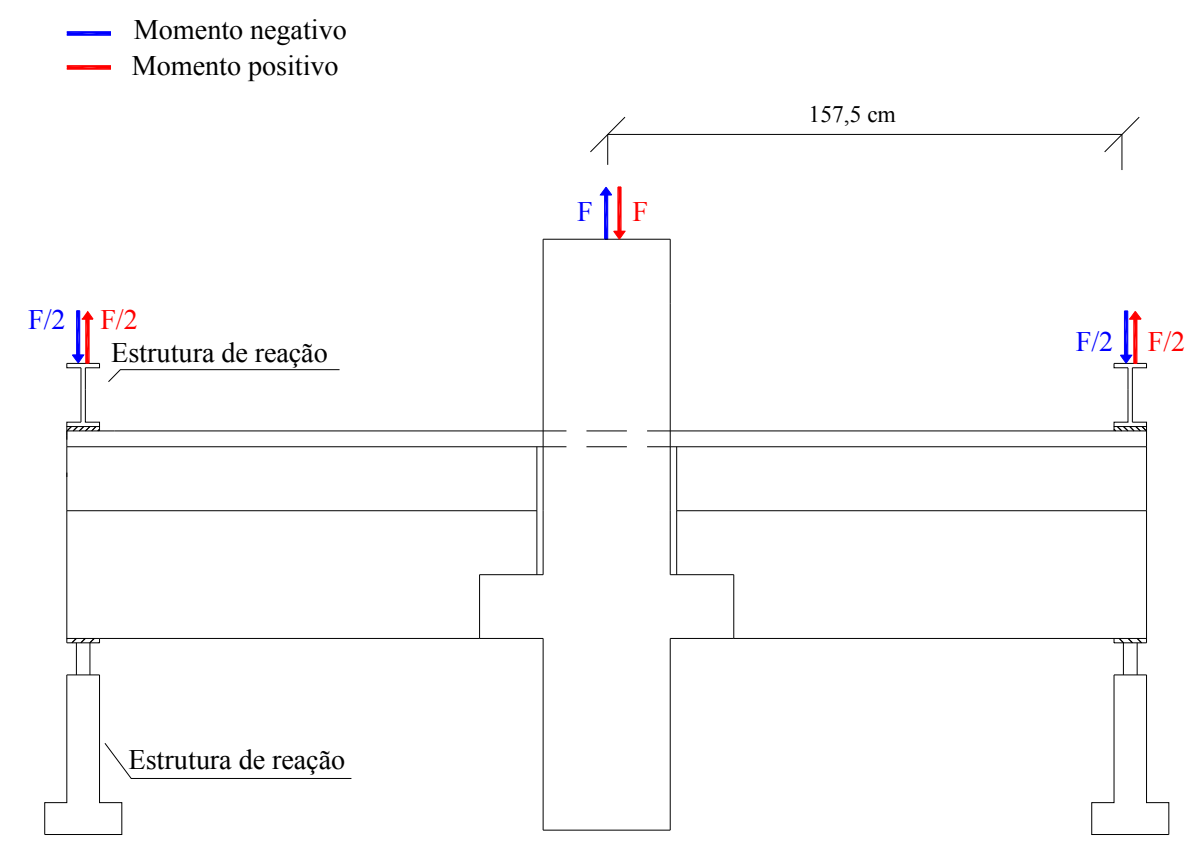

Figura 5.3 - Esquema de solicitação do modelo adotado por Baldissera (2006)

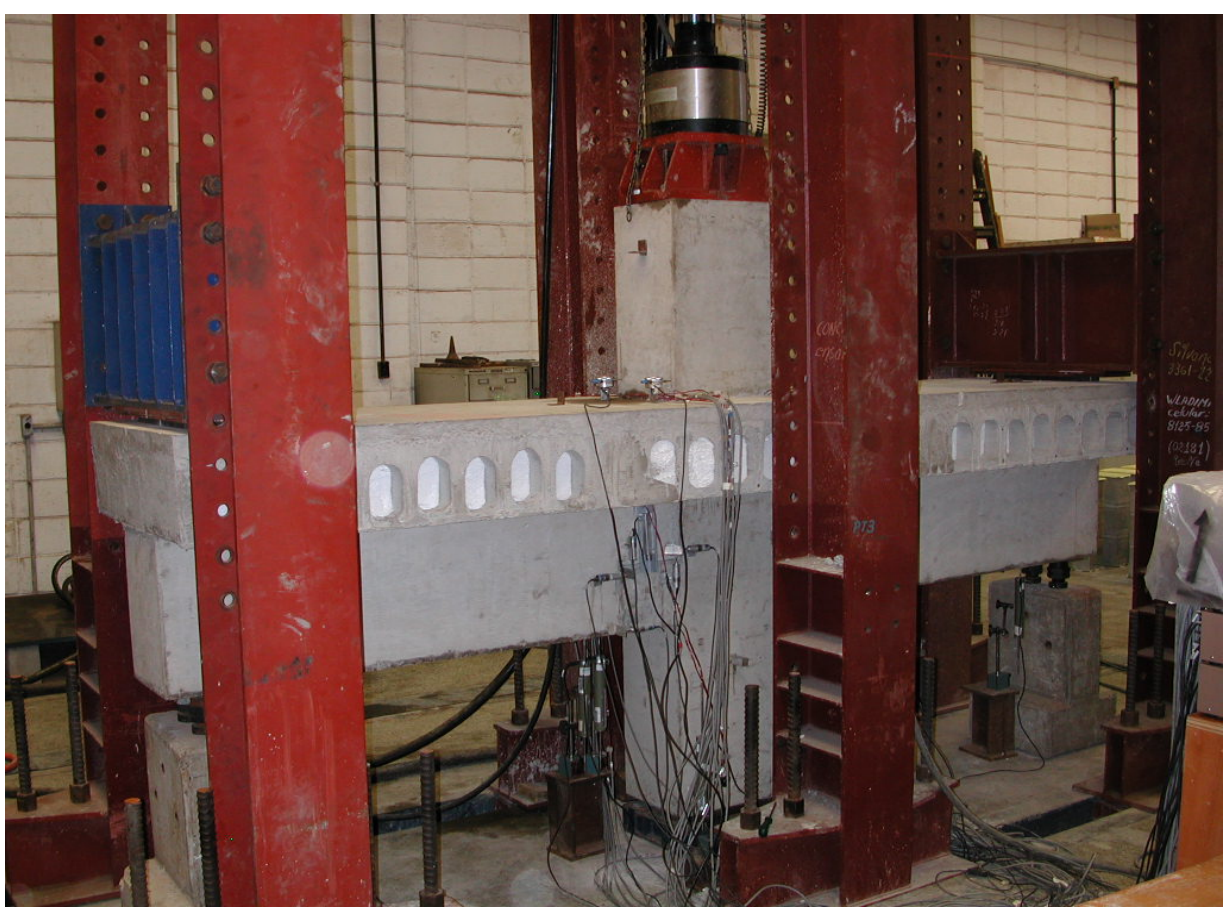

Figura 5.4 - Modelo fixado à estrutura de reação e ao atuador antes do ensaio. 


\begin{tabular}{|l|l|}
\hline \multicolumn{1}{|c|}{ Tipo de modelo } & \multicolumn{1}{c|}{ Modelo I (Pilar Intermediário) } \\
\hline Descrição: & $\begin{array}{l}\text { 01 pilar intermediário com 02 consolos, 02 vigas retangulares e } \\
\text { painéis de laje alveolar. }\end{array}$ \\
\hline Resistência à compressão: & $\begin{array}{l}\text { Vigas e pilares }=50,9 \mathrm{MPa} \text {. Concreto entre as lajes e capa }=34,3 \\
\text { MPa. }\end{array}$ \\
\hline Dimensionamento: & $\begin{array}{l}\text { Cálculo segundo Miotto (2002). Armadura de continuidade: } 50 \% \\
\text { sendo barras passando por dentro do pilar e 50\% sob forma de } \\
\text { malha distribuída na capa. }\end{array}$ \\
\hline Chumbadores: & $\begin{array}{l}\text { Aço CA-50, } \phi=20 \text { mm. } \\
\text { Ancoragem: comprimento embutido dentro do pilar e por meio de } \\
\text { chapa metálica (31 mm de espessura), porcas e arruelas na parte } \\
\text { superior da viga. }\end{array}$ \\
\hline Almofada de apoio: & $\begin{array}{l}\text { Almofada à base de argamassa de cimento e areia, confeccionada } \\
\text { no LE. }\end{array}$ \\
\hline Graute: & Auto-adensável com retração compensada de 37,2 e 27,5 MPa. \\
\hline
\end{tabular}

Quadro 5.1 - Principais características do modelo estudado por Baldissera (2006)

\subsection{Reforço}

O reforço foi realizado pelo grauteamento dos espaços vazios da ligação e pela colagem de laminados no concreto de cobrimento da capa da laje e na lateral inferior da ligação. Na Figura 5.5, pode-se observar o posicionamento dos laminados. Seguiu-se, para colagem dos laminados, o mesmo procedimento descrito no Item 4.1.1 desta tese.

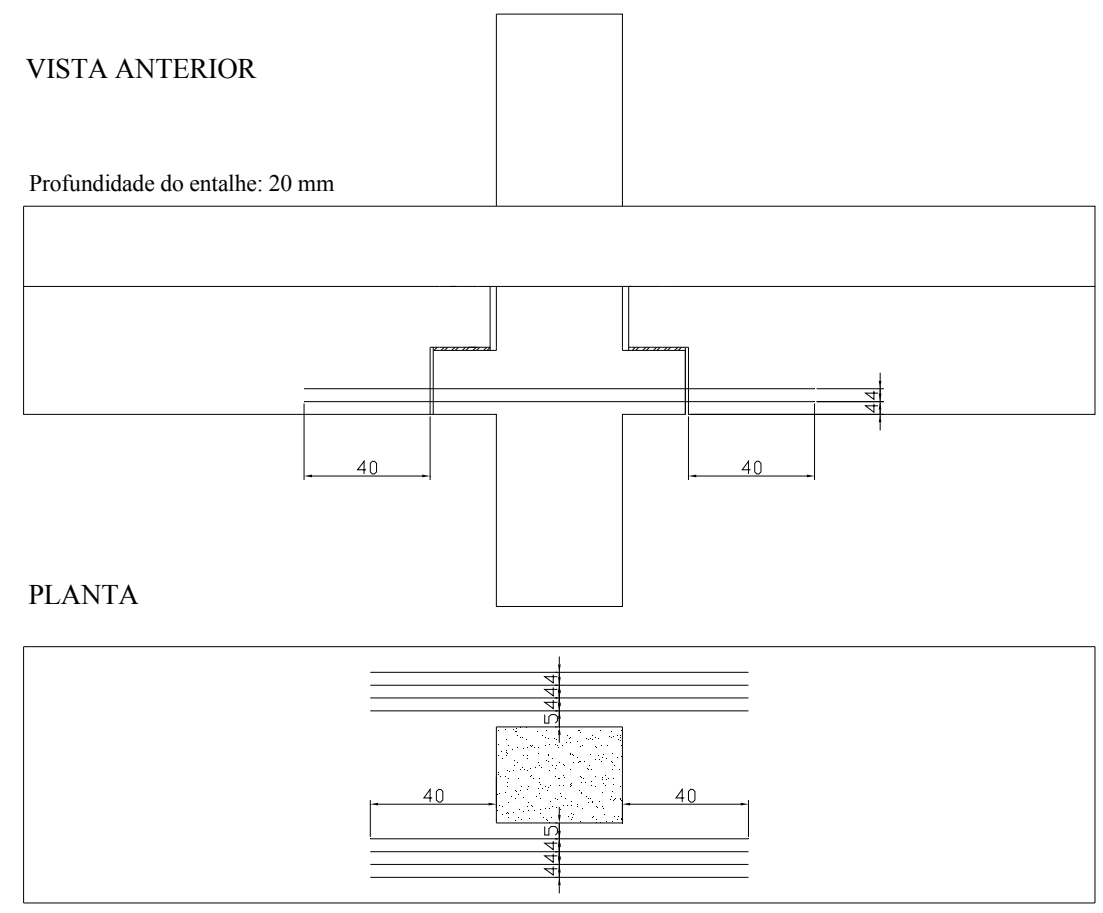

Figura 5.5 - Posicionamento dos laminados para reforço da ligação. 
Para o grauteamento dos espaços entre o consolo e o dente da viga, o modelo posto em posição inclinada no laboratório (Figura 5.6-a). Vedou-se o espaço que se queria preencher com uso de fita adesiva e chapa de madeira (Figura 5.6-b).

Após a cura do graute, o modelo foi reerguido e foram feitos os entalhes no concreto de cobrimento da capa da laje (Figura 5.6-c). Iniciou-se a confecção dos entalhes laterais também com o modelo na posição de ensaio, contudo isso levou a danificação do equipamento de corte em função do contato da água com sua parte elétrica. Um novo equipamento foi adquirido e realizaram-se os entalhes restantes com o modelo inclinado (Figura 5.6-d).

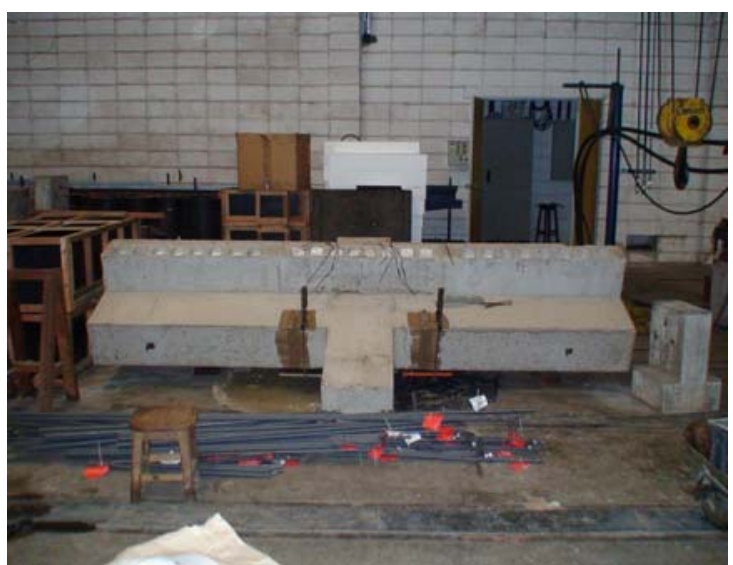

(a)

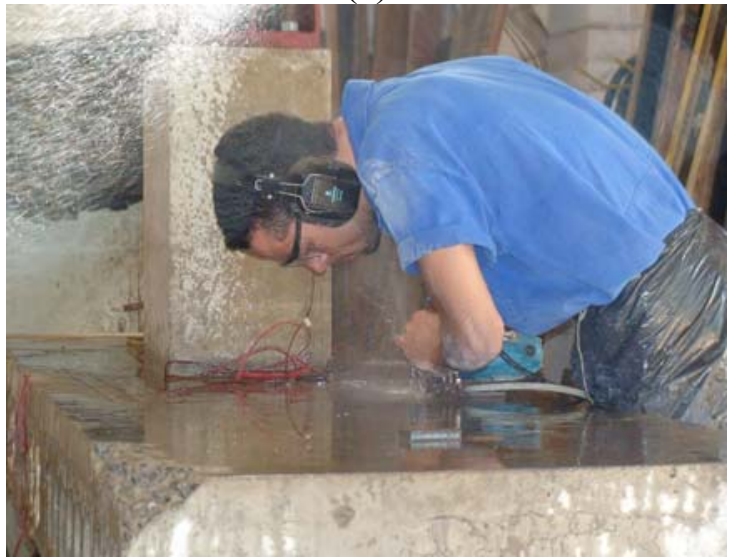

(c)

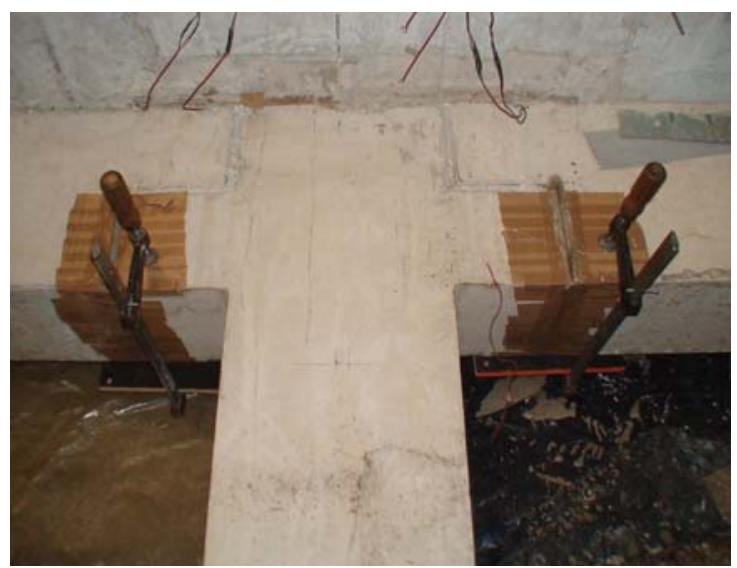

(b)

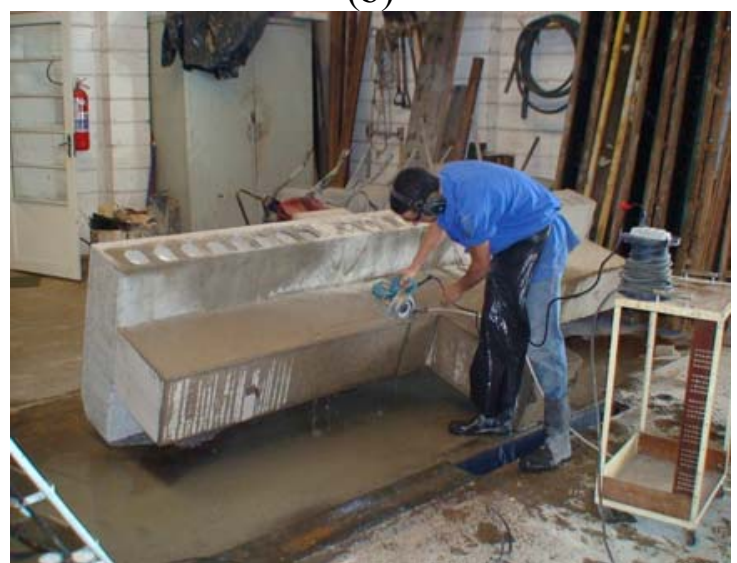

(d)

Figura 5.6 - Etapas do reforço do modelo.

No processo de inclinação e erguimento do modelo, houve a separação do graute e do concreto em uma das ligações (Figura 5.7-a). Na outra ligação, não houve qualquer separação 
na interface concreto/graute (Figura 5.7-b). Tentou-se preencher esse novo espaço que surgiu com nata cimento o que se mostrou inviável em função da sua exiguidade.

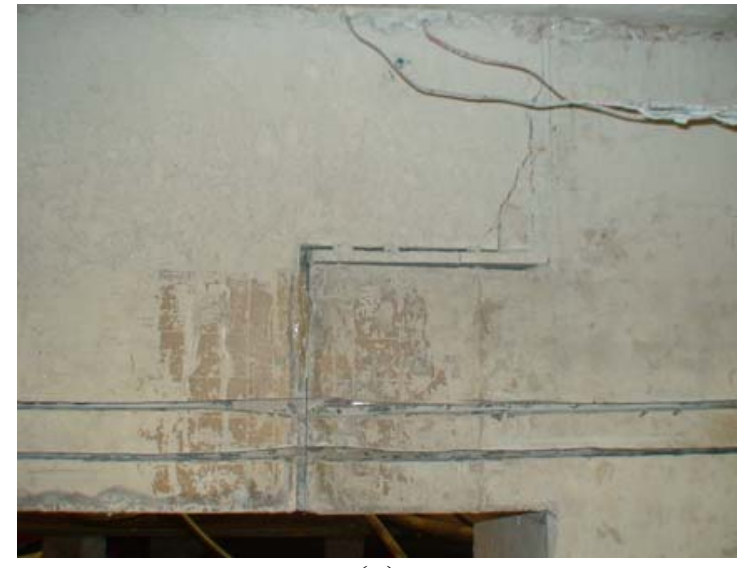

(a)

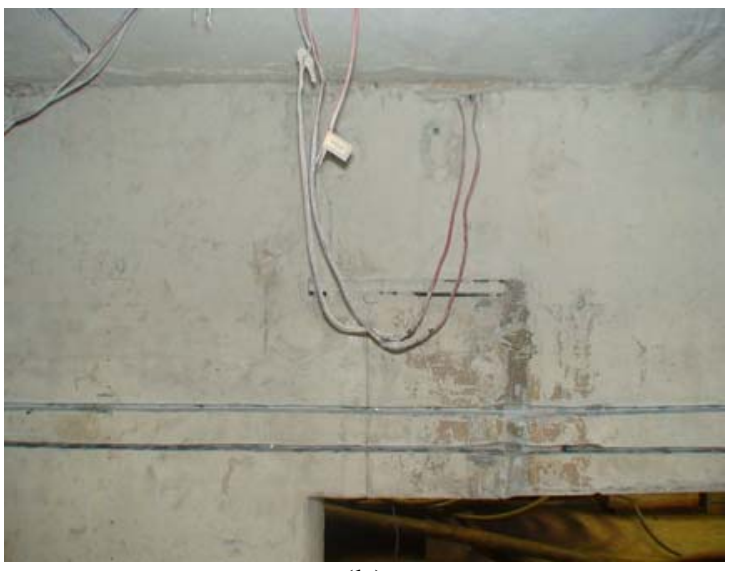

(b)

Figura 5.7 - Aspecto das ligações após grauteamento e confecção dos entalhes.

O modelo foi fixado na estrutura de reação na posição de ensaio e realizou-se a colagem dos laminados (Figura 5.8-a e Figura 5.8-b).

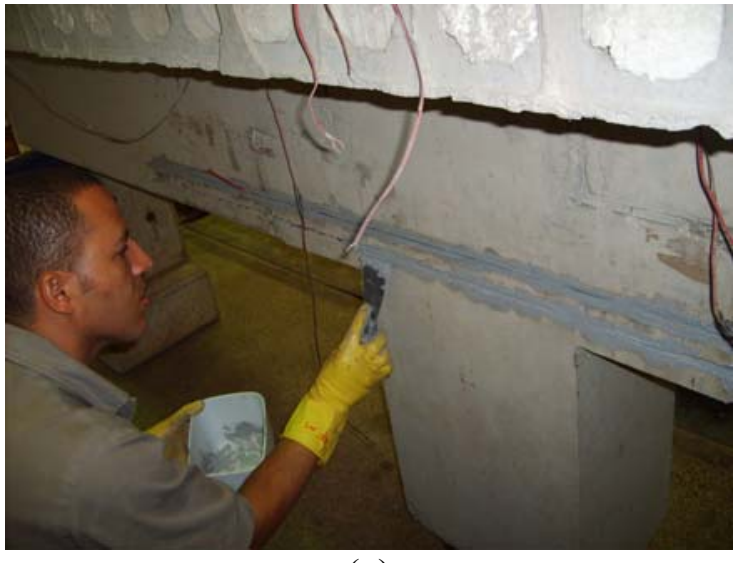

(a)

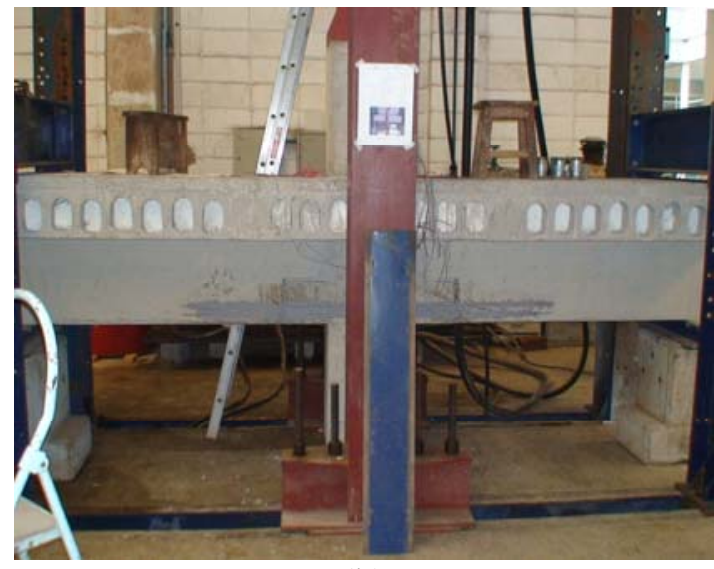

(b)

Figura 5.8 - Colagem dos laminados na lateral do modelo.

\subsection{Propriedades dos materiais}

\section{- Graute}

Utilizou-se graute Super Graute, fabricado pela Weber Quartzolit. Foram adotados corpos-de-prova de $5 \mathrm{~cm}$ de diâmetro e $10 \mathrm{~cm}$ de altura para a caracterização do graute. Os 
ensaios para determinação da resistência à compressão e módulo foram realizados na máquina universal de ensaios servo-hidráulica INSTRON com uso do sistema de aquisição de dados System 5000 da Vishay. As deformações utilizadas na determinação do módulo de elasticidade foram obtidas por meio de extensômetros removíveis com base de leitura de 5 cm. Os ensaios para determinação da resistência a tração por compressão diametral foram realizados na máquina hidráulica ELE Autotest 2000. Os resultados da caracterização estão dispostos na Tabela 5.1 .

Tabela 5.1 - Propriedades do graute.

\begin{tabular}{ccccc}
\hline Corpo-de-prova & Idade (dias) & $\boldsymbol{f}_{\boldsymbol{c}}(\mathbf{M P a})$ & $\boldsymbol{f}_{\boldsymbol{t}}(\mathbf{M P a})$ & $\boldsymbol{E}_{\boldsymbol{c}}(\mathbf{G P a})$ \\
\hline 1 & 97 & 30,40 & - & 39,9 \\
2 & 97 & 33,95 & - & 37,3 \\
3 & 97 & 34,46 & - & 41,2 \\
4 & 97 & - & 2,44 & - \\
5 & 97 & - & - & - \\
6 & 97 & - & 2,51 & - \\
Média & & $\mathbf{3 2 , 9 4}$ & $\mathbf{2 , 4 8}$ & $\mathbf{3 9 , 5}$ \\
\hline
\end{tabular}

- Adesivo

Para a colagem dos laminados, utilizou-se a resina Sikadur ${ }^{\circledR} 30$ cujas propriedades já foram apresentadas no Item 4.2 .

- Laminado

O laminado utilizado tem denominação comercial "Fita de Fibra de Carbono" suas propriedades já foram apresentadas no Item 4.2deste texto.

\subsection{Instrumentação e configuração do ensaio estático}

A instrumentação utilizada no ensaio pode ser visualizada nas Figura 5.9 a Figura 5.12. Utilizaram-se, em uma das faces do modelo (face anterior), transdutores de deslocamento para obtenção do deslocamento relativo entre os elementos estruturais (Figura 5.9). Os dados obtidos por meio de alguns destes transdutores foram utilizados para o cálculo 
da rotação na ligação e consequentemente na determinação da rigidez como se detalha no Item 5.6.3 a seguir.

$\mathrm{Na}$ face posterior, fixaram-se clinômetros para a obtenção da rotação relativa entre as vigas e o pilar (Figura 5.10). Utilizaram-se transdutores também para a obtenção do deslocamento vertical do modelo (Figura 5.11). Nos laminados, nas posições em que se julgava que haveria maiores solicitações, foram fixados extensômetros elétricos (Figura 5.12).

O posicionamento da instrumentação é simétrico em relação ao plano normal ao eixo longitudinal da viga que corta o eixo do pilar. Deste modo, foi possível fazer uma análise do comportamento individual das ligações que compõem o modelo.

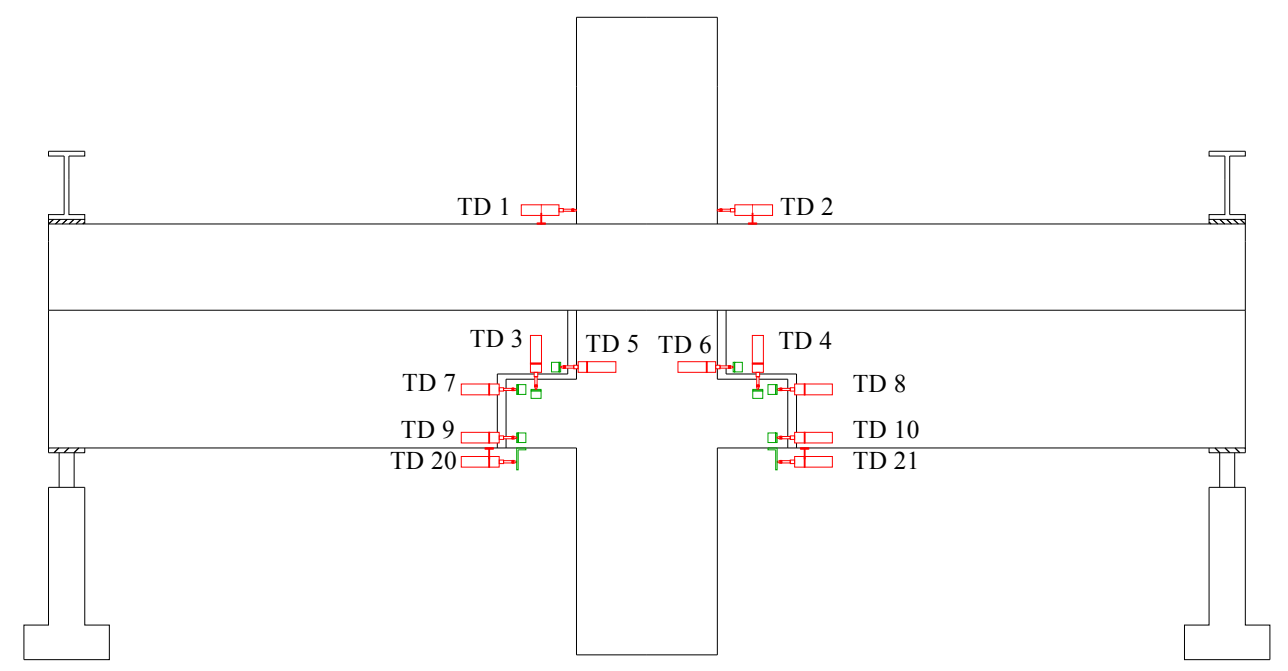

Figura 5.9 - Posicionamento dos transdutores para obtenção dos deslocamentos relativos entre os elementos estruturais.

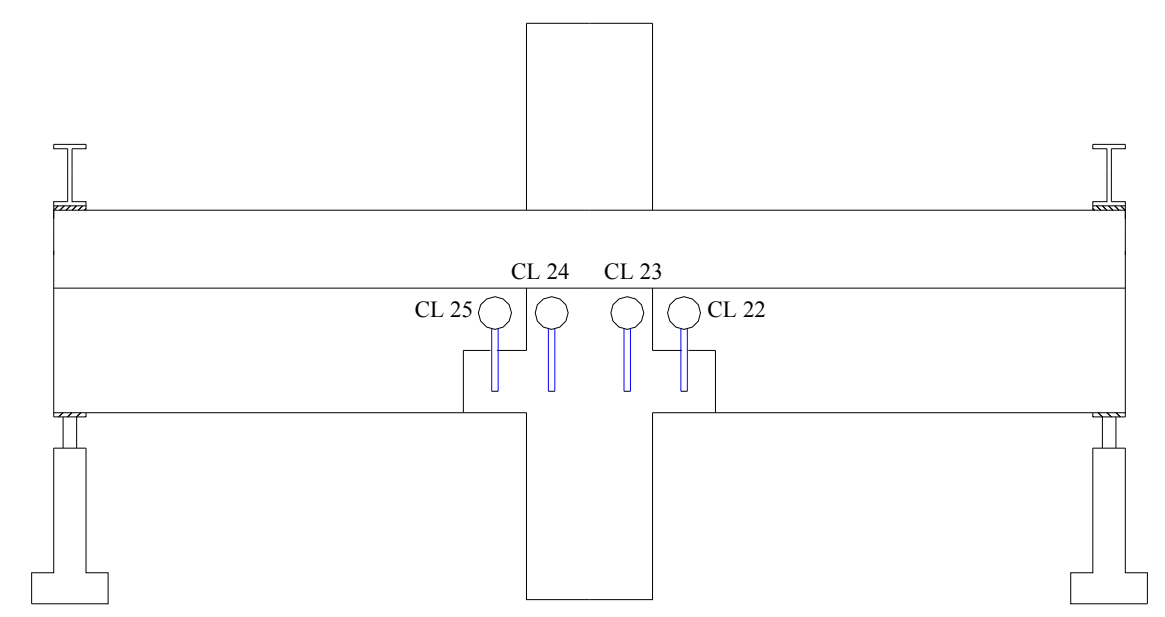

Figura 5.10 - Posicionamento dos clinômetros para obtenção da rotação relativa entre os elementos estruturais. 


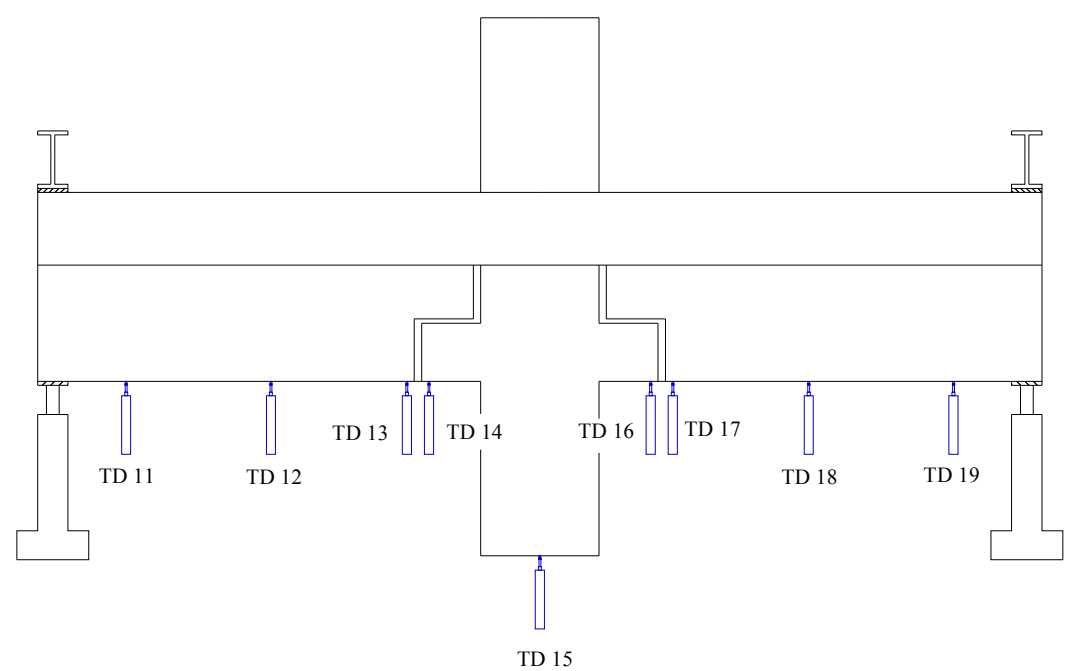

Figura 5.11 - Posicionamento dos transdutores para obtenção dos deslocamentos verticais do modelo.

FRONTAL

Profundidade do entalhe: $20 \mathrm{~mm}$

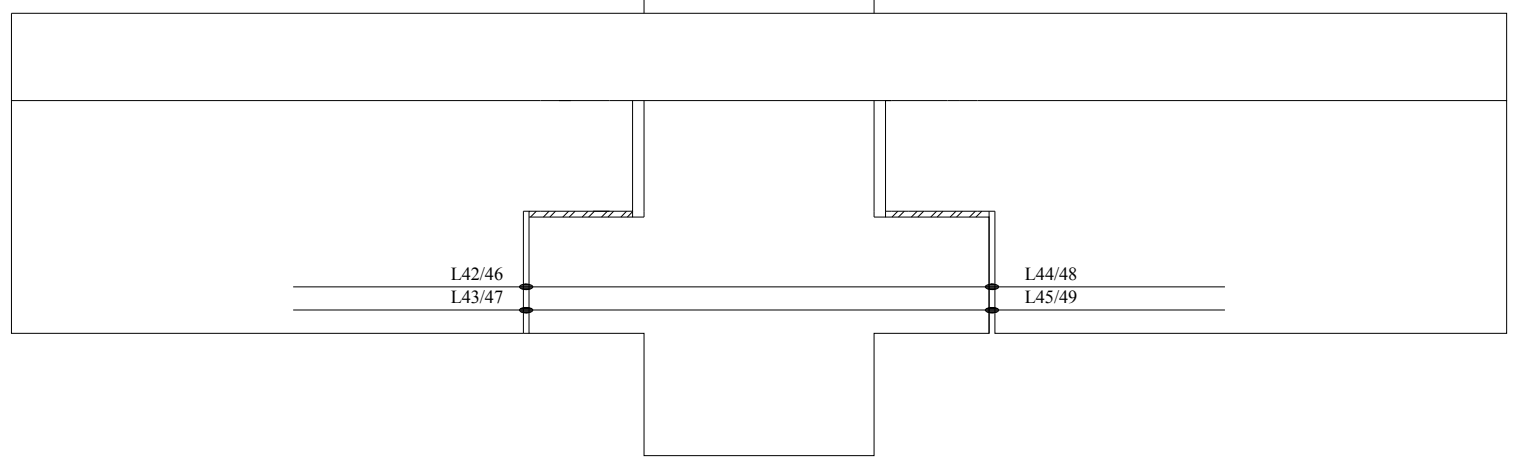

PLANTA

Profundidade do entalhe: $20 \mathrm{~mm}$

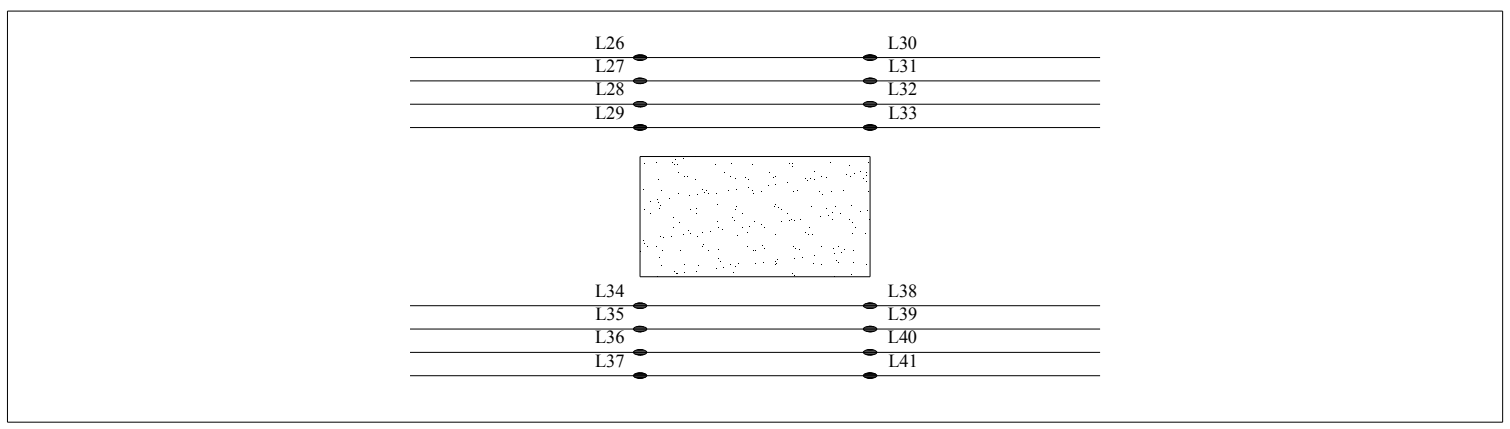

Figura 5.12 - Posicionamento dos extensômetros nos laminados.

A configuração do ensaio reproduz aquela utilizada por Baldissera (2006), inclusive com uso dos mesmos dispositivos para fixação do modelo à estrutura de reação, e está esquematicamente representada na Figura 5.13. 


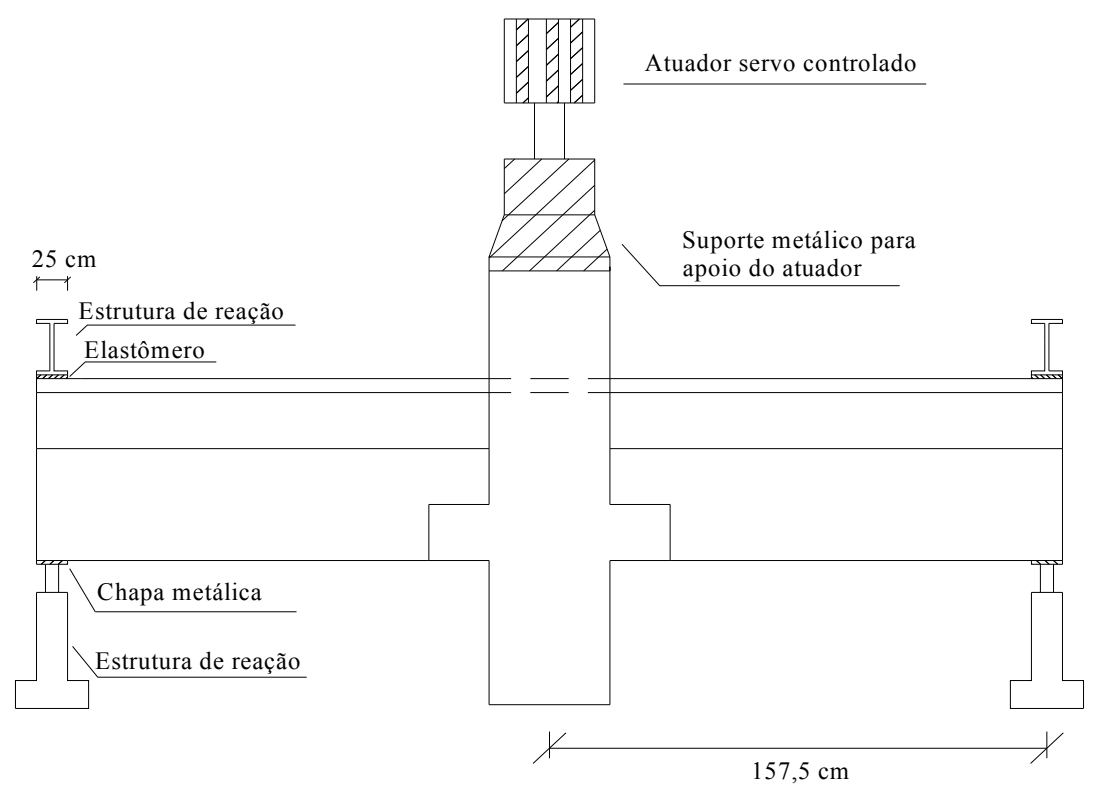

Figura 5.13 - Configuração esquemática do ensaio.

\subsection{Execução do ensaio}

Assim como no ensaio realizado por Baldissera (2006), submeteu-se o modelo a carregamento cíclico alternado segundo esquema de solicitação da Figura 5.14. Ao todo, foram aplicados 21 ciclos de aplicação de força. O procedimento previsto para aplicação de força é apresentado no Quadro 5.2. Nos primeiros vinte ciclos se pretendia aplicar a mesma força que foi aplicada em Baldissera (2006), ou seja, um limite de aproximadamente $+150 \mathrm{kN}$ de força gerando momento negativo na ligação (conforme convenção da Figura 5.14) e um limite de aproximadamente $-70 \mathrm{kN}$ de força gerando momento positivo na ligação. Contudo, por motivo de falha humana, no terceiro ciclo aplicou-se uma força de $-150 \mathrm{kN}$ solicitando a ligação a momento positivo. O erro foi percebido e, nos novos ciclos, respeitou-se o limite de $-70 \mathrm{kN}$, entretanto isto teve implicações nos resultados do ensaio que são demonstradas adiante no Item 5.6.3. No vigésimo primeiro ciclo, aplicou-se uma força de $404 \mathrm{kN}$, próxima do limite máximo do atuador, solicitando o modelo a momento negativo e uma força de 200 $\mathrm{kN}$ solicitando o modelo a momento positivo. 


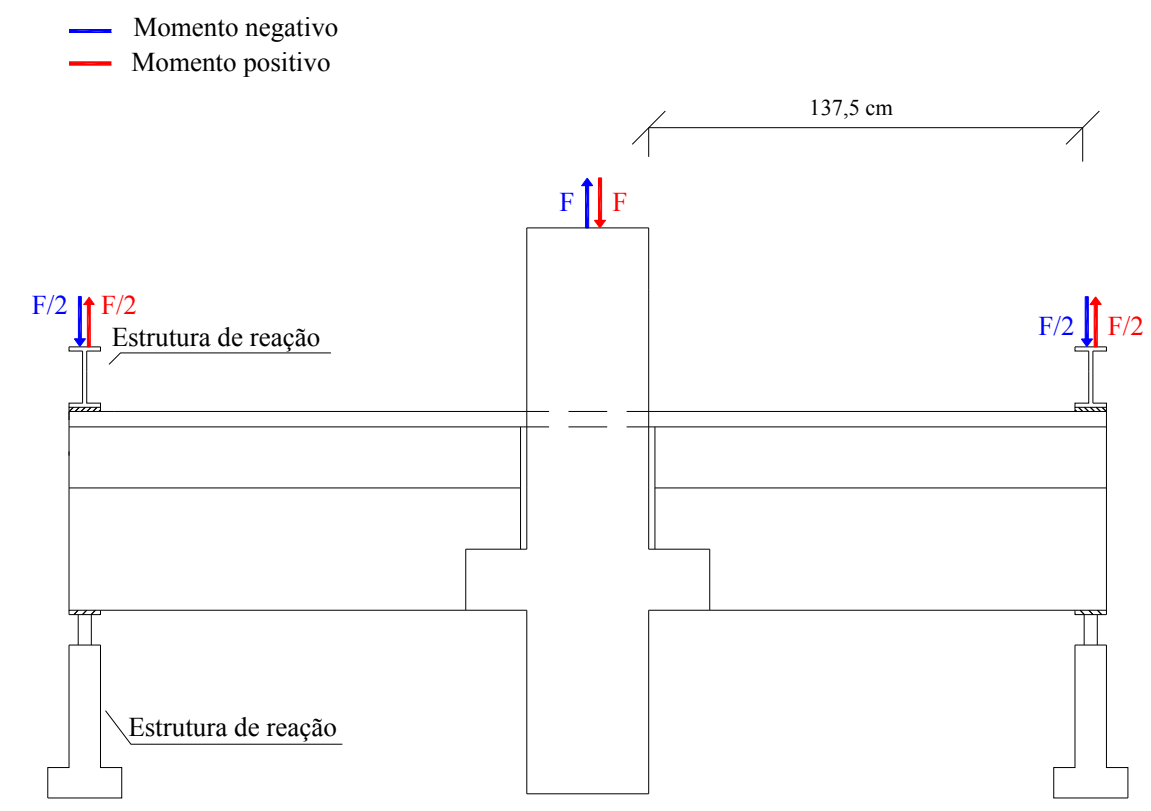

Figura 5.14 - Esquema de solicitação do modelo.

Quadro 5.2 - Procedimento previsto para aplicação de força.

\begin{tabular}{|c|c|}
\hline \multirow{2}{*}{ Etapa } & Força $(\boldsymbol{k N})$ \\
\hline Escorvamento & +12 \\
(v: $0,005 \mathrm{~mm} / \mathrm{s})$ & -6 \\
\hline Ciclo 1 & +150 \\
\hline (v: $0,01 \mathrm{~mm} / \mathrm{s})$ & -70 \\
\hline Ciclo 2 a 20 & +150 \\
(v: $0,08 \mathrm{~mm} / \mathrm{s})$ & -70 \\
\hline Ciclo 21 & Ruptura a momento negativo \\
\cline { 2 - 2 } (v: $0,01 \mathrm{~mm} / \mathrm{s})$ & Ruptura a momento positivo \\
\hline
\end{tabular}

\subsection{Resultados e análises}

\subsubsection{Ruptura}

O modelo já se apresentava inicialmente bastante fissurado em função do ensaio realizado por Baldissera (2006), portanto não se esperava, e não foi de fato possível, realizar uma análise esclarecedora com base na sua fissuração. Pode-se perceber, no entanto o surgimento de novas fissuras na capa da laje, mais distantes da ligação que as do ensaio de Baldissera (2006), após o fim da extremidade aderida dos laminados (Figura 5.15). 


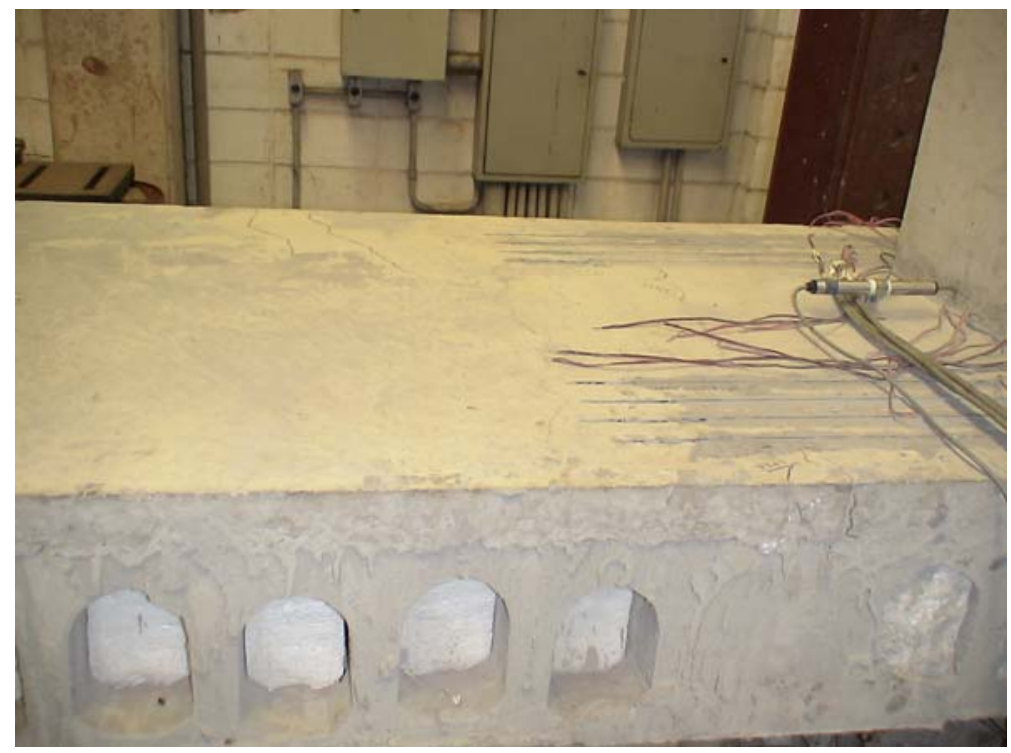

Figura 5.15 - Fissuras na capa da laje apos ensaio no modelo reforçado.

Pretendia-se controlar a parada do ensaio por uma deformação máxima no laminado de aproximadamente $10 \%$. A deformação máxima nos laminados na capa de concreto foi de apenas 4,7\% indicando que a armadura de aço existente teve uma grande contribuição na resistência do modelo. Deste modo, em relação ao momento negativo, o critério de parada do ensaio foi a proximidade da capacidade máxima do atuador. Em relação ao momento positivo, pode-se perceber claramente que uma das ligações (aquela em que houve a separação entre graute e concreto durante o corte dos entalhes) se deformou mais que a outra. $\mathrm{O}$ ensaio foi interrompido por deformação excessiva nesta ligação (Figura 5.16) o que induziu a uma solicitação de cisalhamento no laminado. No instante em que se interrompeu o ensaio, a deformação máxima nos laminados inferiores era de 9,3\%.

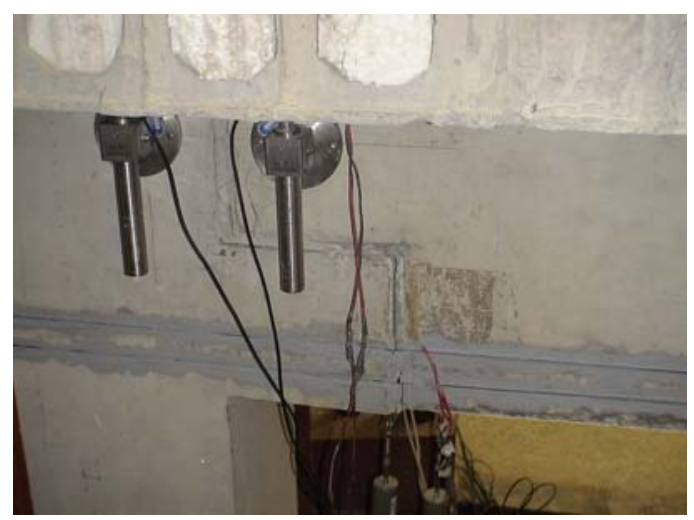

Figura 5.16 - Ligação que apresentou deformação excessiva. 


\subsubsection{Deformação}

Apenas foi possível a avaliação das deformações dos laminados, pois a extensometria utilizada no ensaio de Baldissera (2006) não estava em condições de uso. Na Figura 5.17, estão ilustradas as curvas "força x deformação" típicas para os laminados colados na capa de concreto e na lateral do modelo. Observa-se que os laminados colados na lateral do modelo apresentaram deformações maiores. Isso é justificável já que quando o modelo é solicitado a momento positivo, os esforços de tração são resistidos quase que exclusivamente pelos laminados colados lateralmente. Quando o modelo é solicitado a momento negativo a tração na parte superior do modelo é resistida pela armadura passante no pilar, pela armadura na capa e uma parcela apenas pelo laminado colado na capa.

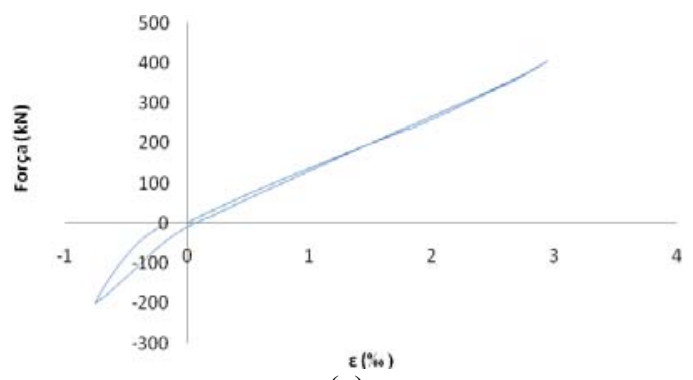

(a)

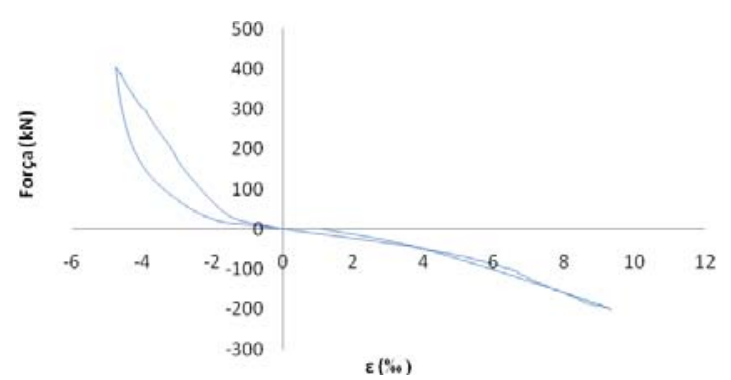

(b)

Figura 5.17 - Deformação nos laminados: (a) extensômetro 29 colado na capa de concreto; (b) extensômetro 42 colado na lateral da ligação.

\subsubsection{Rigidez à flexão}

A rigidez da ligação reforçada foi avaliada em função da curva "momento x rotação". A rotação relativa entre viga e pilar pôde ser obtida por meios dos transdutores de deslocamento (Equações 12) e dos clinômetros (Equação 13).

$$
\begin{aligned}
& \phi_{e, d}=\frac{\text { média }(T 5,6 / T 7,3)-T 1,2}{h_{T D}} \\
& \phi_{e, d}=\phi(C I 23,24)-\phi(C I 22,25)
\end{aligned}
$$

Onde: 
$\phi_{e, d}$ é a rotação relativa global entre a viga e o pilar para a ligação da esquerda e da direita

$\phi(C L 23,24)$ é a rotação global medida pelos clinômetros fixados no pilar $\phi(C L 22,25)$ é a rotação global medida pelos clinômetros fixados na viga $\boldsymbol{h}_{T D}$ é a distancia média entre o transdutor superior e os dois inferiores (Figura 5.18)

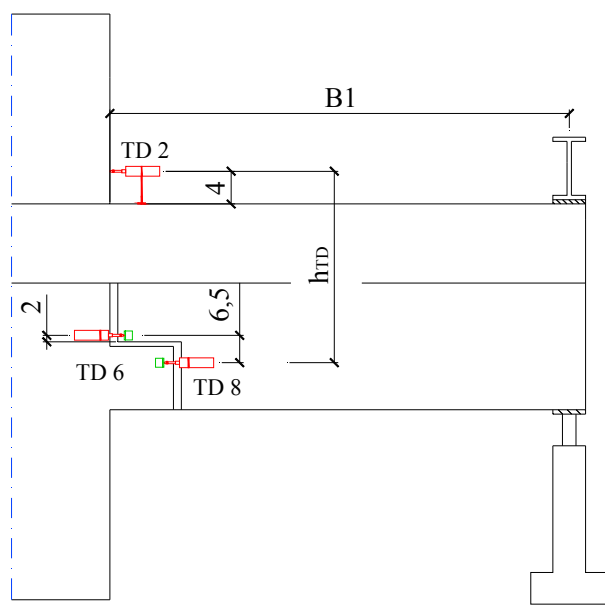

Figura 5.18 - Posicionamento dos transdutores utilizados para determinação da rotação da ligação à direita do modelo.

O momento na ligação foi calculado por meio da Equação 14.

$$
M=\frac{-F}{2} \cdot B_{1}
$$

Onde:

$\boldsymbol{M}$ é o momento na face do pilar

$\boldsymbol{F}$ é a força aplicada pelo atuador

$\boldsymbol{B}_{1}$ é a distancia entre o apoio e a face do pilar (Figura 5.18)

Relata-se, aqui, que se buscou ao máximo a semelhança com o procedimento de ensaio seguido por Baldissera (2006). Na análise dos dados, entretanto, algumas mudanças foram adotadas:

- No cálculo do momento, tomou-se por referência para a definição da distância B1 à face do pilar e não o eixo. 
- Não se realizaram descontos nas medidas dos transdutores em função da deformação do concreto entre a base do transdutor e a chapa colada para referência.

- Para a determinação da rigidez com base na curva "momento x rotação", utilizou-se a regressão linear com uso do programa Excel.

Por essas razões, foi necessário traçar as curvas com dados originais do último ciclo de carregamento de Baldissera (2006) para que se fizesse uma comparação válida entre o comportamento do modelo com e sem reforço. Consequentemente os valores de rigidez aqui atribuídos à ligação antes do reforço não coincidem com aqueles apresentados em Baldissera (2006). Embora ambos fundamentem-se nos mesmos dados, são resultado de metodologias de análise diferentes.

Apresentam-se, na Figura 5.19, os diagramas "momento x rotação" para a ligação a esquerda do modelo, traçados com base nos dados de transdutores (rotação calculada por meio da Equação 12) e dos clinômetros (rotação calculada por meio da Equação 13). Observa uma boa correlação entre eles, melhor para o trecho positivo do diagrama. Isso indica a escolha acertada no posicionamento dos instrumentos de medida e permitiu aferir algum comportamento deficiente em qualquer deles. Embora se considerem que os dados obtidos por meio dos dois tipos de instrumentos de medida sejam válidos, decidiu-se pela utilização dos dados dos transdutores para análise da rigidez, pois esses apresentam menor oscilação conforme se pode perceber na Figura 5.19.

Na Figura 5.20, apresentam-se o trecho positivo do diagrama "momento x rotação" e regressão linear para os trechos iniciais e finais para a ligação à esquerda e à direita do modelo, considerando o primeiro ciclo. Observa-se para este primeiro ciclo um comportamento aproximadamente bi-linear. O valor de rigidez foi obtido por regressão linear para os 8 primeiros ciclos e no último ciclo e são apresentados na Tabela 5.2. 


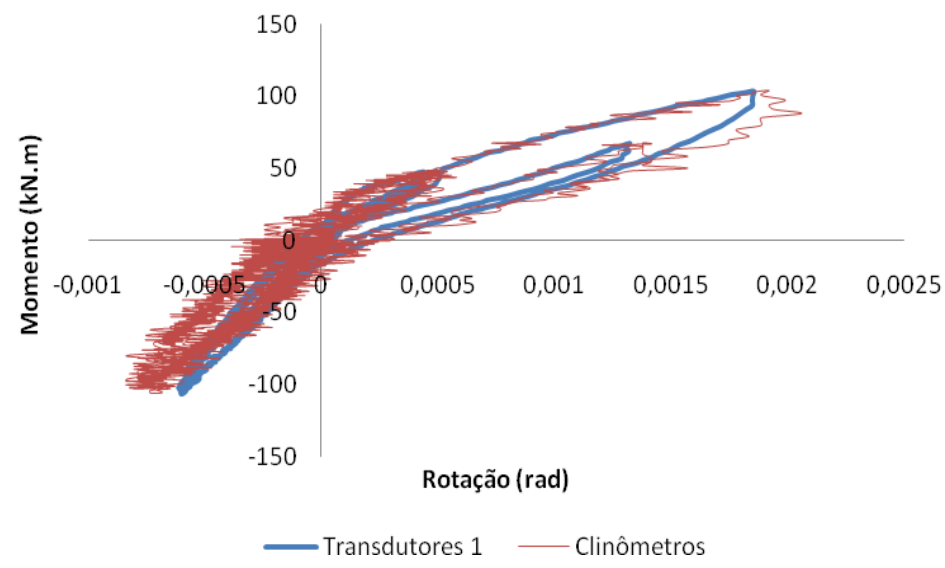

Figura 5.19 - Diagrama "momento x rotação" para os quatro primeiro ciclos de aplicação de força (ligação à esquerda).

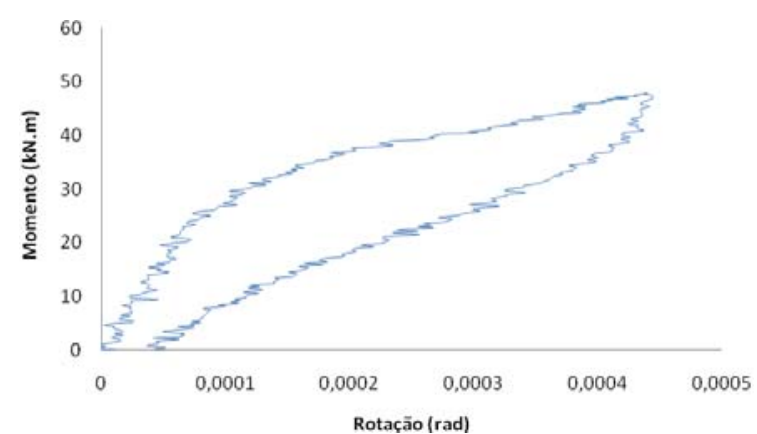

(a)

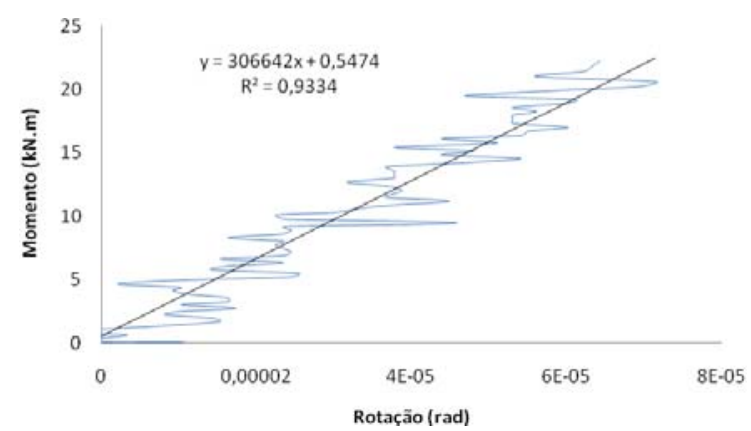

(c)

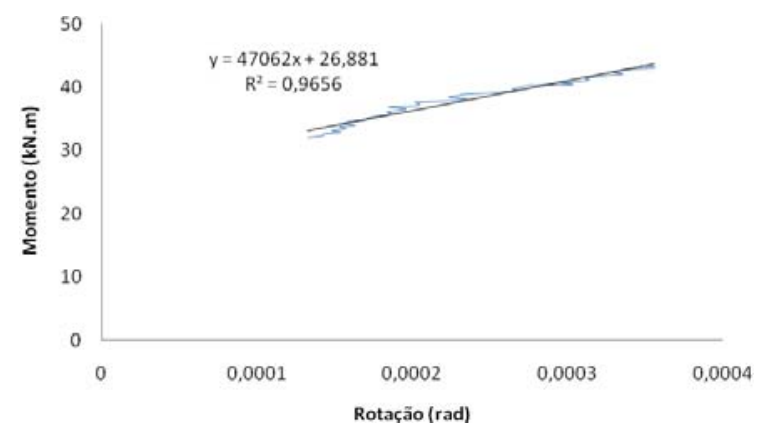

(e)

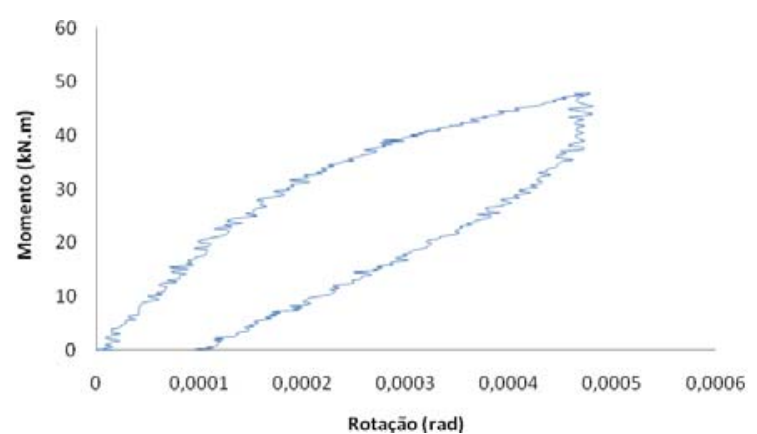

(b)

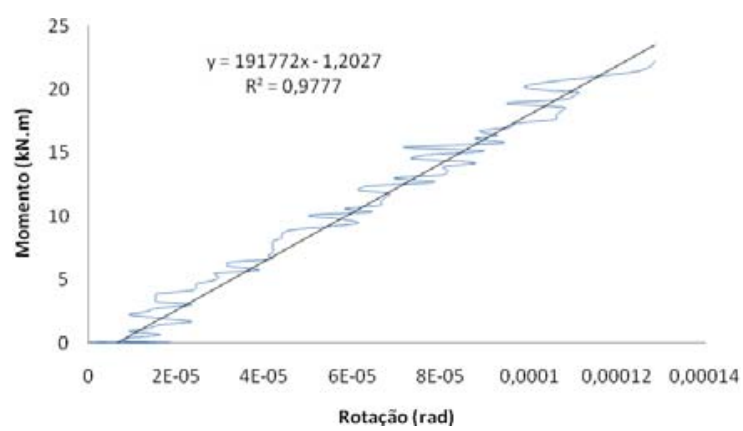

(d)

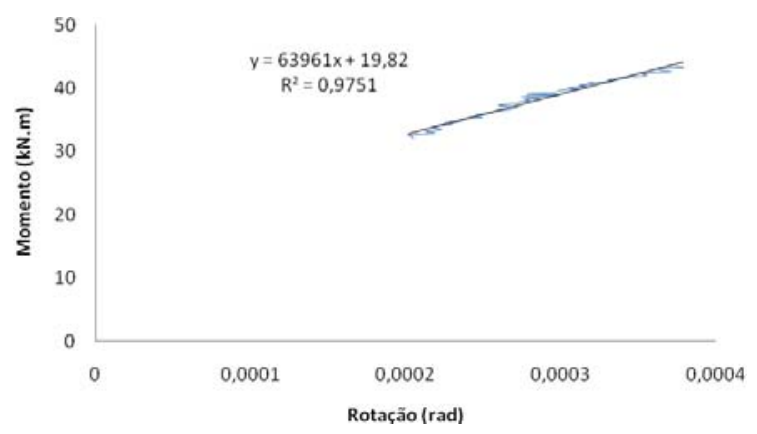

(f)

Figura 5.20 - Trecho positivo do diagramas "momento x rotação" e regressão linear para os trechos iniciais e finais para a ligação a esquerda do modelo ((a),(c) e (e)) e a direita do modelo ((b),(d) e (f)) - Primeiro ciclo. 
Na Figura 5.21, apresentam-se o trecho positivo dos diagramas "momento x rotação" e regressão linear para os trechos iniciais e finais para a ligação a esquerda do modelo considerado o último ciclo do ensaio efetuado por Baldissera (2006). Apenas se apresentam os resultados para uma das ligações, pois, na outra, aparentemente houve um comportamento deficiente dos transdutores. Nota-se um comportamento aproximadamente bi-linear do diagrama.

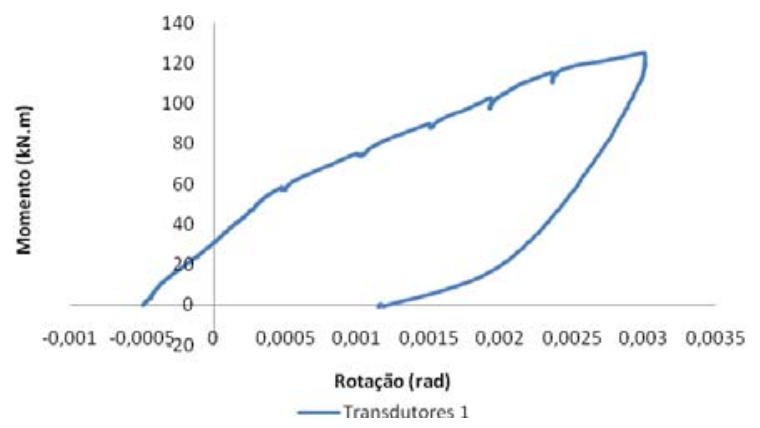

(a)

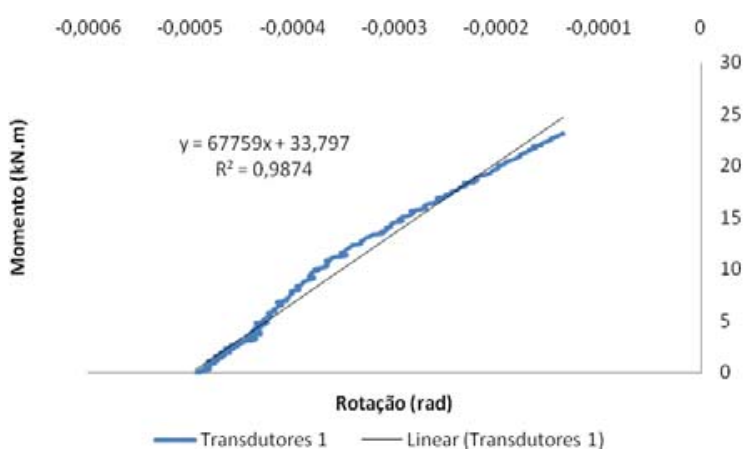

(b)

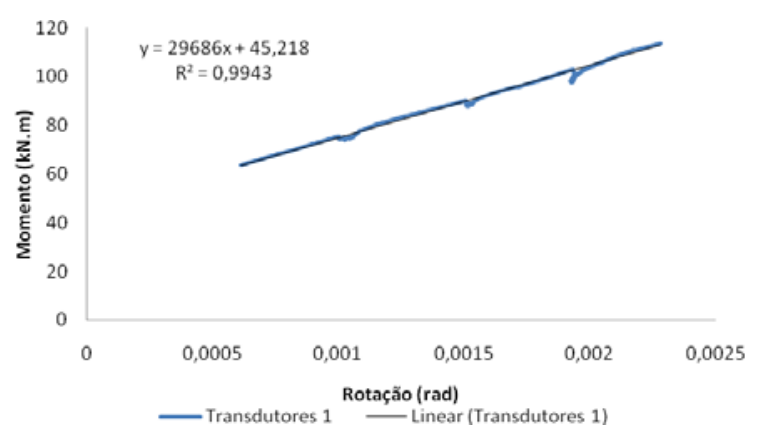

(c)

Figura 5.21 - Trecho positivo do diagramas "momento x rotação" e regressão linear para os trechos iniciais e finais para a ligação a direita do modelo ((a),(b) e (c)) - Ciclo final do ensaio de Baldissera (2006). 
Na Figura 5.22, ilustra-se o trecho positivo dos diagramas "momento x rotação" para os ciclos finais do ensaio do modelo reforçado e antes do reforço. Percebe-se que embora inicialmente a rigidez do modelo antes do reforço seja ligeiramente superior, a do modelo reforçado é praticamente constante até a interrupção do ensaio.

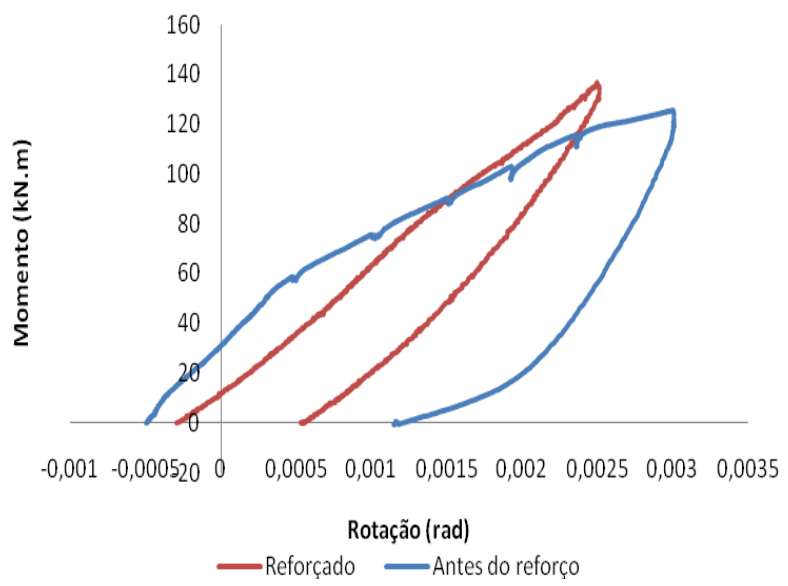

Figura 5.22 - Trecho positivo do diagramas “momento x rotação" para os ciclos finais do ensaio do modelo reforçado e antes do reforço.

Tabela 5.2 - Valores de rigidez a momento positivo para a ligação antes e apos o reforço.

\begin{tabular}{|c|c|c|c|c|c|c|}
\hline \multicolumn{7}{|c|}{ Antes do reforço - Baldissera (2006) } \\
\hline \multirow[b]{2}{*}{ Ciclo } & \multicolumn{2}{|c|}{ Lado direito } & \multicolumn{2}{|c|}{ Lado esquerdo } & \multicolumn{2}{|c|}{ Média } \\
\hline & $\begin{array}{c}K_{i} \\
(k N . m / r a d)\end{array}$ & $\begin{array}{c}K_{f} \\
(k N . m / r a d)\end{array}$ & $\begin{array}{c}K_{i} \\
(k N . m / r a d)\end{array}$ & $\begin{array}{c}K_{f} \\
(k N . m / r a d)\end{array}$ & $\begin{array}{c}K_{i} \\
(k N . m / r a d)\end{array}$ & $\begin{array}{c}K_{f} \\
(k N . m / r a d)\end{array}$ \\
\hline 21 & - & - & 67759 & 29686 & 67759,0 & 29686 \\
\hline \multicolumn{7}{|c|}{ Modelo reforçado } \\
\hline 1 & 306642 & 47062 & 183043 & 63961 & 244842 & 55511 \\
\hline 2 & 81757 & - & 78886 & - & 80321 & - \\
\hline 3 & 76193 & 37656 & 74535 & 42649 & 75364 & 40152 \\
\hline 4 & 48076 & - & 53847 & - & 50961 & - \\
\hline 5 & 45908 & - & 51025 & - & 48466 & - \\
\hline 6 & 43590 & - & 48828 & - & 46209 & - \\
\hline 7 & 42963 & - & 48055 & - & 45509 & - \\
\hline 8 & 43254 & - & 47956 & - & 45605 & - \\
\hline 21 & 25354 & - & 43956 & - & 34655 & - \\
\hline
\end{tabular}

Analisando-se os dados da Tabela 5.2 e o diagrama na Figura 5.20 percebe-se que para um trecho inicial o reforço promoveu um incremento na rigidez em torno de $300 \%$, 
considerando-se o primeiro ciclo de carregamento. Isso não se manteve, contudo para os ciclos de aplicação de força subsequentes. Este incremento não poderia ser considerado no dimensionamento do reforço, pois está relacionado a uma faixa muito restrita da solicitação da ligação (momento de aproximadamente $30 \mathrm{kN} . \mathrm{m}$ ). Para o segundo e terceiro ciclo, observa-se uma rigidez inicial em torno de $80000 \mathrm{kN}$.m/rad que significa um incremento em torno de $15 \%$ se considerada a rigidez inicial do modelo antes do reforço. No terceiro ciclo, aplicou-se, por engano, uma força de $150 \mathrm{kN}$ solicitando o modelo a momento positivo. Isso levou a perda parcial da eficiência dos mecanismos resistentes da ligação, de modo que nos ciclos seguintes a rigidez inicial foi de aproximadamente $45000 \mathrm{kN} . \mathrm{m} / \mathrm{rad}$.

Na Figura 5.23, apresentam-se o trecho negativo dos diagramas "momento x rotação" e regressão linear para os trechos iniciais, para a ligação à esquerda e à direita do modelo, considerado o primeiro ciclo. Observa-se que, no caso da solicitação a momento negativo, o diagrama "momento x rotação" se apresentou linear mesmo no primeiro ciclo de aplicação de força. $O$ valor de rigidez foi obtido por regressão linear para os 8 primeiros ciclos e no último ciclo e são apresentados na Tabela 5.3. Como em todos os ciclos, o diagrama "momento x rotação" se apresentou linear constam na Tabela 5.3 apenas valores de rigidez inicial.

Na Figura 5.24, apresentam-se o trecho negativo dos diagramas "momento x rotação" e regressão linear para os trechos iniciais, para a ligação à esquerda e à direita do modelo, considerado o último ciclo de aplicação de força no modelo não reforçado. Observa-se que também para o modelo não reforçado o diagrama "momento x rotação" se apresentou aproximadamente linear. 


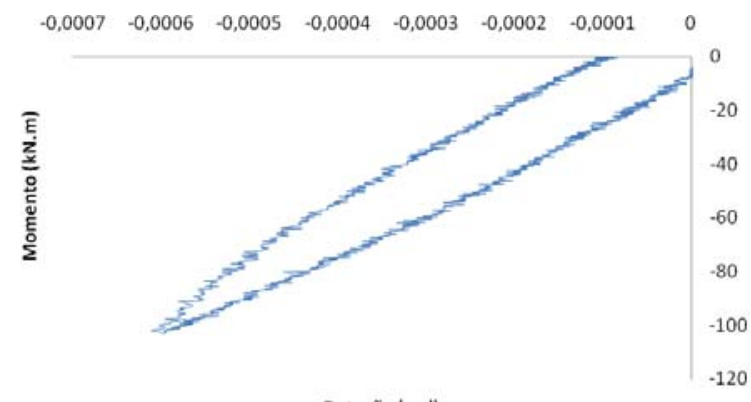

(a)

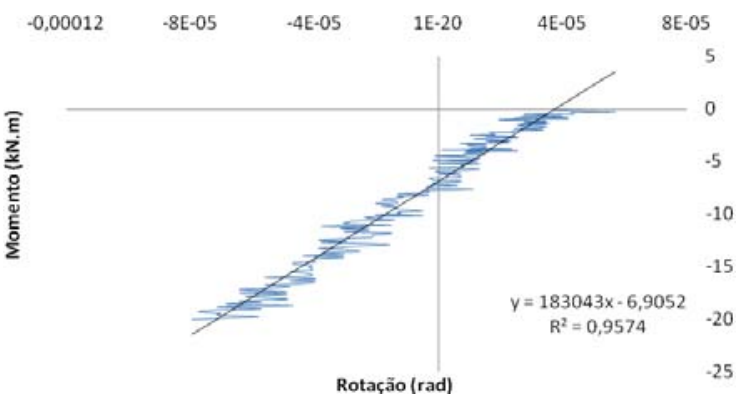

(c)

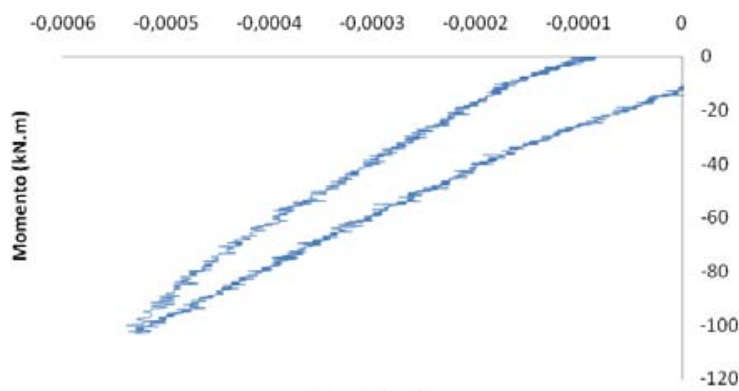

Rotaçăo (rad)

(b)

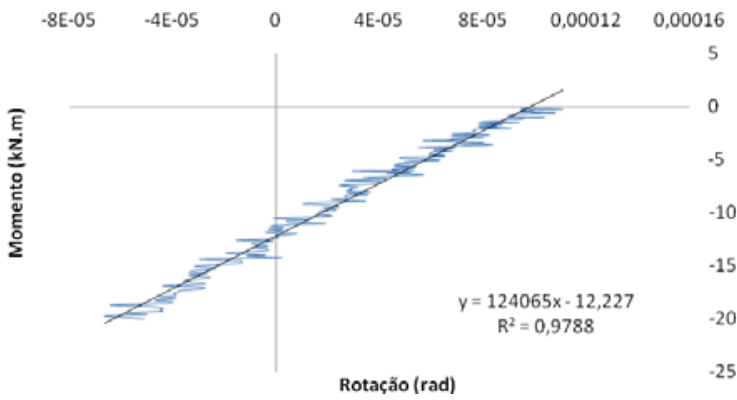

(d)

Figura 5.23 - Trecho negativo do diagrama " momento x rotação" e regressão linear para os trechos iniciais e finais para a ligação a esquerda do modelo ((a), (c)) e a direita do modelo ((b), (d)) - Primeiro ciclo.

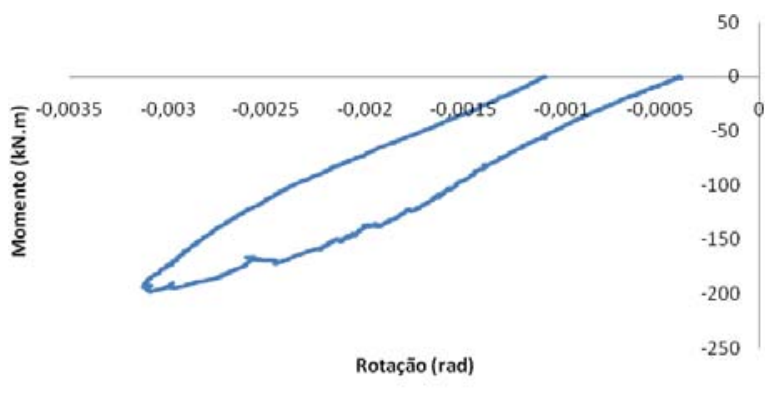

- Transdutores 1

(a)

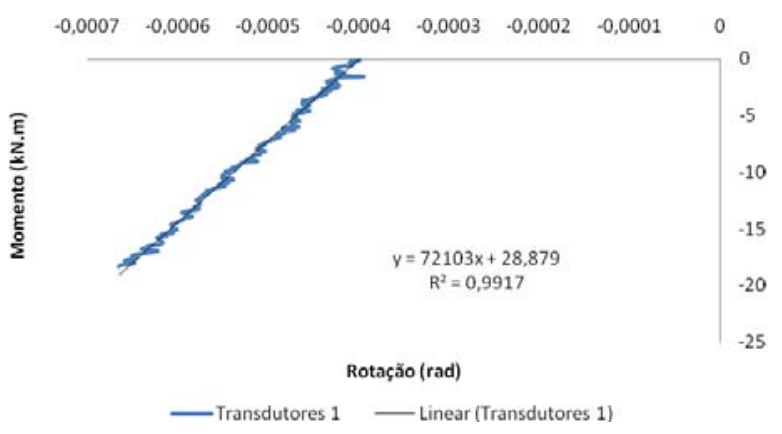

(c)

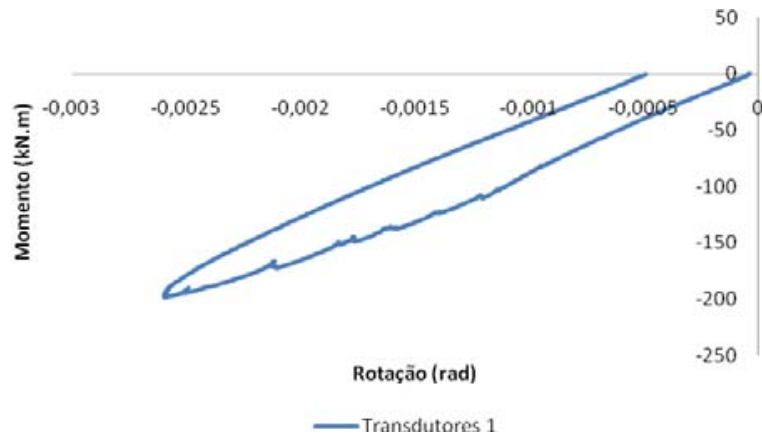

(b)

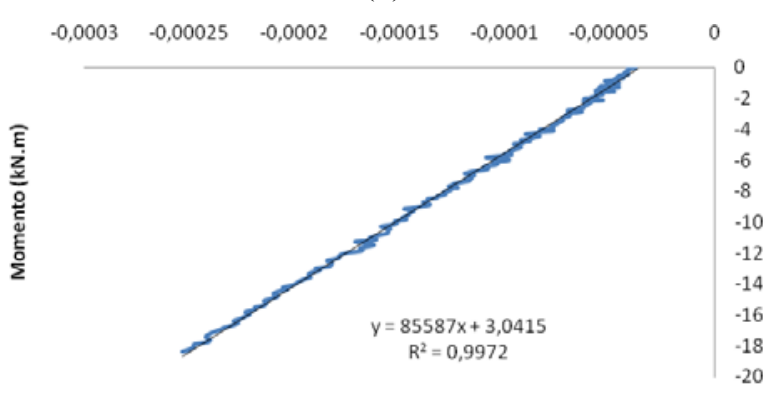

Rotação (rad)

- Transdutores 1 Linear (Transdutores 1)

(d)

Figura 5.24 - Trecho negativo do diagrama "momento x rotação" e regressão linear para os trechos iniciais e finais para a ligação a esquerda do modelo ((a), (c)) e a direita do modelo não antes do reforço ((b), (d)) - Ciclo final do ensaio de Baldissera (2006). 
$\mathrm{Na}$ Figura 5.25, ilustra-se o trecho negativo dos diagramas "momento x rotação" para os ciclos finais do ensaio do modelo reforçado e antes do reforço. Explica-se que o vigésimo primeiro ciclo de aplicação de força foi realizado em um dia posterior aos demais. Não se realizou antes deste ciclo, como antes do primeiro ciclo, a etapa de escorvamento. Por esse motivo, os diagramas correspondentes ao modelo reforçado apresentam um trecho inicial de acomodação do modelo que deve ser desconsiderado na análise. Na Figura 5.25, fica bastante evidente o ganho de rigidez proporcionado pelo reforço, representado pela maior inclinação do diagrama. Na Tabela 5.3, percebe-se que este incremento é da ordem de $100 \%$.

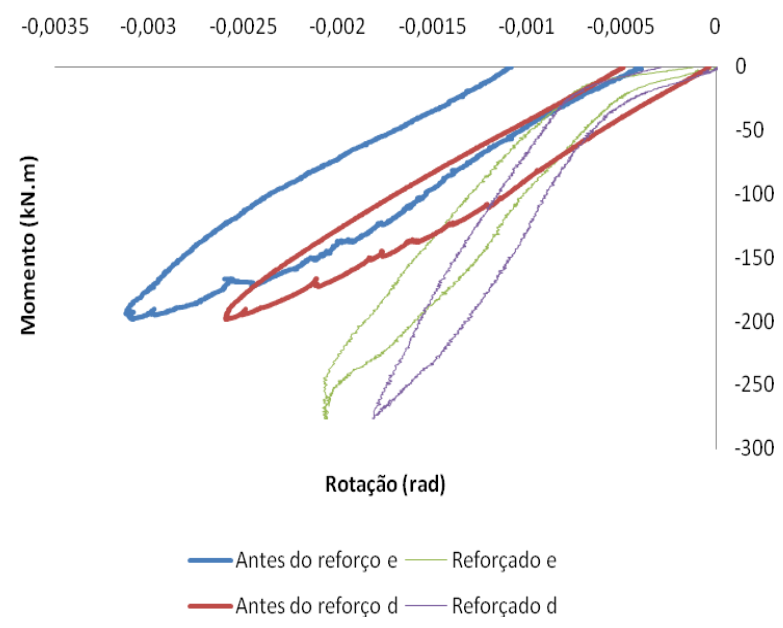

Figura 5.25 - Trecho negativo do diagramas "momento x rotação" para os ciclos finais dos ensaios do modelo reforçado e antes do reforço.

Tabela 5.3 - Valores de rigidez a momento negativo para a ligação antes e apos o reforço.

\begin{tabular}{|c|c|c|c|c|c|c|}
\hline \multicolumn{7}{|c|}{ Antes do reforço - Baldissera (2006) } \\
\hline \multirow[b]{2}{*}{ Ciclo } & \multicolumn{2}{|c|}{ Lado direito } & \multicolumn{2}{|c|}{ Lado esquerdo } & \multicolumn{2}{|c|}{ Média } \\
\hline & $\begin{array}{c}K_{i} \\
(k N . m / r a d)\end{array}$ & $\begin{array}{c}K_{f} \\
(k N . m / r a d)\end{array}$ & $\begin{array}{c}K_{i} \\
(k N . m / r a d)\end{array}$ & $\begin{array}{c}K_{f} \\
(k N . m / r a d)\end{array}$ & $\begin{array}{c}K_{i} \\
(k N . m / r a d)\end{array}$ & $\begin{array}{c}K_{f} \\
(k N . m / r a d)\end{array}$ \\
\hline 21 & 72103 & - & 85587 & - & $\mathbf{7 8 8 4 5 , 0}$ & - \\
\hline \multicolumn{7}{|c|}{ Modelo reforçado } \\
\hline 1 & 183043 & - & 124065 & - & 153554 & - \\
\hline 2 & 169906 & - & 163427 & - & 166666 & - \\
\hline 3 & 126913 & - & 118781 & - & 122847 & - \\
\hline 4 & 154662 & - & 167047 & - & 160854 & - \\
\hline 5 & 159692 & - & 198657 & - & 179174 & - \\
\hline 6 & 162069 & - & 173925 & - & 167997 & - \\
\hline 7 & 168417 & - & 170905 & - & 169661 & - \\
\hline 8 & 159940 & - & 170534 & - & 165237 & - \\
\hline 21 & 159428 & - & 215536 & - & 187482 & - \\
\hline
\end{tabular}




\subsubsection{Força x Deslocamento}

Apresentam-se, nas Figura 5.27 a Figura 5.29, as curvas "força x deslocamento" para diferentes ciclos de carregamento do modelo reforçado acompanhadas da curva "força $\mathrm{x}$ deslocamento" obtida para o último ciclo de carregamento do ensaio realizado por Baldissera (2006). Todas as curvas foram corrigidas para eliminação de um trecho inicial de acomodação que pode ser observado na Figura 5.26.

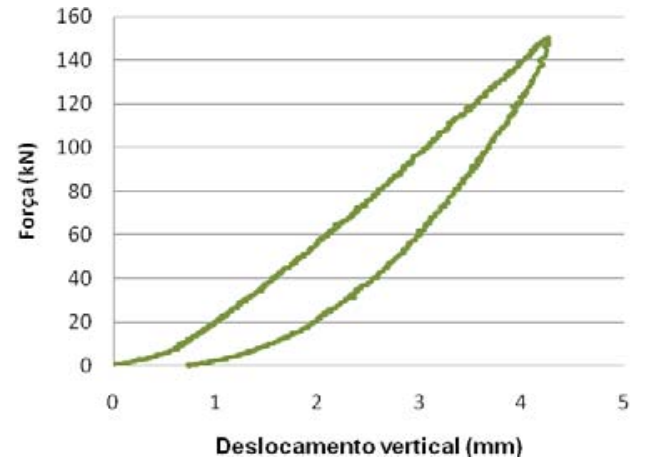

(a)

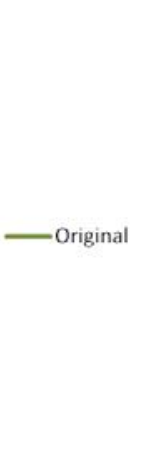

Figura 5.26 - Curvas “força x deslocamento" para o primeiro ciclo de aplicação de força: (a) original; (b) original e corrigida.

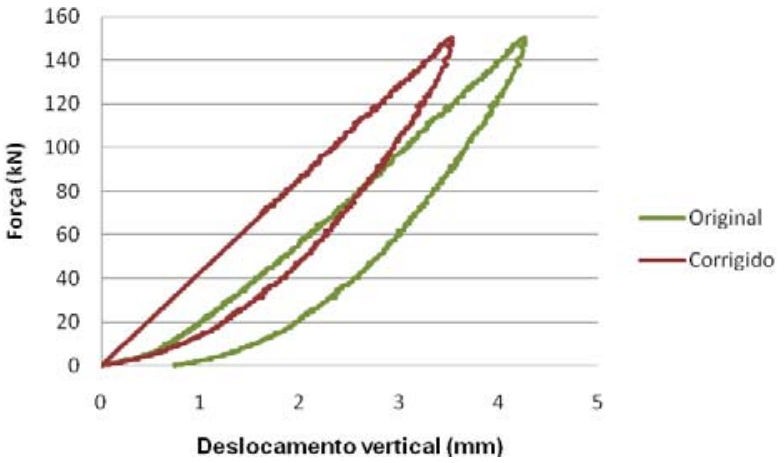

(b)

Na Figura 5.27, comparam-se as curvas obtidas por Baldissera (2006) aos primeiros ciclos de carregamento, positivo e negativo, aplicados ao modelo reforçado. Observa-se que, no caso do modelo solicitado a momento positivo, com deslocamento do pistão para baixo, a curva "força x deslocamento" apresenta uma maior inclinação o que indica que o modelo reforçado apresenta-se mais rígido como um todo. No caso de momento negativo, em que o deslocamento do pistão é para cima, as curvas para o modelo antes e depois do reforço apresentam a mesma inclinação.

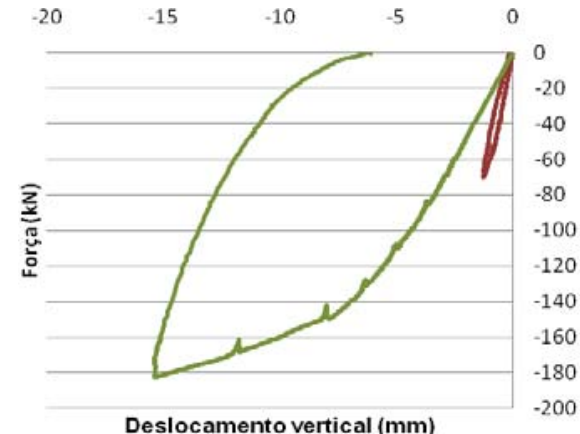

(a)

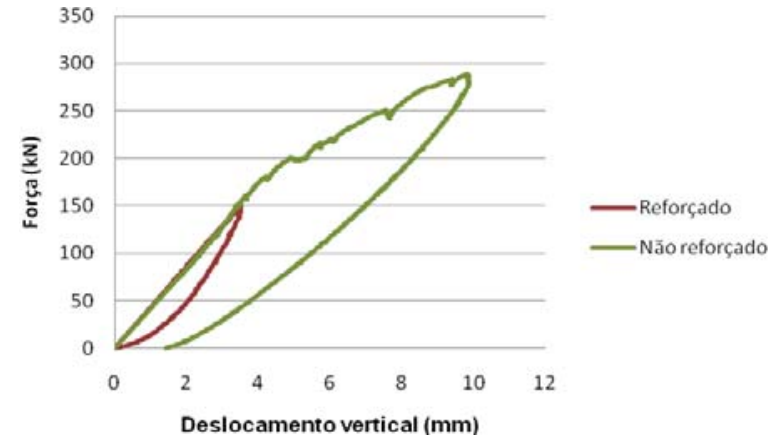

(b)

Figura 5.27 - Curvas “força x deslocamento" para o primeiro ciclo de carregamento do modelo reforçado e último ciclo de carregamento do modelo não reforçado: (a) deslocamento do pistão para baixo; (b) deslocamento do pistão para cima. 
Para o terceiro ciclo de carregamento, positivo e negativo, aplicado ao modelo reforçado observa-se a mesma tendência em comparação ao modelo antes do reforço, notada para o primeiro ciclo, como se pode perceber na Figura 5.28.

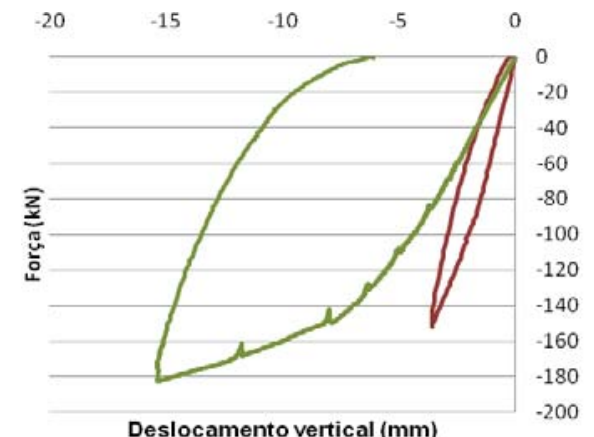

(a)
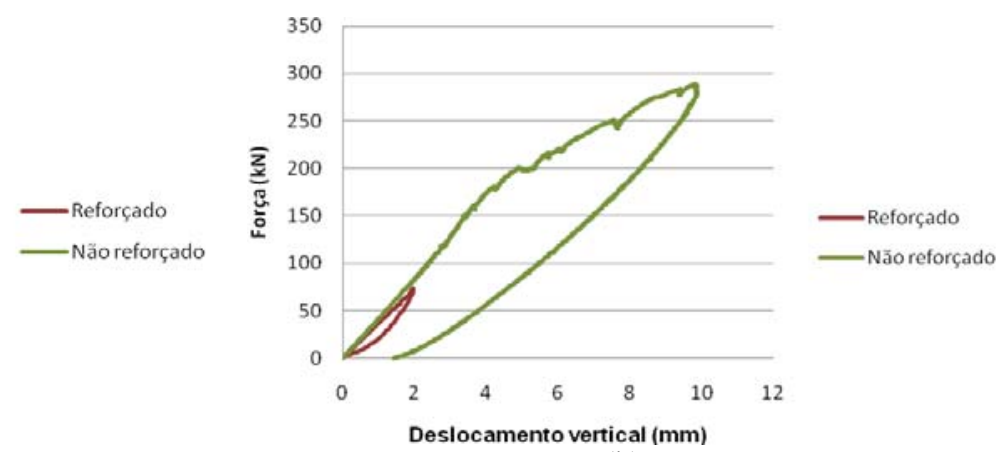

(b)

Figura 5.28 - Curvas "força x deslocamento" para o terceiro ciclo de carregamento do modelo reforçado e último ciclo de carregamento do modelo não reforçado: (a) deslocamento do pistão para baixo; (b) deslocamento do pistão para cima.

Para o vigésimo primeiro ciclo (último aplicado), as curvas para o modelo reforçado e antes do reforço têm praticamente a mesma inclinação inicial (Figura 5.29). O modelo reforçado apresenta uma tendência linear e o modelo antes do reforço apresenta uma queda na inclinação por volta da força de $140 \mathrm{kN}$ no caso de deslocamento do pistão para baixo e de 200 kN no caso de deslocamento do pistão para cima. Em função disto, a partir destas forças os deslocamentos são menores no modelo reforçado. Para a força aplicada de $-182 \mathrm{kN}$, a redução no deslocamento é de aproximadamente $55 \%$ e para a força de $289 \mathrm{kN}$ é de $35 \%$.

O modelo resistiu a uma força $10 \%$ maior, no deslocamento do pistão para baixo e $40 \%$ maior no deslocamento do pistão para cima.

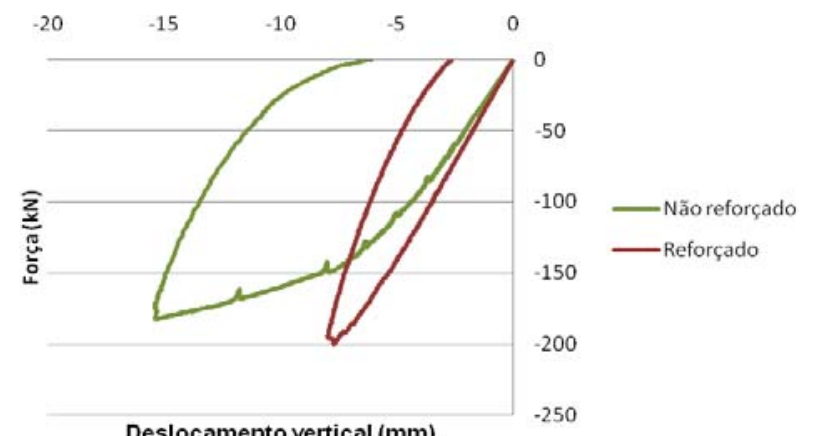

(a)

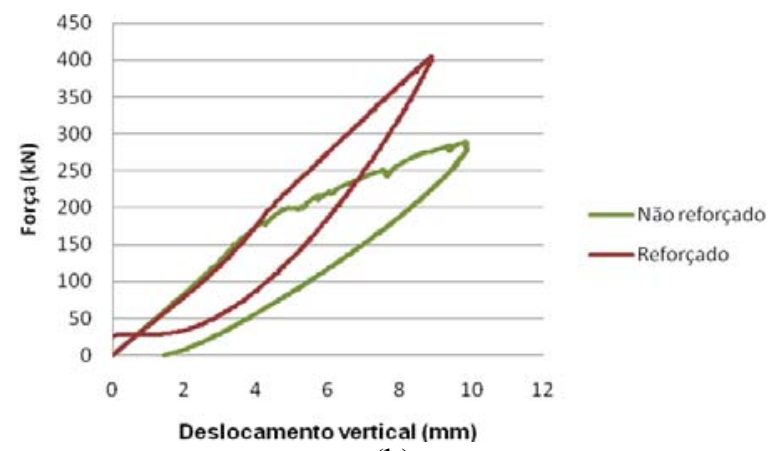

(b)

Figura 5.29 - Curvas "força x deslocamento" para o terceiro ciclo de carregamento do modelo reforçado e último ciclo de carregamento do modelo não reforçado: (a) deslocamento do pistão para baixo; (b) deslocamento do pistão para cima. 


\subsection{Conclusões}

O reforço aparentemente proporcionou uma maior distribuição das fissuras na capa da laje. A análise da fissuração foi prejudicada pela dificuldade em se determinar o que eram fissuras novas ou antigas.

Os laminados foram mais solicitados quando a ligação era submetida a momento positivo. Isso se deve ao fato de haver uma alta taxa de armadura passante no pilar e na capa da laje contribuindo para a resistência a momento negativo, enquanto para o momento positivo a resistência se devia à contribuição dos chumbadores.

Em relação ao reforço a momento positivo observou-se um incremento em torno de $15 \%$ se considerada a rigidez inicial do modelo antes do reforço. Em relação ao reforço momento negativo, observou um incremento em torno de $100 \%$ se considerada a rigidez inicial do modelo antes do reforço. Ressalta-se que em se pretendendo empregar o reforço da ligação a momento negativo como neste ensaio deve-se verificar a capacidade de transferência de esforços entre a capa de concreto e laje.

A curva "força x deslocamento" indica uma maior rigidez inicial do modelo reforçado para o caso de deslocamento do pistão para baixo (momento positivo) considerados os primeiros ciclos de aplicação de força no modelo reforçado e o último ciclo de aplicação de força do modelo antes do reforço. Para o deslocamento do pistão para cima (momento negativo) a inclinação inicial da curva não se alterou com o reforço. Considerado o último ciclo de aplicação de força, a inclinação do modelo reforçado foi igual a do modelo antes do reforço tanto para o deslocamento do pistão para cima, quanto para baixo. O modelo reforçado apresentou um comportamento linear e o modelo antes do reforço bi-linear. Por esta razão, conclui-se que o reforço promove uma redução dos deslocamentos a partir de determinada solicitação. 


\section{CAPÍTULO 6}

\section{ENSAIO-PILOTO}

O ensaio-piloto foi realizado em um modelo reduzido de pórtico idealizado por Almeida (2010) que buscou em sua pesquisa o desenvolvimento de uma metodologia experimental dinâmica para obtenção da rigidez à flexão de ligações.

Na Figura 6.1, ilustram-se as características geométricas do modelo de ensaio antes do reforço das ligações e, na Figura 6.2, o modelo após o reforço das ligações. Trata-se de um pórtico plano composto por dois pilares e uma viga unida a eles por meio de ligações por encaixe de dente Gerber, com uso de chumbador, almofada de apoio e graute.

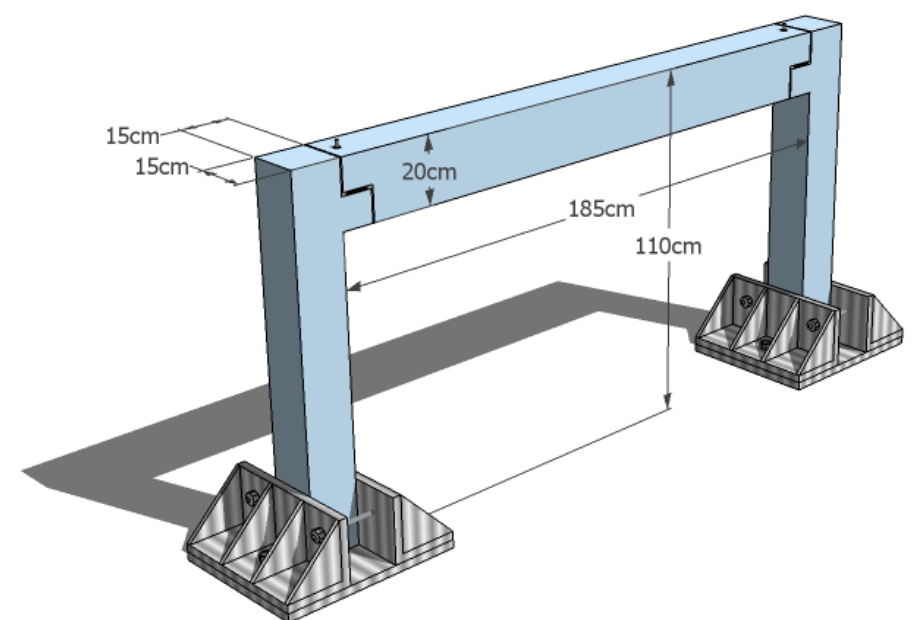

Figura 6.1 - Características geométricas do modelo de ensaio antes do reforço das ligações. 


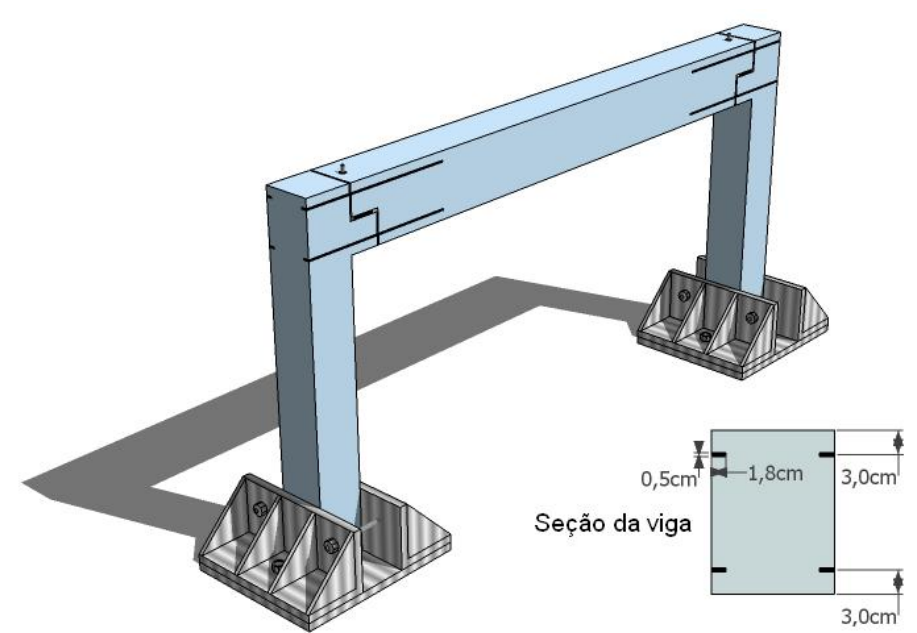

Figura 6.2 - Modelo de ensaio após o reforço das ligações.

A ligação por encaixe de dente Gerber e consolo é presumidamente articulada e é muito usada em estruturas de galpão. Seu emprego também ocorre em estruturas esqueleto de edifício com limitação de altura. Os pilares foram fixados à base de reação do Laboratório de Estruturas do Departamento de Engenharia de Estruturas por meio de um dispositivo metálico, simulando a condição de engaste.

Embora se trate de um modelo com dimensões reduzidas em escala de aproximadamente 1/3, utilizaram-se materiais com dimensões tradicionais, como barras de aço com diâmetro de $8 \mathrm{~mm}$ e $10 \mathrm{~mm}$ e agregado graúdo (brita 1). O cobrimento adotado de 2 cm também não obedece à redução de escala o que inviabilizaria a execução do reforço.

\subsection{Propriedades dos materiais}

\section{- Aço}

Utilizou-se aço CA50 para confecção das armaduras. A determinação das propriedades do aço à tração foi realizada com base na NBR 6152 (1980). Foram utilizados dois corpos-de-prova de $1 \mathrm{~m}$ de comprimento para a determinação das propriedades de cada tipo de barra. Os ensaios de caracterização foram realizados na máquina universal de ensaios servo-hidráulica INSTRON com sistema de aquisição de dados System 5000 da Vishay. As deformações foram obtidas por meio de clip gages (calibres instrumentados com 
extensômetros elétricos). As propriedades do aço utilizado na armadura são apresentadas na Tabela 6.1. Nota-se que os valores dos módulos de elasticidade diferem dos usualmente verificados na bibliografia e indicados em normas como a NBR 8800. Considera-se que pode ter havido algum erro na determinação desta propriedade de modo que na simulação numérica apresentada no Item 6.6, utilizou-se para os aços de todas as bitolas o valor de 200 GPa para o módulo de elasticidade e $500 \mathrm{MPa}$ para a tensão de escoamento.

Tabela 6.1 - Propriedade do aço.

\begin{tabular}{ccccc}
\hline $\begin{array}{c}\text { Diâmetro } \\
(\boldsymbol{m m})\end{array}$ & Corpo-de-prova & $\begin{array}{c}\boldsymbol{E}_{\boldsymbol{s}} \\
(\boldsymbol{G P a})\end{array}$ & $\begin{array}{c}\boldsymbol{f}_{\boldsymbol{y}} \\
(\boldsymbol{M P a})\end{array}$ & $\begin{array}{c}\boldsymbol{f}_{\boldsymbol{u}} \\
(\boldsymbol{M P a})\end{array}$ \\
\hline \multirow{3}{*}{8} & 1 & 174 & 634 & 888 \\
& 2 & 189 & 678 & 937 \\
& Média & $\mathbf{1 8 1}$ & $\mathbf{6 5 6}$ & $\mathbf{9 1 3}$ \\
10 & 1 & 204 & 674 & 1012 \\
& 2 & 169 & 572 & 895 \\
& Média & $\mathbf{1 8 3}$ & $\mathbf{6 2 3}$ & $\mathbf{9 5 3}$ \\
\hline
\end{tabular}

\section{- Concreto}

Para confecção do modelo de ensaio, foi utilizado concreto de cimento de alta resistência inicial com traço em massa de 1:1,20:2,3 (cimento: areia: brita 1) e relação água/cimento de 0,5 . A determinação da resistência à compressão do concreto foi realizada com base na NBR 5739 (1994) e a determinação da resistência à tração com base na NBR 7222 (1994) em duas idades. A primeira idade foi correspondente a etapa de carregamento até fissuração da viga (Etapa 1) e a segunda correspondente ao ensaio do modelo com as ligações reforçadas (Etapa 2). Utilizaram-se corpos-de-prova cilíndricos com dimensões de $10 \mathrm{~cm}$ de diâmetro e $20 \mathrm{~cm}$ de altura. A resistência à compressão calculada para os CPs de $10 \mathrm{~cm}$ x 20 cm deve ser multiplicada por um fator de redução de 0,95 para se equivaler à resistência de CPs de $15 \mathrm{~cm}$ x $30 \mathrm{~cm}$ (segundo especificações do Concrete Manual ${ }^{*}, 1975$ apud MEHTA e MONTEIRO, 1994), que são as dimensões propostas na NBR 5739 (1994). A determinação

\footnotetext{
* "Concrete Manual”, US Bureau of Reclamation, 1975, p. 574-75.
} 
do módulo foi feita em alguns dos CPs submetidos a ensaio de compressão. As deformações foram obtidas por meio de extensômetros removíveis, com base de medida de $10 \mathrm{~cm}$, posicionados em pontos diametralmente opostos em relação à seção do $\mathrm{CP}$ com os cursos de leitura centralizados em relação à altura (Figura 6.3). Na elaboração do diagrama "tensão x deformação", utilizou-se a média das deformações lidas nos dois extensômetros. Os módulos de elasticidade secantes apresentados na Tabela 6.2 e na Tabela 6.3 foram obtidos por meio de regressão linear tomando o trecho do diagrama tensão deformação limitado pelo valor de tensão correspondente a $40 \%$ da tensão de ruptura. Os ensaios para determinação da resistência à compressão e do módulo de elasticidade do concreto foram executados na máquina universal de ensaios servo-hidráulica INSTRON com uso do sistema de aquisição de dados System 5000 da Vishay. Os resultados da caracterização estão apresentados na Tabela 6.2 e na Tabela 6.3.

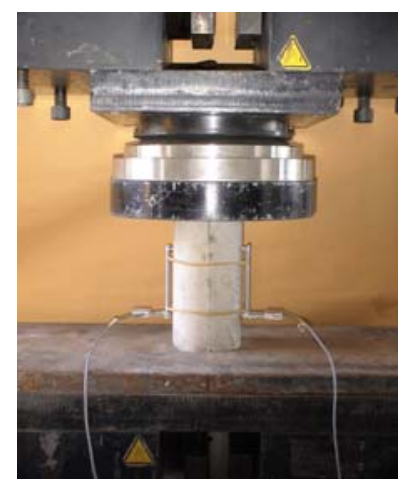

Figura 6.3 - Ensaio para a determinação da resistência à compressão e do módulo de elasticidade.

Tabela 6.2 - Propriedades do concreto - Etapa 1.

\begin{tabular}{ccccc}
\hline Corpo-de-prova & $\begin{array}{c}\text { Idade } \\
\text { (dias) }\end{array}$ & $\boldsymbol{f}_{\boldsymbol{c}}(\mathbf{M P a})$ & $\boldsymbol{f}_{\boldsymbol{t}}(\mathbf{M P a})$ & $\boldsymbol{E}_{\boldsymbol{c}}(\mathbf{G P a})$ \\
\hline 1 & 30 & 56,3 & 3,43 & - \\
2 & 30 & 59,2 & 2,99 & - \\
3 & 30 & 56,1 & - & 33,8 \\
4 & 30 & 57,6 & - & 34,2 \\
Média & & $\mathbf{5 7 , 3}$ & $\mathbf{3 , 2 1}$ & $\mathbf{3 4 , 0}$ \\
\hline
\end{tabular}


Tabela 6.3 - Propriedades do concreto - Etapa 2.

\begin{tabular}{ccccc}
\hline Corpo-de-prova & $\begin{array}{c}\text { Idade } \\
\text { (dias) }\end{array}$ & $\boldsymbol{f}_{\boldsymbol{c}}(\mathbf{M P a})$ & $\boldsymbol{f}_{\boldsymbol{t}}(\mathbf{M P a})$ & $\boldsymbol{E}_{\boldsymbol{c}}(\mathbf{G P a})$ \\
\hline 1 & 44 & 58,7 & 3,5 & 31,2 \\
2 & 44 & 56,4 & - & 29,8 \\
Média & & $\mathbf{5 7 , 5}$ & $\mathbf{3 , 5}$ & $\mathbf{3 0 , 5}$ \\
\hline
\end{tabular}

\section{- Graute}

Utilizou-se graute auto adensável “Fosgrout Plus” da Fosroc com relação água/graute de 0,132 . O grauteamento da ligação foi realizado em duas fases. Na primeira, antes dos ensaios estáticos, grautearam-se o espaço entre o chumbador e o furo da viga e o espaço superior entre viga e pilar. Na segunda, após a primeira etapa de ensaios, com a viga já fissurada, grauteou-se o espaço inferior entre a viga e o pilar.

Foram adotados corpos-de-prova de $5 \mathrm{~cm}$ de diâmetro e $10 \mathrm{~cm}$ de altura para a caracterização do graute. Os ensaios para determinação da resistência à compressão e módulo foram realizados na máquina universal de ensaios servo-hidráulica INSTRON com uso do sistema de aquisição de dados System 5000 da Vishay. As deformações utilizadas na determinação do módulo de elasticidade foram obtidas por meio de extensômetros removíveis com base de leitura de $5 \mathrm{~cm}$. Apenas um ensaio para determinação da resistência à tração foi realizado, referente à segunda fase de grauteamento, na máquina hidráulica ELE Autotest 2000. Os resultados da caracterização dos grautes utilizados na confecção do modelo-piloto estão dispostos na Tabela 6.4 e Tabela 6.5 .

Tabela 6.4 - Propriedades do graute - primeira fase de grauteamento.

\begin{tabular}{cccc}
\hline Corpo-de-prova & $\begin{array}{c}\text { Idade } \\
\text { (dias) }\end{array}$ & $\boldsymbol{f}_{\boldsymbol{c}}(\mathbf{M P a})$ & $\boldsymbol{E}_{\boldsymbol{c}}(\mathbf{G P a})$ \\
\hline 1 & 15 & 43,1 & - \\
2 & 15 & 37,4 & - \\
3 & 15 & 37,4 & - \\
4 & 15 & 31,8 & 35,1 \\
5 & 15 & 27,2 & 28,7 \\
Média & & $\mathbf{3 5 , 4}$ & $\mathbf{3 1 , 9}$ \\
\hline
\end{tabular}


Tabela 6.5 - Propriedades do graute - segunda fase de grauteamento.

\begin{tabular}{ccccc}
\hline Corpo-de-prova & $\begin{array}{c}\text { Idade } \\
\text { (dias) }\end{array}$ & $\boldsymbol{f}_{\boldsymbol{c}}(\mathbf{M P a})$ & $\boldsymbol{E}_{\boldsymbol{c}}(\mathbf{G P a})$ & $\boldsymbol{f t}(\mathbf{M P a})$ \\
\hline 1 & 10 & 39,9 & 26,6 & 2,8 \\
2 & 10 & 35,8 & 26,7 & - \\
3 & 10 & 35,8 & 27,0 & - \\
4 & 10 & 35,9 & 28,2 & - \\
Média & & $\mathbf{3 6 , 8}$ & $\mathbf{2 7 , 1}$ & $\mathbf{2 , 8}$ \\
\hline
\end{tabular}

\section{- Adesivo}

Para a colagem dos laminados nos entalhes foi utilizada a resina epóxi bi-componente “Sikadur® 330”. Não foi realizado qualquer ensaio para caracterização dessas resinas. Suas propriedades físicas, de acordo com informações dos fornecedores, são apresentadas na Tabela 6.6.

Tabela 6.6 - Propriedades físicas do adesivo utilizado para colagem dos laminados (dados do fornecedor).

\begin{tabular}{cccc}
\hline $\begin{array}{c}\text { Resistência à tração } \\
(\mathbf{M P a})\end{array}$ & $\begin{array}{c}\text { Deformação na ruptura } \\
(\%)\end{array}$ & $\begin{array}{c}\text { Módulo à tração } \\
(\mathbf{M P a})\end{array}$ & $\begin{array}{c}\text { Módulo à flexão } \\
(\mathbf{M P a})\end{array}$ \\
\hline 30 & 0,9 & 4500 & 3800 \\
\hline
\end{tabular}

\section{- Laminado}

O laminado foi adquirido junto à empresa "Rogertec" e recebe o nome comercial de "Fita de Fibra de Carbono" ou "FITA MFC". O produto foi desenvolvido para aplicação em reforço segundo a técnica NSM, denominada pela empresa por "incorporação por sulco na superfície (ISS)". Ensaios para determinação das propriedades no laminado à tração baseados na ASTM D3039/D 3039M (2008) foram realizados por Arquez (2010). Os ensaios foram realizados máquina universal de ensaios servo-hidráulica INSTRON com sistema de aquisição de dados System 5000 da Vishay. Utilizaram-se três corpos-de-prova com $100 \mathrm{~cm}$ de comprimento e largura e espessura do laminado. Na região da garra, foram coladas pastilhas (tabs), confeccionadas com o laminado, com comprimento de $15 \mathrm{~cm}$ para impedir o esmagamento do compósito nesta região. $\mathrm{Na}$ metade do comprimento dos $\mathrm{CPs}$, foram posicionados extensômetros elétricos e extensômetros removíveis que permitiram a obtenção 
da deformação. Os valores da deformação na ruptura e da resistência à tração, obtidos experimentalmente, ficaram bem abaixo dos fornecidos pela empresa, contudo obteve-se um valor próximo para o módulo de elasticidade, como se pode notar pela comparação entre a Tabela 6.7 e a Tabela 6.8. A dificuldade na determinação da tensão de ruptura se deve a tendência de esmagamento na região das garras. A colagem de tabs provavelmente não foi eficiente em evitar esse problema. Apesar disso, o comportamento linear do diagrama tensão deformação e a uniformidade do comportamento dos três corpos de prova podem ser observados na Figura 6.4. Nas análises apresentadas neste documento, foram considerados os valores de módulo de elasticidade e tensão última fornecidos pelos fabricantes.

Tabela 6.7 - Propriedades físicas do laminado (dados do fornecedor).

\begin{tabular}{ccccccc}
\hline $\begin{array}{c}\text { Largura } \\
(\mathbf{m m})\end{array}$ & $\begin{array}{c}\text { Espessura } \\
(\mathbf{m m})\end{array}$ & $\begin{array}{c}\text { Resistência } \\
\text { à tração } \\
(\mathbf{M P a})\end{array}$ & $\begin{array}{c}\text { Módulo de } \\
\text { elasticidade } \\
(\mathbf{G P a})\end{array}$ & $\begin{array}{c}\boldsymbol{\varepsilon}_{\boldsymbol{u}} \\
(\%)\end{array}$ & $\begin{array}{c}\text { Coeficiente de dilatação térmica } \\
\text { Transversal } \\
\left(\mathbf{x 1 0}^{\mathbf{6}} /^{\mathbf{0}} \mathbf{C}\right)\end{array}$ & $\begin{array}{c}\text { Longitudinal } \\
\left(\mathbf{x 1 0} /{ }^{\mathbf{0}} \mathbf{C}\right)\end{array}$ \\
\hline 16 & 2 & 2068 & 131 & 1,7 & 74 a 104 & 9 a 0,0 \\
\hline
\end{tabular}

Tabela 6.8 - Propriedades físicas do laminado (dados obtidos experimentalmente).

\begin{tabular}{cccc}
\hline Corpo-de-prova & $\begin{array}{c}\text { Resistência à tração } \\
(\boldsymbol{M P a})\end{array}$ & $\begin{array}{c}\text { Módulo de elasticidade } \\
(\boldsymbol{G P a})\end{array}$ & $\boldsymbol{\varepsilon}_{\boldsymbol{u}}(\%)$ \\
\hline 1 & 1588 & 115 & 1,26 \\
2 & 1479 & 118 & 1,18 \\
3 & 1617 & 116 & 1,30 \\
Média & $\mathbf{1 5 6 2}$ & $\mathbf{1 1 6}$ & $\mathbf{1 , 2 5}$ \\
\hline
\end{tabular}

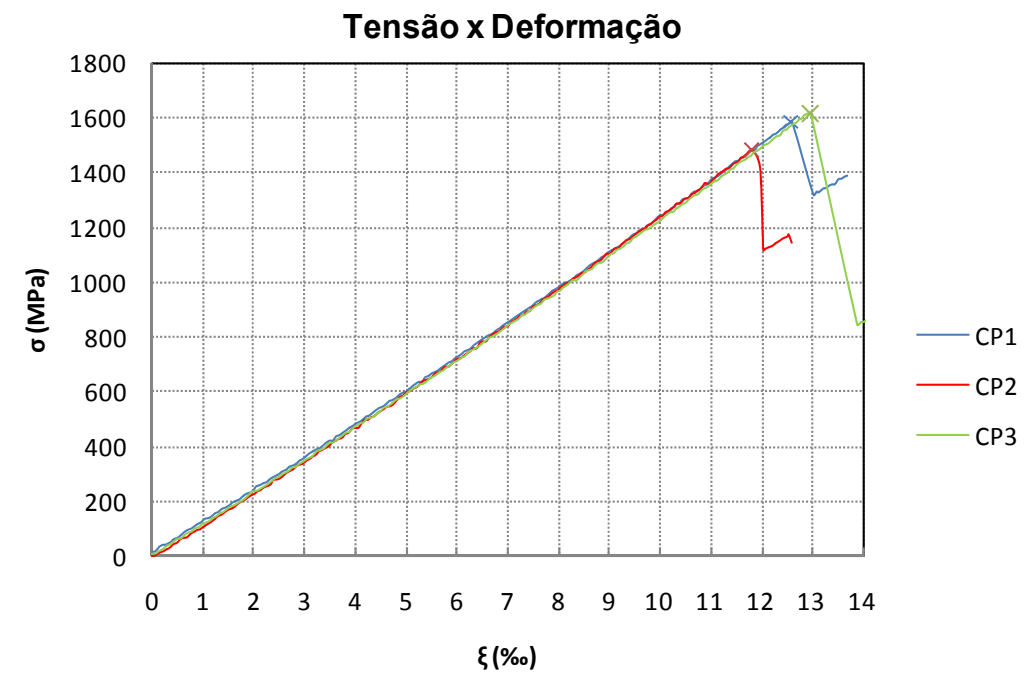

Figura 6.4 - Diagrama tensão x deformação para os três corpos-de-prova. 


\section{- Almofada de apoio}

Utilizou-se almofada de apoio de borracha natural "NR 1087" da marca "ORION", dureza Shore 70 A. Este é um material adequado para uso em estruturas de concreto prémoldado, ainda que o mais comum seja a utilização de almofada de apoio em elastômero ao invés de borracha natural. A almofada possui espessura de 9,3 mm e peso específico de 1,60 $\mathrm{g} / \mathrm{cm}^{3}$. Na Figura 6.5, ilustra-se as características geométricas da almofada de apoio.

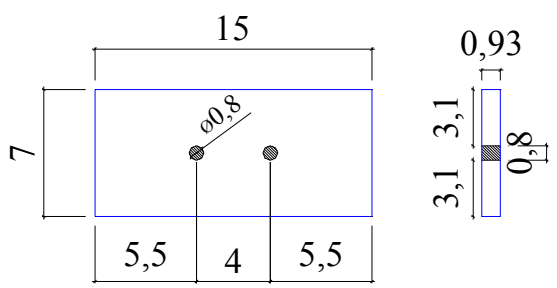

Figura 6.5 - Características geométricas da almofada de apoio.

\subsection{Confecção do modelo}

As fôrmas para os elementos de concreto (viga e pilares) que compuseram o modelo de ensaio foram confeccionadas em madeira laminada colada. $\mathrm{Na}$ fôrma da viga, posicionaram-se mangueiras plásticas untadas com desmoldante para confecção dos furos para encaixe dos chumbadores (Figura 6.6-b). Na Figura 6.6-a, pode-se observar que o dispositivo metálico para fixação do pórtico à base de reação foi acoplado à fôrma. As barras longitudinais do pilar foram solidarizadas ao dispositivo por meio de porcas e arruelas.

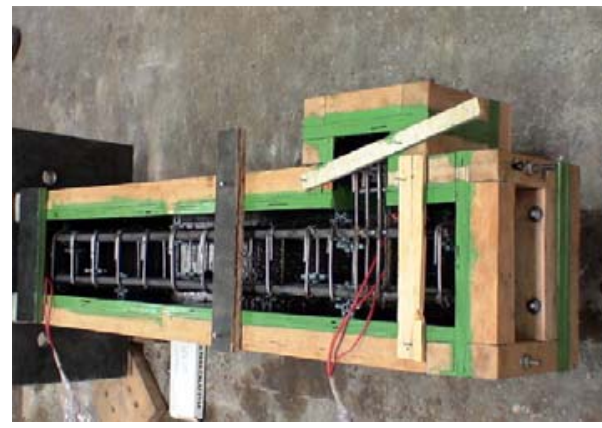

(a)

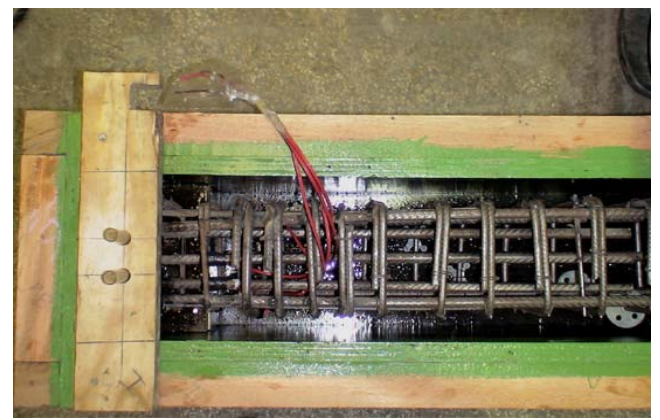

(b)

Figura 6.6 - Formas do pilar (a) e da viga (b).

Os elementos foram concretados e adensados com uso de vibrador de imersão (tipo agulha, Figura 6.7-a). Após período de cura e desfôrma, os pilares foram postos na posição 
definitiva de ensaio e fixados por meio do dispositivo metálico à base de reação do laboratório. Posicionaram-se as almofadas de apoio nos consolos (Figura 6.7-b) e sobre elas assentou-se a viga, com os chumbadores sendo introduzidos nos furos dos dentes da viga. $\mathrm{Na}$ Figura 6.7-c observa-se o pórtico montado.

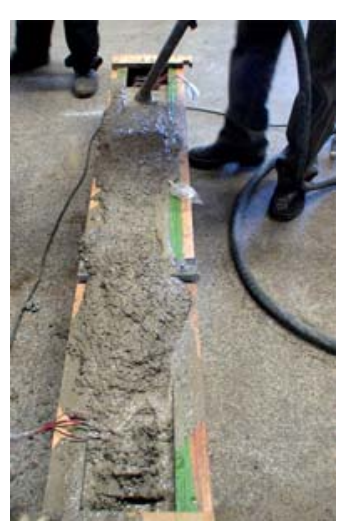

(a)

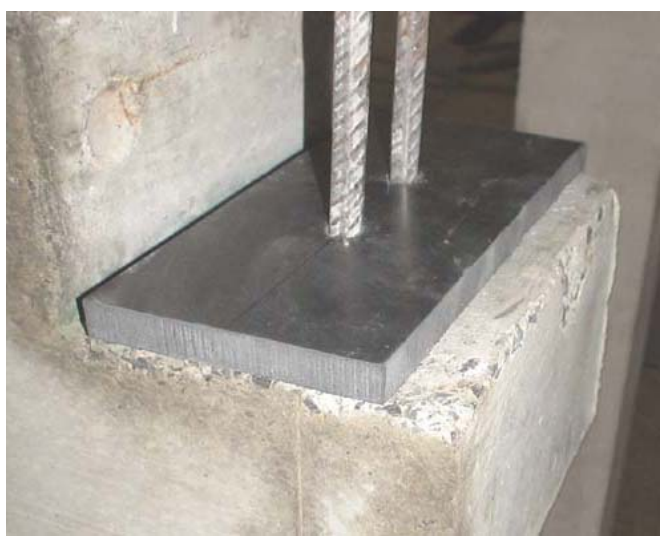

(b)

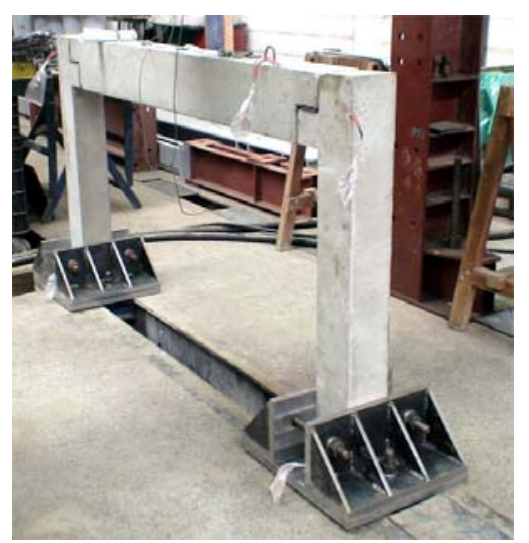

(c)

Figura 6.7 - Adensamento da viga e montagem do pórtico.

Após a colocação da viga sobre os pilares, vedou-se lateralmente o espaço superior entre a viga e o pilar com laminas de madeira compensada (Figura 6.8-a) e realizou-se a primeira fase de grauteamento (Figura 6.8-b) em que foram preenchidos o espaço superior entre viga e pilares e os vazios entre os chumbadores e os furos na viga. Com isso, o modelo ficou pronto para a primeira etapa de ensaios.

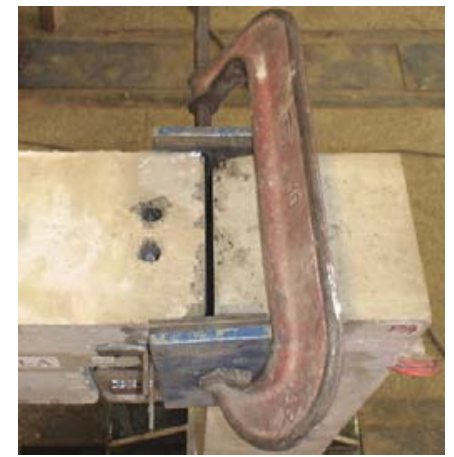

(a)

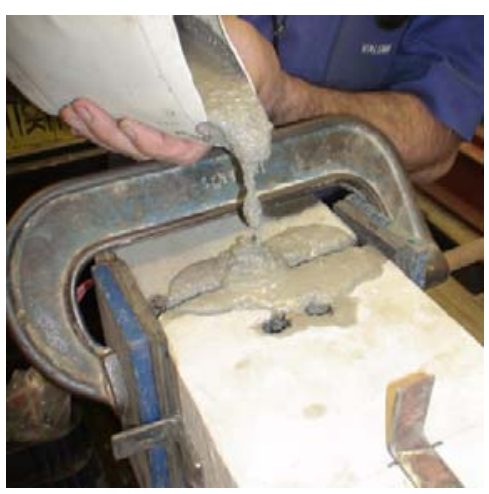

(b)

Figura 6.8 - Primeira fase de grauteamento.

O reforço das ligações foi realizado para a segunda etapa de ensaios e consistiu no grauteamento do espaço inferior entre viga e pilares e na colagem de laminados em entalhes no concreto de cobrimento lateral, na região da ligação. Os laminados foram colados ao longo 
de um comprimento de $50 \mathrm{~cm}$ com uma distância dos bordos superior e inferior da viga de 3 $\mathrm{cm}$. O reforço com o laminado de PRFC envolveu os seguintes procedimentos:

- Realização de entalhe com uso de ferramenta elétrica com dois discos de corte justapostos, por via úmida com o alargamento da sua seção nas regiões em que havia extensômetros colados ao laminado.

- Lavagem das peças entalhadas com água e secagem;

- Limpeza dos entalhes por jateamento de ar comprimido;

- Limpeza dos laminados com estopa embebida em álcool isopropílico;

- Aplicação da resina no entalhe com uso de espátula (Figura 6.9-a);

- Aplicação da resina no laminado (Figura 6.9-b);

- Introdução do laminado no entalhe;

- Acabamento com espátula (Figura 6.9-c).

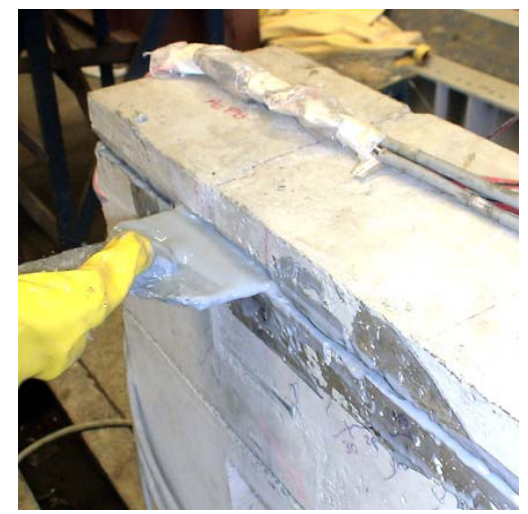

(a)

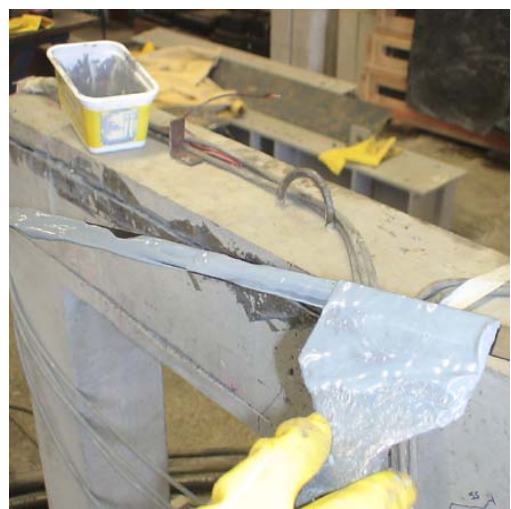

(b)

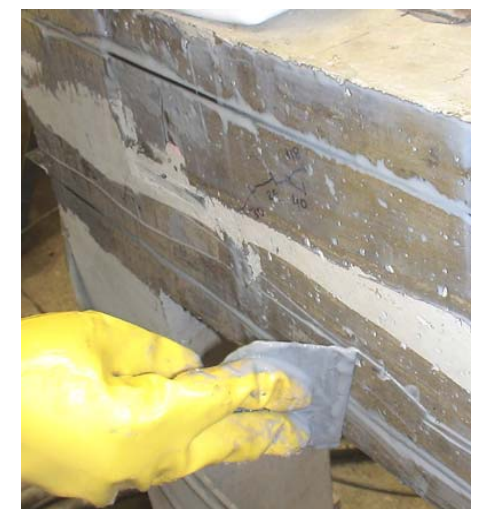

(c)

Figura 6.9 - Execução do reforço com laminado de PRFC: (a) aplicação de resina no entalhe; (b) aplicação de resina no laminado; (c) acabamento.

\subsection{Instrumentação e configuração do ensaio estático}

O ensaio contou com instrumentação interna e externa. A instrumentação interna ilustrada na Figura 6.10 consistiu em extensômetros colados nas armaduras dos pilares e da viga e nos laminados em seções de interesse. 


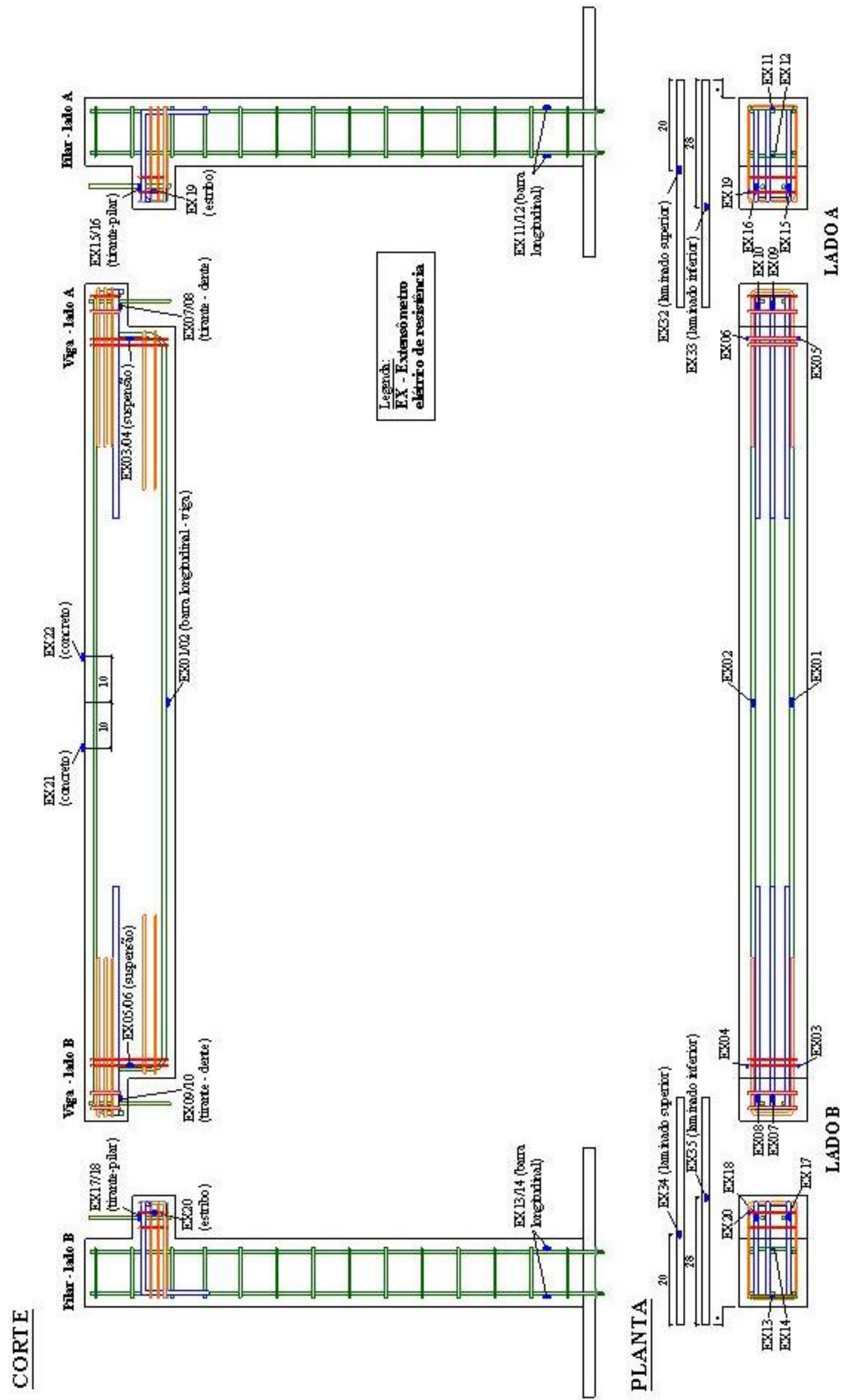

Figura 6.10 - Instrumentação interna (figura adaptada de Almeida, 2010). 
A instrumentação externa é apresentada na Figura 6.11. Utilizaram-se transdutores de deslocamento e clinômetros fixados na região das ligações para obtenção da rotação relativa entre viga e pilares. Um transdutor de deslocamento foi posicionado verticalmente a meio vão da viga para medição da flecha. Um extensômetro foi colado no bordo comprimido da viga, aproximadamente a meio vão, para obtenção das deformações no concreto.

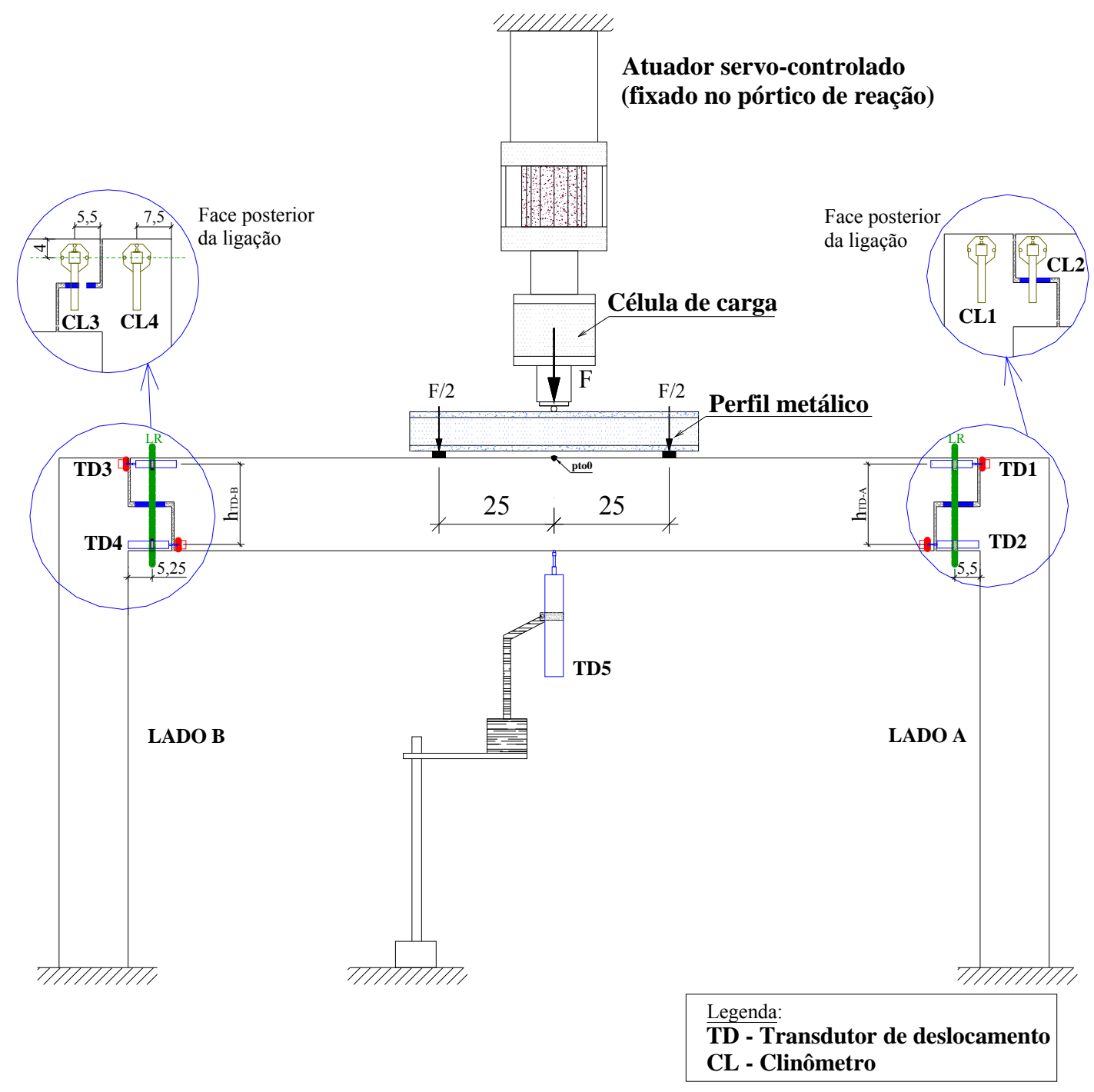

Figura 6.11 - Instrumentação externa e configuração do ensaio estático (figura adaptada de Almeida, 2010).

Também na Figura 6.11, se explicita a configuração do ensaio estático. O modelo de pórtico fixado por meio dos dispositivos metálicos nas bases dos pilares foi submetido à força aplicada por um atuador servo-controlado Instron, distribuída a duas seções da viga por meio de um perfil metálico. 


\subsection{Execução do ensaio}

A execução do ensaio foi dividida em duas etapas principais: a primeira (Etapa 1), em que o modelo ensaiado exibia ligações articuladas e a segunda (Etapa 2), em que as ligações haviam sido reforçadas. Em cada uma dessas etapas o modelo foi submetido a solicitações estáticas e dinâmicas, conforme a sequência:

\section{Etapa 1 (ligações articuladas)}

- Realização de ensaio dinâmico no modelo íntegro;

- Ciclo de aplicação de força com controle de deslocamento a uma taxa de $0,005 \mathrm{~mm} / \mathrm{s}$ e retirada de força a uma taxa de $0,01 \mathrm{~mm} / \mathrm{s}$ com pico de $35 \mathrm{kN}$;

- Realização de ensaio dinâmico;

- Ciclo de aplicação de força com controle de deslocamento a uma taxa de $0,005 \mathrm{~mm} / \mathrm{s}$ e retirada de força a uma taxa de $0,01 \mathrm{~mm} / \mathrm{s}$ com pico de $55 \mathrm{kN}$;

- Realização de ensaio dinâmico no modelo fissurado.

\section{Etapa 2 (ligações reforçadas)}

- Realização de ensaio dinâmico no modelo com ligações reforçadas;

- Ciclo de aplicação de força com controle de deslocamento a uma taxa de 0,005 $\mathrm{mm} / \mathrm{s}$ e retirada de força a uma taxa de $0,01 \mathrm{~mm} / \mathrm{s}$ com pico de $41 \mathrm{kN}$;

- Realização de ensaio dinâmico;

- Ciclo de aplicação de força com controle de deslocamento a uma taxa de 0,005 $\mathrm{mm} / \mathrm{s}$ com pico de $94 \mathrm{kN}$ correspondente a ruptura de uma das ligações;

- $\quad$ Realização de ensaio dinâmico no modelo após ruptura.

Apenas são apresentados na tese detalhes e resultados dos ensaios estáticos. Os resultados dos ensaios dinâmicos podem ser consultados em Almeida (2010). 


\subsection{Resultados e análises}

Os resultados estão apresentados separadamente conforme os itens que se julgaram mais importantes na avaliação do reforço: ruptura, rigidez à flexão e deslocamento vertical.

\subsubsection{Ruptura}

$\mathrm{Na}$ Etapa 1 do ensaio, aplicou-se força até que a viga apresentou fissuração expressiva no bordo tracionado, evitando-se, contudo que este elemento se aproximasse do seu estado limite último. Não houve escoamento de nenhuma das armaduras e o concreto do bordo comprimido apresentou deformação máxima de $1,2 \%$ (valor absoluto). A ruptura se deu na Etapa 2 do ensaio, de forma brusca com arrancamento do laminado com uma porção de concreto aderida quando a força aplicada no modelo era de $94 \mathrm{kN}$ e a deformação no laminado de 5,3 \%. Na Figura 6.12, podem-se observar a fissuração e o isolamento de uma porção de concreto no canto da viga na região da ligação. Esse tipo de ruptura já foi observado em outras investigações (DE LORENZIS E TENG, 2006) e está relacionado com a distância do laminado inserido ao canto da viga. No modelo de ensaio, adotou-se a distância de $3 \mathrm{~cm}$ que é indicada por Blaschko (2003). Kang et al. (2005) recomendam que o espaçamento entre laminados e a distância do reforço ao canto da viga sejam sempre superiores a $40 \mathrm{~mm}$, contudo essa distância seria muito elevada consideradas as dimensões do modelo de ensaio. 


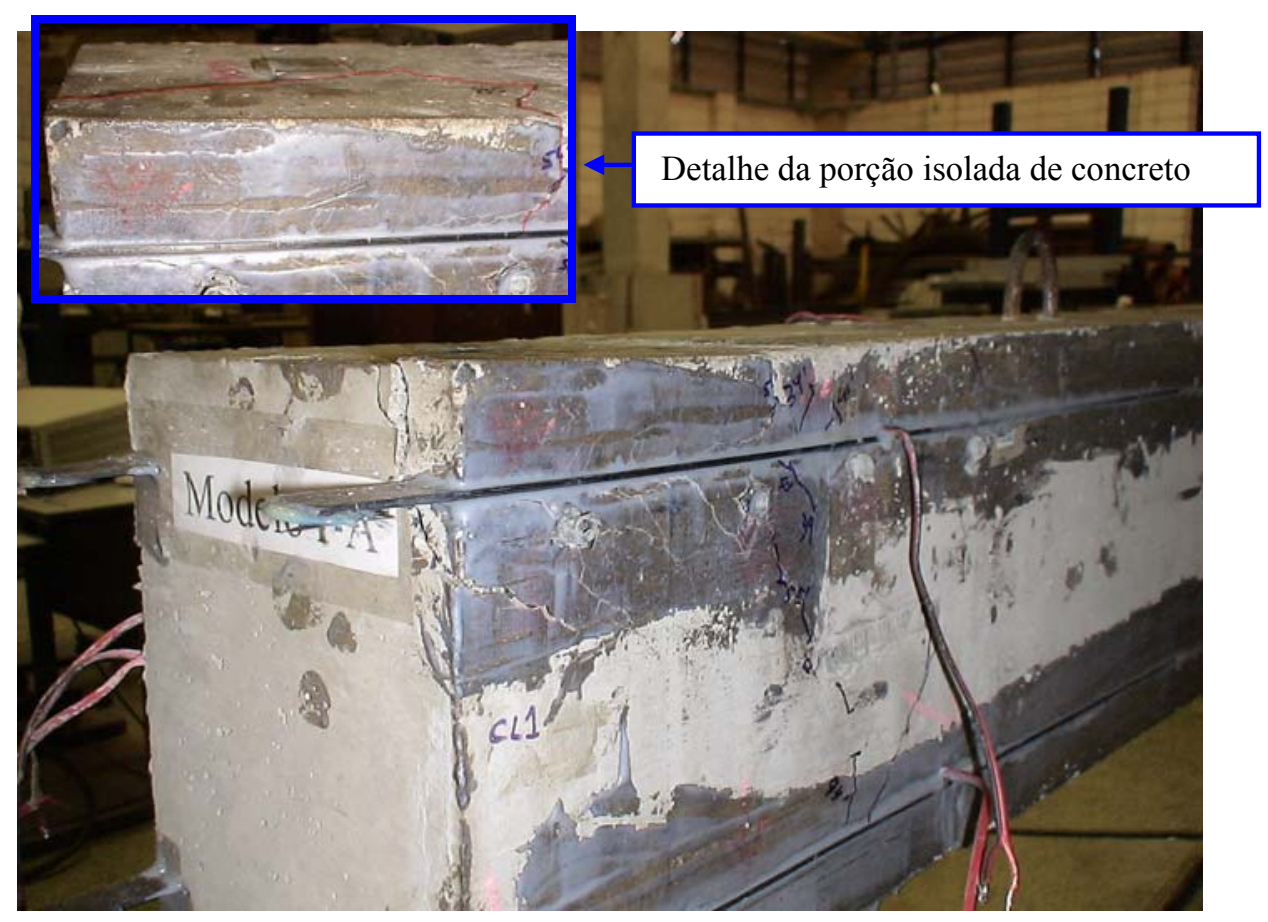

Figura 6.12 - Aspecto da ligação após a ruptura.

\subsubsection{Deformação}

A análise das deformações que se apresenta em sequência é interessante, pois permite que se avalie a alteração da distribuição dos esforços promovida pelo reforço. O posicionamento dos extensômetros por meio dos quais foram obtidas as deformações é apresentado na Figura 6.10.

\section{- Armadura de suspensão do dente da viga}

A armadura de suspensão da viga apresentou uma deformação máxima em torno de 0,5\% \%, para uma força de $56 \mathrm{kN}$, antes do reforço da ligação. Após o reforço, essa armadura praticamente não foi solicitada até a ruptura do modelo. A deformação máxima observada, para a ligação reforçada foi de 0,2 \% para a força de $94 \mathrm{kN}$. As curvas "força x deformação nas armaduras de suspensão" das ligações do modelo para as duas condições, antes e depois do reforço são apresentadas na Figura 6.13. 


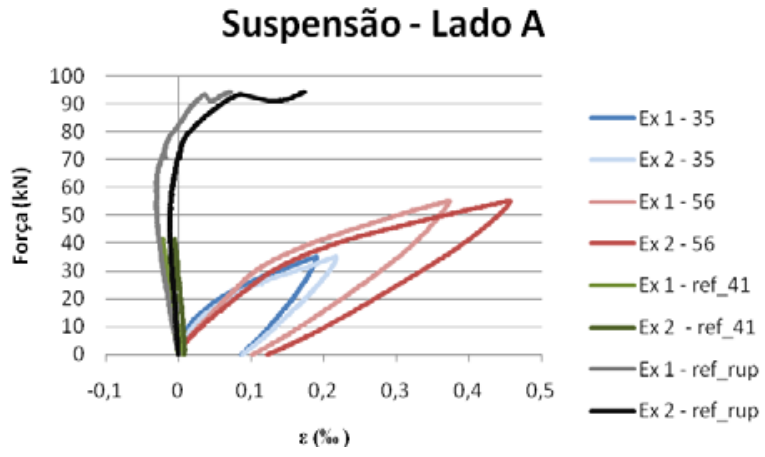

(a)

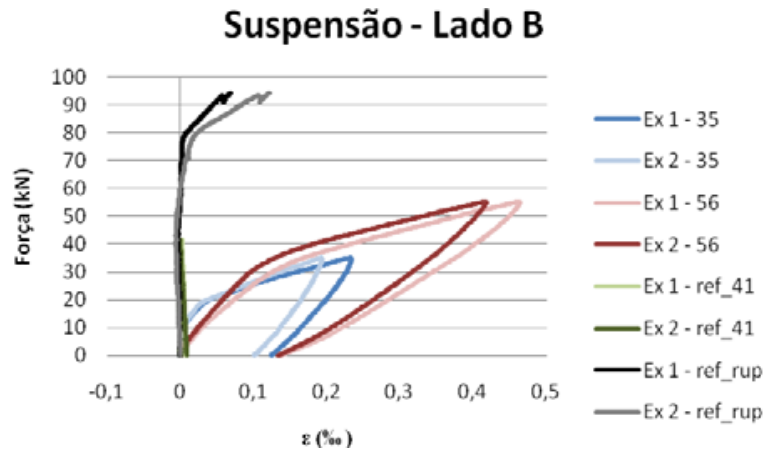

(b)

Figura 6.13 - Curvas "força x deformação na suspensão", antes e depois do reforço: (a) Lado A; (b) Lado B

\section{- Tirante do dente}

O comportamento das armaduras do tirante do dente apresenta uma tendência semelhante ao da armadura de suspensão. Elas apresentaram uma deformação máxima de aproximadamente $0,6 \%$ para a força de $56 \mathrm{kN}$, antes do reforço da ligação. Após o reforço, essa armadura praticamente não foi solicitada até a ruptura do modelo. A deformação máxima observada, para a ligação reforçada foi de aproximadamente $0,2 \%$, para a força de $94 \mathrm{kN}$. As curvas "força x deformação nas armaduras do tirante do dente" para as duas condições, antes e depois do reforço, são apresentadas na Figura 6.14.

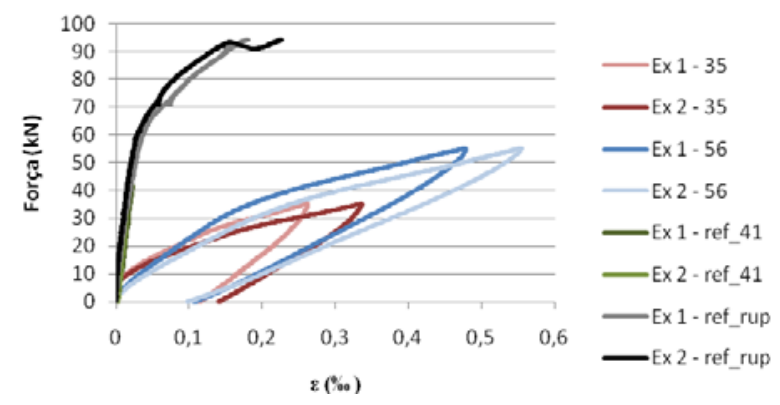

(a)

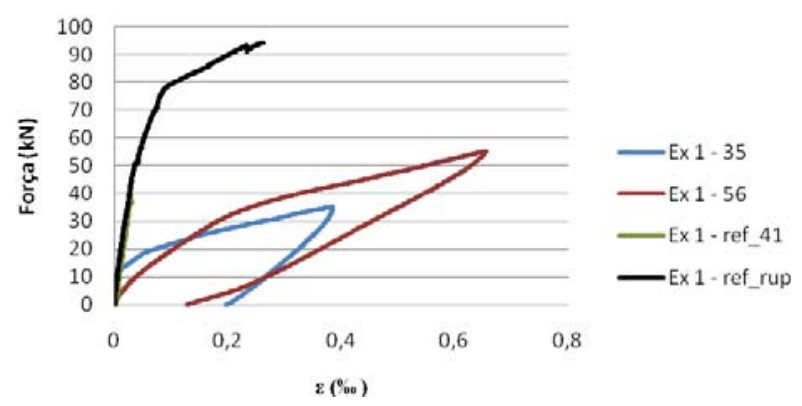

(b)

Figura 6.14 - Curvas "força x deformação na armadura do tirante do dente", antes e depois do reforço: (a) Lado A; (b) Lado B

\section{- Tirante do consolo}

Os tirantes dos consolos foram mais solicitados após o reforço das ligações, como se pode observar na Figura 6.15. Dois dos extensômetros posicionados na ligação do Lado B apresentaram comportamento incoerente após o reforço, indicando compressão. 


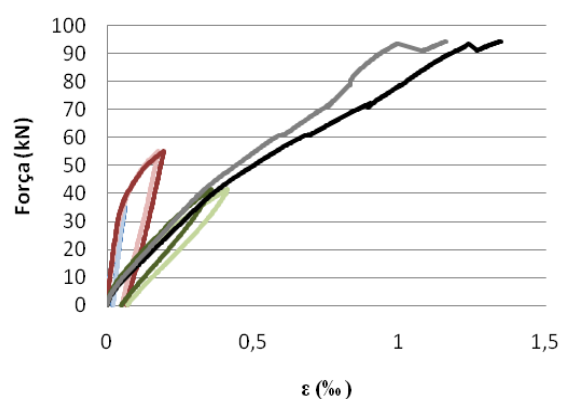

(a)

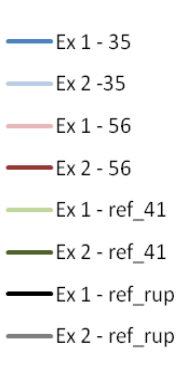

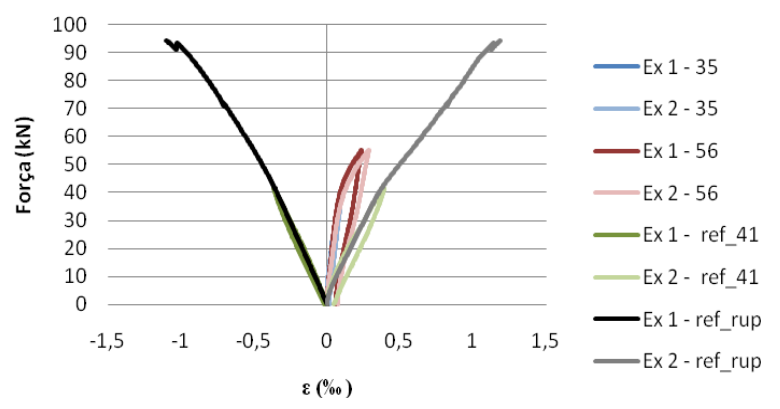

(b)

Figura 6.15 - Curvas "força x deformação na armadura do tirante do consolo", antes e depois do reforço: (a) Lado A; (b) Lado B

\section{- Estribo do consolo}

As leituras obtidas pelos extensômetros posicionados no Lado A do modelo (Figura 6.16-a) não ofereceram possibilidade de análise, pois não indicam qualquer tendência. Aparentemente, não representam o comportamento da armadura. Analisando a Figura 6.16-b percebe-se que os estribos praticamente não foram solicitados antes do reforço. Após o reforço, essas armaduras começaram a apresentar deformação a partir da força de aproximadamente $45 \mathrm{kN}$ e apresentaram deformação máxima de aproximadamente 0,5 \%o.

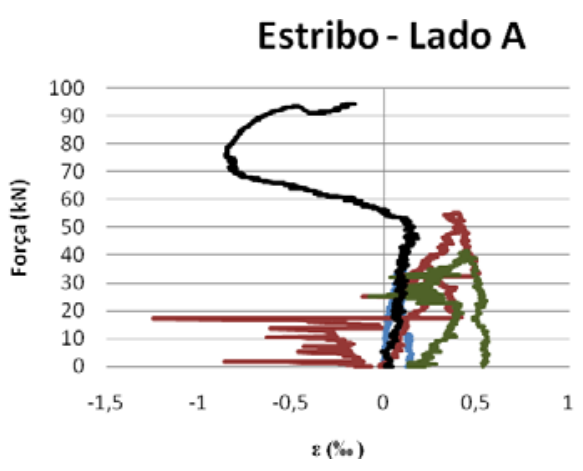

(a)

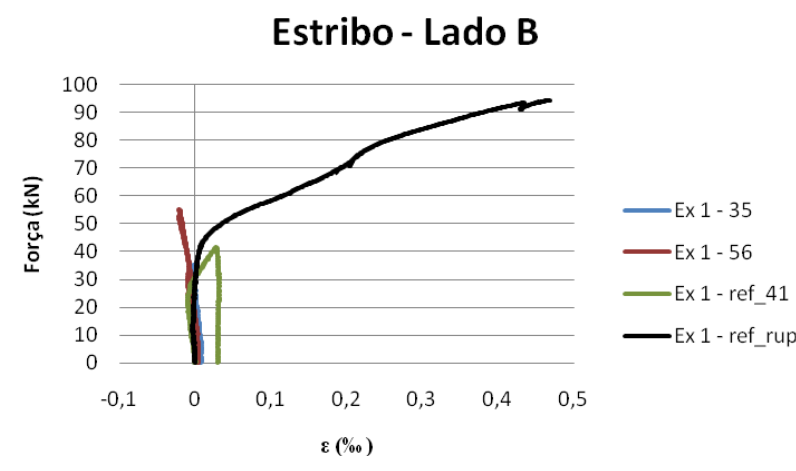

(b)

Figura 6.16 - Curvas "força x deformação na armadura do estribo", antes e depois do reforço: (a) Lado A; (b) Lado B

\section{- Armadura longitudinal do pilar}

As armaduras longitudinais dos pilares foram pouco solicitadas tanto antes como depois do reforço como se pode observar na Figura 6.17. Após o reforço apenas se obtiveram 
as leituras dos extensômetros posicionados nas armaduras comprimidas que apresentaram deformação máxima de $0,15 \%$ na ruptura.

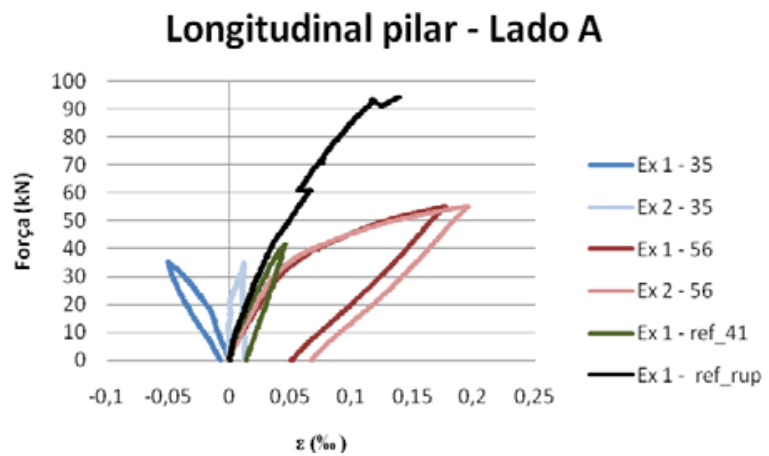

(a)

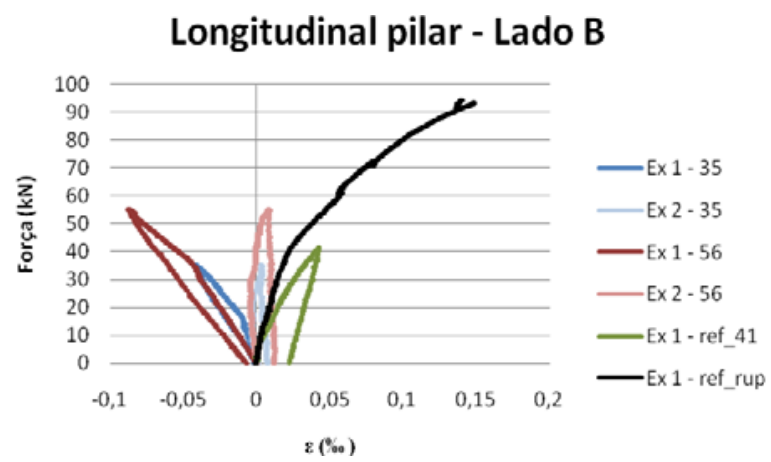

(b)

Figura 6.17 - Curvas “força x deformação na armadura longitudinal do pilar”, antes e depois do reforço: (a) Lado A; (b) Lado B

\section{- Armadura longitudinal da viga}

As armaduras longitudinais foram menos solicitadas após o reforço das ligações, como se pode observar na Figura 6.18. A deformação máxima observada, para a ligação reforçada foi de aproximadamente $4 \%$, para a força de $94 \mathrm{kN}$

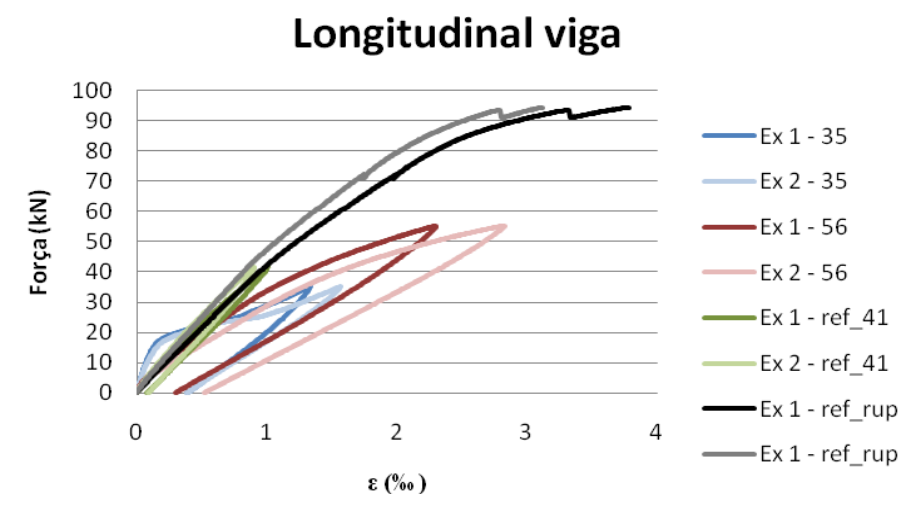

Figura 6.18 - Curvas “força x deformação na armadura longitudinal da viga", antes e depois do reforço.

\section{- Região comprimida de concreto}

Os extensômetros fixados na região comprimida apresentaram comportamento discrepante entre si. Aparentemente houve uma redução das deformações após o reforço. 


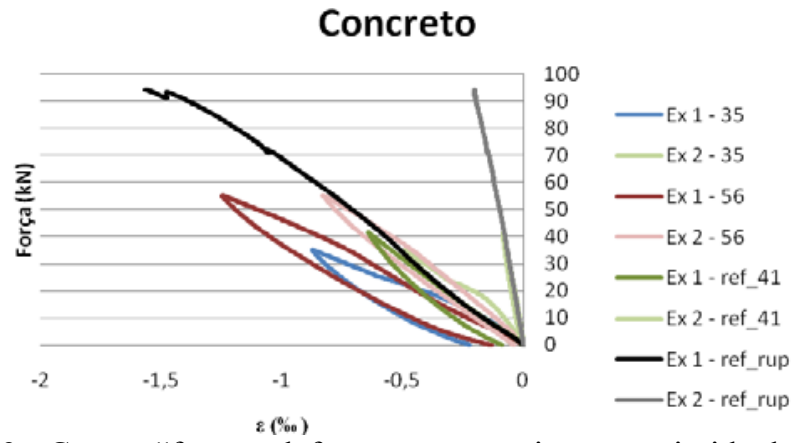

Figura 6.19 - Curvas "força x deformação na região comprimida de concreto".

\section{- Laminados}

A deformação nos laminado apresentou uma tendência de aumento linear com o incremento de força como se pode observar na Figura 6.20. Os laminados posicionados na região inferior das ligações apresentaram uma deformação de aproximadamente $-0,3$ \%o na ruptura. Não se esperava uma contribuição destes laminados para o tipo de carregamento empregado ao modelo. A colagem destes laminados foi efetuada, pois se esperava realizar outro tipo de carregamento em que a ligação ficaria submetida a momento positivo e então estes laminados seriam tracionados, o que não ocorreu. A deformação máxima observada nos laminados tracionados (posicionados na parte superior da ligação) foi de aproximadamente $5,3 \%$, para a força de $94 \mathrm{kN}$.

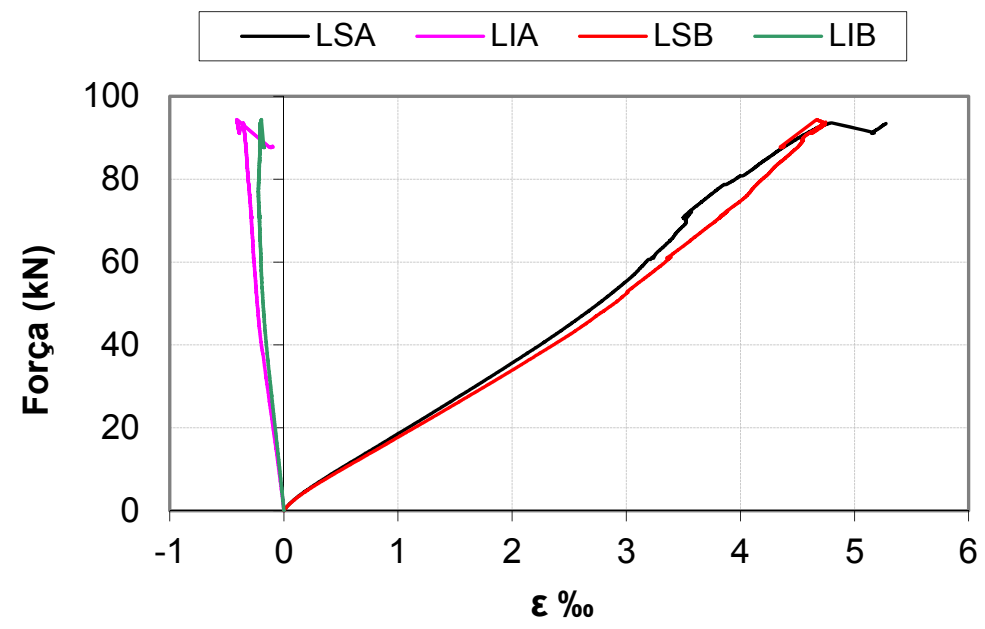

Figura 6.20 - Curvas “força x deformação nos laminados”. 


\subsubsection{Rigidez à flexão}

A rigidez da ligação reforçada foi avaliada em função da curvas "momento x rotação". A rotação relativa entre viga e pilar pôde ser obtida por meios dos transdutores de deslocamento (Equação 15) e dos clinômetros (Equação 16).

$$
\begin{aligned}
& \phi=\frac{\text { média }(T 1,3)-\text { média }(T 2,4)}{h_{T D}} \\
& \phi=\phi(C L B)-\phi(C L A)
\end{aligned}
$$

Onde:

$\phi$ é a rotação relativa global entre a viga e o pilar

$\phi(C L A)$ é a rotação global medida pelo clinômetro CLA fixado no pilar

$\phi(C L B)$ é a rotação global medida pelo clinômetro CLB fixado na viga

Destaca-se que por meio das Equações 15 e 16 as rotações são dadas em radianos e graus, respectivamente. Adotou-se utilizar radianos, assim converteu-se para esta unidade a rotação obtida por meio da Equação 16. Na Figura 6.21, observa-se que não houve concordância entre as rotações obtidas por meio de transdutores e clinômetros, porém nota-se semelhança de forma entre as curvas “força x rotação". Se minorarmos as rotações obtidas por meio dos clinômetros, as curvas praticamente se superpõem (Figura 6.22). A defasagem entre as rotações é função do diferente posicionamento dos instrumentos de medida. Ressalta-se que ambos, aparentemente, foram eficientes na medição da rotação. Contudo, como foram fixados em seções diferentes, apresentaram uma pequena diferença em suas medições. Na elaboração da curva "momento x rotação" apresentada posteriormente e, consequentemente na determinação da rigidez, utilizaram-se os dados obtidos por meio dos transdutores que apresentam menos oscilações como se pode observar na Figura 6.21. 


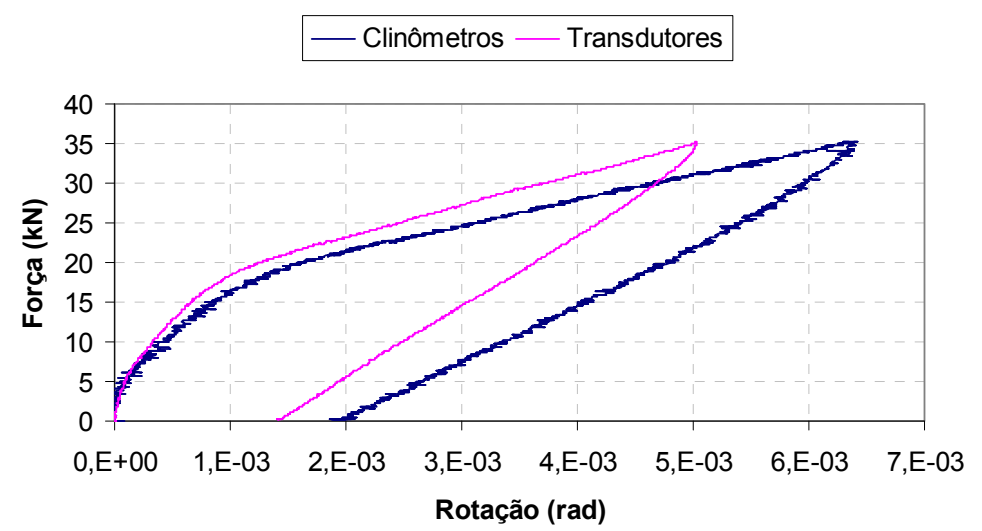

Figura 6.21 - Relação força x rotação obtida por meio de clinômetros e transdutores.

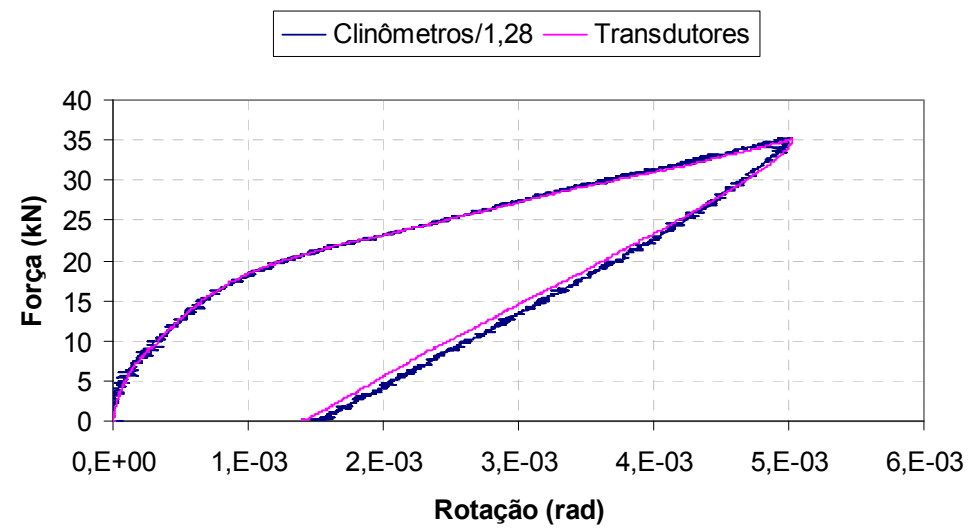

Figura 6.22 - Relação força x rotação por meio de clinômetros (minorada por 1,28) e transdutores.

Para a determinação do momento atuante nas ligações reforçadas, utilizou-se a metodologia desenvolvida por Catoia (2007). Ela se baseia na equivalência entre força e curvatura no meio do vão da viga nas etapas 1 e 2 do ensaio, com ligações articuladas e reforçadas.

Inicialmente calcula-se a curvatura na viga a meio vão por meio da Equação 17.

$$
\left(\frac{1}{r}\right)_{v a \tilde{o}}=\frac{\left(\varepsilon_{i m}-\varepsilon_{S m}\right)}{d}
$$

Onde:

$$
\left(\frac{1}{r}\right)_{\text {vão }} \text { é a curvatura no meio do vão }
$$

$\varepsilon_{i m}$ é a deformação média na armadura longitudinal da viga a meio vão 
$\varepsilon_{s m}$ é a deformação média no bordo comprimido da viga a meio vão

$d$ é a distância vertical entre a armadura longitudinal e o bordo comprimido da viga

Traçam-se as curvas força curvatura na viga para o modelo com ligações articuladas e reforçadas. Utilizaram-se o terceiro e o quarto ciclos de carregamento para esta análise (Figura 6.23).

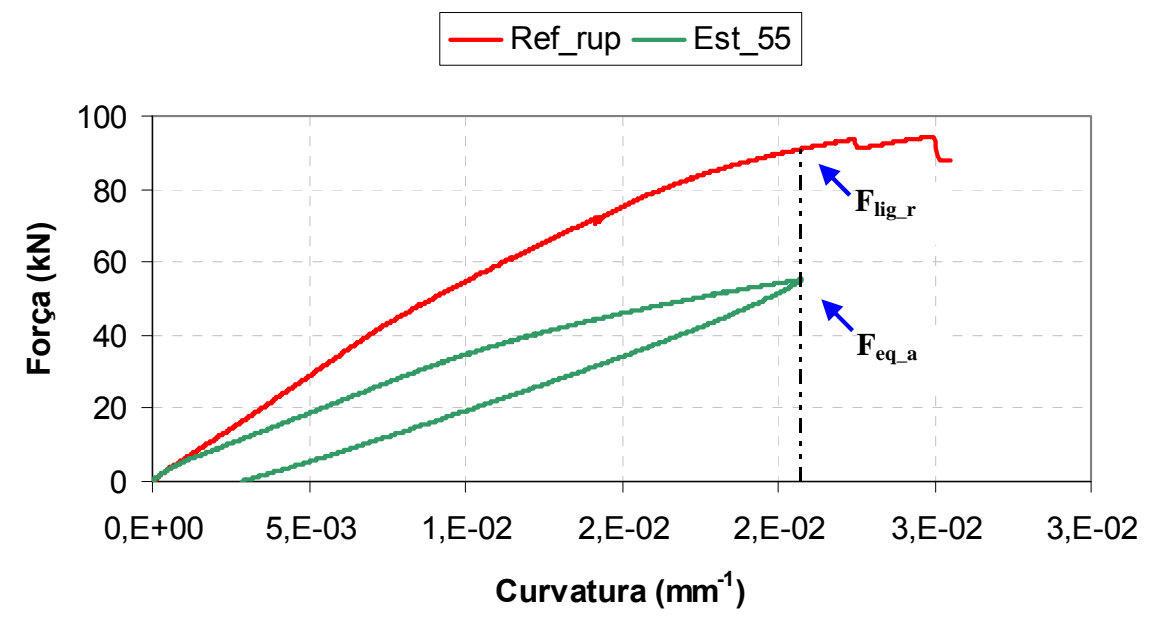

Figura 6.23 - Curvas "força x curvatura".

Para uma determinada curvatura, determinam-se as forças correspondentes ao modelo com ligações reforçadas $\left(\mathrm{F}_{\text {lig_ }_{\mathrm{r}}}\right)$ e com ligações articuladas $\left(\mathrm{F}_{\text {eq_a }}\right)$. $\mathrm{O}$ momento atuante na ligação é então calculado por meio da Equação 18.

$$
M_{\text {lig_r }}=\frac{F_{\text {lig_r }}}{2} \cdot a-\frac{F_{\text {eq_a }} a}{2} \cdot a
$$

Onde:

$M_{\text {lig_r é o momento atuante na ligação }}$

$F_{\text {lig_r }}$ é a força aplicada pelo atuador, igual a 2.F (ver F na Figura 6.24)

$a$ é a distância entre o apoio e o ponto de aplicação da força

$F_{\text {eq_a }}$ é a força equivalente à curvatura definida para o modelo com ligações articuladas 


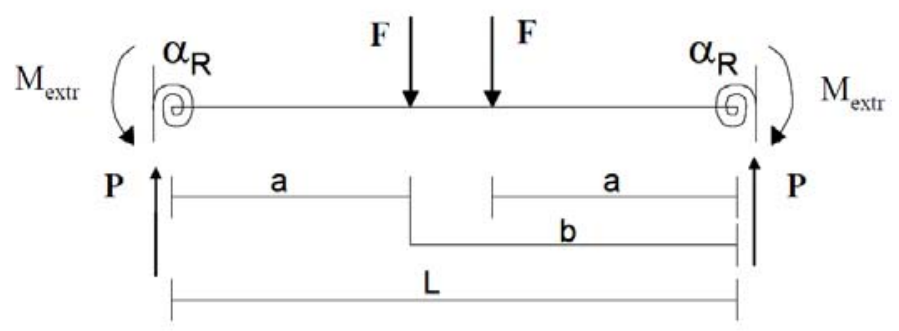

Figura 6.24 - Representação esquemática de viga com ligações semirrígidas (CATOIA, 2007).

A curva "momento x rotação" é notadamente não-linear com os trechos inicial e final próximos da linearidade (Figura 6.25). Em vista disso se adotou uma simplificação do comportamento da ligação dividindo-o em dois estágios aproximando-se a curva a um comportamento bi-linear. As inclinações dos trechos inicial $\left(\mathrm{K}_{\mathrm{i}}\right)$ e final $\left(\mathrm{K}_{\mathrm{f}}\right)$ foram definidas pela regressão linear. $K_{\mathrm{i}}$ e $\mathrm{K}_{\mathrm{f}}$ apresentaram os valores de $3506 \mathrm{kN} . \mathrm{m} / \mathrm{rad}$ e $1405 \mathrm{kN} . \mathrm{m} / \mathrm{rad}$, respectivamente. $\mathrm{O}$ valor de rigidez $\mathrm{K}_{\mathrm{i}}$ permite que a ligação reforçada seja classificada como semirrígida com média resistência à flexão, segundo a proposta de Ferreira, El Debs e Elliot (2002).

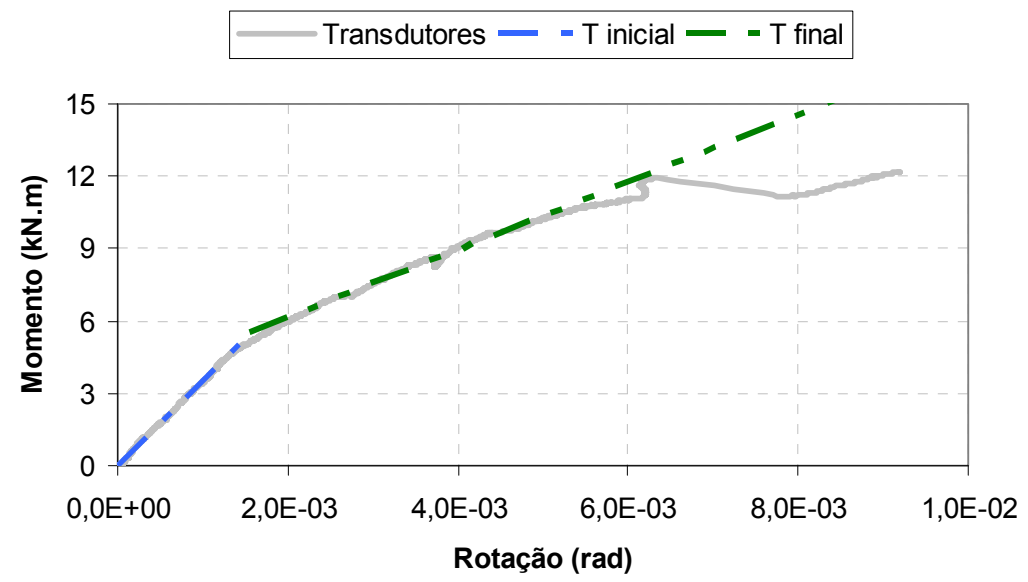

Figura 6.25 - Curva "momento x rotação" e aproximação bi-linear.

\subsubsection{Deslocamento vertical}

Apresentam-se, na Figura 6.26, os diagramas força $\mathrm{x}$ deslocamento vertical para todas as etapas de carregamento estático, desconsiderados os deslocamentos residuais em cada ciclo. 
Observa-se que a curva correspondente ao segundo ciclo de carregamento (Art_55), apresentou, no trecho inicial, uma inclinação menor que as demais. Nessa etapa de carregamento, a viga já apresentava fissuras em função do primeiro carregamento e tinha, portanto, uma menor rigidez. Com o reforço (Ref_41 e Ref_rup), praticamente restaurou-se a inclinação do trecho inicial da curva obtida para o primeiro ciclo de carregamento (Art_35).

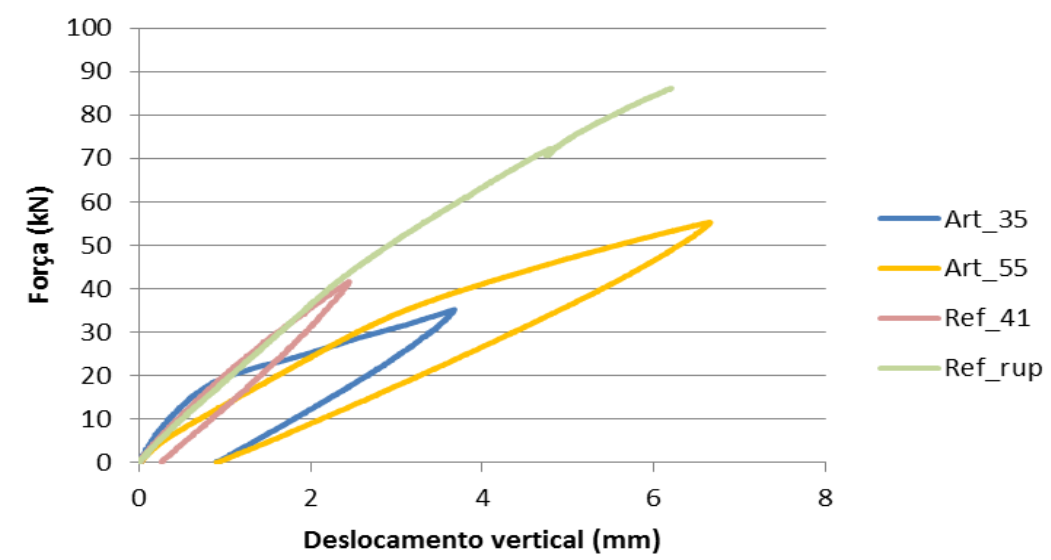

Figura 6.26 - Diagrama força x deslocamento vertical, desconsiderados os deslocamentos residuais nos ciclos.

$\mathrm{Na}$ Figura 6.27, observa-se que, para a força de $55 \mathrm{kN}$, o reforço promoveu uma redução do deslocamento vertical da viga de $2,2 \mathrm{~cm}$, aproximadamente $30 \%$ do deslocamento total experimentado pela viga antes do reforço.

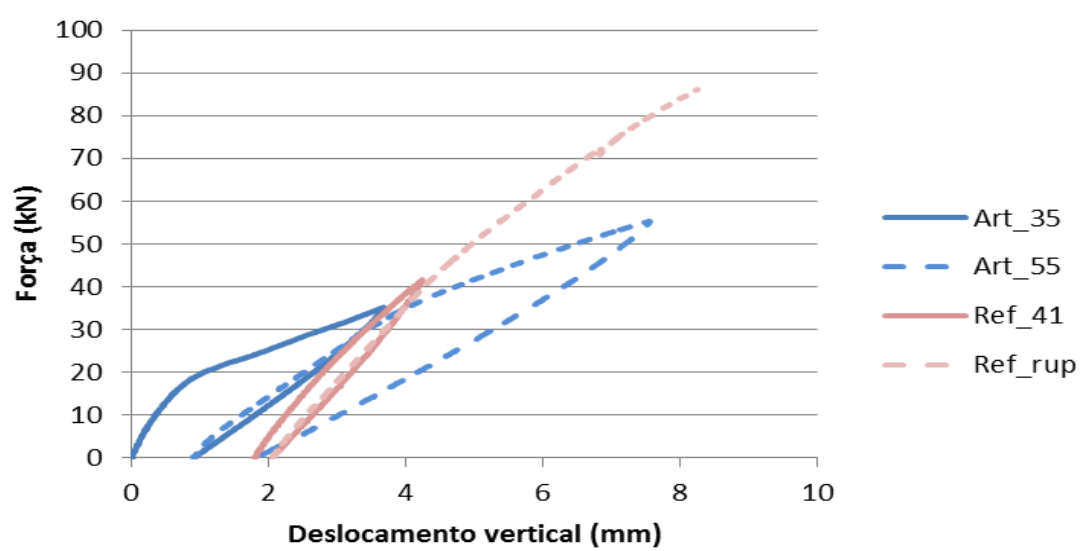

Figura 6.27 - Diagrama força x deslocamento vertical.

\subsubsection{Conclusões}

O reforço foi eficiente no aumento de rigidez da ligação. Isso determinou uma redução significativa no deslocamento vertical da viga. 
O reforço alterou solicitação das armaduras principais da ligação. Isso leva a duas conclusões principais: o reforço pode ser utilizado para solução de problemas relacionados à deficiência de armadura de suspensão e tirante do dente; em se reforçando a ligação deve-se verificar que as amaduras do tirante do consolo resistam às novas condições já que o reforço promoveu um aumento da solicitação destas.

A ruptura brusca da ligação era algo esperado em virtude do comportamento elástico linear do laminado, entretanto, no ensaio, a ruptura ocorreu quando este apresentava somente $30 \%$ da sua deformação última. $\mathrm{O}$ arrancamento prematuro afetou negativamente a avaliação da ductilidade da estrutura. Embora se devam reconhecer os problemas em relação ao descolamento prematuro, conclui-se que o modelo de ensaio foi satisfatório para avaliação do reforço no tocante à rigidez à flexão.

\subsection{Simulação numérica com base nos resultados do Ensaio-Piloto}

Para a simulação numérica, utilizou-se o pacote computacional DIANA que foi desenvolvido e continua sendo aprimorado pela TNO DIANA bv., companhia à parte do Departamento de Mecânica Computacional do Instituto de Pesquisa em Construção TNO, da Holanda. A escolha do programa dentre os disponibilizados pelo Departamento de Estruturas se justifica por sua maior adequação à análise de estruturas de concreto. O DIANA permite a consideração de fenômenos complexos que interferem na resposta de estruturas de concreto como: fissuração, plasticidade, confinamento, fluência, cura, histórico de carregamento. Além disso, há no departamento diversos pesquisadores que tem domínio na utilização do programa, o que permite a troca de conhecimentos. Numa primeira etapa, a simulação numérica foi empregada na reprodução do ensaio-piloto. Desta forma, se buscou, além do melhor entendimento do efeito do reforço, definições em relação ao modelo definitivo de ensaio como, por exemplo, o posicionamento da instrumentação. Uma discussão sobre os recursos utilizados na simulação numérica e resultados obtidos são apresentados a seguir. 


\subsubsection{Modelo numérico}

Optou-se pela utilização de um modelo sólido tridimensional (Figura 6.28-a). Devido às condições de simetria do modelo e da solicitação, a análise poderia ter sido feita, a princípio, em apenas um quarto do modelo. A consideração da simetria do modelo em relação ao plano vertical que corta o eixo longitudinal não foi empregada, pois em testes realizados o modelo apresentou problemas de convergência. Empregou-se apenas a simetria em relação ao plano transversal, ou seja, a análise foi realizada em meio modelo com geometria apresentada na Figura 6.28-b. Na Figura 6.29, observa-se o modelo numérico com as restrições impostas. $\mathrm{Na}$ base, foram impedidos os deslocamentos em $\mathrm{x}$, y e z para simular o engaste e no plano de simetria restringiram-se os deslocamentos em x. Não foi necessário restringir as rotações, pois o elemento finito utilizado não apresenta esse grau de liberdade.

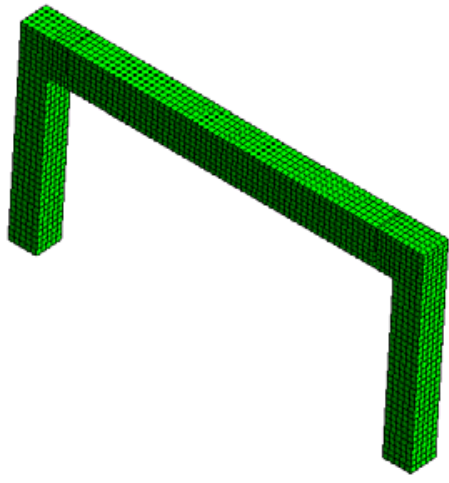

(a)

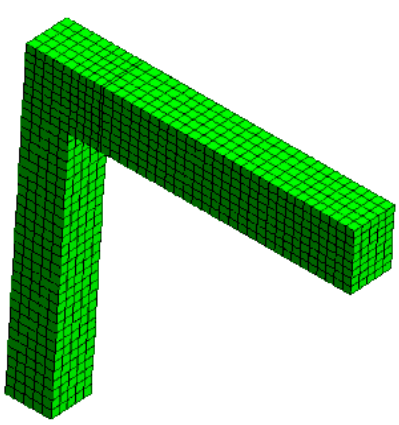

(b)

Figura 6.28 - (a) Modelo tridimensional discretizado em elementos finitos sólidos; (b) modelo tridimensional utilizado nas análises em função da simetria em relação ao plano transversal.

Figura 6.29 - Modelo com as restrições impostas na base do pilar e no plano de simetria. 


\subsubsection{Elementos finitos}

Para a discretização do concreto, foi utilizado o elemento finito isoparamétrico sólido CHX60 (Figura 6.30). Este elemento de 20 nós é baseado em interpolação quadrática e integração de Gauss.

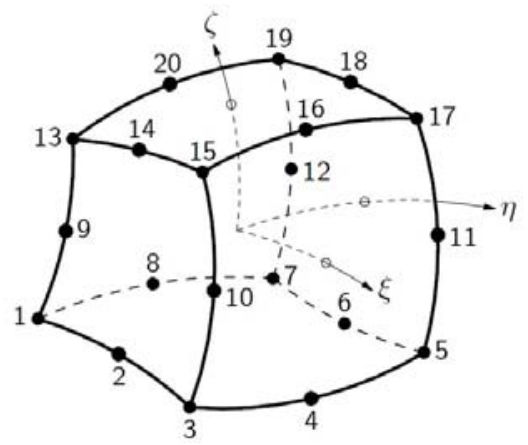

Figura 6.30 - Elemento CHX60

Para simulação das juntas entre a viga e o pilar, utilizou-se o elemento finito CQ48I (Figura 6.31). Trata-se de um elemento de interface estrutural que descreve o comportamento da interface em função das relações entre força e deslocamentos normal e tangencial.
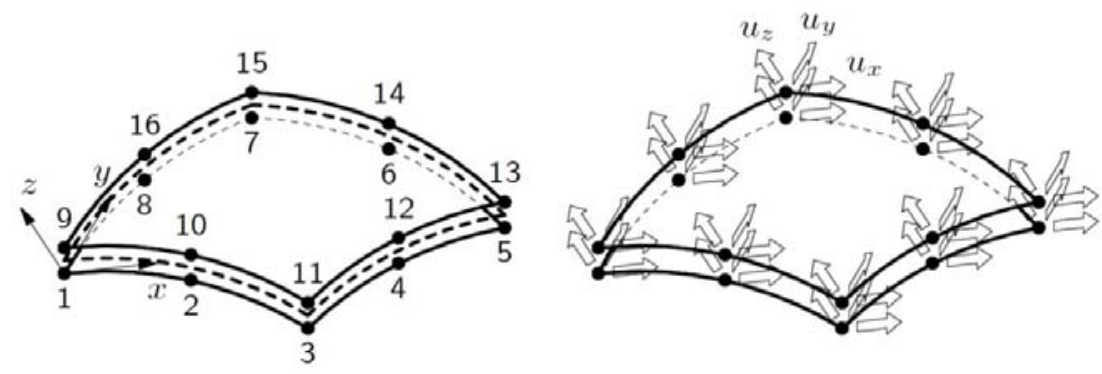

Figura 6.31 - Elemento CQ48I

Para a representação das armaduras e laminados, utilizou-se o elemento denominado Embedded Reinforcement. Por padrão, esse elemento não possui graus de liberdade próprios e sua deformação é computada a partir do campo de deslocamento do elemento no qual está inserido. Isso implica aderência perfeita entre a armadura e o material adjacente (DIANA, 2005). Na Figura 6.32, apresentam-se todas as armaduras empregadas no modelo, inclusive laminados, por meio do recurso Embedded Reinforcement. 


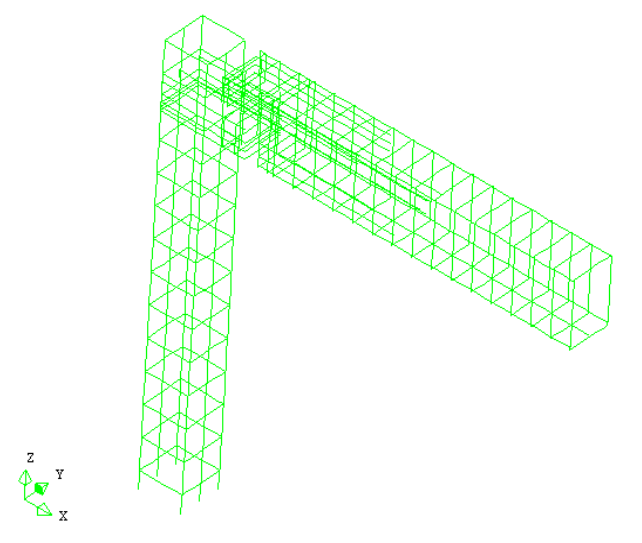

Figura 6.32 - Representação da armadura.

\subsubsection{Modelos constitutivos}

A princípio pretendeu-se utilizar o modelo constitutivo Total Strain Fixed Crack para a representação do comportamento do concreto. Os modelos Total Strain descrevem o comportamento do concreto sob tensões de compressão e de tração por meio de uma relação tensão-deformação. No modelo Total Strain Fixed Crack, as relações tensão-deformação são avaliadas segundo um sistema de coordenadas fixo sobre a fissura, conservando a sua orientação inicial nos estágios subsequentes o que demanda menor custo computacional.

Os dados de entrada são compostos por duas partes: (1) propriedades básicas, tais como módulo de elasticidade, coeficiente de Poisson, etc; (2) definição do comportamento do concreto quando submetido à compressão, tração e cisalhamento. As propriedades básicas podem ser fornecidas diretamente ao DIANA ou serem calculadas de acordo com normas específicas para o concreto. Os comportamentos do concreto sob tração e compressão podem ser definidos por meio da escolha de funções predefinidas no DIANA (Figura 6.33 e Figura 6.34) ou por meio de funções fornecidas pelo usuário por meio de sub-rotinas. Nos modelos Total Strain de fissura fixa, o comportamento quanto ao cisalhamento é avaliado por meio da função que descreve a retenção ao cisalhamento e pode ser constante ou variável. Em se utilizando a função constante, o usuário deve fornecer o valor do fator de retenção ao cisalhamento $\beta$, que é por padrão igual a 0,01 . 


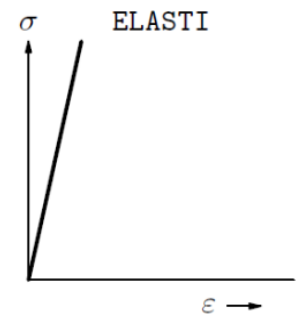

(a) elastic

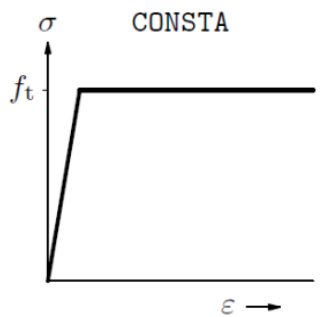

(b) ideal

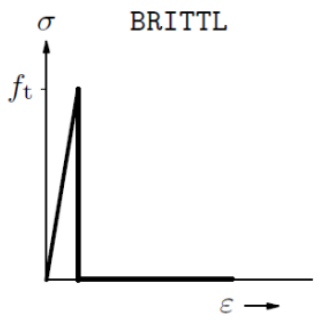

(c) brittle

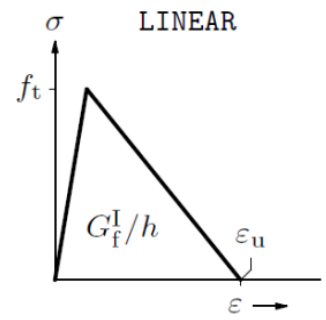

(d) linear

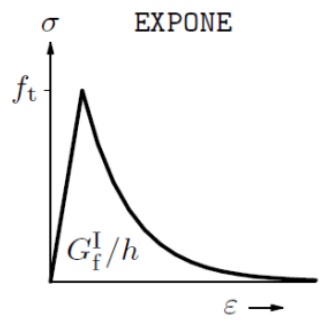

(e) exponential

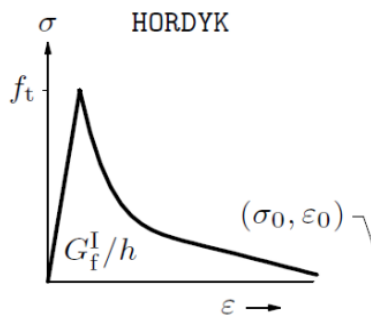

(f) Hordijk

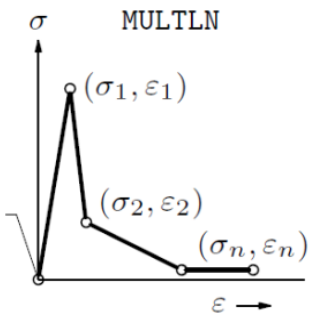

(g) multi-linear

Figura 6.33 - Modelos predefinidos para representação do comportamento do concreto submetido à tração.

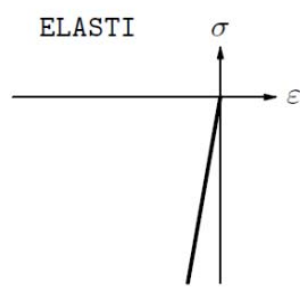

(a) elastic

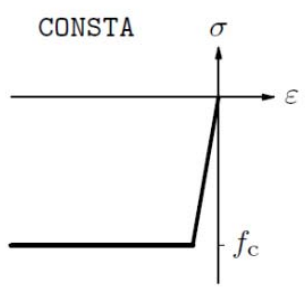

(b) ideal

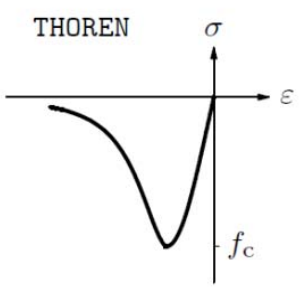

(c) Thorenfeldt

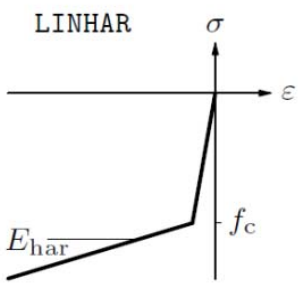

(d) linear

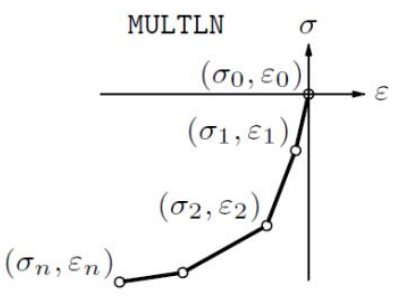

(e) multi-linear

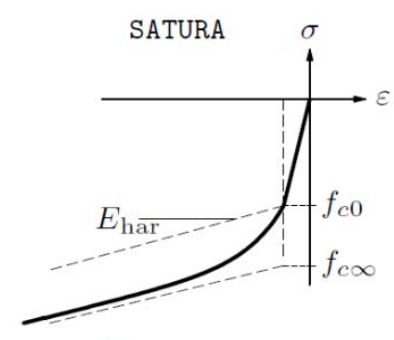

(f) saturation type

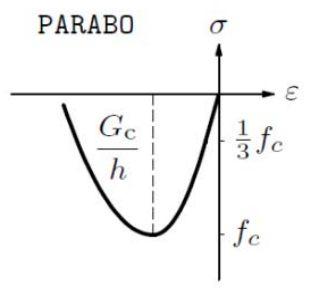

(g) parabolic

Figura 6.34 - Modelos predefinidos para representação do comportamento do concreto submetido à compressão.

Os parâmetros utilizados na primeira tentativa de simulação são apresentados no Quadro 6.1. Na Figura 6.35, apresentam-se as curvas "força x deslocamento vertical" experimental e numérica com uso do modelo constitutivo Total Strain Fixed Crack. Observase que há uma boa correlação entre as curvas na fase de carregamento, entretanto o trecho de descarregamento é representado por uma reta que parte do ponto final de carregamento até 
aproximadamente a origem. Ou seja, nessa análise é como se quase não existisse deformação plástica o que não condiz com o observado experimentalmente.

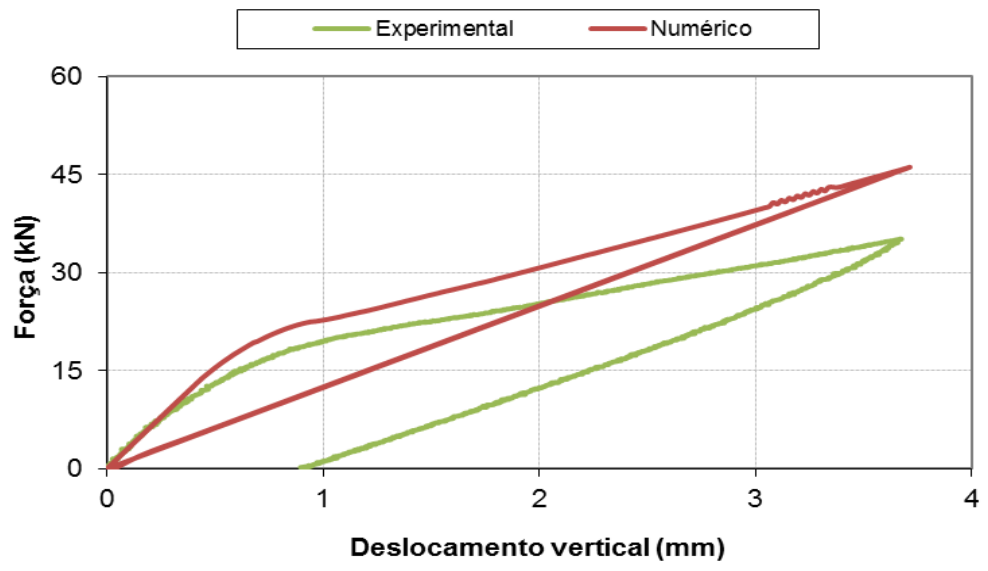

Figura 6.35 - Curvas “força $\mathrm{x}$ deslocamento vertical” experimental e numérica.

Quadro 6.1 - Parâmetros utilizados na primeira tentativa de simulação numérica com modelo Total Strain Fixed Crack.

\begin{tabular}{|c|c|c|c|}
\hline Parte estrutural & Material & Propriedade & Descrição \\
\hline \multirow{11}{*}{ Viga e pilar } & \multirow{11}{*}{ Concreto } & Modelo constitutivo & Total Strain Fixed Crack \\
\hline & & Módulo de elasticidade & $30 \mathrm{GPa}$ \\
\hline & & Coeficiente de Poison & 0,2 \\
\hline & & Curva na tração & Exponencial \\
\hline & & Curva na compressão & Parabólica \\
\hline & & Resistência à compressão & $54,5 \mathrm{MPa}$ \\
\hline & & Resistência à tração & $3,2 \mathrm{MPa}$ \\
\hline & & Energia de fratura (GF1) & 0,09831 \\
\hline & & Energia de fratura na compressão (GC) & 0,00983 \\
\hline & & Influência lateral & REDCRV VC1993 \\
\hline & & Fator de retenção ao cisalhamento $(\beta)$ & 0,999999 \\
\hline \multirow{4}{*}{ Armadura } & \multirow{4}{*}{ Aço } & Módulo de elasticidade & $200 \mathrm{GPa}$ \\
\hline & & Coeficiente de Poison & 0,3 \\
\hline & & Critério de resistência & Von Mises \\
\hline & & fy & $500 \mathrm{MPa}$ \\
\hline \multirow{2}{*}{$\begin{array}{l}\text { Interface vertical } \\
\text { superior }\end{array}$} & \multirow{2}{*}{-} & Rigidez normal & $1.10^{-11} \mathrm{~N} / \mathrm{mm}^{3}$ \\
\hline & & Rigidez tangencial & $1.10^{-11} \mathrm{~N} / \mathrm{mm}^{3}$ \\
\hline \multirow{2}{*}{$\begin{array}{l}\text { Interface vertical } \\
\text { inferior (fase } 2 \text { ) }\end{array}$} & \multirow[b]{2}{*}{ - } & Rigidez normal & $2,7.10^{3} \mathrm{~N} / \mathrm{mm}^{3}$ \\
\hline & & Rigidez tangencial & $10 \mathrm{~N} / \mathrm{mm}^{3}$ \\
\hline \multirow{2}{*}{ Interface horizontal } & \multirow{2}{*}{ - } & Rigidez normal & $0,7 \mathrm{~N} / \mathrm{mm}^{3}$ \\
\hline & & Rigidez tangencial & $0,4 \mathrm{~N} / \mathrm{mm}^{3}$ \\
\hline \multirow{4}{*}{$\begin{array}{l}\text { Armadura } \\
\text { (fase2) }\end{array}$} & \multirow{4}{*}{ Laminado } & Módulo de elasticidade & $131 \mathrm{GPa}$ \\
\hline & & Coeficiente de Poison & 0,3 \\
\hline & & Critério de resistência & Von Mises \\
\hline & & fy & $2000 \mathrm{MPa}$ \\
\hline
\end{tabular}


Em virtude da inadequação do modelo Total Strain Fixed Crack na representação do comportamento da estrutura, optou-se pela utilização do modelo Modified Maekawa Concrete, ou Modelo Maekawa Modificado que combina um modelo plástico multi-axial de dano para representar o efeito de ruptura do concreto sob compressão e um modelo de fissuração baseado nos modelos Total Strain para representar o concreto sob tração. Para a simulação em questão, esse modelo é particularmente interessante por sua capacidade de simular o efeito de histerese em ciclos de carregamento e descarregamento. Existem três modelos disponíveis para tratar a fissuração no "Maekawa": fissuras fixas, fissuras rotacionais e fissuras não ortogonais. Neste trabalho, se optou pelo modelo de fissuras fixas, como especificado no Quadro 6.2 em que constam os demais parâmetros utilizados nas simulações. O comportamento do concreto submetido à tração pode ser definido por meio da escolha de funções predefinidas apresentadas na Figura 6.36.

Quadro 6.2 - Resumo dos parâmetros utilizados na simulação numérica com modelo Maekawa.

\begin{tabular}{|c|c|c|c|}
\hline Parte estrutural & Material & Propriedade & Descrição \\
\hline \multirow{9}{*}{ Viga e pilar } & \multirow{9}{*}{ Concreto } & Modelo constitutivo & Maekawa fixed \\
\hline & & Módulo de elasticidade & $30 \mathrm{GPa}$ \\
\hline & & Coeficiente de Poison & 0,2 \\
\hline & & Fator de correção da plastificação (bfac) & 1 \\
\hline & & Resistência à compressão & $54,5 \mathrm{MPa}$ \\
\hline & & Resistência à tração & $3,2 \mathrm{MPa}$ \\
\hline & & Curva na tração & Exponencial \\
\hline & & Energia de fratura (GF1) & 0,09831 \\
\hline & & Fator de retenção ao cisalhamento $(\beta)$ & 0,999999 \\
\hline \multirow{4}{*}{ Armadura } & \multirow{4}{*}{ Aço } & Módulo de elasticidade & $200 \mathrm{GPa}$ \\
\hline & & Coeficiente de Poison & 0,3 \\
\hline & & Critério de resistência & Von Mises \\
\hline & & fy & $500 \mathrm{MPa}$ \\
\hline \multirow{2}{*}{$\begin{array}{l}\text { Interface vertical superior } \\
\text { (fase } 2)\end{array}$} & \multirow{2}{*}{-} & Rigidez normal & $1.10^{-11} \mathrm{~N} / \mathrm{mm}^{3}$ \\
\hline & & Rigidez tangencial & $1.10^{-11} \mathrm{~N} / \mathrm{mm}^{3}$ \\
\hline \multirow{2}{*}{$\begin{array}{l}\text { Interface vertical inferior } \\
\text { (fase } 2)\end{array}$} & \multirow{2}{*}{-} & Rigidez normal & $2,7.10^{3} \mathrm{~N} / \mathrm{mm}^{3}$ \\
\hline & & Rigidez tangencial & $10 \mathrm{~N} / \mathrm{mm}^{3}$ \\
\hline \multirow{2}{*}{ Interface horizontal } & \multirow{2}{*}{-} & Rigidez normal & $0,7 \mathrm{~N} / \mathrm{mm}^{3}$ \\
\hline & & Rigidez tangencial & $0,4 \mathrm{~N} / \mathrm{mm}^{3}$ \\
\hline \multirow{4}{*}{$\begin{array}{l}\text { Armadura } \\
\text { (fase2) }\end{array}$} & \multirow{4}{*}{ Laminado } & Módulo de elasticidade & $131 \mathrm{GPa}$ \\
\hline & & Coeficiente de Poison & 0,3 \\
\hline & & Critério de resistência & Von Mises \\
\hline & & fy & $2000 \mathrm{MPa}$ \\
\hline
\end{tabular}




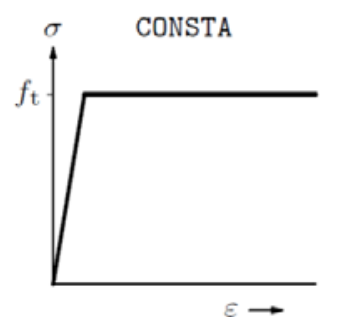

(a) ideal

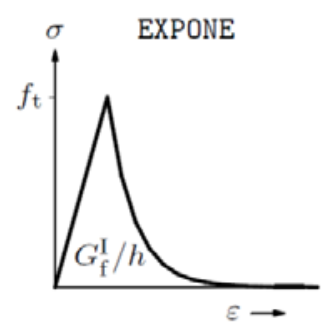

(d) exponential

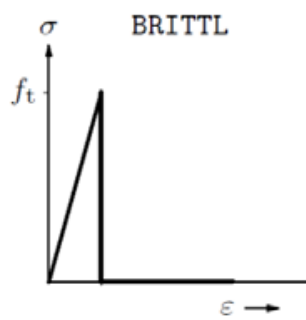

(b) brittle

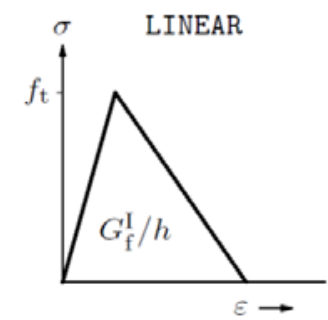

(c) linear

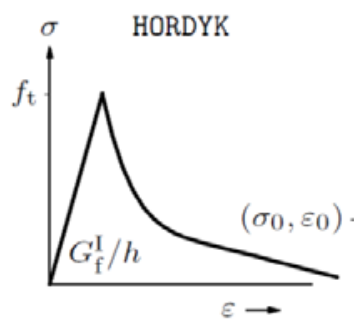

(e) Hordijk

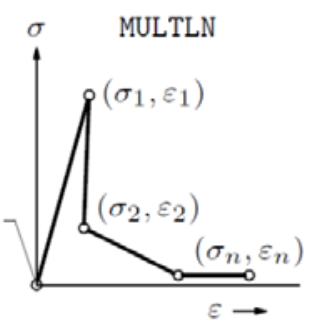

(f) multi-linear

Figura 6.36- Modelos predefinidos para representação do comportamento do concreto submetido à tração.

O comportamento das interfaces foi descrito por valores de rigidez axial $\left(D_{n}\right)$ e tangencial $\left(D_{t}\right)$. Para a junta vertical superior, adotaram-se valores desprezíveis de rigidez já que ela foi tracionada ao longo do ensaio em virtude do modo de solicitação da estrutura.

Para a almofada de apoio, calculou-se a rigidez axial em função do seu módulo de elasticidade (9,5 MPa) determinado experimentalmente em Rodrigues (2008). A rigidez transversal foi determinada por meio do módulo de elasticidade transversal (1,2 Mpa) que é função da Dureza Shore.

Como a energia de fratura não foi determinada experimentalmente estimou-se seu valor com base no CEB-FIP Model Code (1990) que indica a Equação 19.

$$
G_{f}=G_{F O}\left(\frac{f_{c m}}{f_{c m o}}\right)^{0,7}
$$

Sendo $f_{\text {cmo }}=10 \mathrm{MPa}$.

A resistência à compressão média $\left(f_{c m}\right)$ é determinada pela Equação 20 .

$$
f_{c m}=f_{c k}+8
$$


$G_{F O}$ é função do diâmetro máximo do agregado, conforme Tabela 6.9.

Tabela 6.9 - Valores de em função do diâmetro do agregado.

\begin{tabular}{cc}
\hline $\boldsymbol{D}_{\boldsymbol{m a x}}(\boldsymbol{m m})$ & $\boldsymbol{G}_{\boldsymbol{F O}}\left(\mathbf{N} . \mathbf{m m} / \mathbf{m m}^{\mathbf{2}}\right)$ \\
\hline 8 & 0,025 \\
16 & 0,030 \\
32 & 0,058 \\
\hline
\end{tabular}

O valor da rigidez axial da junta vertical inferior foi calculado por meio do módulo de elasticidade do graute e o valor da rigidez tangencial foi arbitrado. Para o caso desta junta, não se considerou adequado o cálculo da rigidez transversal por meio do módulo de elasticidade transversal do graute, pois certamente o comportamento da junta é governado principalmente pelo atrito entre o graute e o concreto.

Utilizaram-se valores nominais para as propriedades do aço e valores informados pelos fabricantes para as propriedades do laminado. Para ambos, adotou-se o critério de resistência de Von Mises. Para o aço, esse critério é perfeitamente adequado. O laminado tem, na realidade, comportamento perfeitamente elástico e ruptura frágil, contudo, esta foi uma aproximação aceitável já que ao longo do ensaio não foi atingida a deformação última.

O carregamento foi aplicado em uma linha na superfície superior da viga. Inicialmente se tentou aplicar força o que facilitava a limitação dos ciclos, contudo esta opção levou a problemas de convergência. A aplicação de deslocamento conduziu aos mesmos resultados e não apresentou problemas de convergência, embora tenha sido mais trabalhosa por se ter que fazer mais de um processamento para ajuste dos passos de carga que conduzissem a representação dos ciclos de carregamento aplicado.

Análises lineares foram realizadas apenas para os ajustes iniciais do modelo. Todos os resultados apresentados são referentes a análises não-lineares. A análise teve que ser realizadas em duas fases, pois no ensaio alterou-se a geometria da estrutura pela adição do graute na junta inferior e dos laminados. Para isso, utilizou-se o recurso Phased Analysis. 


\subsubsection{Resultados}

$\mathrm{Na}$ Figura 6.37, apresentam-se as curvas "força $\mathrm{x}$ deslocamento", numéricas e experimentais, para o primeiro ciclo de carregamento. No gráfico à esquerda, limitou-se o carregamento numérico pelo deslocamento máximo do ciclo experimental. Neste caso, a força alcançada na simulação foi aproximadamente $28 \%$ maior que a experimental e os deslocamentos residuais foram praticamente coincidentes. No gráfico à direita, limitou-se o carregamento numérico pela força máxima do ensaio experimental. Neste caso, o deslocamento alcançado na simulação foi de aproximadamente $67 \%$ do experimental e o deslocamento residual numérico foi aproximadamente 56\% do experimental. Pretendia-se continuar com as duas propostas de análise, entretanto no segundo ciclo de carregamento o modelo experimental atingiu o deslocamento de 7,5 $\mathrm{mm}$ e no modelo numérico o escoamento da armadura longitudinal ocorreu quando o deslocamento vertical era de aproximadamente $6,5 \mathrm{~mm}$ (Figura 6.38). Isso promoveu uma grande alteração no comportamento do gráfico de modo que não seria representativo levar a estrutura até o deslocamento de $7,5 \mathrm{~mm}$, descarregá-la e seguir com a segunda fase da análise numérica. Optou-se por utilizar a coincidência da força nos ciclos de carregamento numérico e experimental para as análises.
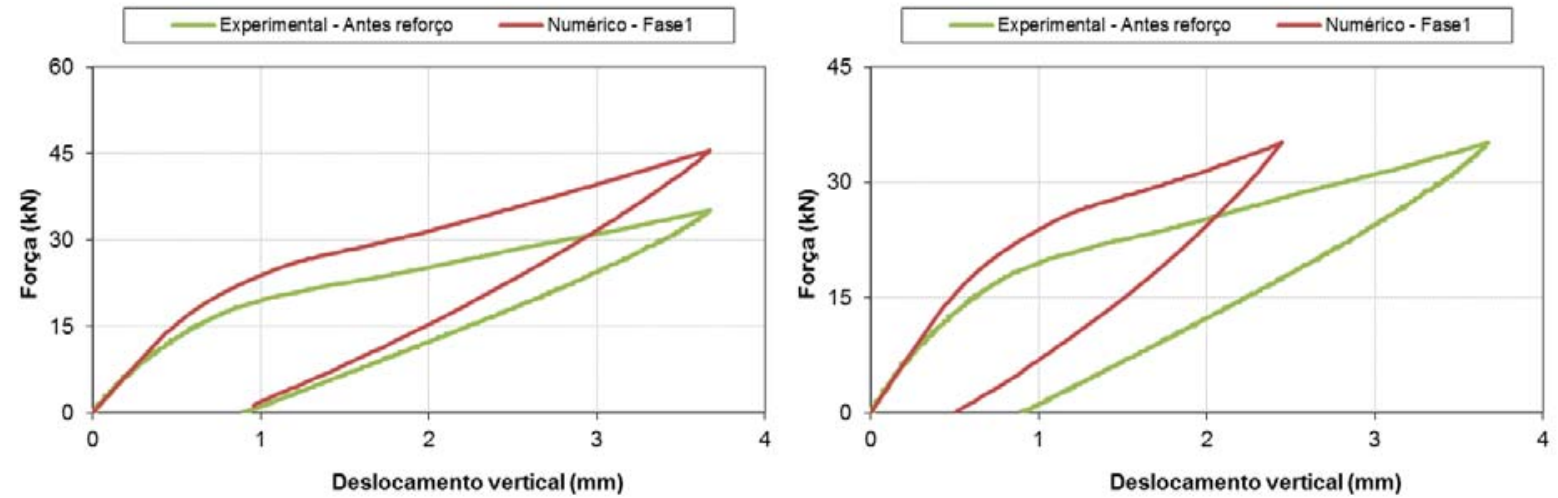

Figura 6.37 - Curvas "força x deslocamento vertical", numéricas e experimentais, para o primeiro ciclo de carregamento. 


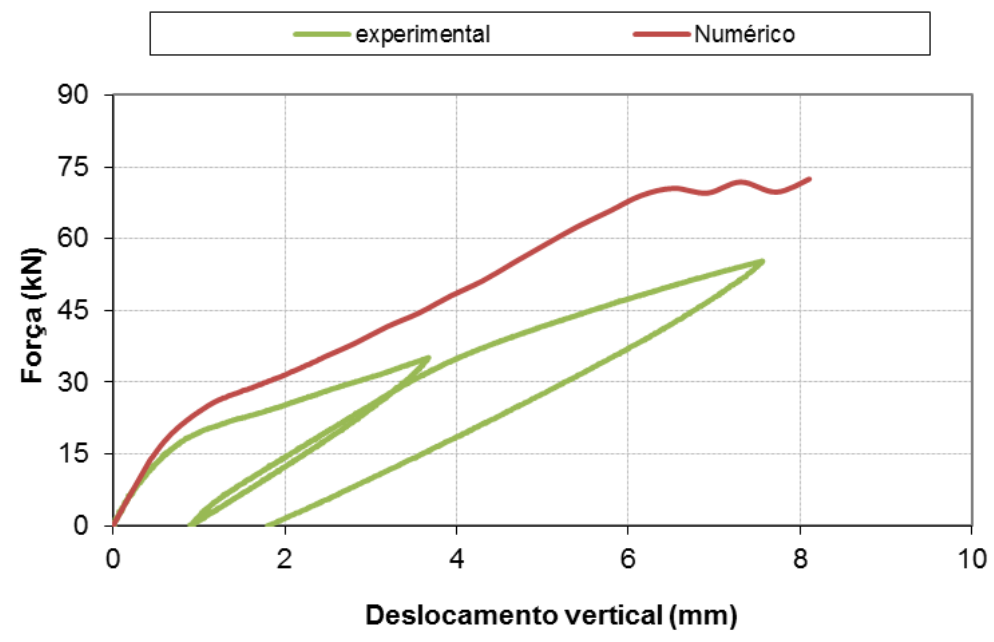

Figura 6.38 - Curvas "força x deslocamento vertical”, experimental e numérica.

Na Figura 6.38, apresentam-se as curvas "força x deslocamento vertical”, numérica e experimental para as duas etapas de carregamento e fases da análise, separadamente. Observase que as curvas são bastante semelhantes em forma. Na Figura 6.39, apresentam-se as curvas num mesmo gráfico onde fica claro que o modelo numérico é menos deformável que o experimental. Poder-se-ia ter buscado um melhor ajuste com a alteração dos dados de entrada da análise, contudo uma correspondência perfeita entre os resultados não era necessária já que não se pretendia fazer análises paramétricas com base neste modelo e sim obter informações adicionais acerca do comportamento da estrutura.
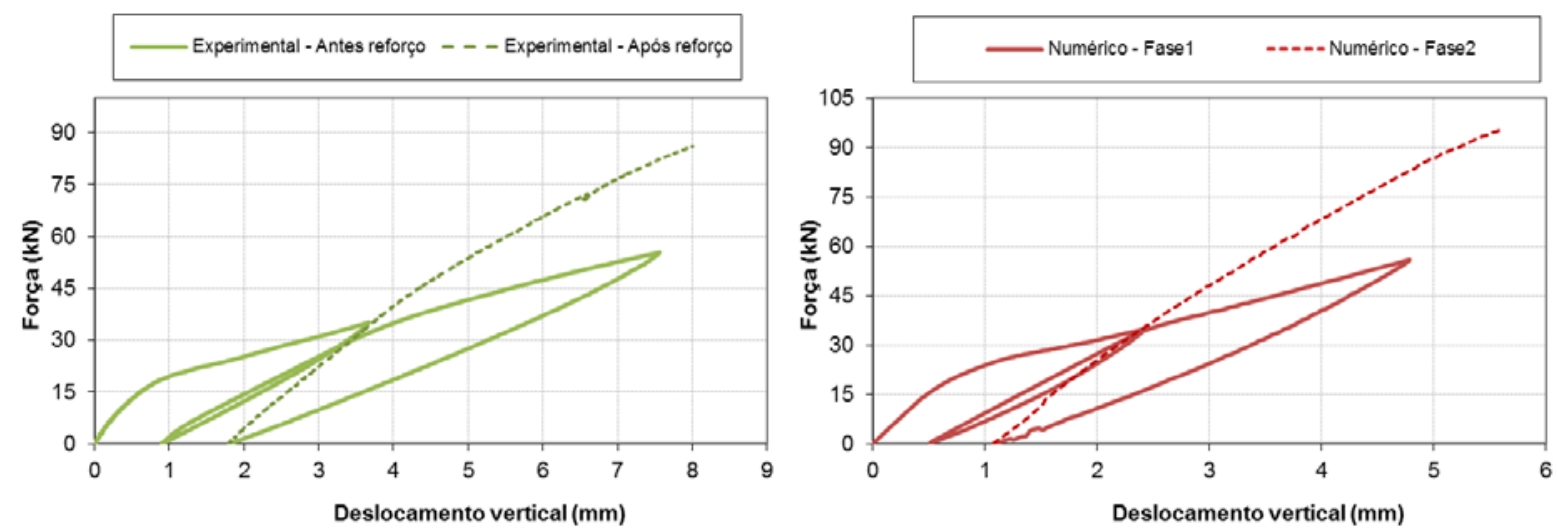

Figura 6.39 - Curvas "força x deslocamento vertical" para as duas etapas de carregamento experimental e fases da análise numérica. 


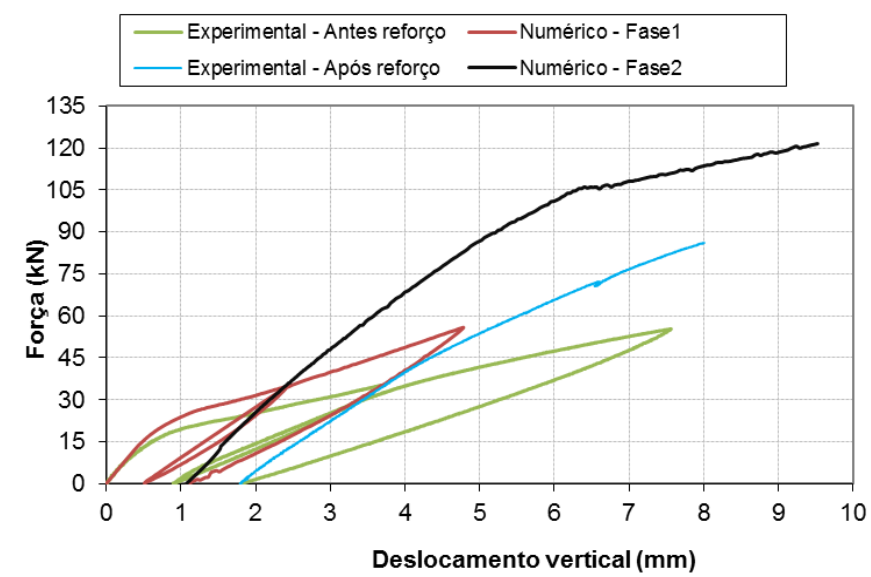

Figura 6.40 - Curvas "força x deslocamento" para as duas fases da análise.

Observa-se, na Figura 6.40, que a partir da força de $105 \mathrm{kN}$ a inclinação da curva numérica na fase 2 diminui o que está relacionado ao escoamento da armadura longitudinal como se pode confirmar na Figura 6.41. A ruptura em uma das ligações do modelo experimental ocorreu para a força de $94 \mathrm{kN}$ quando a armadura já havia escoado. Na Figura 6.40, a curva experimental é limitada a um valor inferior porque o transdutor de deslocamento foi removido antes do fim do ensaio para que não fosse danificado. Podemos considerar que se o modelo experimental continuasse a ser carregado após o desprendimento do laminado a estrutura continuaria a suportar carregamento, e a curva "força x deslocamento vertical" teria uma inclinação menor em virtude da perda de rigidez da ligação e talvez se assemelhasse ao que foi observado numericamente. Da comparação da Figura 6.38 e Figura 6.40, conclui-se que, com o reforço, o escoamento da armadura longitudinal que ocorreria para uma força de $70 \mathrm{kN}$ passa a ocorrer apenas para a força de $105 \mathrm{kN}$. Isso pode ser considerado um acréscimo na capacidade da estrutura de 50\%. Ainda em relação às curvas "força $\mathrm{x}$ deslocamento vertical” (Figura 6.39 e Figura 6.40), sua análise permite depreender o acerto em algumas definições do estudo numérico. Nota-se a eficiência do modelo constitutivo adotado (Maekawa) na representação do comportamento da estrutura submetida a carregamento cíclico. Pode-se observar a queda da inclinação do trecho inicial no segundo ciclo de 
carregamento em relação ao primeiro de cerca de $45 \%$. No ensaio experimental, essa queda é de $60 \%$. A opção pela analise phased também foi acertada já que notadamente o reforço, que na análise numérica significou a ativação do laminado e da interface vertical inferior, alterou o comportamento do modelo e promoveu um aumento da inclinação da curva na segunda fase da análise de aproximadamente $26 \%$. Experimentalmente se verificou um aumento de $48 \%$.

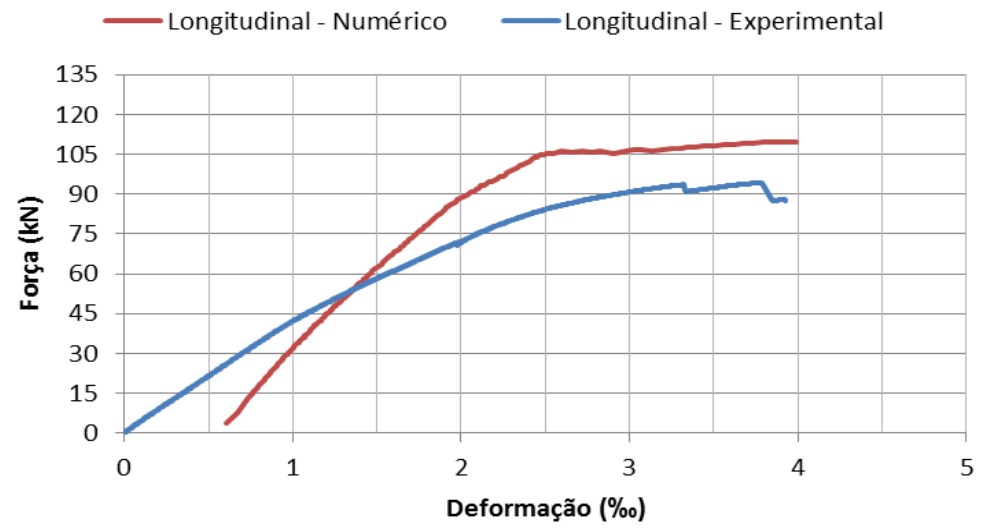

Figura 6.41 - Curvas “força x deformação na armadura longitudinal da viga", experimental e numérica.

Na Figura 6.42, apresentam-se as curvas "força x deformação no laminado", experimental e numérica e observa-se que há uma boa correlação entre elas.

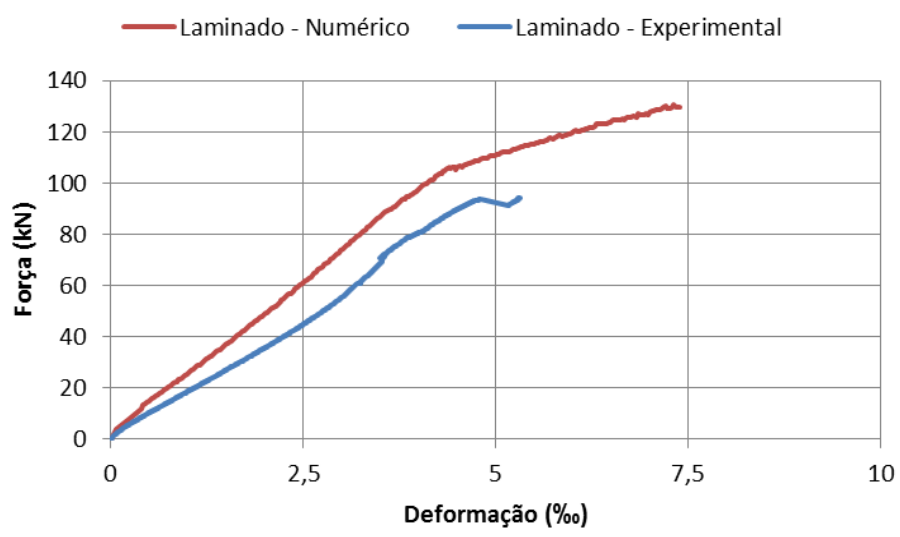

Figura 6.42 - Curvas “força x deformação no laminado”, experimental e numérica.

As deformadas verticais do modelo para os passos 280 da fase 1 de análise e 180 da fase 2 são apresentadas na Figura 6.43 e na Figura 6.44 . Eles correspondem ao pico do segundo ciclo de carregamento e à força aplicada de $105 \mathrm{kN}$, respectivamente. Da 
comparação das duas figuras percebe-se que, na fase 1, a viga e o pilar tem comportamento mais independente. Há um deslocamento diferencial entre a extremidade da viga e do pilar coerente com a inexistência de interfaces verticais. Na segunda fase, a deformada tem o comportamento visualmente próximo ao de uma estrutura monolítica, com pilar e viga se deslocando conjuntamente.

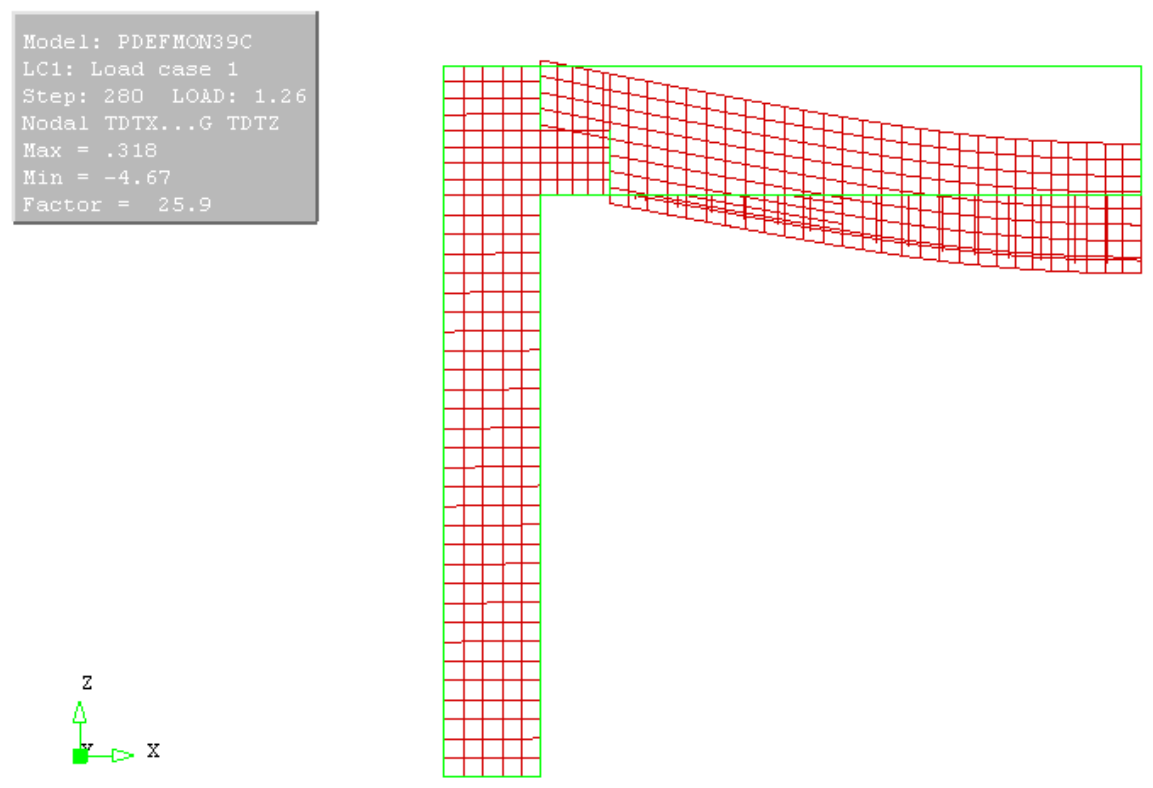

Figura 6.43 - Deformada vertical do modelo para o passo 280 da fase 1.

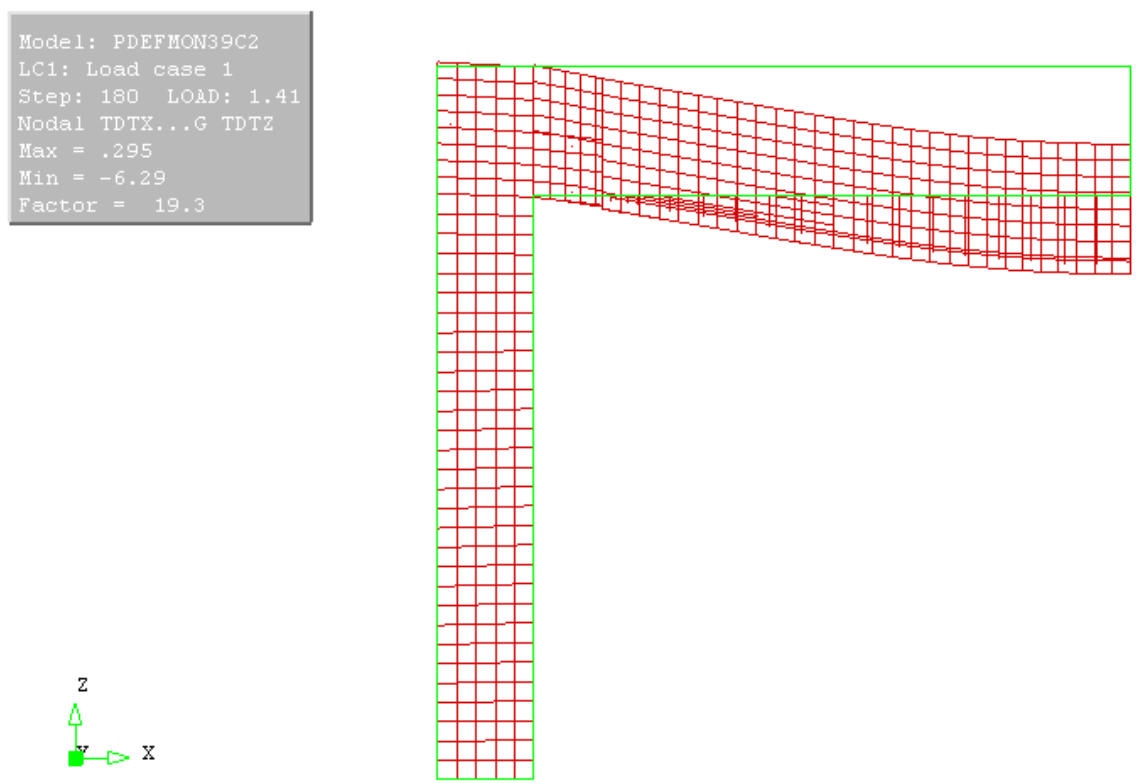

Figura 6.44 - Deformada vertical do modelo para o passo 180 da fase 2. 
Na Figura 6.45 e na Figura 6.46, estão representadas as tensões principais mínimas no modelo. Na primeira fase da análise, as tensões de compressão se dirigem da linha de aplicação da força ao consolo. A maior concentração da compressão ocorre no ponto de aplicação da força.

Na segunda fase, observa-se a mudança no caminhamento das forças em função do reforço. Nota-se que surge uma concentração de esforços na região inferior do consolo, coerente com a ativação da interface vertical inferior nesta fase e na linha do laminado tracionado.

Claramente o mecanismo principal de transferência de esforços entre a viga e o pilar, antes do reforço da ligação, pode ser descrito pelo modelo de bielas e tirantes, o que é usualmente empregado no dimensionamento de consolo e dente Geber. Após o reforço a distribuição de tensões na região da ligação se assemelha ao que ocorre em nós de pórtico de estruturas monolíticas, verificando-se tração na parte superior da ligação e compressão na inferior.
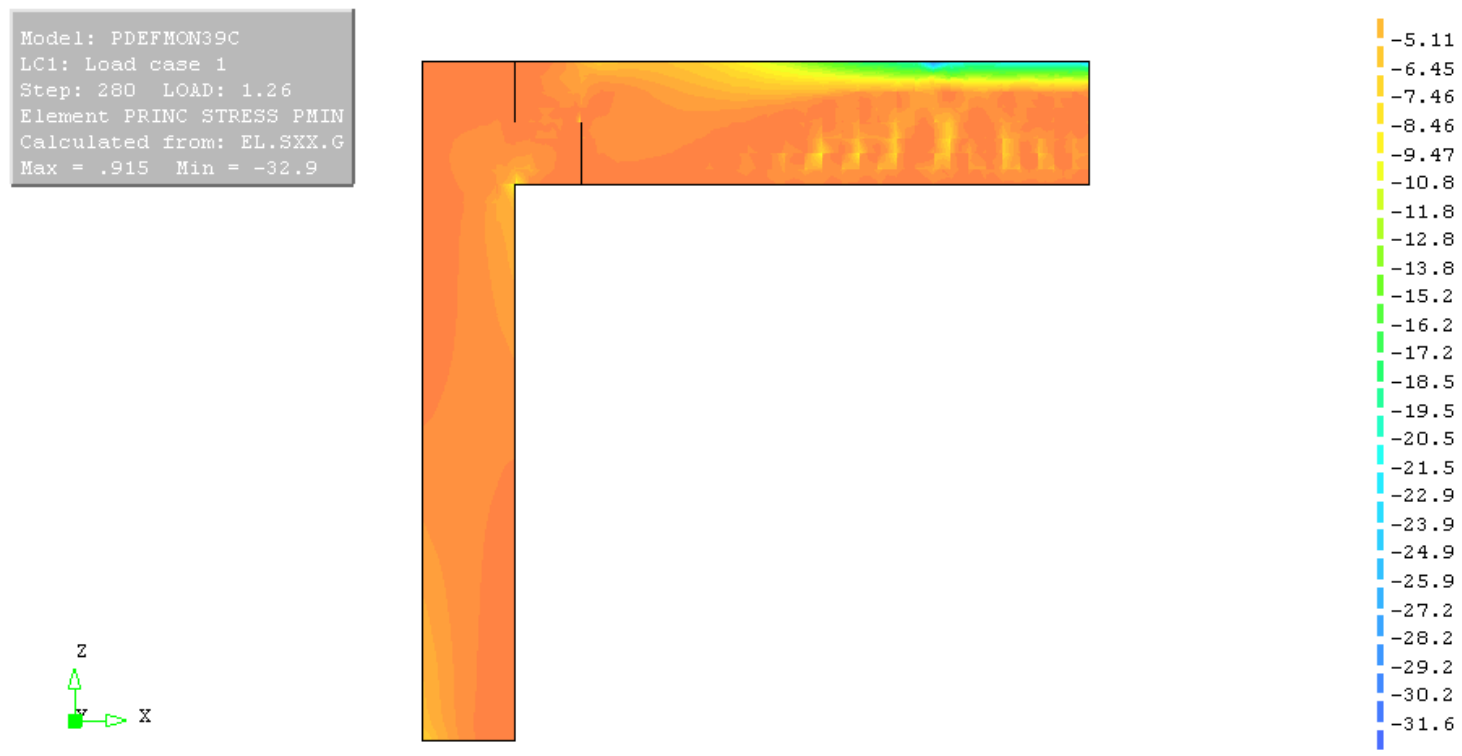

Figura 6.45 - Tensões principais no modelo para o passo 280 da fase 1. 


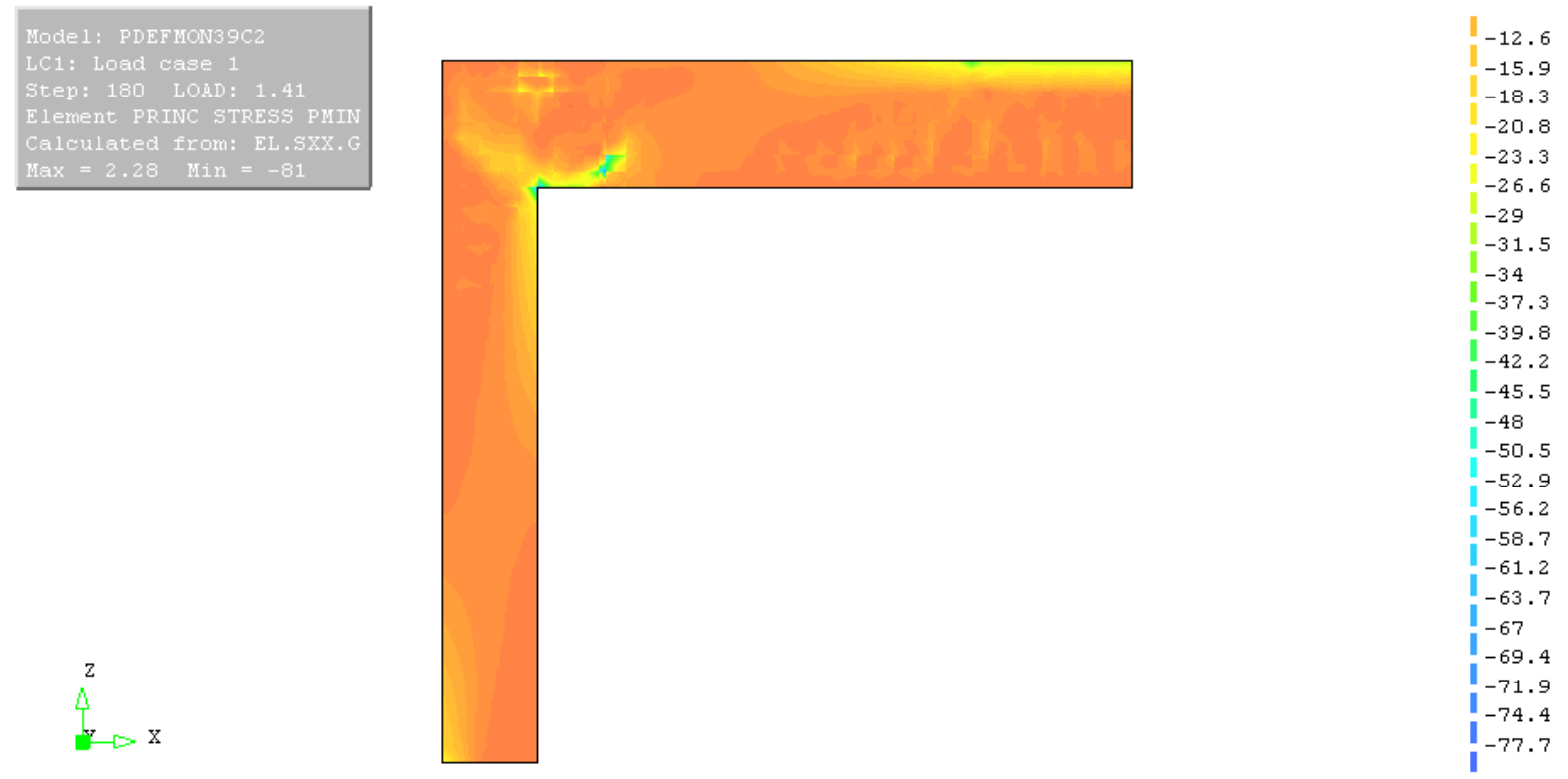

Figura 6.46 - Tensões principais no modelo para o passo 180 da fase 2.

A armadura mais solicitada na primeira fase da análise foi a longitudinal da viga

(Figura 6.47). Na fase 2, os laminados tracionados apresentam as maiores tensões (Figura $6.48)$.

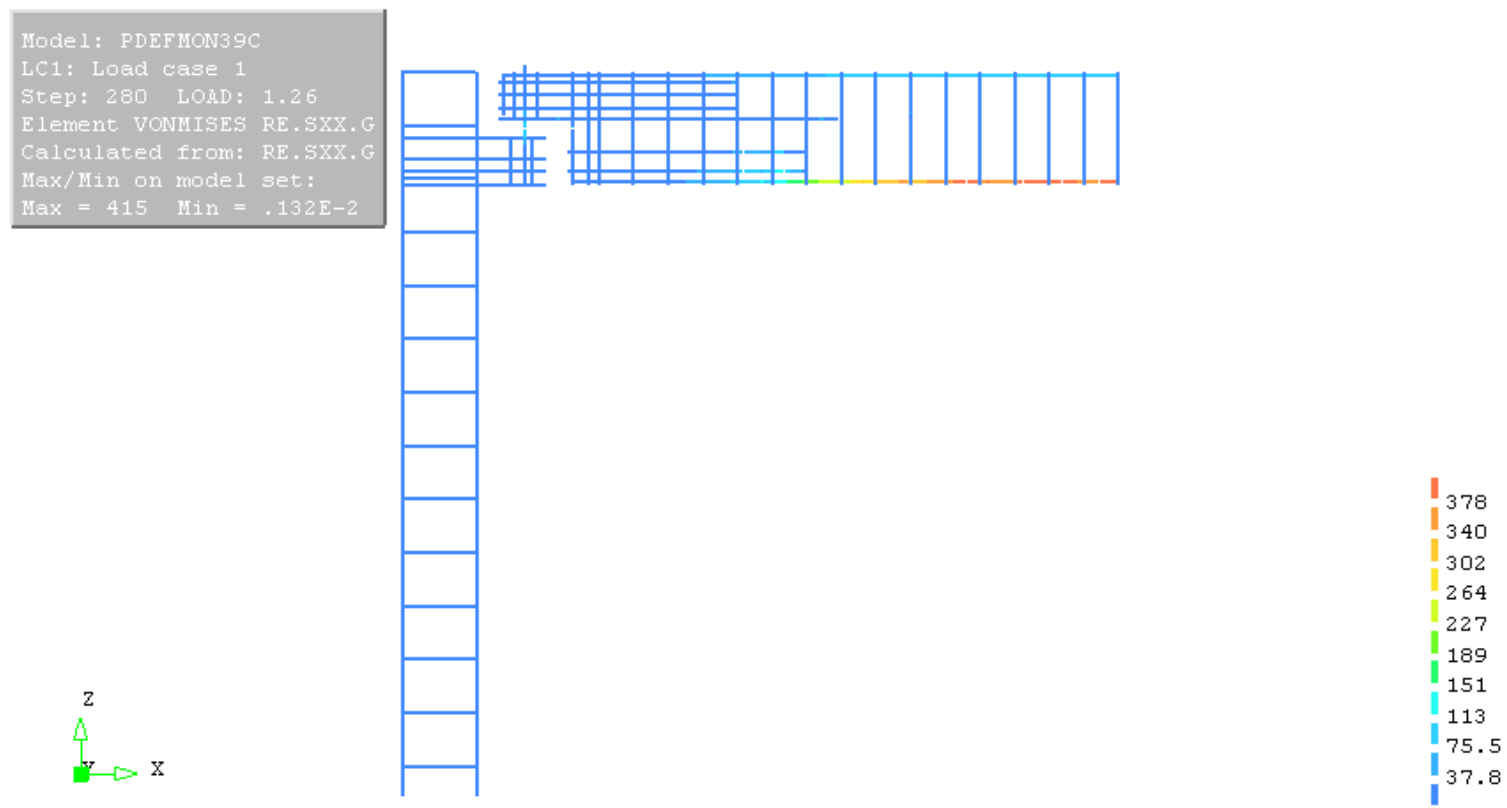

Figura 6.47 - Tensões nas armaduras para o passo 280 da fase 1. 

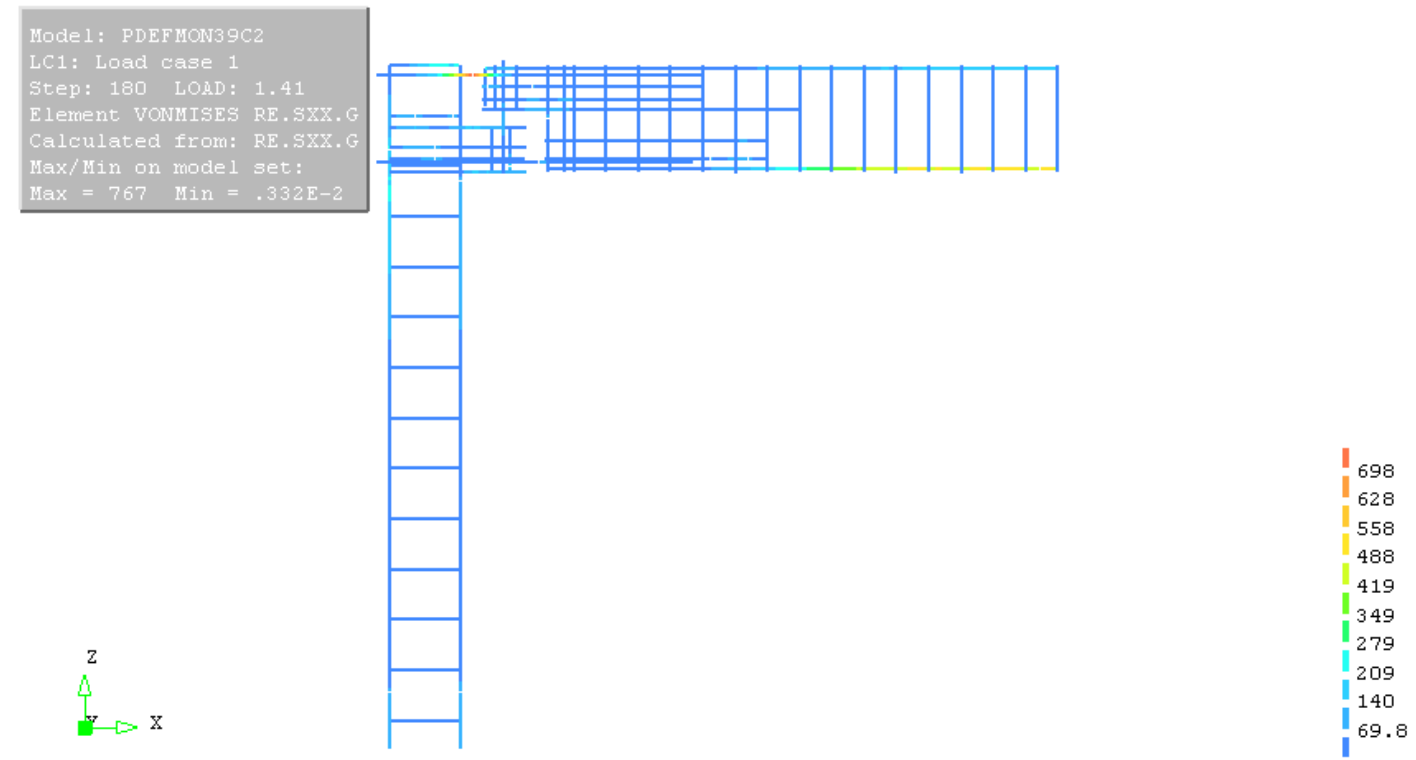

Figura 6.48 - Tensões nas armaduras para o passo 180 da fase 2.

Na Figura 6.49, apresenta-se a fissuração do modelo na fase 1, para três passos . Os passos correspondem aos seguintes trechos da curva "força x deslocamento vertical" (Figura 6.39): passo 3 - trecho linear com força aplicada de $14 \mathrm{kN}$; passo 30 - início do trecho acentuadamente não linear com força aplicada de $23 \mathrm{kN}$; passo 169 - pico de força do segundo ciclo de carregamento. Na Figura 6.50, apresenta-se a fissuração para os seguintes passos da fase 2 de análise; passo 5 - trecho aproximadamente linear com força aplicada de $14 \mathrm{kN}$; passo 24 - trecho aproximadamente linear com força aplicada de $23 \mathrm{kN}$; passo 180 corresponde aproximadamente ao escoamento da armadura longitudinal com força aplicada de $105 \mathrm{kN}$. Antes do reforço, a fissuração praticamente se restringe à viga se concentrando no banzo inferior na região central e no banzo superior e canto do dente Gerber para o carregamento máximo. Não se observam fissuras no pilar que, conforme a Figura 6.45 , está sujeito a baixas tensões. Após o reforço, a fissuração se distribui mais uniformemente na viga e ocorre também nos pilares. Surgem concentrações de tensão na região da ligação, principalmente na linha correspondente ao laminado tracionado. 

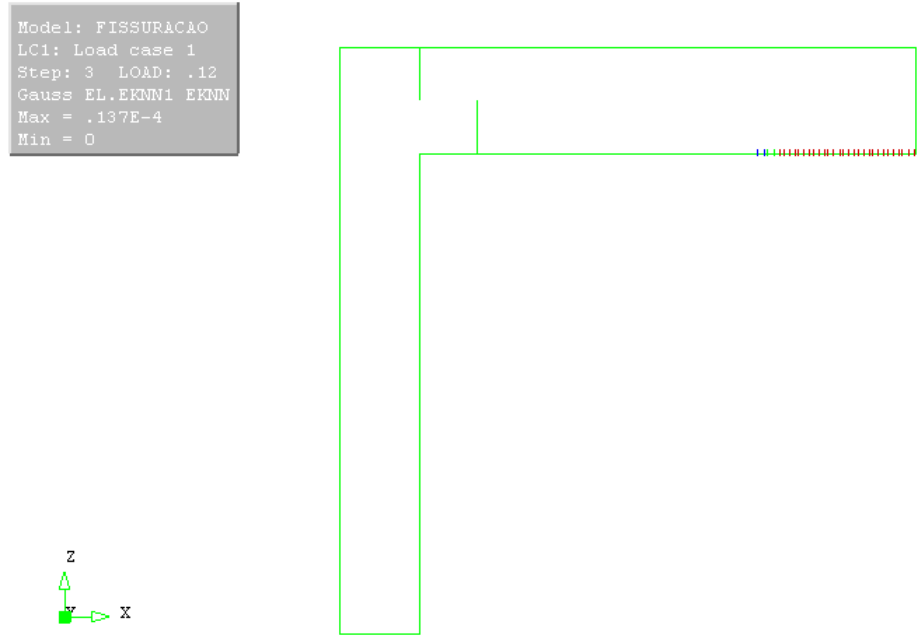

$-.91 \mathrm{E}-5$

(a)
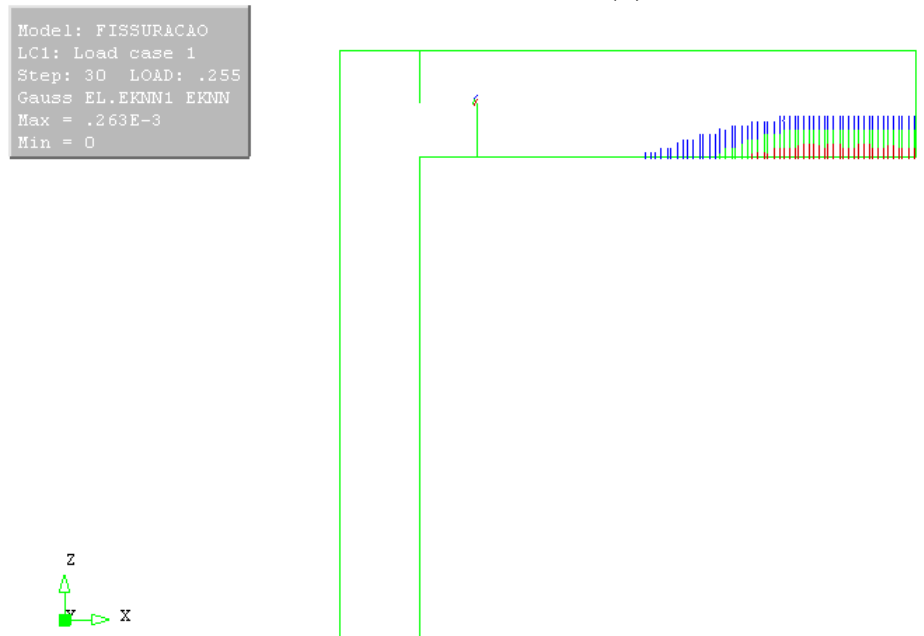

$-.175 \mathrm{E}-3$

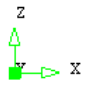

(b)
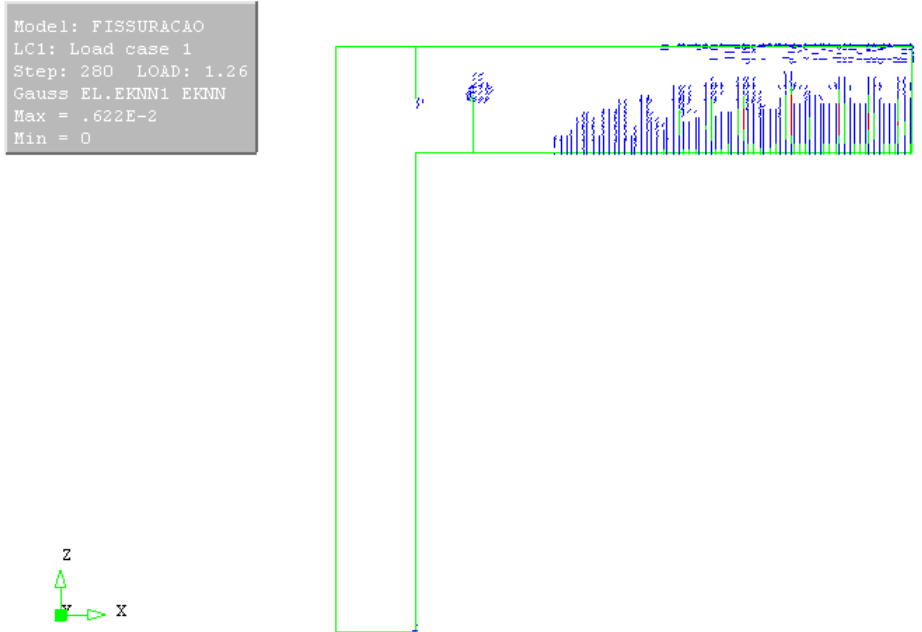

$-.415 \mathrm{E}-2$

(c)

Figura 6.49 - Configuração de fissuras: (a) passo 3 da fase 1; (b) passo 30 da fase 1; (c) passo 280 da fase 1. 

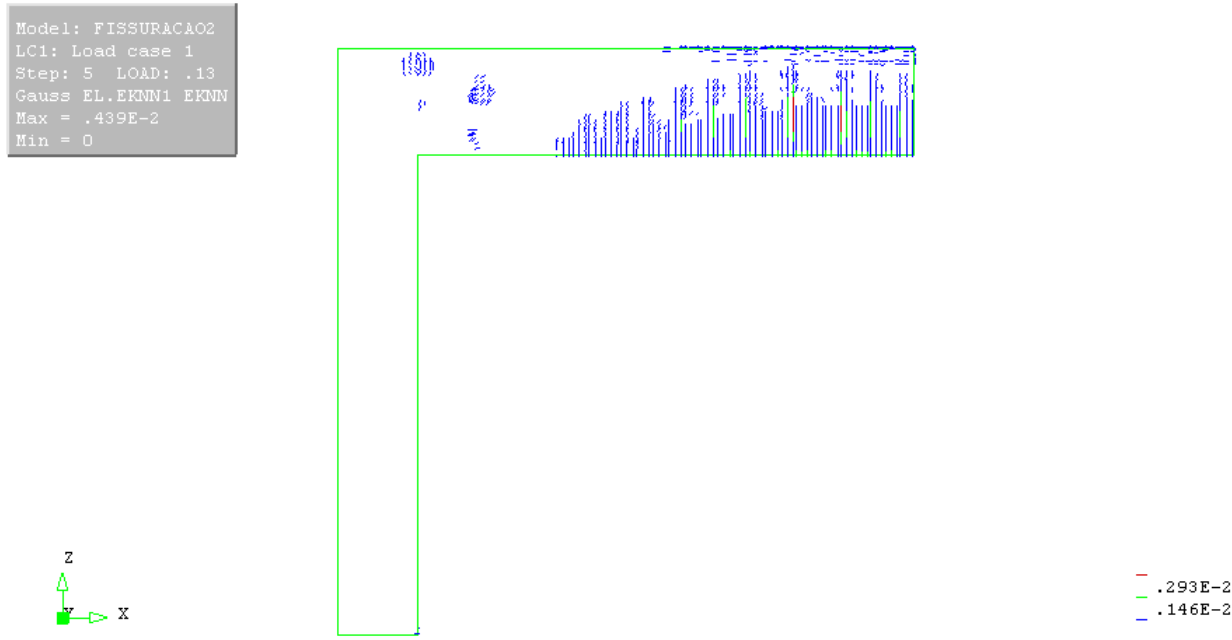

(a)
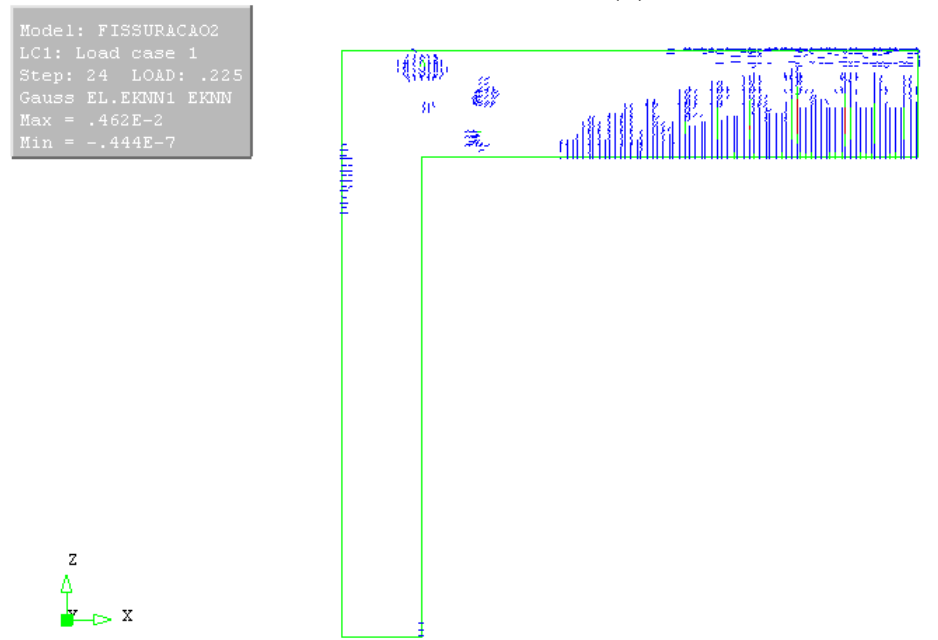

- .308E-2

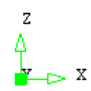

(b)
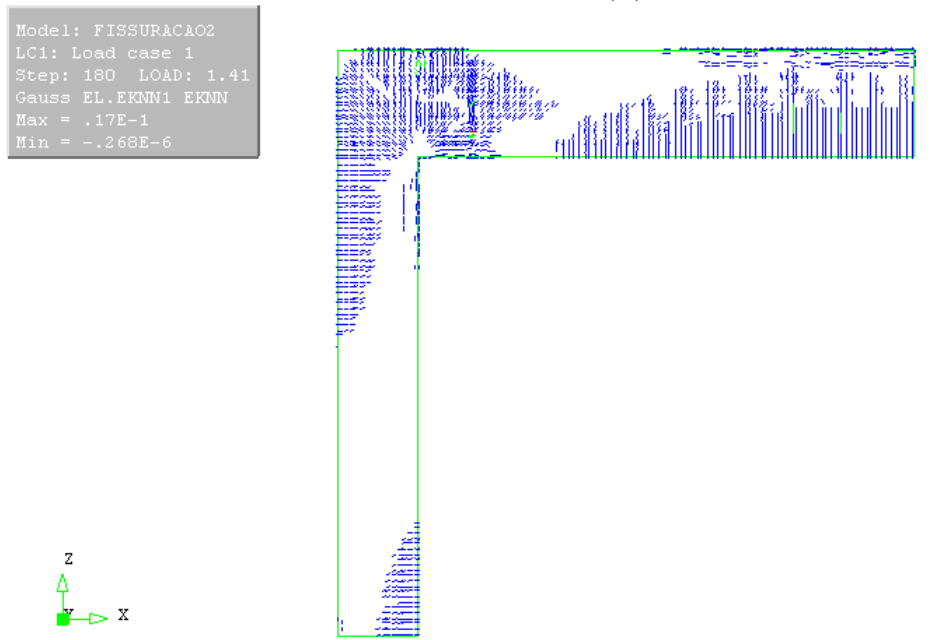

(c)

Figura 6.50 - Configuração de fissuras: (a) passo 5 da fase 2; (b) passo 24 da fase 2; (c) passo 180 da fase 2. 


\subsubsection{Conclusões}

As análises aqui apresentadas permitem algumas conclusões.

- O modelo constitutivo adotado para o concreto, Maekawa, permitiu a simulação do efeito da perda de rigidez do concreto com os ciclos de carregamento, que era fundamental para a representação do ensaio como foi realizado;

- A análise em fases proporcionou que as deformações plásticas e a rigidez reduzida fossem consideradas como condições iniciais na fase 2;

- A análise numérica confirmou a mudança na distribuição das tensões e permitiu uma visualização mais clara de como essa alteração ocorre. 


\section{CAPÍTULO 7}

\section{ENSAIOS PRINCIPAIS}

\subsection{Modelo de ensaio}

Os ensaios anteriores serviram dentre outras coisas para definição do tipo de modelo que seria adotado para os ensaios principais, se cruciforme ou em pórtico. O modelo cruciforme é mais usualmente empregado em pesquisas sobre ligação, pois o comportamento dos elementos de viga e pilar tem menos interferência no comportamento do modelo e é mais fácil alcançar a ruptura na ligação para esse tipo de configuração. Para esta pesquisa, especificamente, o modelo em pórtico, embora exija análise mais complexa, se mostra mais interessante. Como se trata do estudo do reforço de uma ligação articulada, apenas com essa configuração é possível ter um referencial antes do reforço. Cita-se também que o colapso por ruptura do laminado em um modelo com escala real seria perigoso mesmo em laboratório. Além disso, a montagem do modelo é facilitada em uma configuração de pórtico. Por essas razões, definiu-se o modelo de ensaio com características apresentadas na Figura 7.1. 


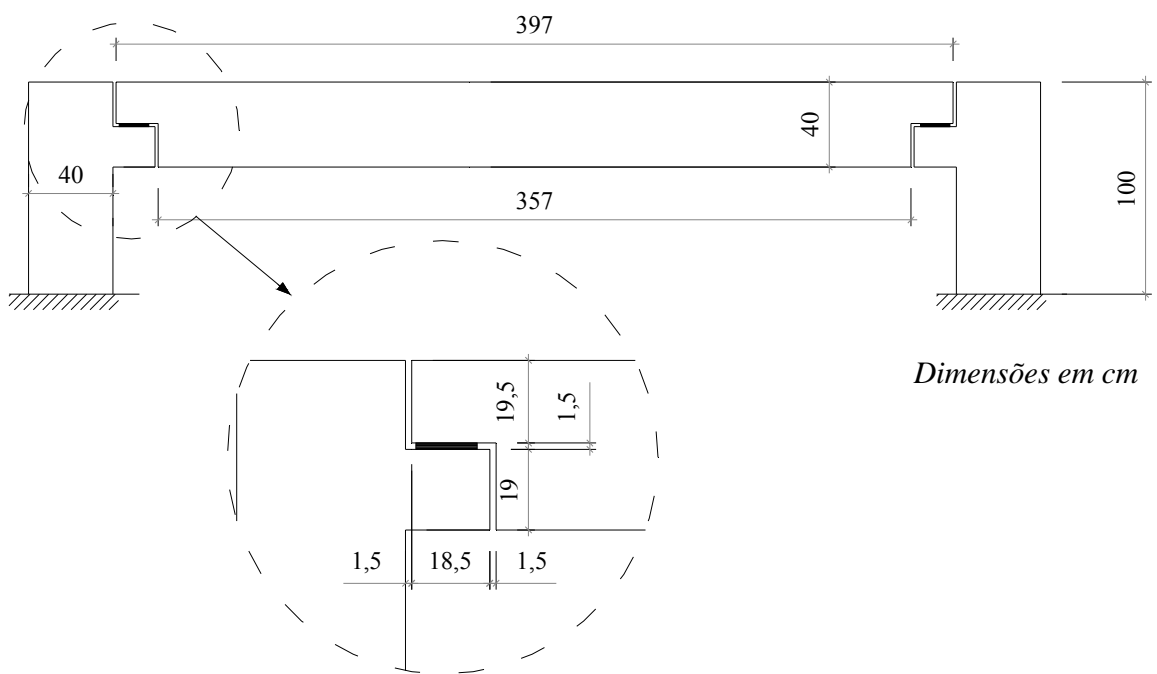

Figura 7.1 - Características geométricas do modelo de ensaio.

Trata-se de um pórtico com $20 \mathrm{~cm}$ de profundidade e ligações viga-pilar compostas por encaixe de dente Geber e consolo. Entre o dente e o consolo utilizou-se uma almofada de apoio em argamassa polimérica. Como é comum nesse tipo de ligação, foram empregados dois chumbadores (barras de $10 \mathrm{~mm}$ de diâmetro) por ligação. Utilizou-se o dispositivo metálico detalhado na Figura 7.2 para fixação do pórtico na base de reação do laboratório. Para união do pilar à base, suas barras longitudinais atravessaram uma chapa metálica de 1" de espessura e suas extremidades foram travadas por porcas. Barras de aço rosqueadas e porcas fixaram o dispositivo à base de reação.

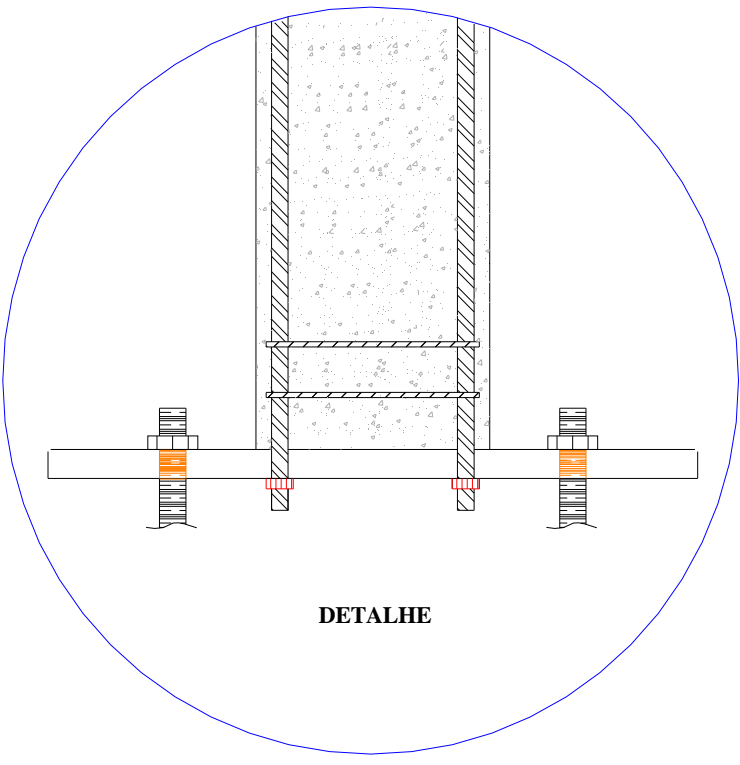

PLANTA
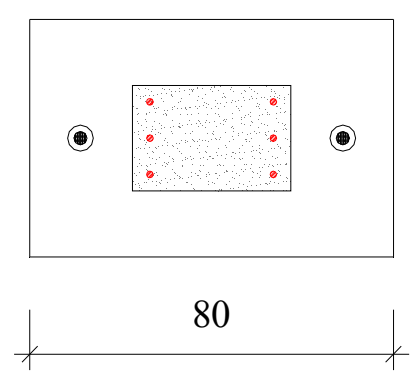

Figura 7.2 - Detalhes da estrutura de fixação do pórtico a base de reação. 
Três modelos de pórtico foram ensaiados: Portico1, Portico2 e Portico3. Também se realizou ensaio em uma viga bi-apoiada, com características apresentadas na Figura 7.1, cujos resultados foram utilizados como referência para a análise dos ensaios dos pórticos.

A seguir, apresenta-se o modo como serão referenciados os ensaios realizados nos modelos de pórticos e suas características, de forma resumida:

- Pórtico1_a - Primeira fase do ensaio do Pórtico1 (ensaio dinâmico e estático) em que as ligações apresentam a configuração usual e comportamento próximo ao de uma articulação;

- Pórtico1_b - Segunda fase do ensaio do Pórtico1 (ensaio dinâmico e estático) em que o modelo apresenta fissuras e as ligações já estão reforçadas pelo grauteamento dos espaços verticais e colagem de 3 laminados em cada face da ligação;

- Pórtico2_a - Ensaio dinâmico do Pórtico2 antes do reforço em que as ligações apresentam a configuração usual e comportamento próximo ao de uma articulação;

- Pórtico2_b - Ensaio dinâmico e estático do Pórtico2 íntegro com ligações reforçadas pelo grauteamento dos espaços verticais e pela colagem de 3 laminados em cada face da ligação;

- Pórtico3 - Ensaio dinâmico e estático do Pórtico3 íntegro com ligações reforçadas pelo grauteamento dos espaços verticais e pela colagem de 2 laminados em cada face da ligação.

Para dimensionamento das armaduras da viga, ela foi considerada bi-apoiada submetida a duas cargas concentradas de $170 \mathrm{kN}$ (conforme ilustrado na Figura 7.3), estimando-se a resistência do concreto em $50 \mathrm{MPa}$. Os pilares foram dimensionados para os 
esforços que estas forças, aplicadas na viga que compõe o pórtico, gerariam caso as ligações viga-pilar fossem rígidas.

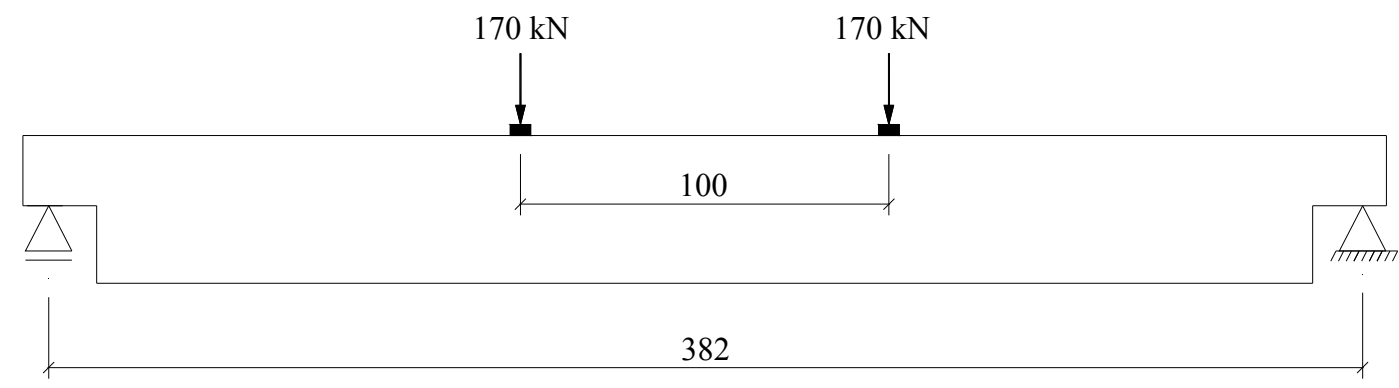

Figura 7.3 - Esquema em que se baseou o dimensionamento da viga.

Os detalhamentos das armaduras das vigas e pilares são apresentados respectivamente na Figura 7.4 e Figura 7.5.

\section{Detalhamento Viga (x4)}

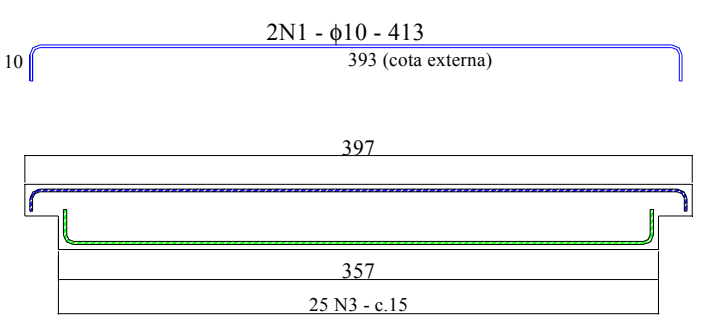

$20 \|$
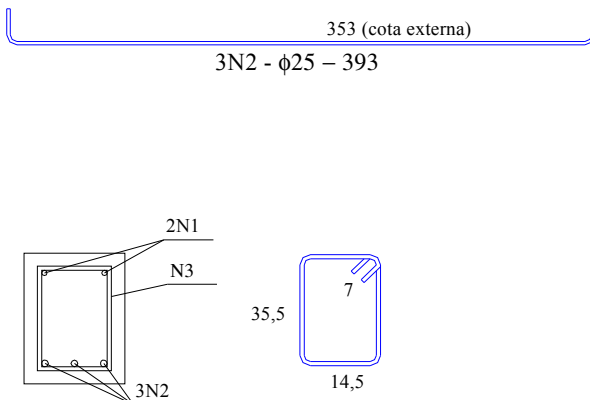

$25 \mathrm{~N} 3-\phi 6.3-114$

$$
\begin{aligned}
& 4 \mathrm{~N} 4 \phi 5.0-74 \\
& 2 \mathrm{~N} 6-\phi 12,5-12 \\
& 10 \mathrm{~N} 8-\phi 5-80 \\
& 13,5 \text { Barra soldada } \\
& \hline 55
\end{aligned}
$$

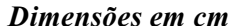
(desenho sem escala)

DETALHE DO DENTE

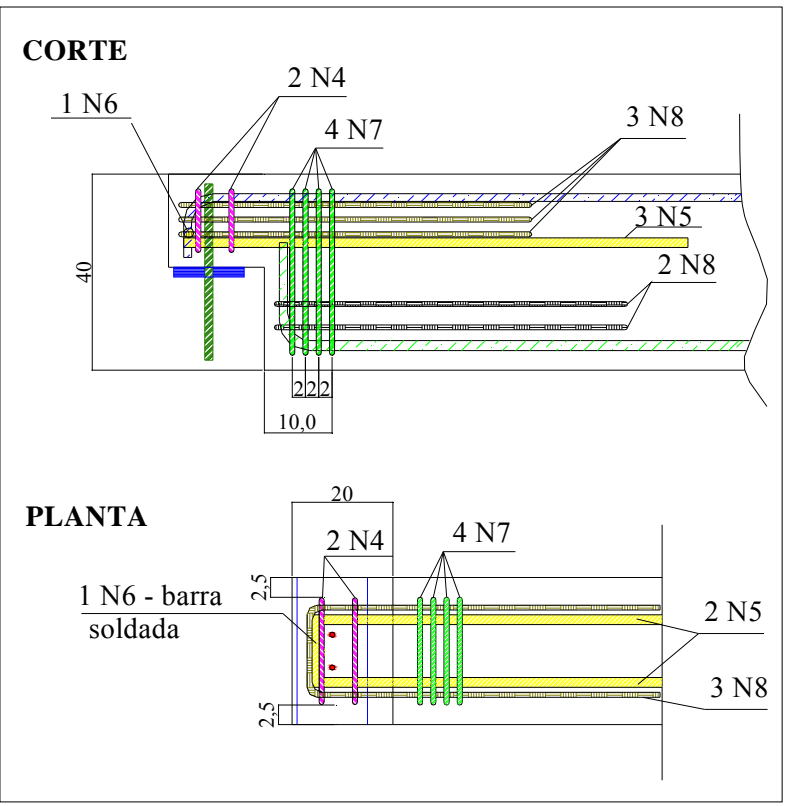

DETALHE DA ARMADURA DO TIRANTE (SOLDA)

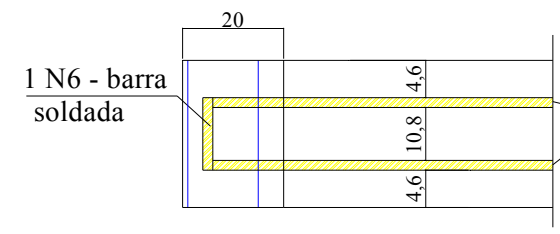

2 N5

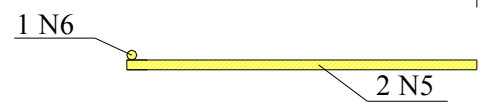

Figura 7.4 - Detalhamento da armadura da viga e dente Gerber. 
Detalhamento Pilar (x6)
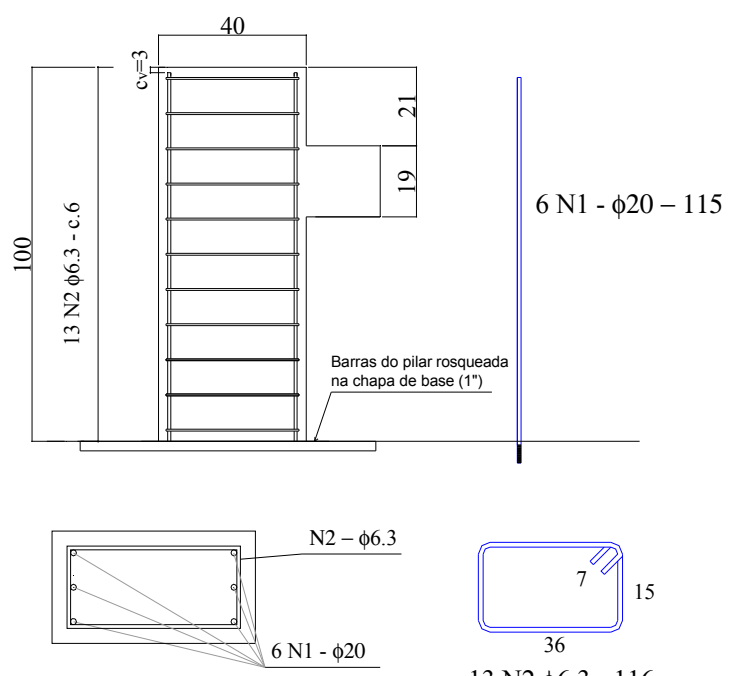

$13 \mathrm{~N} 2 \phi 6.3-116$

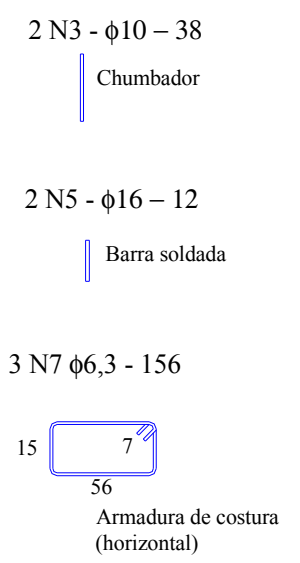

$3 \mathrm{~N} 4 \phi 5.0-73$

$1 5 \longdiv { 7 } \frac { 7 } { 1 4 , 5 }$ Estribo vertical

$2 \mathrm{~N} 6-\phi 16-76$

$2 0 \longdiv { 5 6 }$

$4 \mathrm{~N} 8-\phi 5-71$

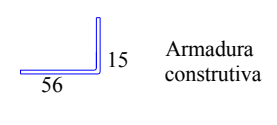

Figura 7.5 - Detalhamento do pilar e consolo.

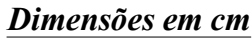
(desenho sem escala)

DETALHE DO CONSOLO

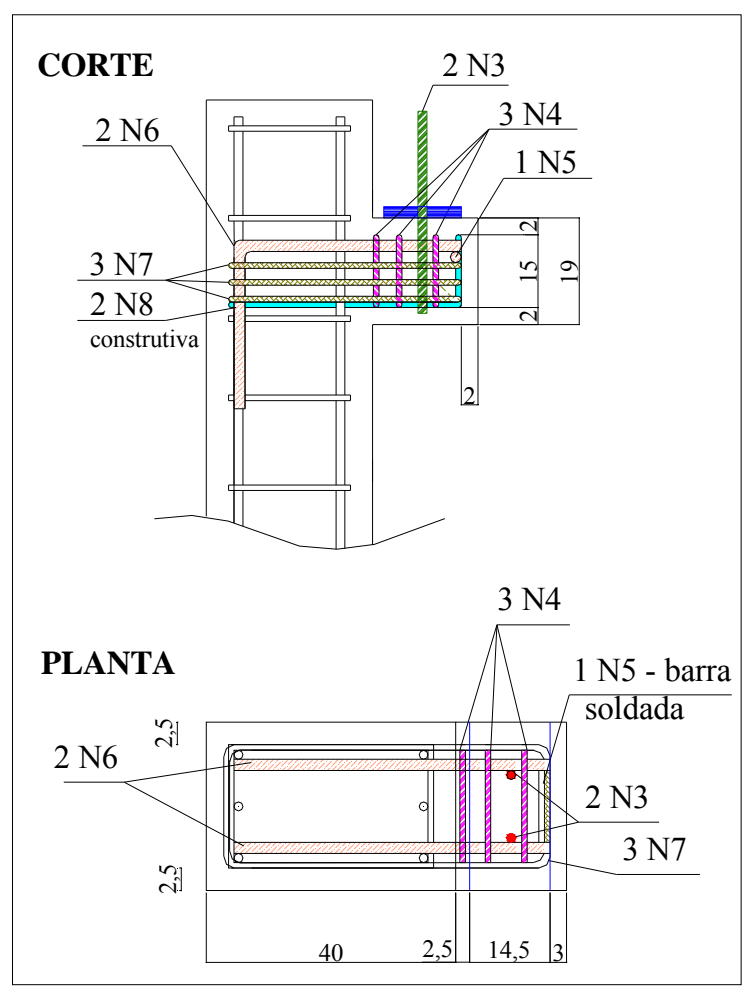

DETALHE DA ARMADURA DO TIRANTE (SOLDA)

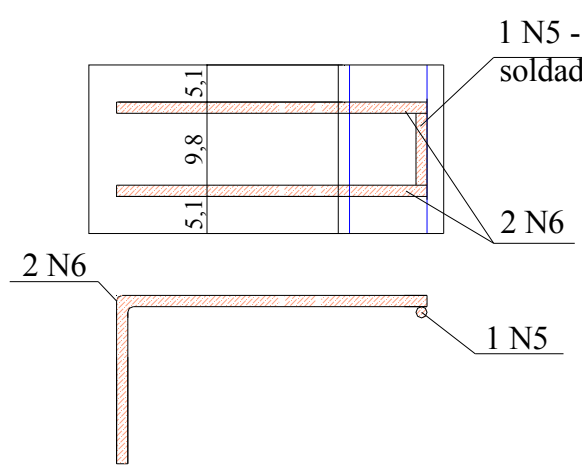

\subsection{Propriedades dos materiais}

- Aço

Utilizou-se aço CA50 para confecção das armaduras. Realizaram-se ensaios de tração para determinação do módulo de elasticidade, tensão de escoamento e resistência em três corpos de prova de 1 metro, para cada bitola utilizada. Os resultados obtidos são apresentados na Tabela 7.1. 
Tabela 7.1 - Propriedades do aço.

\begin{tabular}{cccc}
\hline $\begin{array}{c}\text { Diâmetro } \\
(\boldsymbol{m m})\end{array}$ & $\begin{array}{c}\boldsymbol{E}_{\boldsymbol{s}} \\
(\boldsymbol{G P a} \boldsymbol{a})\end{array}$ & $\begin{array}{c}\boldsymbol{f}_{\boldsymbol{y}} \\
(\boldsymbol{M P a} \boldsymbol{a})\end{array}$ & $\begin{array}{c}\boldsymbol{f}_{\boldsymbol{u}} \\
(\boldsymbol{M P a} \boldsymbol{a})\end{array}$ \\
\hline 5 & 207,7 & 770 & 866,5 \\
6,3 & 179,4 & 548 & 820,2 \\
8 & 174,2 & 498 & 740,5 \\
10 & 193,5 & 580 & 856,4 \\
12,5 & 211,3 & 660 & 721,3 \\
16 & 228,0 & 614 & 817,2 \\
20 & 237,0 & 571 & 681,6 \\
25 & 198 & 554 & 676,5 \\
\hline
\end{tabular}

\section{- Concreto}

Para confecção dos modelos de pórtico, foi utilizado concreto usinado para o qual se especificou fck de $45 \mathrm{MPa}$. Foram realizados ensaios de caracterização em corpos-de-prova cilíndricos de 10 x $20 \mathrm{~cm}$ para determinação da resistência a compressão, resistência à tração e módulo de elasticidade do concreto, em datas preferencialmente próximas as dos ensaios estáticos. Um resumo dos resultados destes ensaios é apresentado na Tabela 7.2. Ressalta-se que a resistência à compressão calculada para os CPs de $10 \times 20 \mathrm{~cm}$ foi multiplicada por um fator de redução de 0,95 para se equivaler à resistência de CPs de 15 x $30 \mathrm{~cm}$ (baseado nas especificações do Concrete Manual ${ }^{\dagger}, 1975$ apud MEHTA e MONTEIRO, 1994), que são as dimensões propostas na NBR 5739 (1994).

Também se determinou o modulo dinâmico do concreto utilizando-se 7 corpos-deprova cilíndricos com uso do equipamento Sonelastic $\AA$, como ilustrado na Figura 7.6. Os resultados obtidos são apresentados na Tabela 7.3.

\footnotetext{
$\dagger$ “Concrete Manual”, US Bureau of Reclamation, 1975, p. 574-75.
} 
Tabela 7.2 - Propriedades do concreto.

\begin{tabular}{cccccc}
\hline Corpo-de-prova & Data & Idade (dias) & $\boldsymbol{f}_{\boldsymbol{c}}(\mathbf{M P a})$ & $\boldsymbol{f}_{\boldsymbol{t}}(\mathbf{M P a})$ & $\boldsymbol{E}_{\boldsymbol{c}}(\mathbf{M P a})$ \\
\hline 1 & $16 / 02 / 2012$ & 35 & 38,7 & 3,8 & 45466 \\
2 & $16 / 02 / 2012$ & 35 & 41,8 & 3,1 & 38572 \\
3 & $16 / 02 / 2012$ & 35 & 44,4 & 3,9 & 42169 \\
Média & & & $\mathbf{4 1 , 6}$ & $\mathbf{3 , 6}$ & $\mathbf{4 2 0 6 9}$ \\
1 & $10 / 04 / 2012$ & 89 & 51,5 & - & 38509 \\
2 & $10 / 04 / 2012$ & 89 & 49,3 & - & 45860 \\
3 & $10 / 04 / 2012$ & 89 & 47,8 & - & 44246 \\
Média & & & $\mathbf{4 9 , 5}$ & - & $\mathbf{4 2 8 7 2}$ \\
1 & $02 / 05 / 2012$ & 111 & 49,8 & 4,5 & 40837 \\
2 & $02 / 05 / 2012$ & 111 & 50,1 & 3,0 & 35659 \\
3 & $02 / 05 / 2012$ & 111 & 47,9 & 2,9 & 33577 \\
Média & & & $\mathbf{4 9 , 3}$ & $\mathbf{3 , 5}$ & $\mathbf{3 6 6 9 1}$ \\
1 & $30 / 05 / 2012$ & 139 & 50,5 & 3,0 & 43652 \\
2 & $30 / 05 / 2012$ & 139 & 49,8 & 2,8 & 49459 \\
3 & $30 / 05 / 2012$ & 139 & 51,8 & - & 42872 \\
Média & & & $\mathbf{5 0 , 7}$ & $\mathbf{2 , 9}$ & $\mathbf{4 5 3 2 8}$ \\
\hline
\end{tabular}
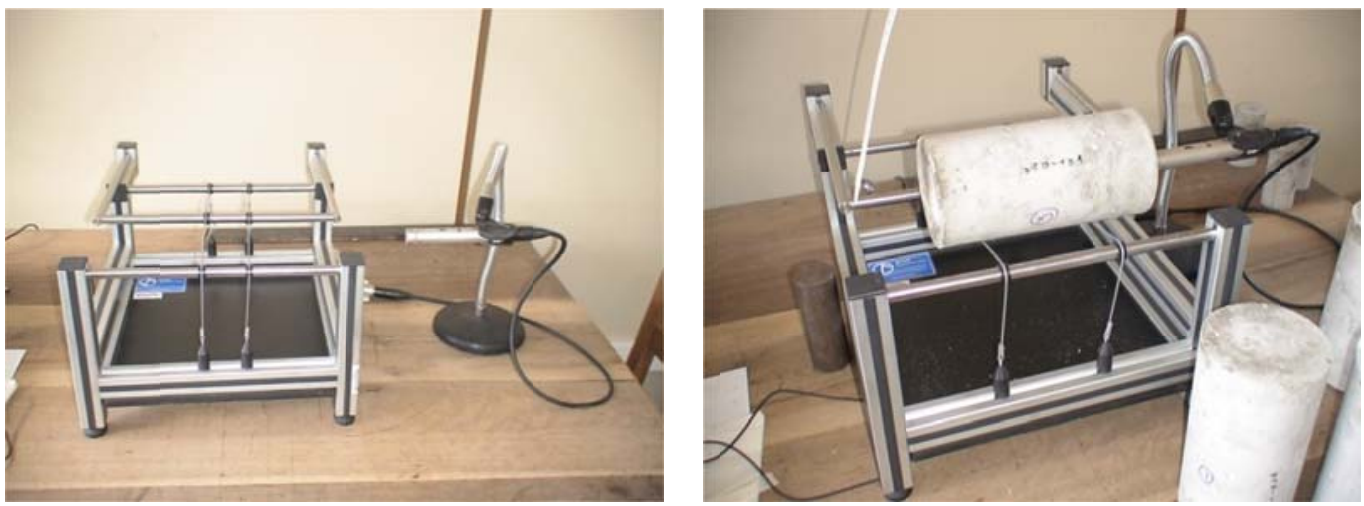

Figura 7.6 - Equipamento Sonelastic ${ }^{\circledR}$, à esquerda e ensaio para determinação do módulo de elasticidade dinâmico do concreto, à direita.

Tabela 7.3 - Módulo de elasticidade dinâmico do concreto.

\begin{tabular}{cccc}
\hline Corpo-de-prova & Data & Idade (dias) & $\boldsymbol{E}_{c, \text { din }}(\mathbf{M P a})$ \\
\hline 1 & $10 / 04 / 2012$ & 89 & 42,91 \\
2 & $10 / 04 / 2012$ & 89 & 43,16 \\
3 & $10 / 04 / 2012$ & 89 & 43,92 \\
4 & $10 / 04 / 2012$ & 89 & 44,03 \\
5 & $10 / 04 / 2012$ & 89 & 42,85 \\
6 & $10 / 04 / 2012$ & 89 & 44,15 \\
7 & $10 / 04 / 2012$ & 89 & 44,28 \\
Média & & & $\mathbf{4 3 , 6 1}$ \\
\hline
\end{tabular}




\section{- Graute}

Para o preenchimento dos espaços vazios da ligação, utilizou-se o Supergraute Quartzolit em uma proporção de $175 \mathrm{ml}$ de água para cada kg de graute. Foram realizados ensaios para a determinação da resistência a compressão, resistência à tração e módulo de elasticidade em corpos-de-prova de 5 x $10 \mathrm{~cm}$ nas datas próximas aos ensaios estáticos dos modelos reforçados. Os resultados dos ensaios estão reunidos na Tabela 7.4.

Tabela 7.4 - Propriedades do graute.

\begin{tabular}{cccccc}
\hline Corpo-de-prova & Data & $\begin{array}{c}\text { Idade } \\
\text { (dias) }\end{array}$ & $\boldsymbol{f}_{\boldsymbol{c}}(\mathbf{M P a})$ & $\boldsymbol{f}_{\boldsymbol{t}}(\mathbf{M P a})$ & $\boldsymbol{E}_{\boldsymbol{c}}(\mathbf{M P a})$ \\
\hline 1 & $11 / 04 / 2012$ & 30 & 51,3 & - & 29192 \\
2 & $11 / 04 / 2012$ & 30 & 43,3 & - & 33003 \\
3 & $11 / 04 / 2012$ & 30 & 40,7 & - & 26899 \\
Média & & & $\mathbf{4 5 , 1}$ & - & $\mathbf{2 9 6 9 8}$ \\
1 & $30 / 05 / 2012$ & 26 & 44,0 & 2,4 & 29038 \\
2 & $30 / 05 / 2012$ & 26 & 50,8 & 3,7 & 26831 \\
3 & $30 / 05 / 2012$ & 26 & 49,3 & 2,7 & 29129 \\
Média & & & $\mathbf{4 8 , 0}$ & $\mathbf{2 , 9}$ & $\mathbf{2 8 3 3 3}$ \\
\hline
\end{tabular}

Também se determinou o módulo dinâmico do graute utilizando-se 6 corpos-de-prova cilíndricos com uso do equipamento Sonelastic ${ }^{\circledR}$, como ilustrado na Figura 7.6. Os resultados obtidos são apresentados na Tabela 7.5.

Tabela 7.5 - Módulo de elasticidade dinâmico do graute.

\begin{tabular}{ccc}
\hline Corpo-de-prova & Idade (dias) & $\boldsymbol{E}_{\boldsymbol{c}, \text { din }}(\mathbf{M P a})$ \\
\hline 1 & 89 & 35,6 \\
2 & 89 & 35,6 \\
3 & 89 & 31,5 \\
4 & 89 & 31,6 \\
5 & 89 & 30,5 \\
6 & 89 & 30,3 \\
Média & & $\mathbf{3 2 , 5}$ \\
\hline
\end{tabular}

- Adesivo

Para a colagem dos laminados nos entalhes foi utilizada a resina epóxi bi-componente “Sikadur ${ }^{\circledR} 330 ”$. Suas propriedades físicas, de acordo com informações dos fornecedores são apresentadas no Item 6.1. 


\section{- Laminado}

Utilizou-se o laminado que tem nome comercial de "Fita de Fibra de Carbono" comercializado pela Rogertec ${ }^{\circledR}$. Suas propriedades físicas, de acordo com informações dos fornecedores, são apresentadas no Item 6.1.

\section{- Almofada de apoio}

Utilizou-se almofada de apoio de argamassa. O comportamento deste tipo de almofada foi avaliado em pesquisas desenvolvidas no Departamento de Estruturas da USP como Montedor (2004), Siqueira (2007) e Bellucio (2010). Segundo Bellucio (2010) a utilização de almofada de compósitos possui a vantagem de aumentar a rigidez da ligação quando comparado com ligações utilizando o elastômero, além de ter um custo menor e não precisar de manutenção. Também apresenta a capacidade de moldagem de acordo com a tipologia da ligação, apresentando flexibilidade de geometria e propriedades. A composição da argamassa utilizada nesta pesquisa foi baseada em Bellucio (2010) e está indicada no Quadro 7.1.

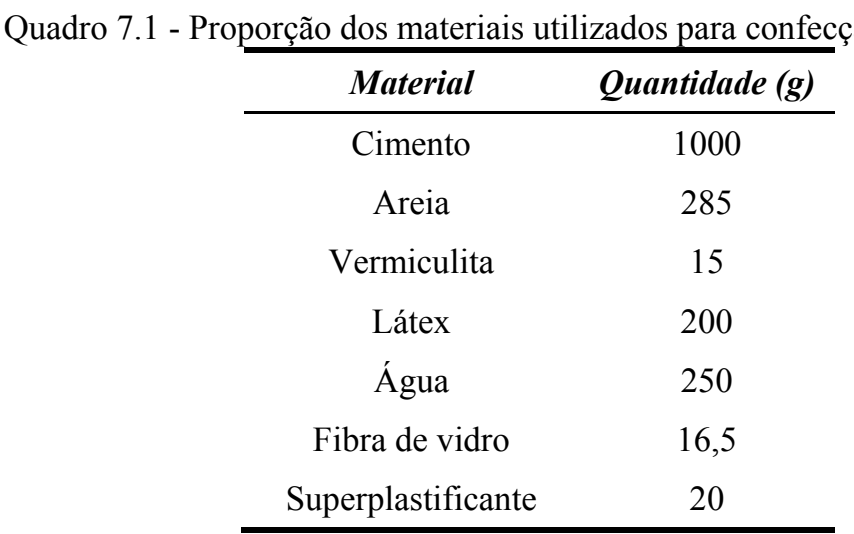

Realizou-se ensaio de compressão em uma placa de argamassa com as mesmas dimensões daquelas utilizadas nos modelos de pórticos: $20 \mathrm{~cm}$ de comprimento, 14,5 de largura e 1,5 cm de espessura (Figura 7.7). O ensaio foi feito com controle de deslocamento do pistão a velocidade de $0,01 \mathrm{~mm} / \mathrm{s}$. Com base nos resultados deste ensaio, traçou-se a curva "Força x Deslocamento vertical" apresentada na Figura 7.8. Desprezando-se o trecho inicial de acomodação, obteve-se por meio de regressão linear o coeficiente de $328 \mathrm{kN} / \mathrm{mm}$ que é 
uma grandeza relacionada à rigidez normal da almofada e que será discutida no Item 4.1.1 que trata dos parâmetros adotados na simulação numérica.
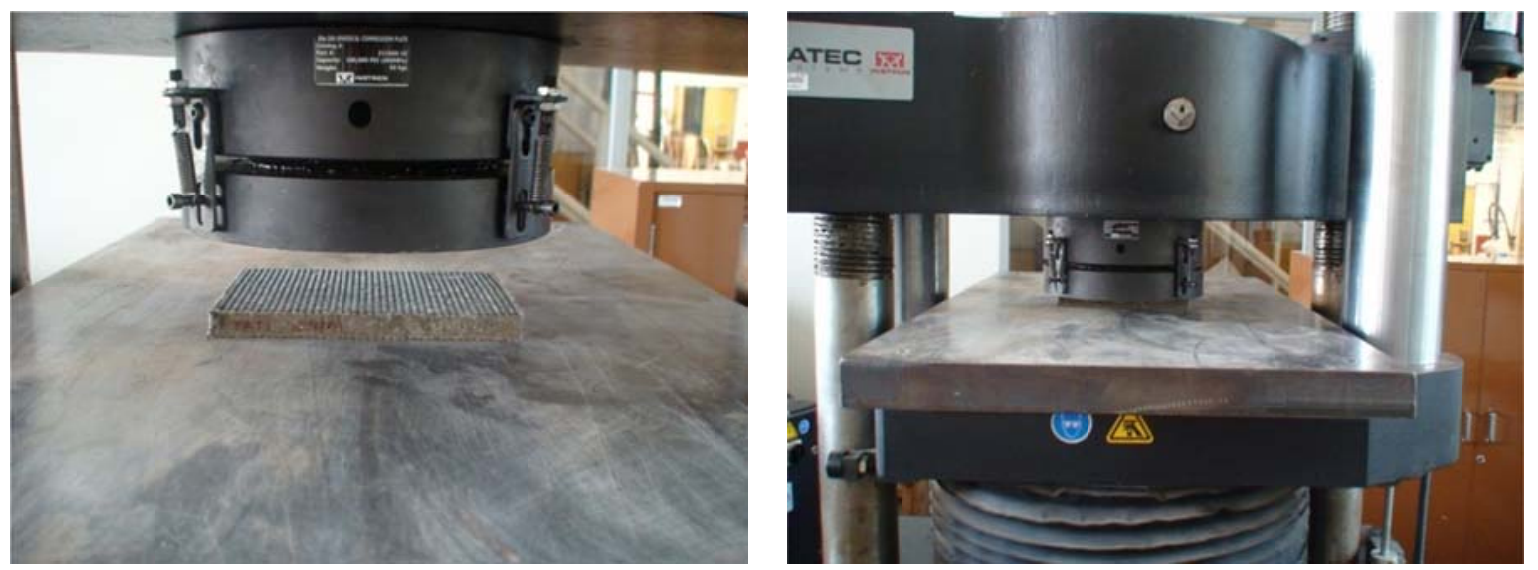

Figura 7.7 - Ensaio de compressão da almofada de apoio.

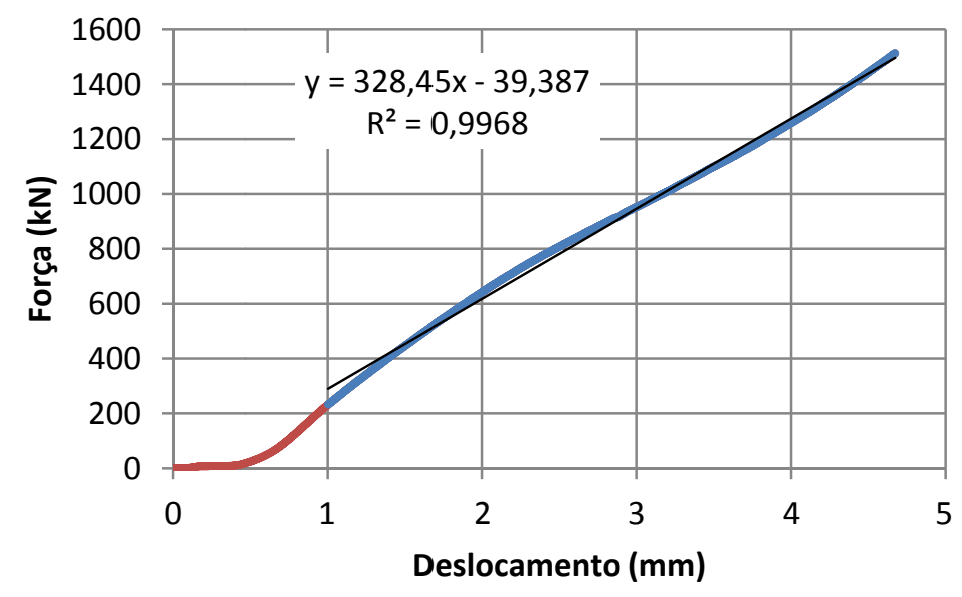

Figura 7.8 - Curva "Força x Deslocamento" relativa ao ensaio de compressão da almofada.

\subsection{Confecção do modelo}

Os elementos de pilar e viga foram moldados no laboratório do Departamento de Estruturas da USP em fôrmas constituídas de madeira laminada colada que são apresentadas na Figura 7.9. Observa-se, na foto à esquerda, que a chapa metálica, parte constituinte do dispositivo de fixação do modelo, foi utilizada como fechamento da fôrma do pilar de modo a 
garantir um perfeito ajuste entre a base do pilar e a base metálica. Na foto à direita, destaca-se a colocação de tubos para formação dos espaços para introdução dos chumbadores.
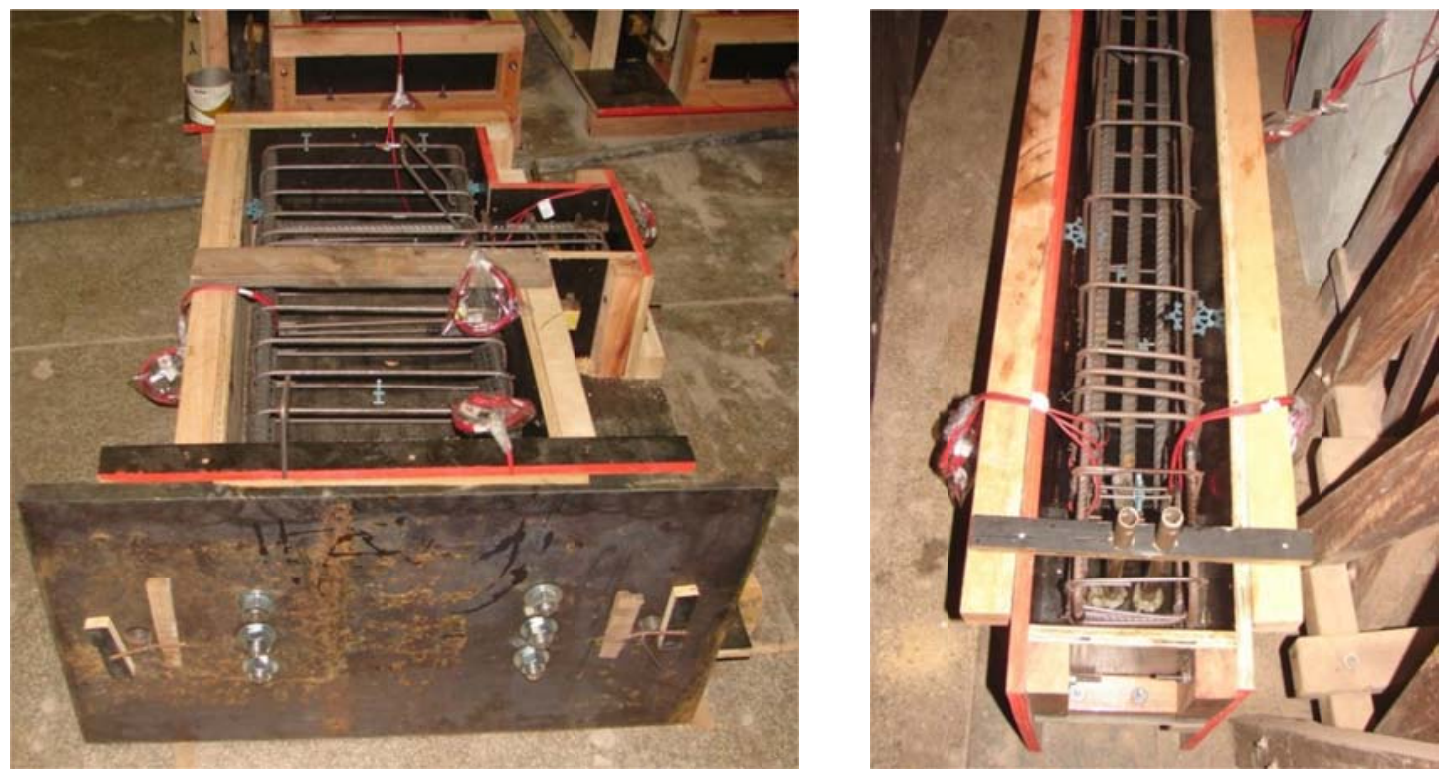

Figura 7.9 - Fôrma do pilar e da viga.

O concreto usinado foi adquirido da concreteira Constroeste. No recebimento, o abatimento do tronco de cone foi de $70 \mathrm{~mm}$ (Figura 7.10 à esquerda). $\mathrm{O}$ concreto foi adensado com vibrador de agulha conforme se observa na Figura 7.10, à direita, e mesmo tendo

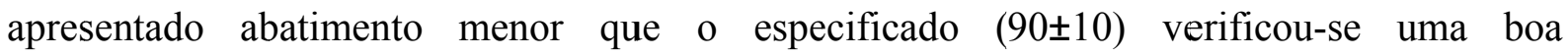
trabalhabilidade e preenchimento da fôrma o que se confirmou, após a desfôrma, pela observação do bom acabamento superficial das peças.
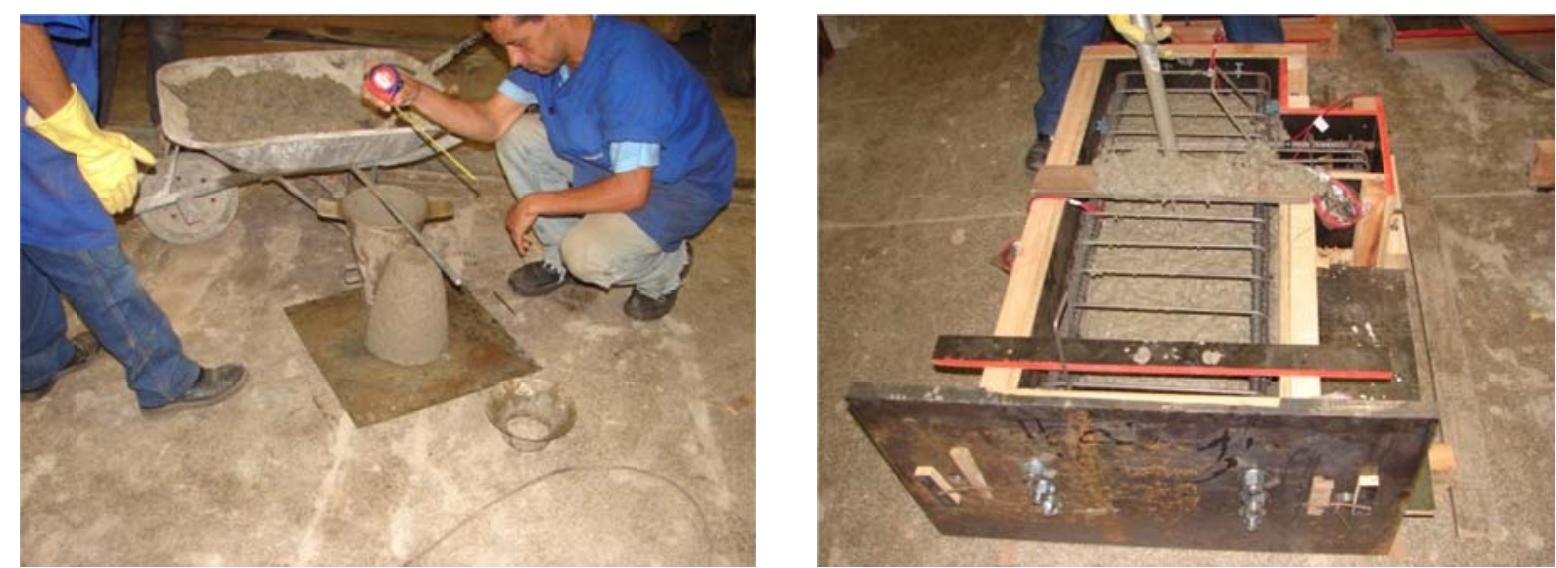

Figura 7.10 - Ensaio de consistência e adensamento do concreto. 


\subsection{Montagem e reforço dos pórticos}

Para montagem dos pórticos inicialmente fixaram-se os pilares à base de reação do laboratório (Figura 7.11). Devido defeitos geométricos de alguns pilares e vigas (falta de esquadro e alinhamento), foi necessário o uso de calços entre a base metálica e o piso do laboratório. Após a fixação dos pilares, posicionaram-se as almofadas de apoio sobre os consolos e sobre elas a viga. Em alguns casos, foi necessário utilizar massa plástica abaixo da almofada de apoio de modo a alcançar um posicionamento correto da viga (Figura 7.12). Na Figura 7.13, ilustra-se o pórtico com ligações articuladas, montado para ensaio.
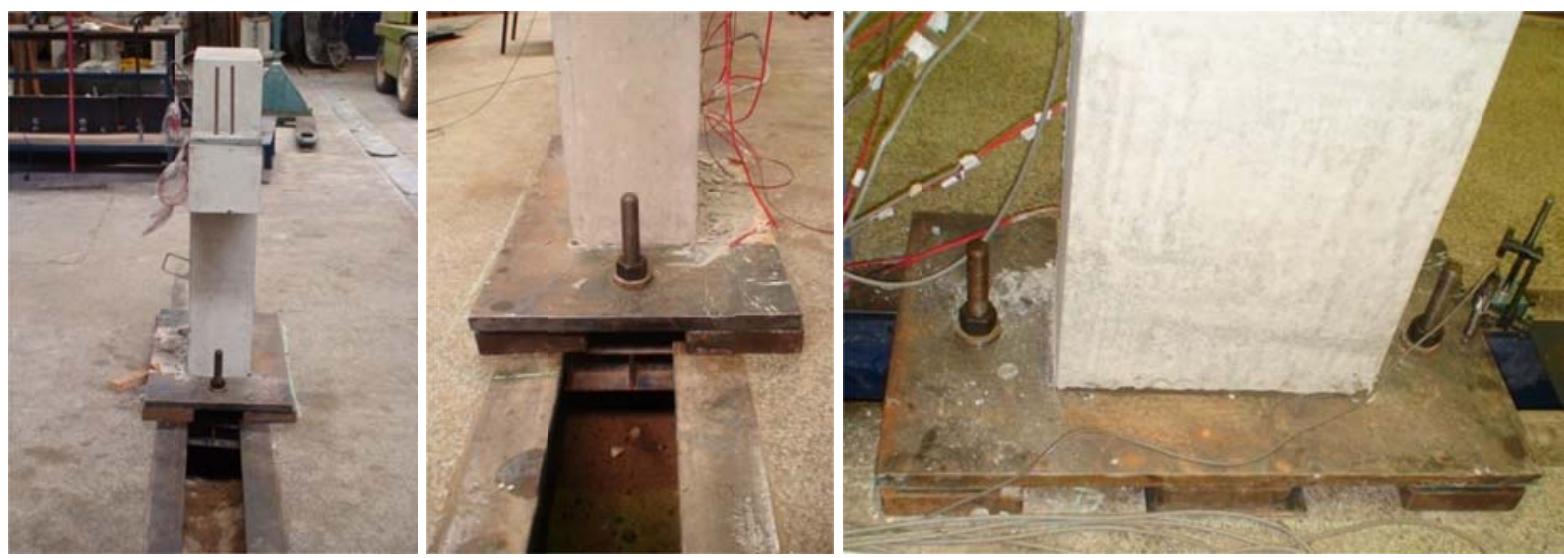

Figura 7.11 - Detalhes da fixação do pilar
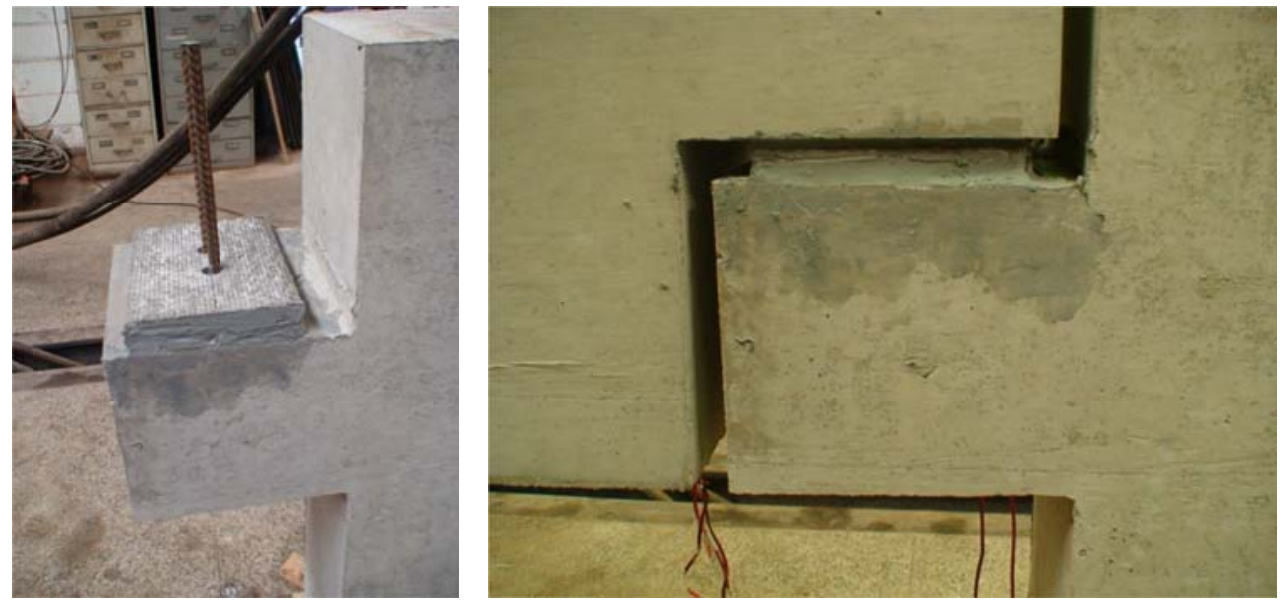

Figura 7.12 - Detalhes do posicionamento da almofada de apoio. 


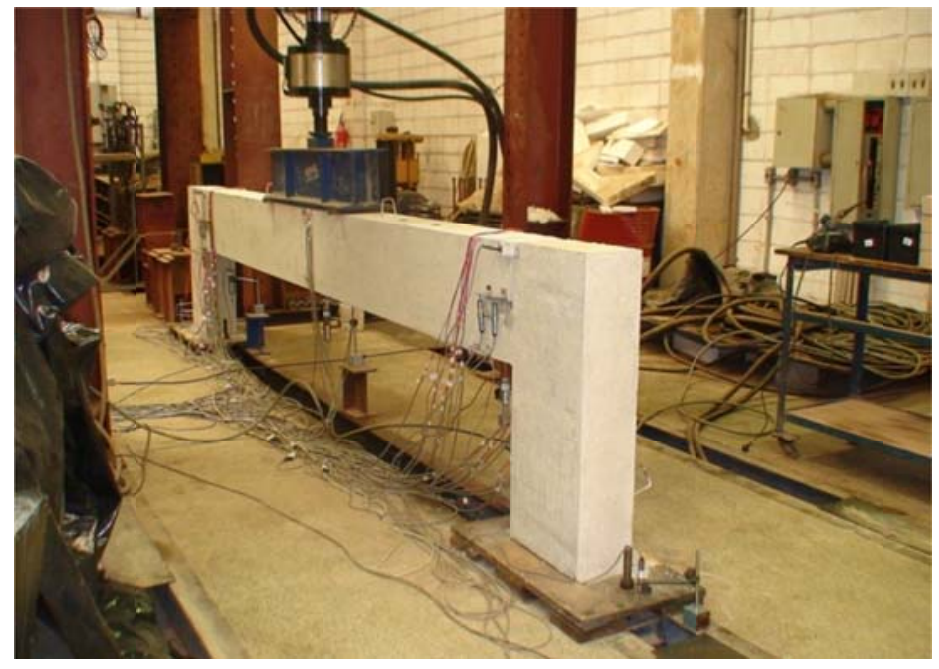

Figura 7.13 - Visão geral do pórtico montado.

O reforço dos modelos consistiu do grauteamento dos espaços verticais entre a viga e o pilar e na colagem de laminados em entalhes no concreto de cobrimento. Para o grauteamento da região da ligação, foi necessário vedar as laterais dos espaços e o fundo do espaço inferior com pedaços de madeira e isopor e fios de aço passantes (Figura 7.14). A solução adotada foi eficiente impedindo que o graute, bastante fluido, escorresse e proporcionando um bom acabamento, como se percebe na Figura 7.15, à esquerda. Nesta figura também se pode ver a marcação das linhas para execução dos entalhes. A Figura 7.15, à direita, ilustra a região da ligação já com os entalhes, de aproximadamente $4 \mathrm{~mm}$ de espessura e $18 \mathrm{~mm}$ de profundidade. Na Figura 7.16 ilustra-se o modelo com o reforço das ligações concluído.
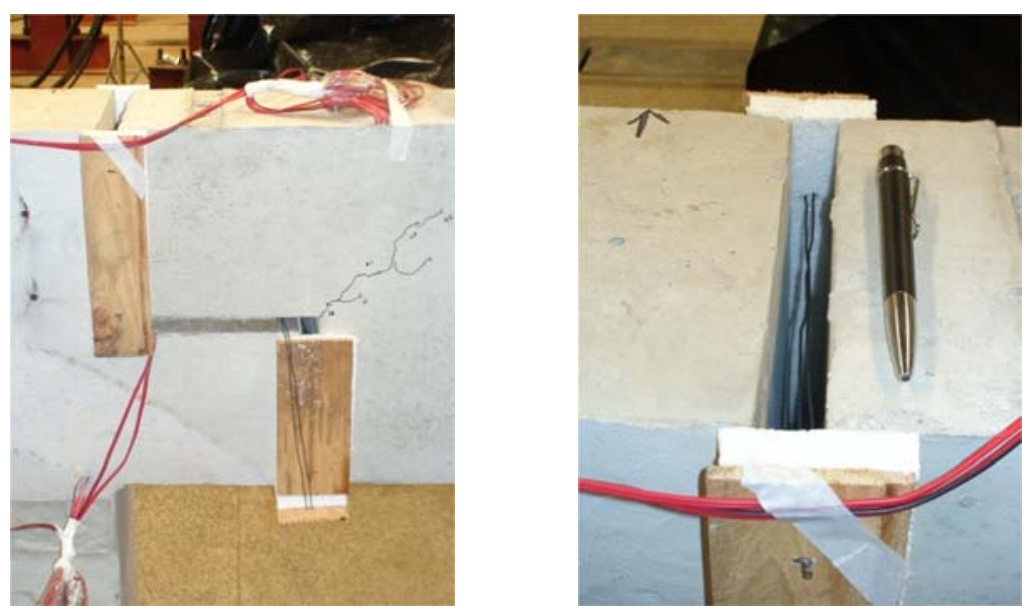

Figura 7.14 - Sistema de vedação para grauteamento da ligação. 

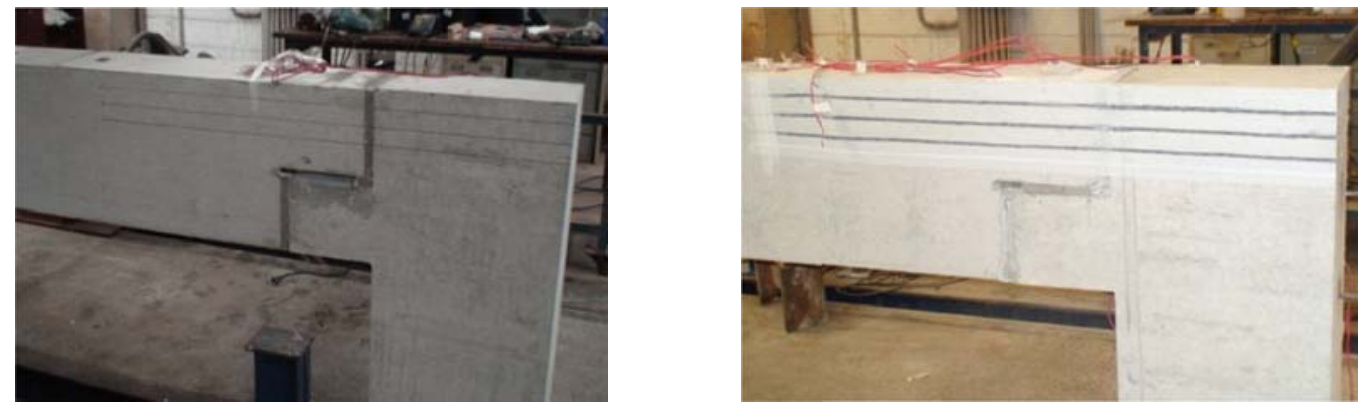

Figura 7.15 - Ligação após o grauteamento com marcação para corte dos entalhes (à esquerda) e com entalhes prontos (à direita).

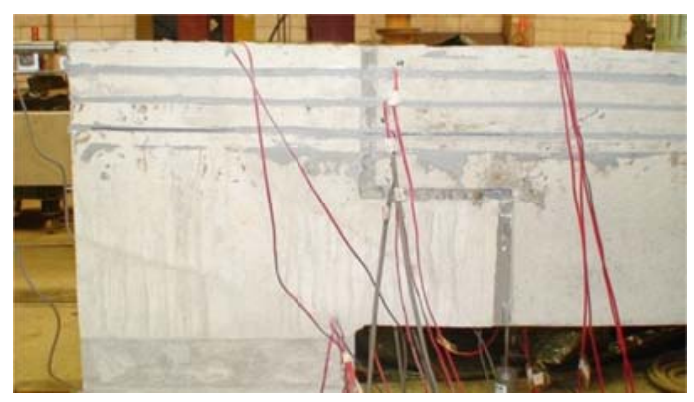

Figura 7.16 - Ligação após o reforço.

\subsection{Instrumentação e configuração do ensaio estático}

A instrumentação interna do ensaio da viga consistiu em extensômetros colados nas armaduras. Buscou-se determinar as deformações nas barras que se julgavam mais relevantes para a resistência do modelo em questão ou cuja comparação com suas equivalentes nos demais modelos fosse de especial interesse.
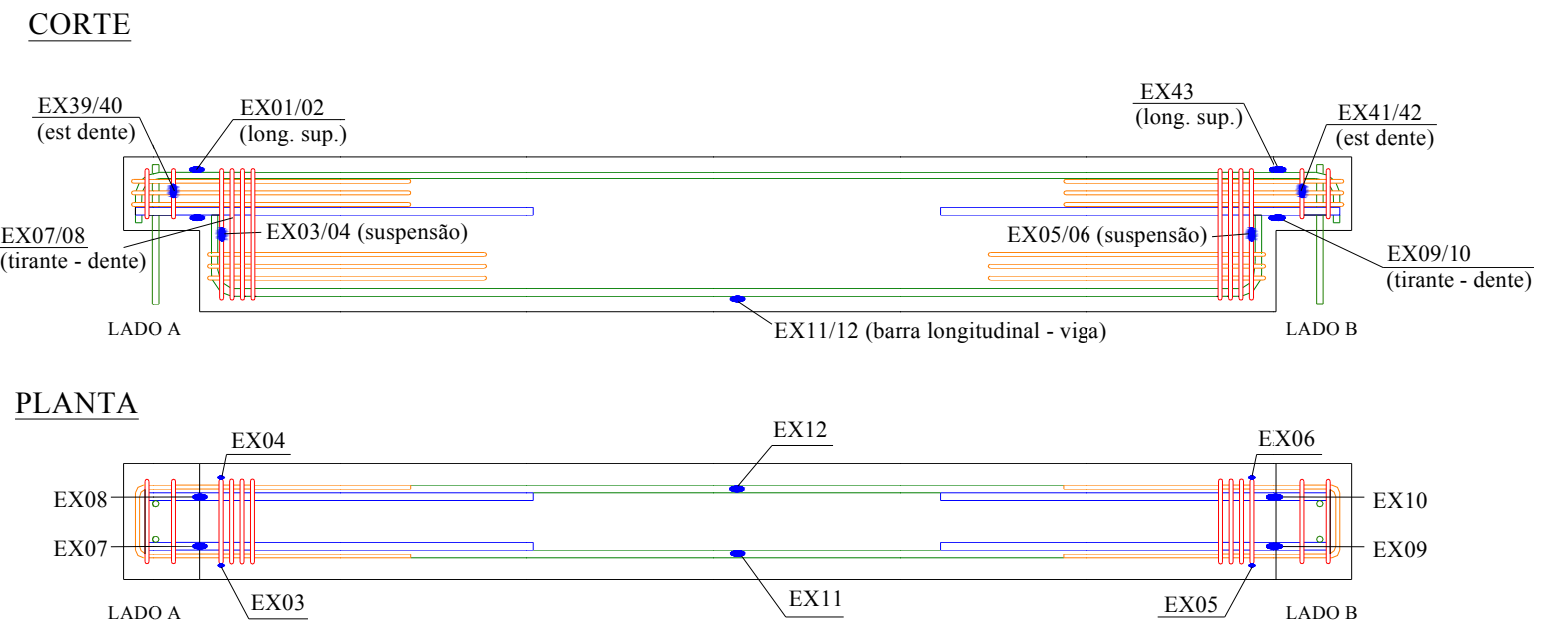

Figura 7.17 - Posicionamento e identificação dos extensômetros colados na armadlura viga. 
A instrumentação externa é ilustrada na Figura 7.18. Utilizaram-se transdutores de deslocamento posicionados verticalmente na região do apoio (TDVE_AE, TDVE_AI, TDAE_AE, TDAE_AI no lado esquerdo e TDVD_AE, TDVD_AI, TDAE_AD, TDAD_AI no lado direito) para obtenção dos deslocamentos relativos e rotações relativas entre a viga e o apoio. Outros 3 transdutores foram utilizados para determinação do deslocamento vertical da viga. A viga foi bi-apoiada em dispositivos que simulam o comportamento de rótula (Figura 7.19). Indiretamente, com uso de um perfil metálico (Figura 7.20), o carregamento aplicado por atuador servo-controlado foi distribuído a duas seções da viga. A Figura 7.21 ilustra a montagem do ensaio.

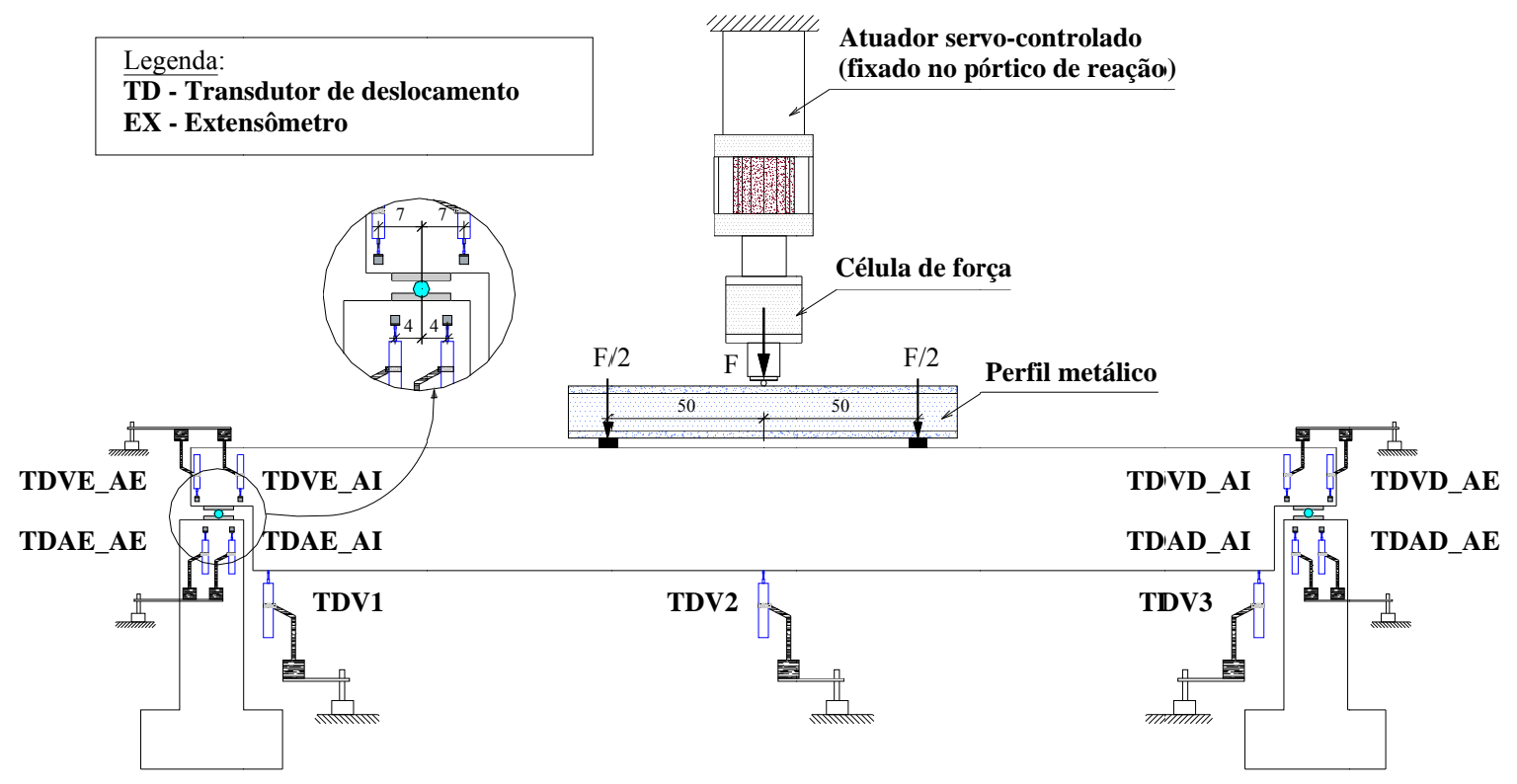

Figura 7.18 - Esquema de ensaio e instrumentação externa.

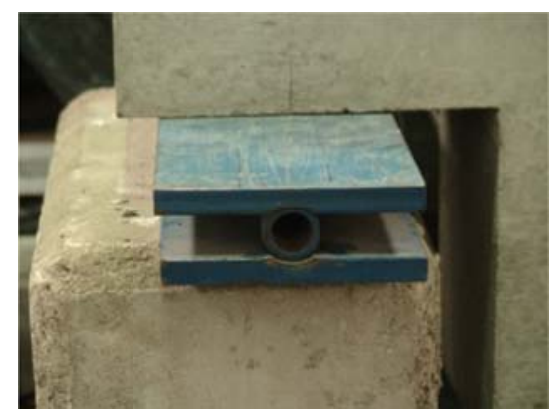

Figura 7.19 - Dispositivo de apoio. 


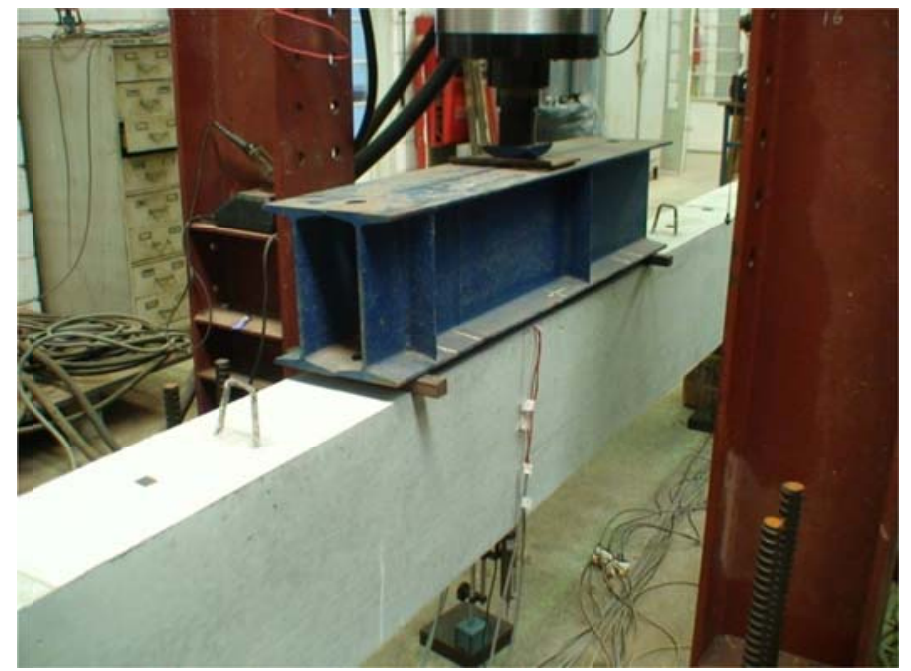

Figura 7.20 - Detalhe do sistema de distribuição da força.

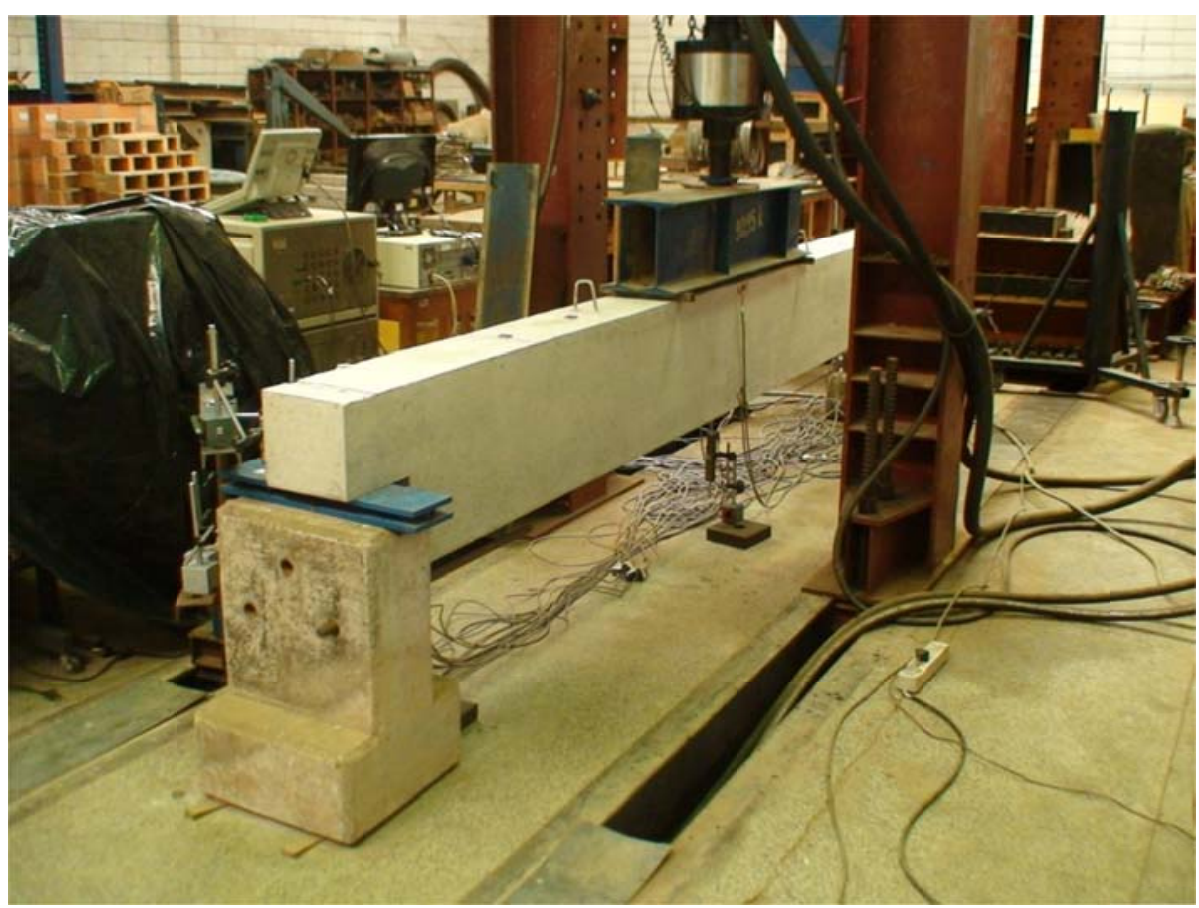

Figura 7.21 . Montagem do ensaio da viga.

A instrumentação interna das vigas utilizadas para a composição do pórtico foi posicionada da mesma forma que a apresentada na Figura 7.17. O posicionamento dos extensômetros na armadura dos pilares está ilustrado na Figura 7.22. Nos ensaios dos pórticos reforçados, acrescentaram-se extensômetros nos laminados na seção da junta vertical superior entre a viga e o pilar (Figura 7.23). 


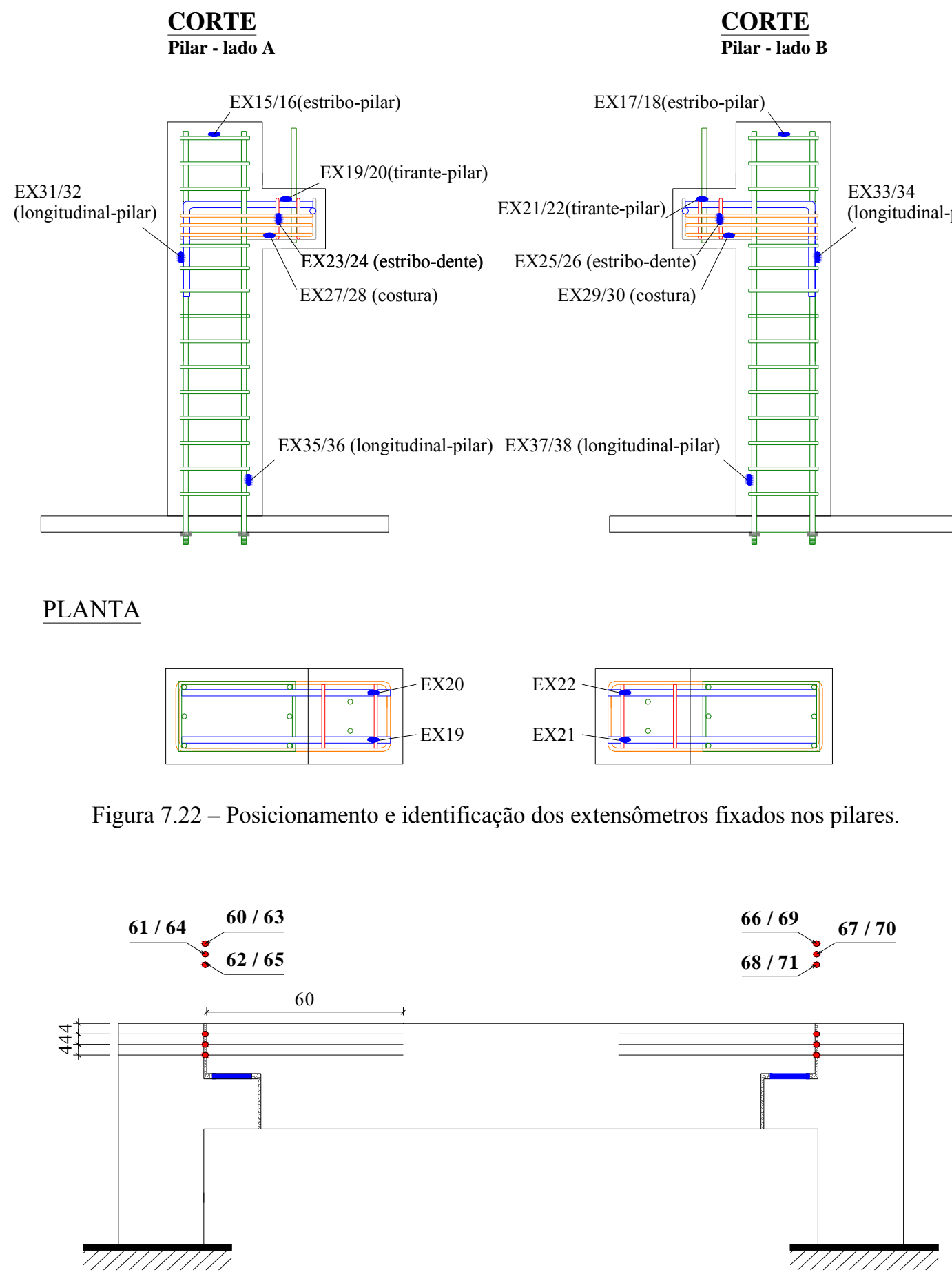

Figura 7.23 - Posicionamento e identificação dos extensômetros fixados nos laminados (desenho fora de escala, dimensões em centímetros).

A Figura 7.24 ilustra a instrumentação externa e o esquema de ensaio dos pórticos. Os transdutores numerados de 1 a 8 foram utilizados para determinação da rotação ao longo do ensaio, os transdutores de 9 a 11 foram utilizados para medição do deslocamento vertical nas extremidades e no centro da viga e os transdutores 12 e 13 para monitoração do deslocamento 
vertical da base. No ensaio dos pórticos reforçados, utilizaram-se transdutores também para verificar o deslizamento entre o laminado mais próximo do topo do pórtico e o concreto (Figura 7.25, à direita).

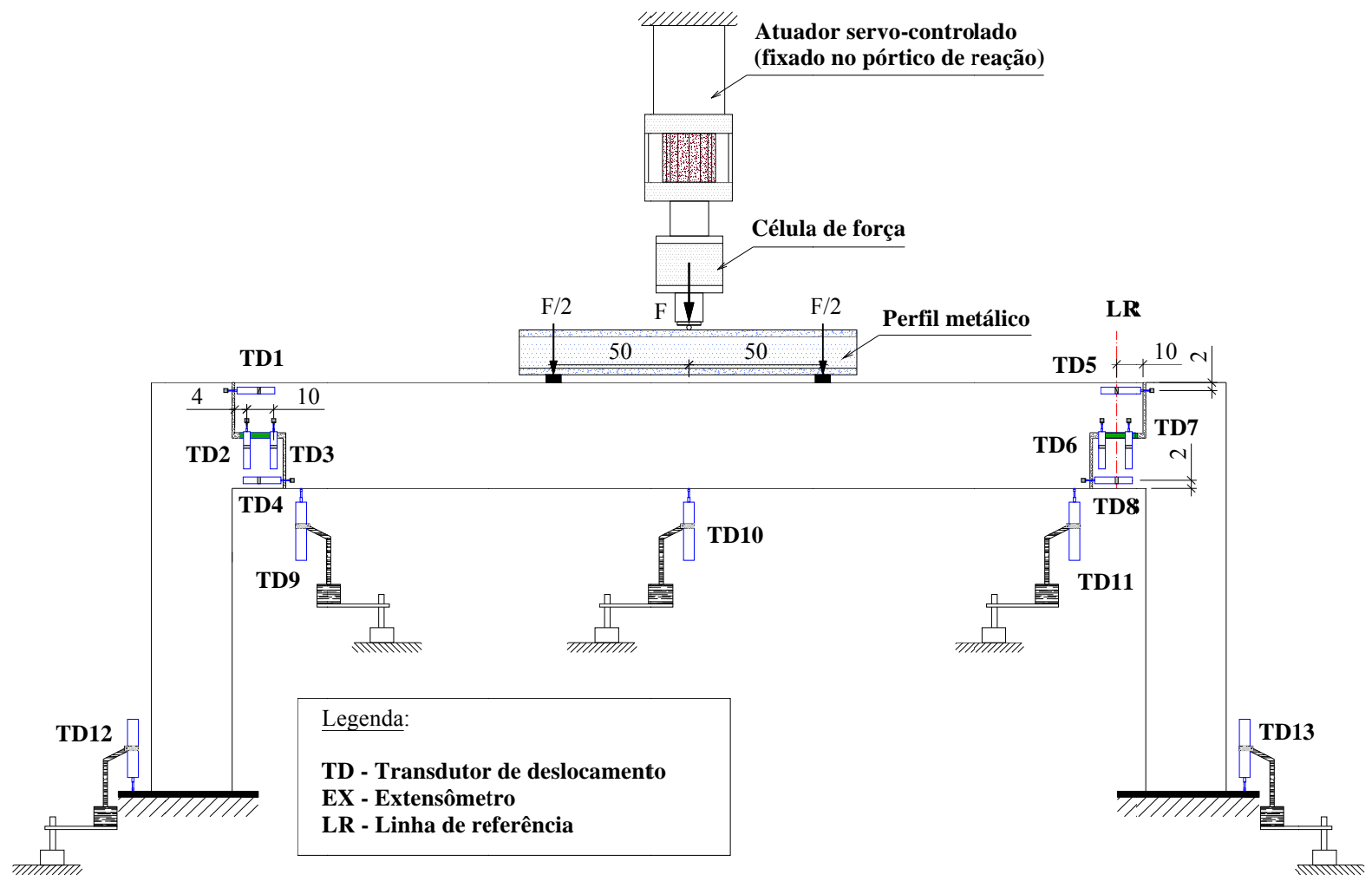

Figura 7.24 - Esquema do ensaio dos pórticos e instrumentação externa.
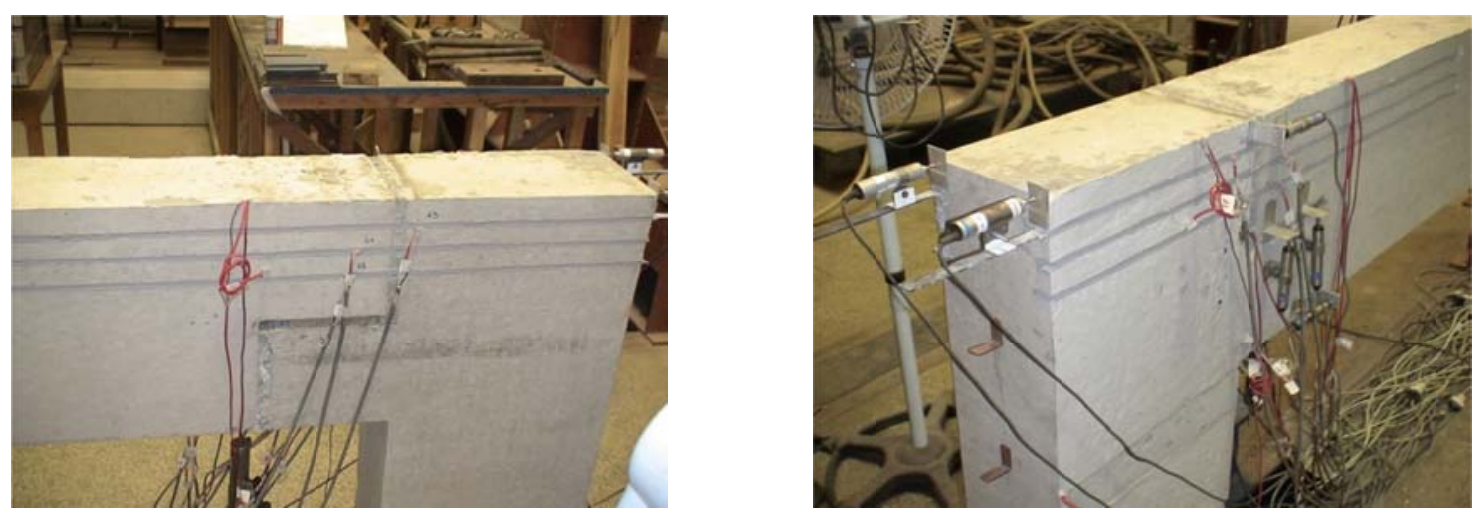

Figura 7.25 - Posicionamento dos extensômetros e transdutores de deslocamento nos laminados, à esquerda e à direita, respectivamente.

\subsection{Execução dos ensaios estáticos}

Todos os ensaios foram realizados com uso do atuador servo-controlado com capacidade de $500 \mathrm{kN}$, sob controle de deslocamento do pistão com velocidade de 0,005 
$\mathrm{mm} / \mathrm{s}$ mantida ao longo da maior parte do ensaio. A seguir, descrevem-se as etapas de execução de cada ensaio individualmente.

\subsubsection{Ensaio da viga}

- Realização de ensaio dinâmico no modelo íntegro;

- $\quad$ Escorvamento pela aplicação de força de $20 \mathrm{kN}$;

- Aplicação de força até a ruptura do modelo $(244 \mathrm{kN})$.

\subsubsection{Portico1}

A execução do ensaio do Pórticol foi dividida em duas fases. Numa primeira fase, o pórtico tinha as ligações articuladas (Pórtico1_a). As etapas da execução desta fase do ensaio são descritas abaixo.

\section{Portico1_a (ligações articuladas)}

- Realização de ensaio dinâmico no modelo íntegro;

- $\quad$ Aplicação de força de escorvamento de $30 \mathrm{kN}$;

- $\quad$ Aplicação de força de $100 \mathrm{kN}$;

- Retirada da força aplicada;

Após essa primeira fase, o modelo foi reforçado pelo grauteamento dos espaços da ligação e pela colagem de 3 laminados na face lateral na região da ligação. Abaixo, descrevem-se etapas da execução do ensaio do Pórtico1_b.

\section{Portico1_b (ligações reforçadas)}

- Realização de ensaio dinâmico no modelo com ligações reforçadas;

- $\quad$ Aplicação de escorvamento $15 \mathrm{kN}$;

- $\quad$ Aplicação de força até o valor máximo de $438 \mathrm{kN}$.

\subsubsection{Pórtico2}

Também se realizou ensaio dinâmico no pórtico com ligações articuladas (Pórtico2_a). Em seguida, reforçou-se o modelo com 3 laminados por face da ligação assim como no 
Pórtico1. Buscou-se, deste modo, a possibilidade de comparar o efeito do reforço em um pórtico com elementos fissurados e outro com elementos íntegros.

\section{Portico2_a (ligações articuladas)}

- Realização de ensaio dinâmico no modelo íntegro com ligações articuladas;

\section{Portico2_b (ligações reforçadas)}

- Realização de ensaio dinâmico no modelo com ligações reforçadas;

- $\quad$ Aplicação de escorvamento $20 \mathrm{kN}$;

- Aplicação de força até o valor máximo de $450 \mathrm{kN}$.

\subsubsection{Pórtico3}

Para o Pórtico3 foram realizados ensaios somente após o reforço do mesmo. Neste caso utilizaram-se 2 laminados por face de ligação. Deste modo, buscou-se a comparação entre pórticos reforçados com diferentes quantidades de laminado.

\section{Portico3 (ligações reforçadas)}

- Realização de ensaio dinâmico no modelo com ligações reforçadas;

- $\quad$ Aplicação de escorvamento $50 \mathrm{kN}$;

- $\quad$ Aplicação de força até um valor máximo de $438 \mathrm{kN}$.

\subsection{Resultados e discussões do ensaio estático}

\subsubsection{Fissuração e ruptura}

Discutem-se neste item os aspectos relacionados à fissuração e modo de ruptura, observados experimentalmente, para cada ensaio.

\section{Ensaio da viga}

Quando aplicada uma força de $20 \mathrm{kN}$, surgiram as primeiras fissuras inclinadas no canto reentrante na região do dente Gerber (Figura 7.26, à esquerda). Fissuras de flexão verticais surgiram no banzo tracionado, aproximadamente a meio vão, quando aplicada uma 
força de $50 \mathrm{kN}$. Até uma força aplicada de $100 \mathrm{kN}$, se observou a evolução das fissuras já existentes e o surgimento de novas fissuras de flexão na região central da viga e inclinadas na região do dente. Com força aplicada de $122 \mathrm{kN}$, sugiram fissuras inclinadas de cisalhamento aproximadamente no terço do vão. A fissuração evoluiu até a aplicação da força de $244 \mathrm{kN}$ quando ocorreu a ruptura do dente da viga (Figura 7.26, à direita, e Figura 7.27).
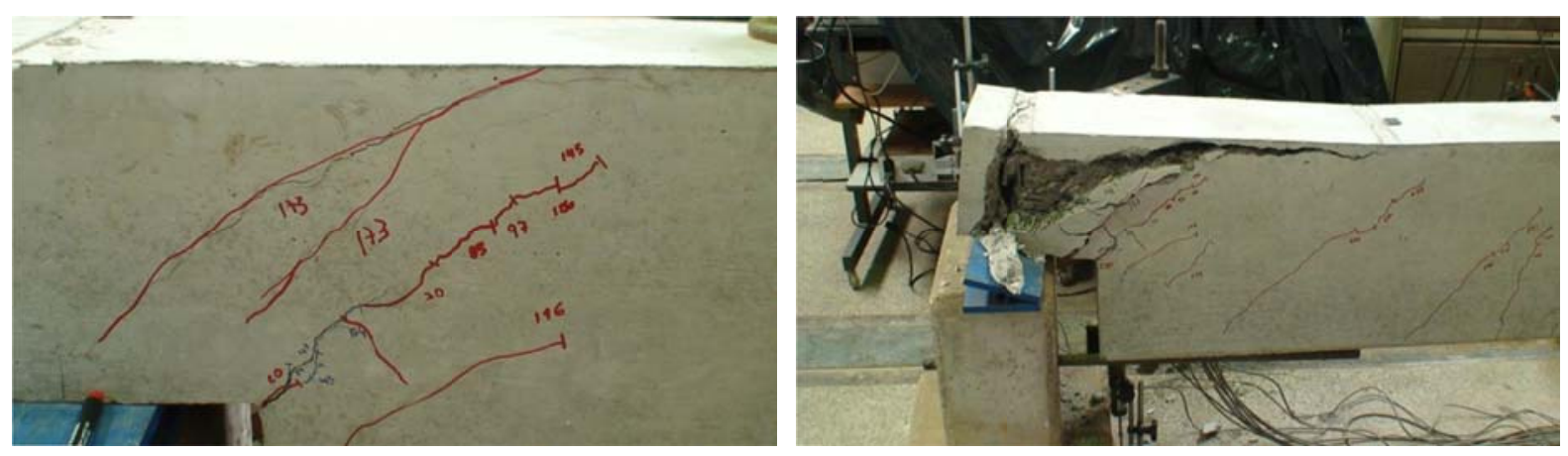

Figura 7.26 - À esquerda - Fissuração na região do dente Gerber; à direita - mesma região após ruptura.

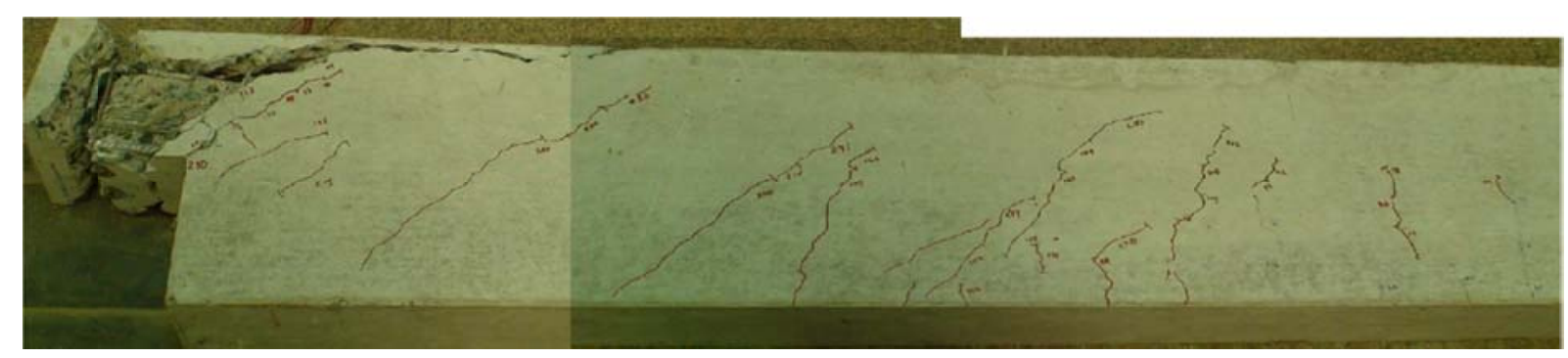

Figura 7.27 - Panorama de fissuração da viga pós ruptura (montagem de fotos).

\section{Portico1_a}

Inicialmente, surgiram fissuras características de flexão no banzo tracionado, na região central da viga, quando a força aplicada era de $34 \mathrm{kN}$ (Figura 7.28, à esquerda). Com a aplicação de uma força de $51 \mathrm{kN}$ surgiram as primeiras fissuras inclinadas no canto reentrante do dente Gerber (Figura 7.28, à esquerda). Quando a força aplicada era de 100 kN (máxima aplicada antes do reforço do modelo) havia um predomínio de fissuras quase verticais no banzo tracionado da viga e inclinadas na região do dente Gerber. 

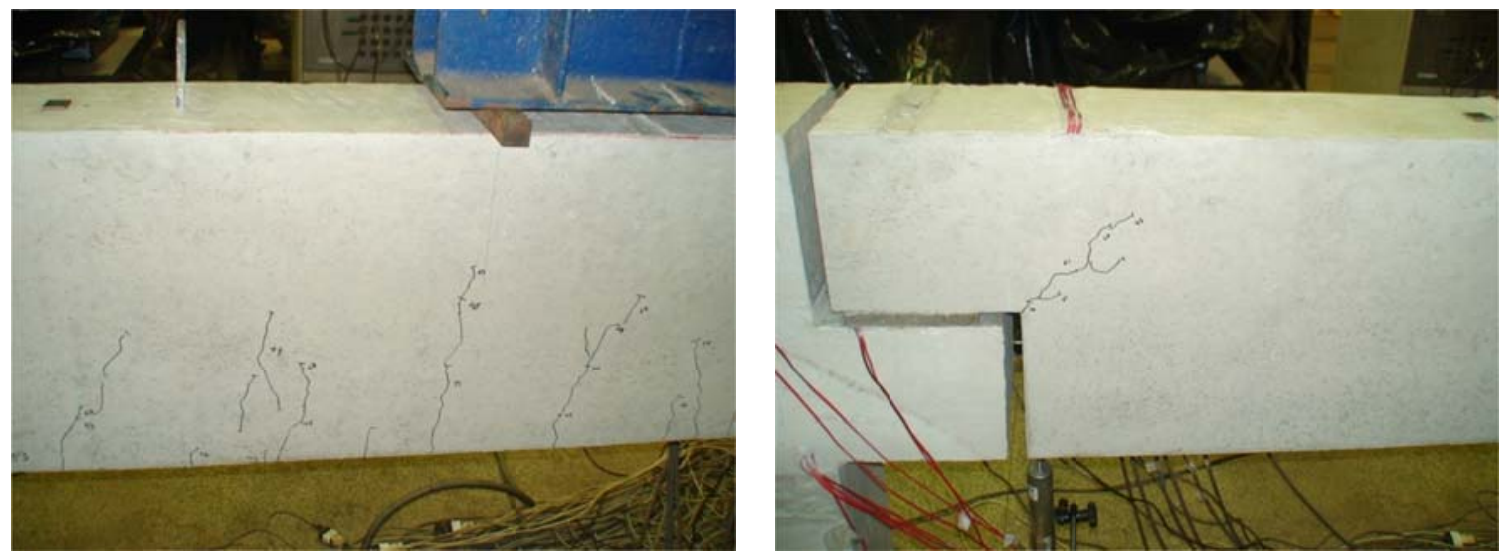

Figura 7.28 - À esquerda, fissuração na região central; à direita, fissuração na região do dente Gerber.

\section{Portico1_b}

Quando aplicada uma força de $140 \mathrm{kN}$, surgiram as primeiras fissuras da segunda etapa de ensaio do Pórticol (marcadas em vermelho) e se observou o prolongamento das fissuras originadas na primeira etapa do ensaio (marcadas em azul) como se pode observar na Figura 7.29, à esquerda. Fissuras inclinadas na viga características de cisalhamento surgiram quando havia uma força aplicada de aproximadamente $200 \mathrm{kN}$ (Figura 7.30). Com força aplicada superior a $300 \mathrm{kN}$ se tornaram visíveis fissuras nos pilares, inclinadas na região da ligação e horizontais na face lateral do modelo (Figura 7.31). Com o aumento progressivo da força aplicada as fissuras se prolongaram. O modelo suportou uma força máxima de $438 \mathrm{kN} \mathrm{e}$ não apresentou modo de ruptura bem definido, tendo-se interrompido o ensaio porque o modelo passou a apresentar deslocamento sem incremento de força.
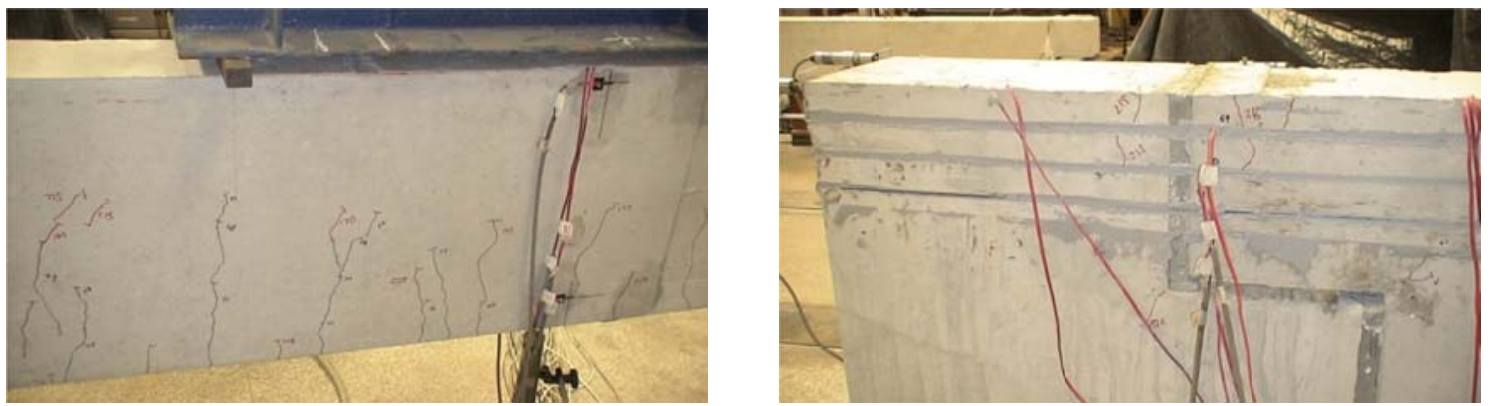

Figura 7.29 - À esquerda, fissuração na região central; à direita, fissuração a região do dente. 


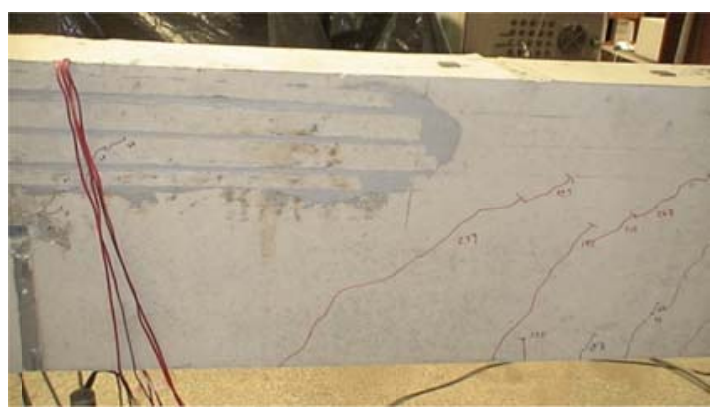

Figura 7.30 - Fissuras características de cisalhamento.
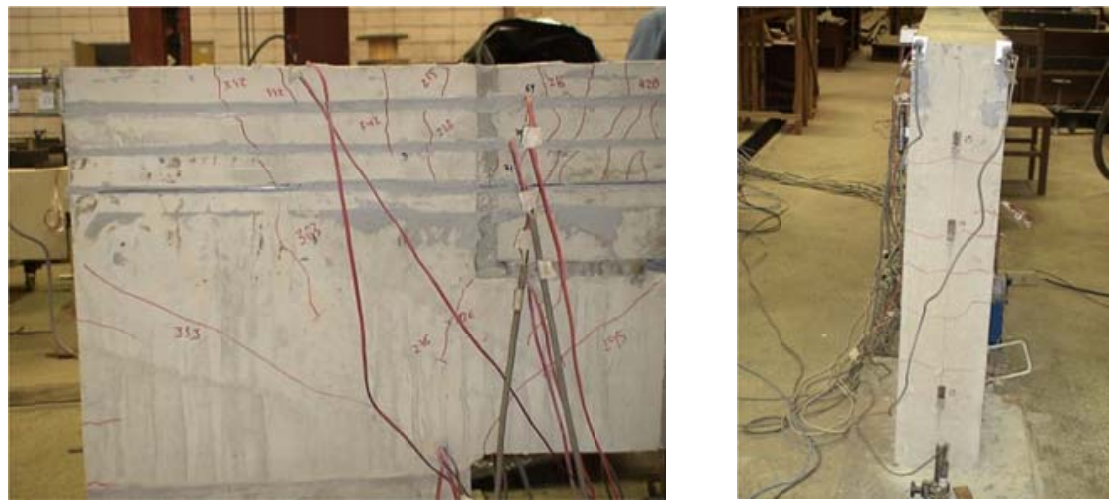

Figura 7.31 - Fissuração do pilar na região da ligação (à esquerda) e na face lateral (à direita).

\section{Pórtico2_b}

Com força aplicada de aproximadamente $70 \mathrm{kN}$, surgiram fissuras de flexão no banzo tracionado (Figura 7.32, á esquerda). Fissuras inclinadas, características de cisalhamento, surgiram quando a força aplicada era de $145 \mathrm{kN}$ (Figura 7.32, à direita). Para uma força de $185 \mathrm{kN}$, se observou uma fissura no consolo (Figura 7.33, à esquerda). Com força aplicada superior a $300 \mathrm{kN}$ se evidenciaram fissuras no pilar, inclinadas na região da ligação e horizontais na lateral do pilar. O modelo resistiu a uma força máxima de $450 \mathrm{kN}$. Na Figura 7.33 (ao centro e à direita), observa-se o destacamento de uma cunha de concreto na quina do pilar na região do reforço. 

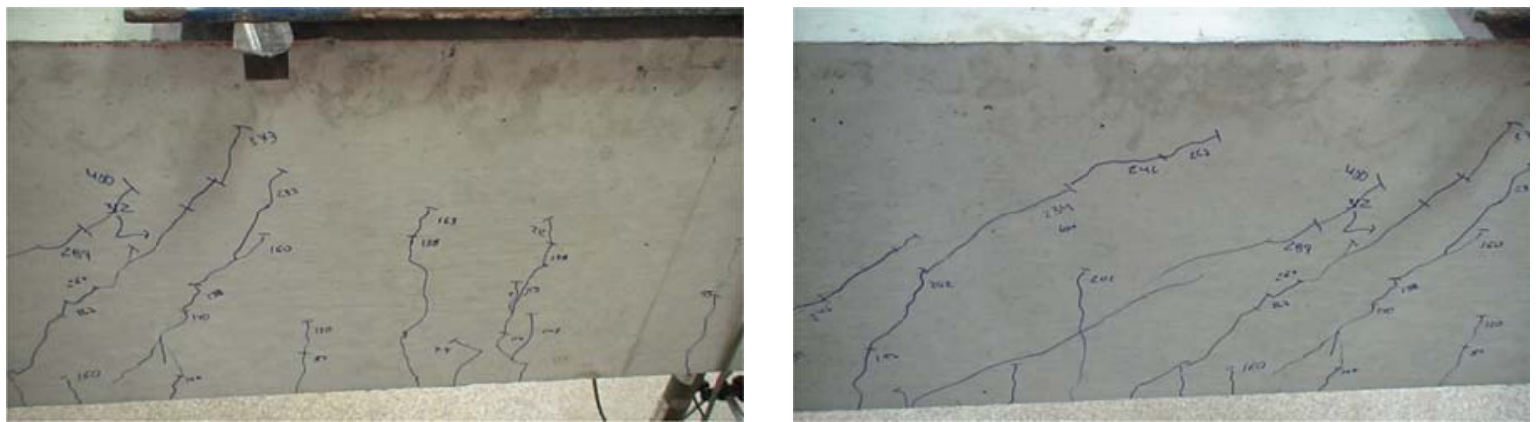

Figura 7.32 - Fissuração na região central, à esquerda; fissuração no terço da viga, à direita.
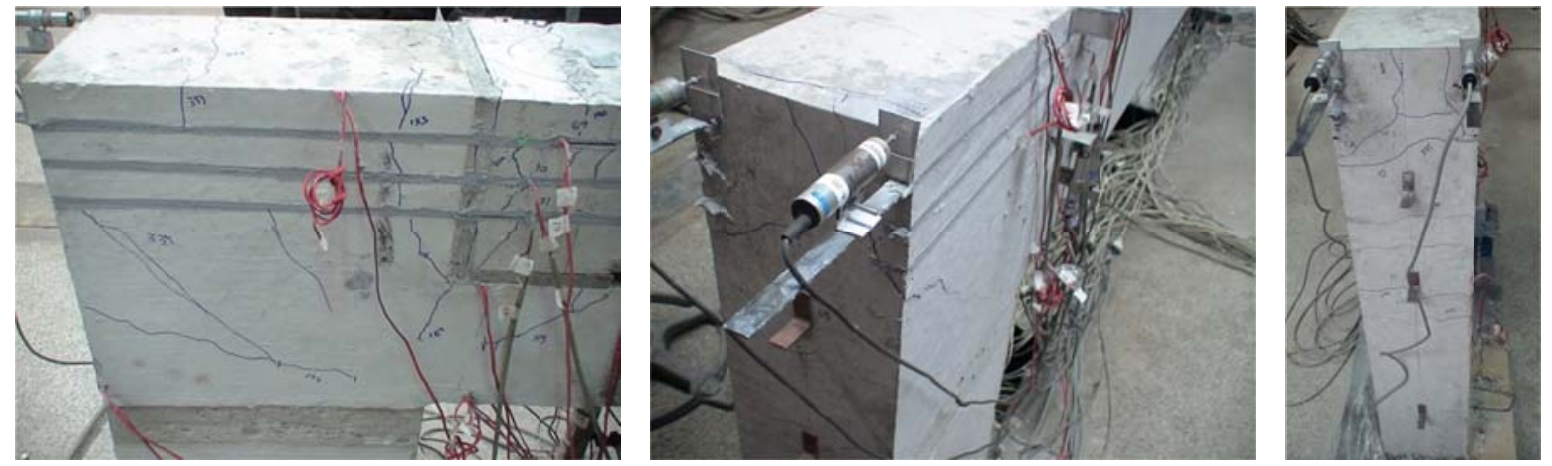

Figura 7.33 - Fissuração na região da ligação, à esquerda; detalhe do destacamento de concreto em cunha, ao centro; fissuração na lateral do pilar, à direita.

\section{Pórtico3}

Fissuras de flexão aproximadamente verticais surgiram com uma força aplicada de 70 $\mathrm{kN}$ no banzo tracionado da viga (Figura 7.34, à esquerda). Com o aumento da força, surgiram novas fissuras com as mesmas características e as primeiras, se prolongaram. Com força aplicada de $140 \mathrm{kN}$, surgiram fissuras inclinadas características de cisalhamento (Figura 7.34, à direita). Para força superior a $220 \mathrm{kN}$, se intensificaram as fissuras inclinadas de cisalhamento na viga e na região da ligação. Na Figura 7.35 e observam-se fissuras horizontais na face lateral do pilar. Destaca-se, na Figura 7.35, a abertura da fissura no consolo e na Figura 7.36, o panorama final de fissuração. 

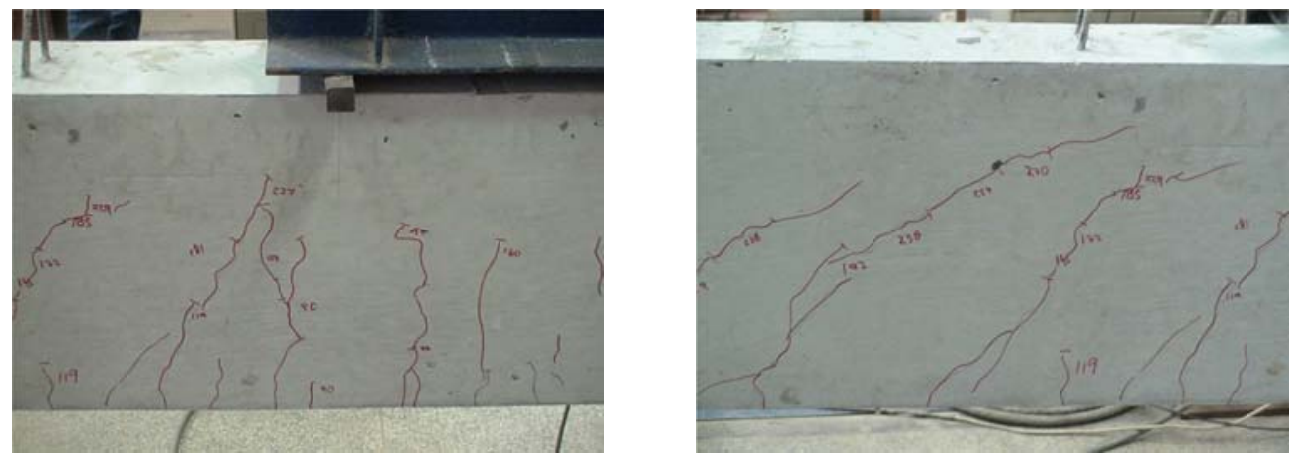

Figura 7.34 - Fissuração na região central, à esquerda; fissuração no terço dla viga, à direita.
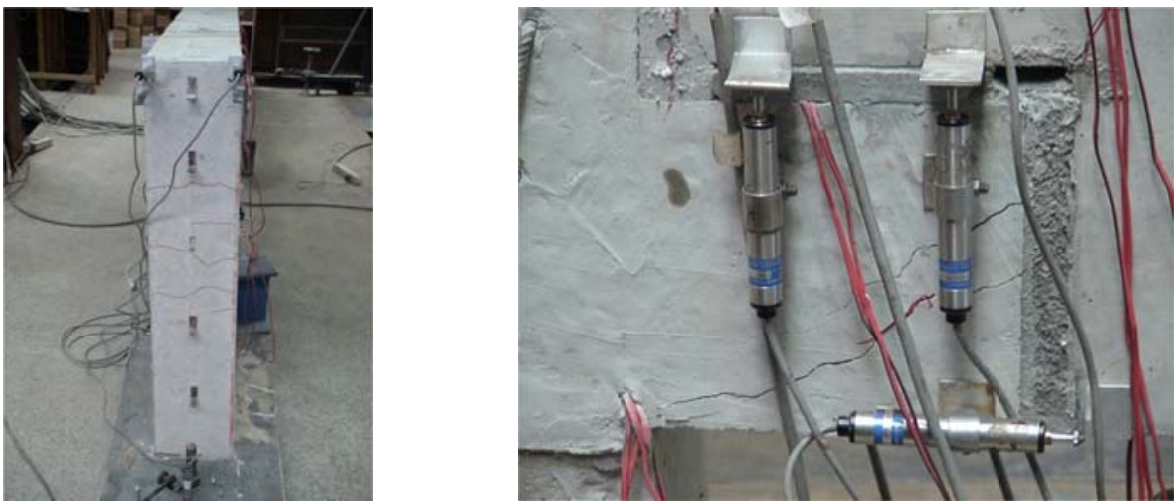

Figura 7.35 - Fissuração na lateral do pilar, à esquerda; detalhe de fissura em um dos consolos, à direita.

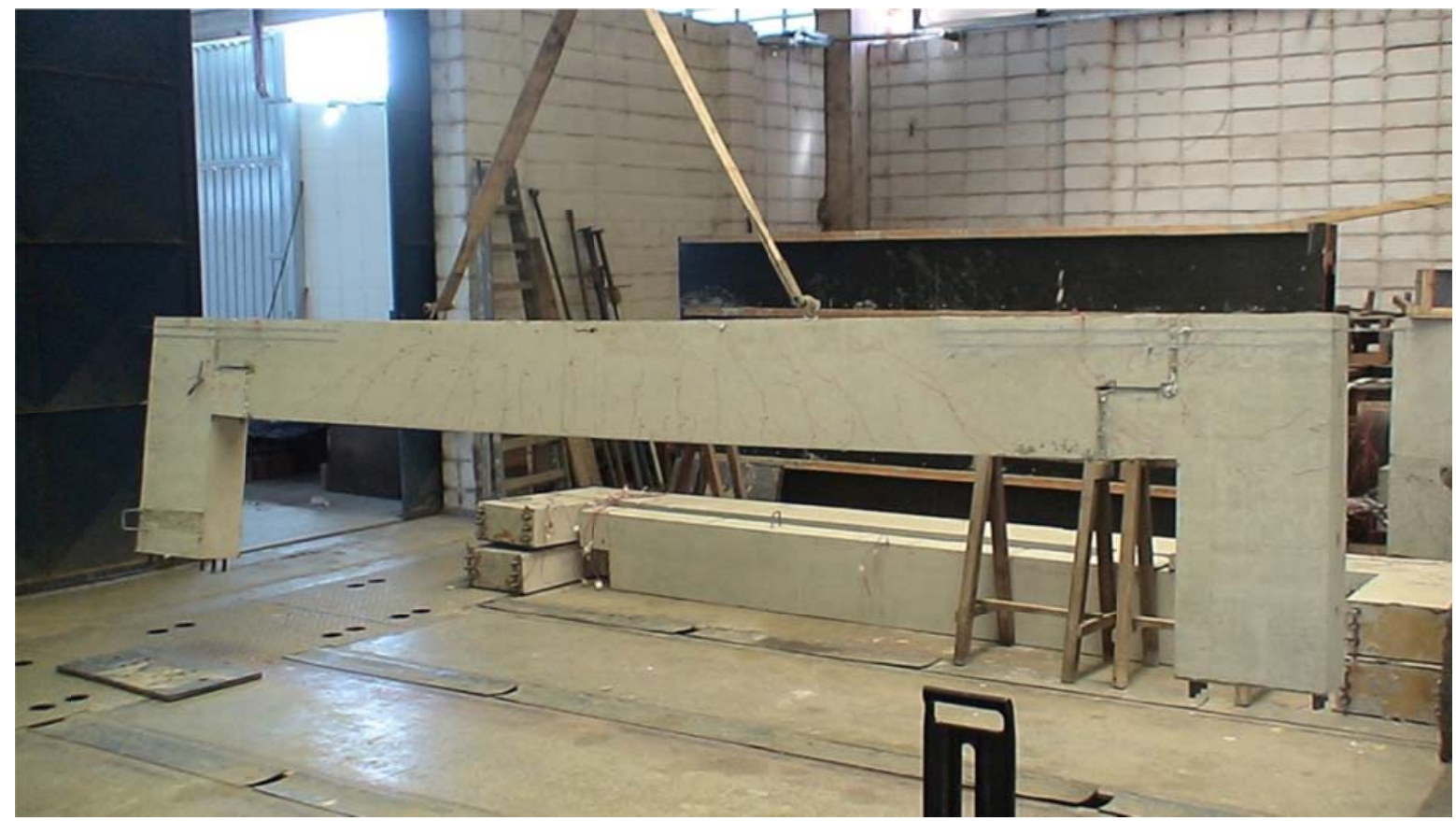

Figura 7.36 - Panorama de fissuração pós-ruptura. 


\subsubsection{Deformação das armaduras}

As relações entre as deformações das armaduras instrumentadas com a aplicação da força são apresentadas nas Figura 7.37 a Figura 7.48. Destaca-se que as curvas apresentadas foram traçadas com base na média das deformações obtidas por meio dos extensômetros colados em cada tipo de armadura. Na Tabela 7.6, os valores máximos correspondem à curva média. Esclarece-se, também, que os resultados gráficos apresentados para o ensaio Pórtico1_b não contemplam a deformação residual em função da primeira etapa de ensaio (Pórtico1_a), para facilitar a comparação visual. Na Tabela 7.6, em que se apresentam as deformações máximas das armaduras para o ensaio Pórticol_b, as deformações residuais estão inclusas.

\section{Suspensão}

No ensaio da viga bi-apoiada, a deformação da armadura de suspensão se iniciou para a força aplicada de $25 \mathrm{kN}$. A curva "Força x Deformação" (Figura 7.37) apresentou comportamento linear até a força de $50 \mathrm{kN}$ a partir da qual a curva teve comportamento não linear com decréscimo contínuo da inclinação até a ruptura.

No ensaio do Pórtico1_a, a curva "Força x Deformação" tem comportamento aproximadamente bi-linear com mudança de inclinação ocorrendo para a força de $50 \mathrm{kN}$. As curvas traçadas para o ensaio da viga e do Pórtico1_a são bastante semelhantes, como se observa na Figura 7.37.

A deformação da armadura de suspensão se inicia pra a força de $50 \mathrm{kN}$ no ensaio do Pórtico1_b e aumenta linearmente com a força até 200 kN. No intervalo de $200 \mathrm{kN}$ a $300 \mathrm{kN}$ ocorre alternância de trechos de aumento de força e deformação intercalados por patamares em que a força se mantem constante e a deformação aumenta. A partir da força de $300 \mathrm{kN}$ observa-se uma tendência de crescimento linear da deformação até que cessa o acréscimo da força. 
Para o Pórtico2_b e Pórtico3, a armadura de suspensão inicia a se deformar consideravelmente a partir da força de $250 \mathrm{kN}$ e a curva tem comportamento perturbado, sem tendência clara, no intervalo de $250 \mathrm{kN}$ a $320 \mathrm{kN}$. Após isso a curva se apresenta linear até o fim do carregamento.

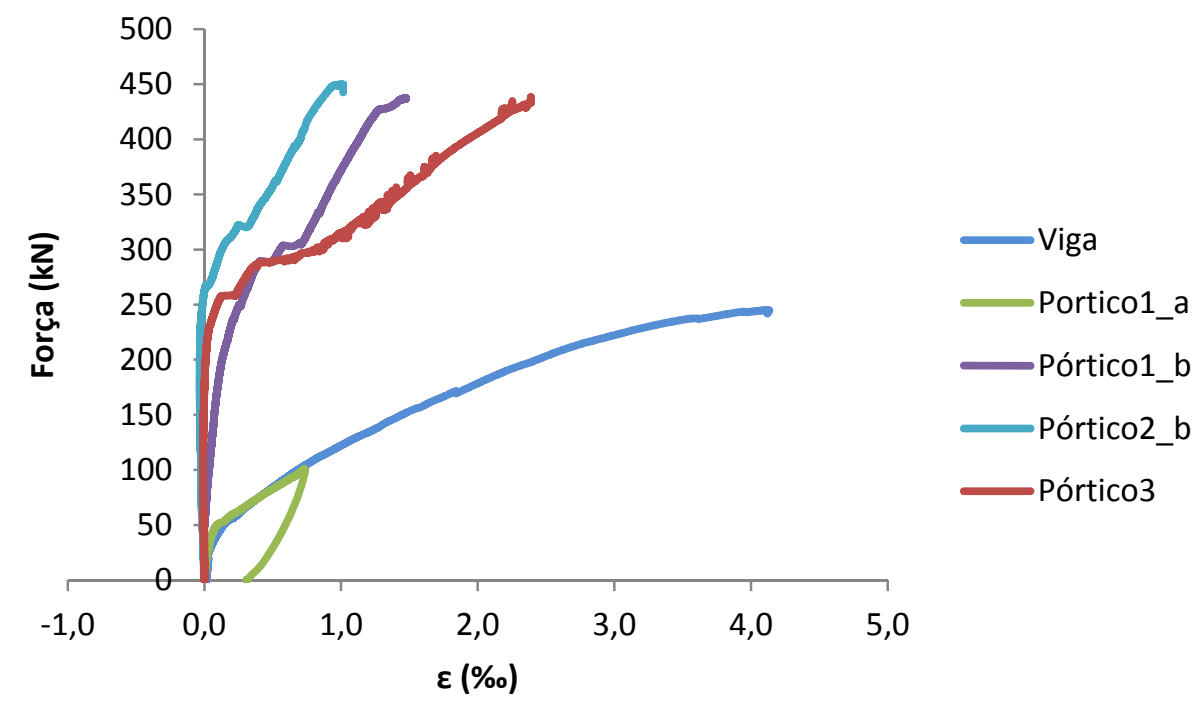

Figura 7.37 - Gráfico "Força x Deformação da armadura de suspensão".

\section{Tirante do dente}

No ensaio da viga, a deformação do tirante do dente se inicia com a força de $25 \mathrm{kN}$ e aumenta de forma não-linear com decréscimo da inclinação da curva "Força x Deformação" até a força de $50 \mathrm{kN}$ (Figura 7.38). Para este carregamento, ocorre um aumento da inclinação da curva que se aproxima da linearidade até a força de $170 \mathrm{kN}$. A partir desta força, a curva exibe comportamento não-linear com decréscimo da inclinação até a ruptura.

O início da deformação do tirante do dente ocorre para a força de $25 \mathrm{kN}$ no ensaio do Pórtico1_a . A curva "Força x Deformação" tem comportamento não-linear até 50 kN quando se percebe um aumento na inclinação que se mantem constante, após isso, até o descarregamento.

Na Figura 7.39, apresentam-se as curvas "Força x Deformação do tirante do dente" traçadas apenas para os ensaios dos pórticos. A retirada da curva correspondente à viga 
facilita a análise das curvas dos pórticos, pois nestes as armaduras apresentam deformações máximas semelhantes de modo que se pode utilizar uma escala horizontal mais adequada. Nota-se a semelhança grande que existe entre as curvas que podem ter seus comportamentos divididos em quatro trechos. Num primeiro trecho de $0 \mathrm{kN}$ a $100 \mathrm{kN}$ o comportamento é linear; de 100 kN a 230 kN o comportamento é não-linear com inclinação decrescente; entre 230 kN e 330 kN não se observa uma tendência clara no comportamento da curva; a partir da força de $300 \mathrm{kN}$ a curva tem comportamento linear até a interrupção do ensaio.

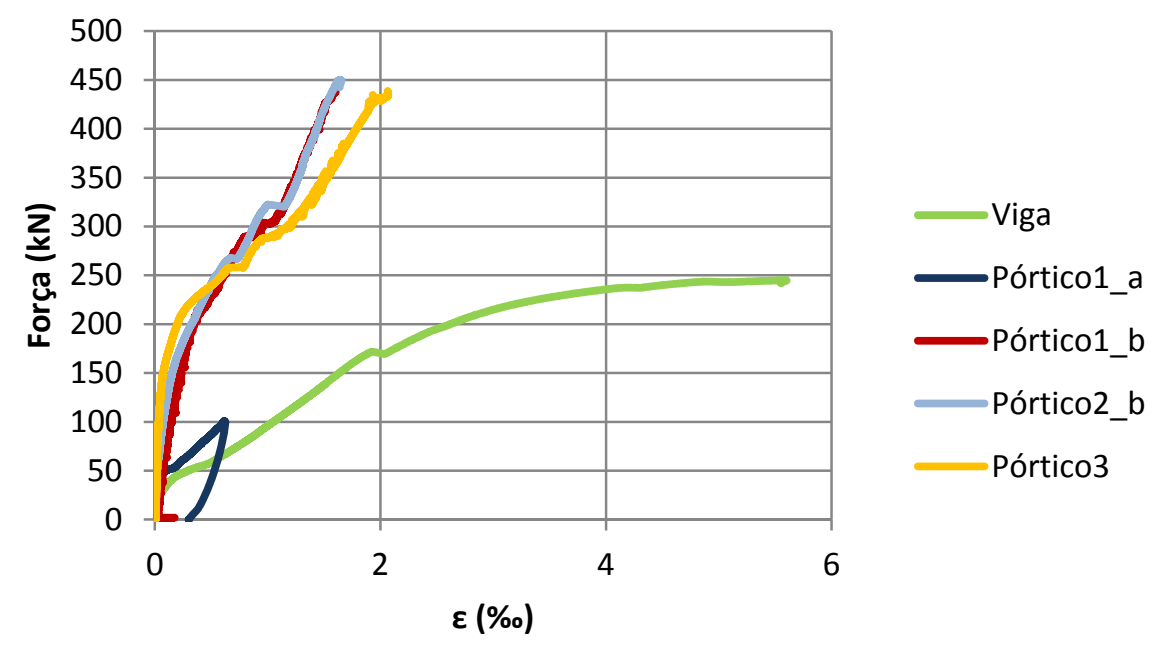

Figura 7.38 - Gráfico "Força x Deformação" da armadura do tirante do dente.

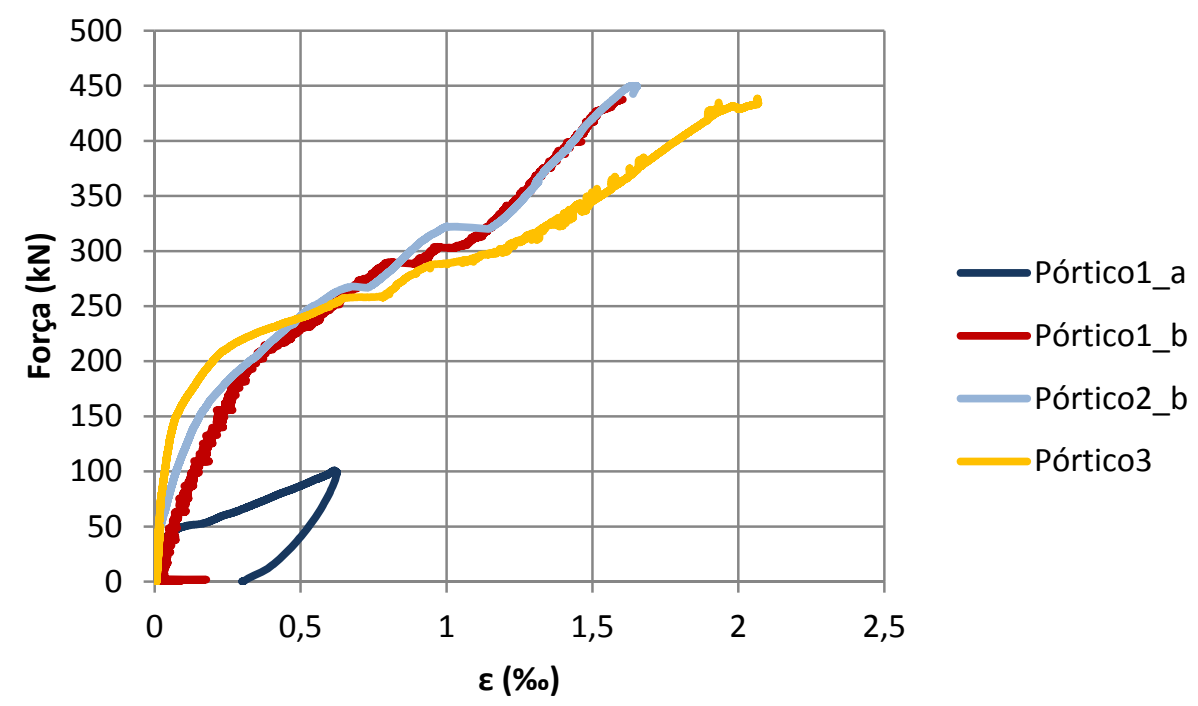

Figura 7.39 - Gráfico "Força x Deformação da armadura do tirante do dente" apenas dos ensaios dos pórticos. 


\section{Tirante do consolo}

No ensaio do Pórticol_a, a deformação do tirante do consolo se inicia pra a força de 20 kN. A curva "Força x Deformação" é não-linear com decréscimo de inclinação até a força de $50 \mathrm{kN}$ e deformação de $0,1 \%$. Entre as deformações de $0,1 \%$ e 0,15 \%o ocorre um patamar e após ele a inclinação aumenta e o comportamento da curva é linear até o descarregamento.

A curva "Força x Deformação" do Pórtico1_b é aproximadamente linear até a força de 200 kN. Após isso, se observa um segundo trecho linear com menor inclinação até a força de 280 kN. Entre 280 kN e 310 kN a curva oscila entre inclinação positiva e patamares e a partir da força de $310 \mathrm{kN}$ exibe comportamento linear até a ruptura.

As curvas correspondentes aos ensaios do Pórtico2_b e Pórtico3 têm um primeiro trecho aproximadamente linear de $0 \mathrm{kN}$ a $50 \mathrm{kN}$ e um segundo trecho linear com menor inclinação de 50 kN a 210 kN. Entre 210 kN e 320 kN há uma perturbação da curva e que se observa diminuição da deformação que pode estar relacionada a fissuração na região em que está posicionado o extensômetro ou deslizamento da armadura. Após isso, a curva volta a ter comportamento próximo a linearidade até a interrupção do ensaio.

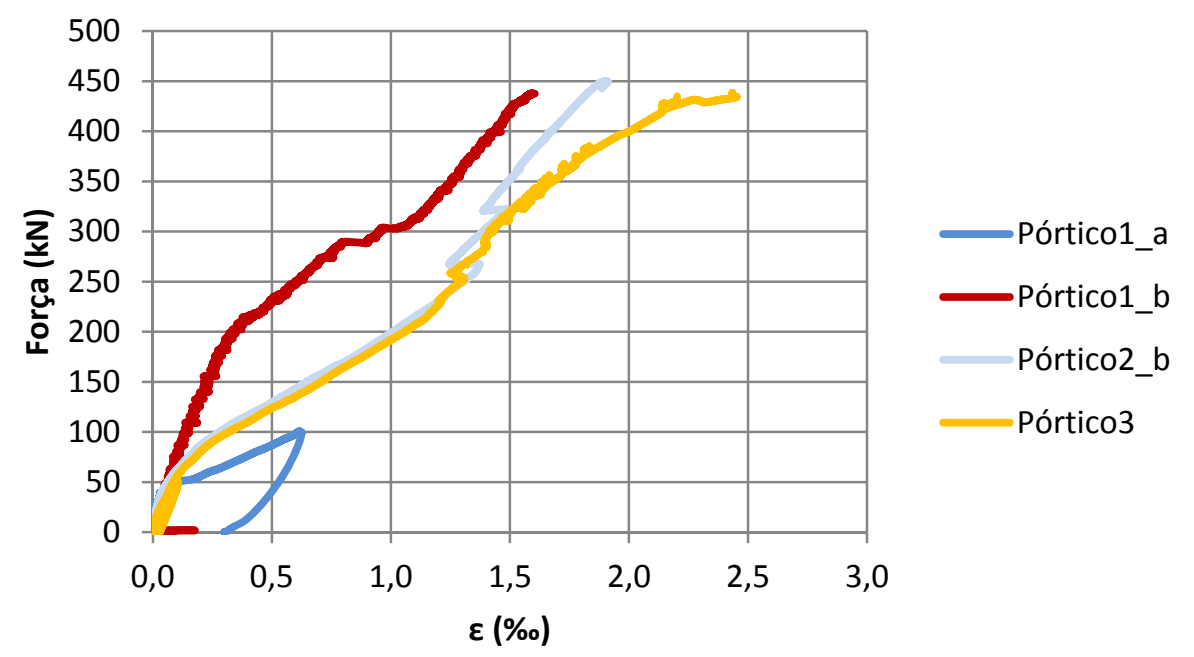

Figura 7.40 - Gráfico "Força x Deformação da armadura do tirante do consolo". 


\section{Armadura longitudinal inferior da viga}

$\mathrm{Na}$ Figura 7.41, observa-se que as curvas "Força $\mathrm{x}$ Deformação da armadura longitudinal inferior da viga" são bastante semelhantes para os ensaios da Viga e do Pórtico1_a, bem como são semelhantes as curvas para os ensaios do Pórtico1_b, Pórtico2_b e Pórtico3. Nos ensaios da Viga e do Pórtico1_a, a curva tem comportamento bi-linear com mudança de inclinação ocorrendo para a força de $20 \mathrm{kN}$.

Nos ensaios do Pórtico1 b, Pórtico2 b e Pórtico3, as curvas podem ser divididas em trechos aproximadamente lineares de $0 \mathrm{kN}$ a $50 \mathrm{kN}$, de $50 \mathrm{kN}$ a $350 \mathrm{kN}$ e de $350 \mathrm{kN}$ a $450 \mathrm{kN}$ com inclinação decrescendo com aumento da força. No caso do Pórtico3 (Figura 7.42), é notável um quarto trecho em que a deformação aumenta sem incremento de força para carregamento de aproximadamente $440 \mathrm{kN}$.

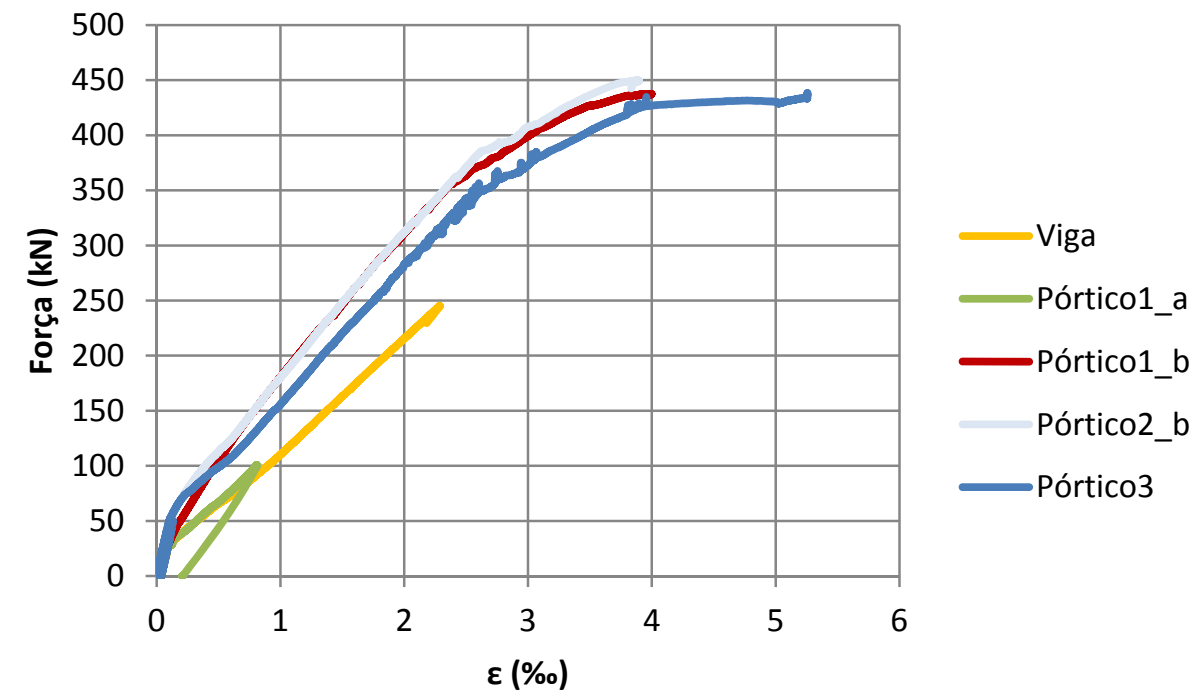

Figura 7.41 - Gráfico "Força x Deformação da armadura longitudinal inferior da viga". 


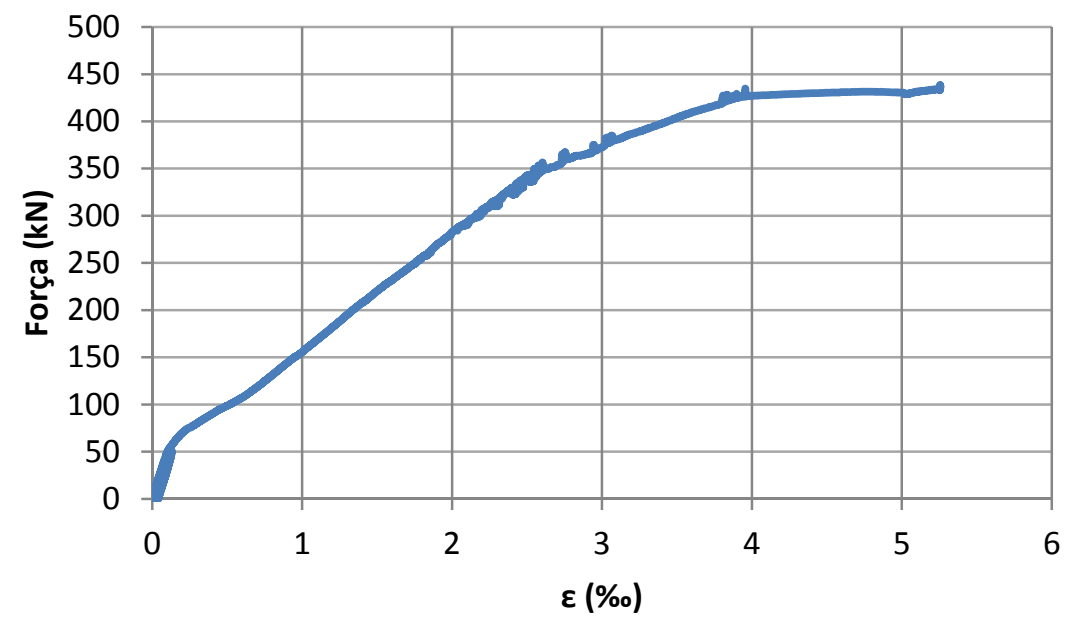

Figura 7.42 - Gráfico "Força x Deformação da armadura longitudinal inferior da viga", para o ensaio do Pórtico3.

\section{Armadura longitudinal superior da viga}

A curva "Força x Deformação" da armadura longitudinal superior da viga apresentou comportamento linear no ensaio da viga. A deformação foi negativa ao longo de todo o ensaio o que se observou também para o ensaio do Pórtico1_a.

Nos ensaios do Pórtico1_b, Pórtico2_b e Pórtico3, a armadura longitudinal superior da viga passou a ser tracionada. O comportamento geral das curvas "Força x Deformação" correspondentes a esses ensaios foi bastante semelhante e pode ser dividido em dois trechos lineares: o primeiro até aproximadamente $150 \mathrm{kN}$ e um segundo a partir de $250 \mathrm{kN}$.

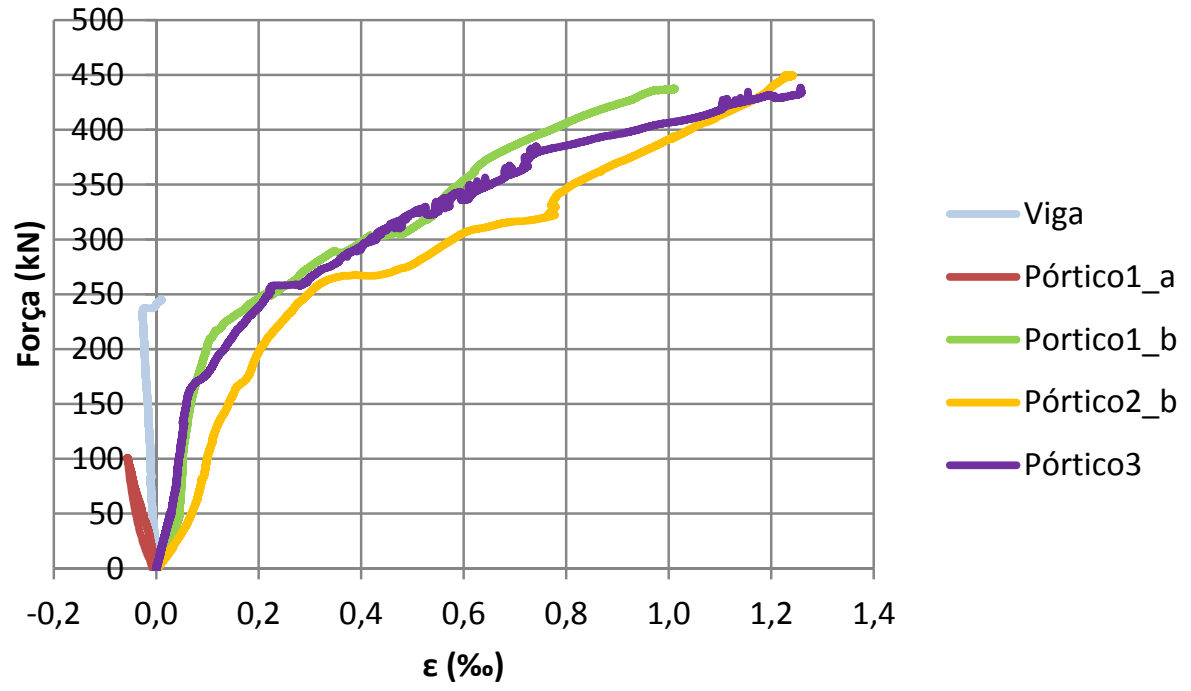

Figura 7.43 - Gráfico "Força x Deformação da armadura longitudinal superior da viga". 


\section{Armadura longitudinal do pilar - extensômetro superior}

No ensaio do Pórtico1_a, a deformação da armadura longitudinal do pilar obtida por meio do extensômetro superior foi inferior a 0,1 \% . Nos modelos reforçados houve maior solicitação da armadura. A curva "Força x Deformação" para estes modelos pode ser dividida em três trechos: de $0 \mathrm{kN}$ a $130 \mathrm{kN}$; de $130 \mathrm{kN}$ a $230 \mathrm{kN}$; de $230 \mathrm{kN}$ a $450 \mathrm{kN}$. Do primeiro para o segundo trecho ocorre diminuição da inclinação e do segundo para o terceiro um ligeiro aumento.

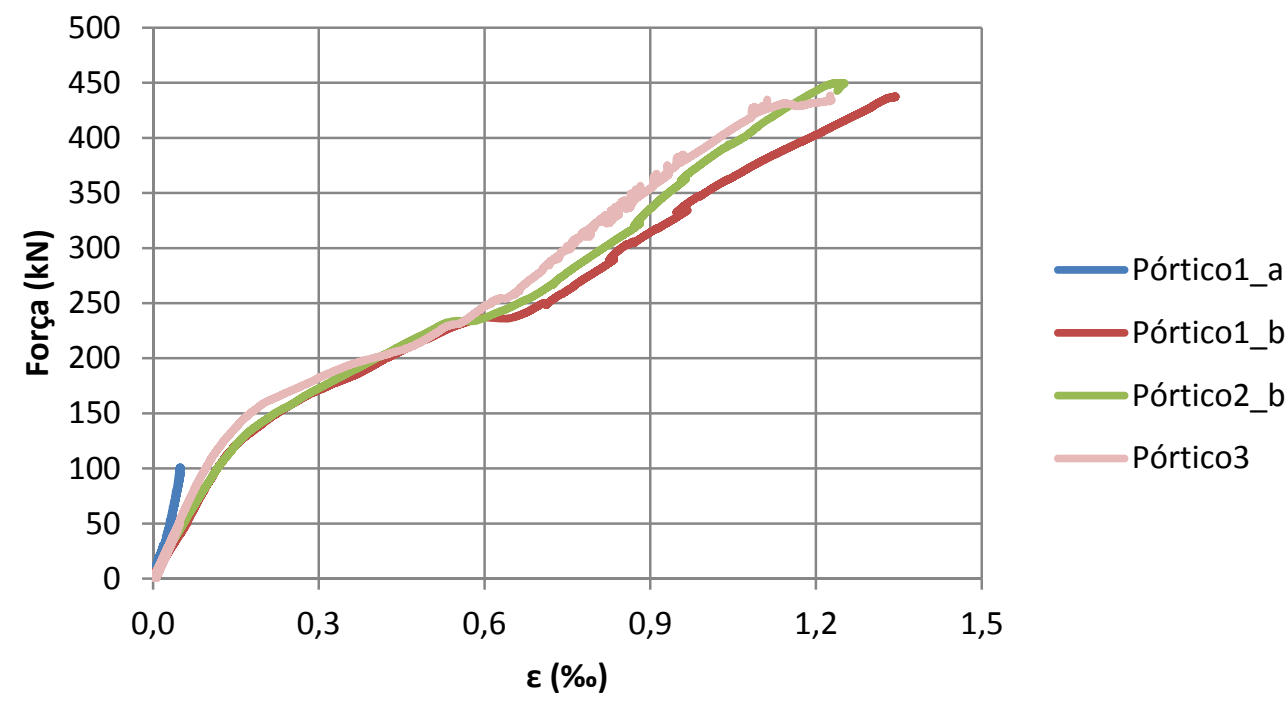

Figura 7.44 - Gráfico "Força x Deformação da armadura longitudinal do pilar", extensômetro superior.

\section{Armadura longitudinal do pilar - extensômetro inferior}

Em todos os ensaios, a armadura longitudinal do pilar obtida por meio do extensômetro inferior foi negativa (compressão). O comportamento das curvas "Força $\mathrm{x}$ Deformação", para o Pórtico1_a e para o Pórtico1_b foi linear. Nos ensaios do Pórtico2_b e Pórtico3 pode ser dividida em três trechos com mudança mais evidente de inclinação ocorrendo com forças aplicadas de $50 \mathrm{kN}$ e $200 \mathrm{kN}$. 


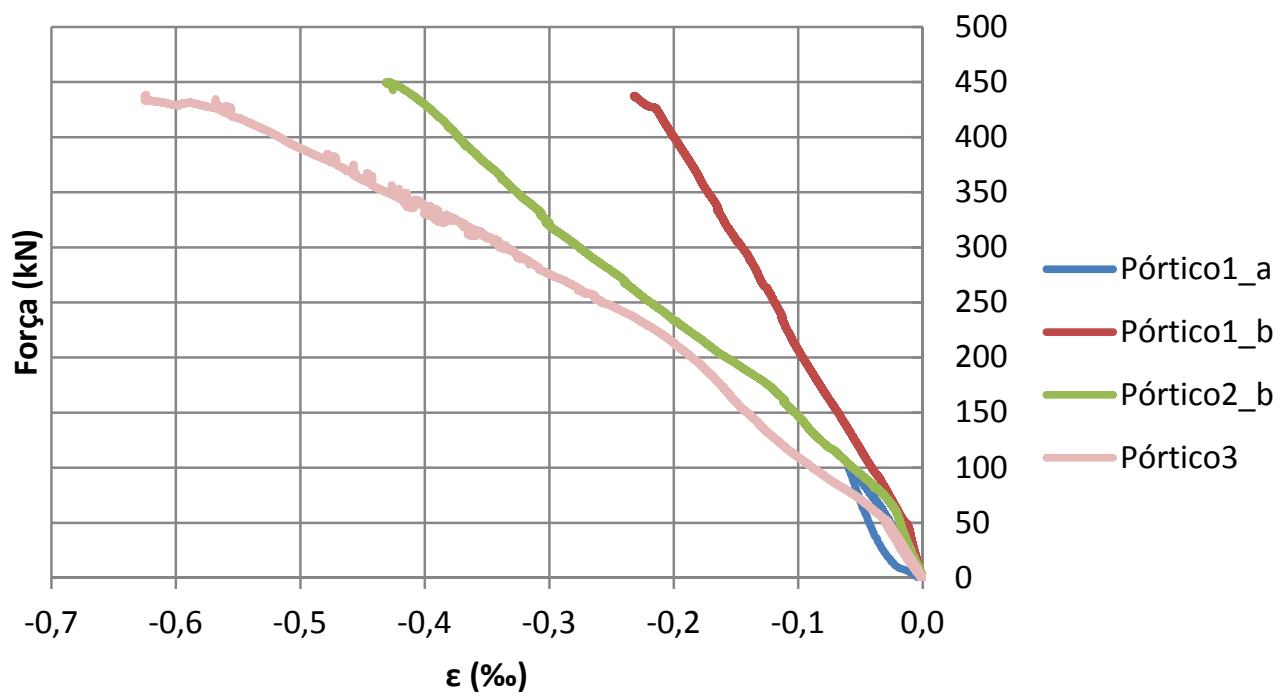

Figura 7.45 - Gráfico “Força x Deformação da armadura longitudinal do pilar”, extensômetro inferior.

\section{Laminados}

As curvas "Força x Deformação" dos laminados foram aproximadamente lineares para força acima de $50 \mathrm{kN}$. Nota-se que o comportamento linear é mais evidente para o ensaio do Pórtico1_b que havia sido submetido a carregamento prévio.

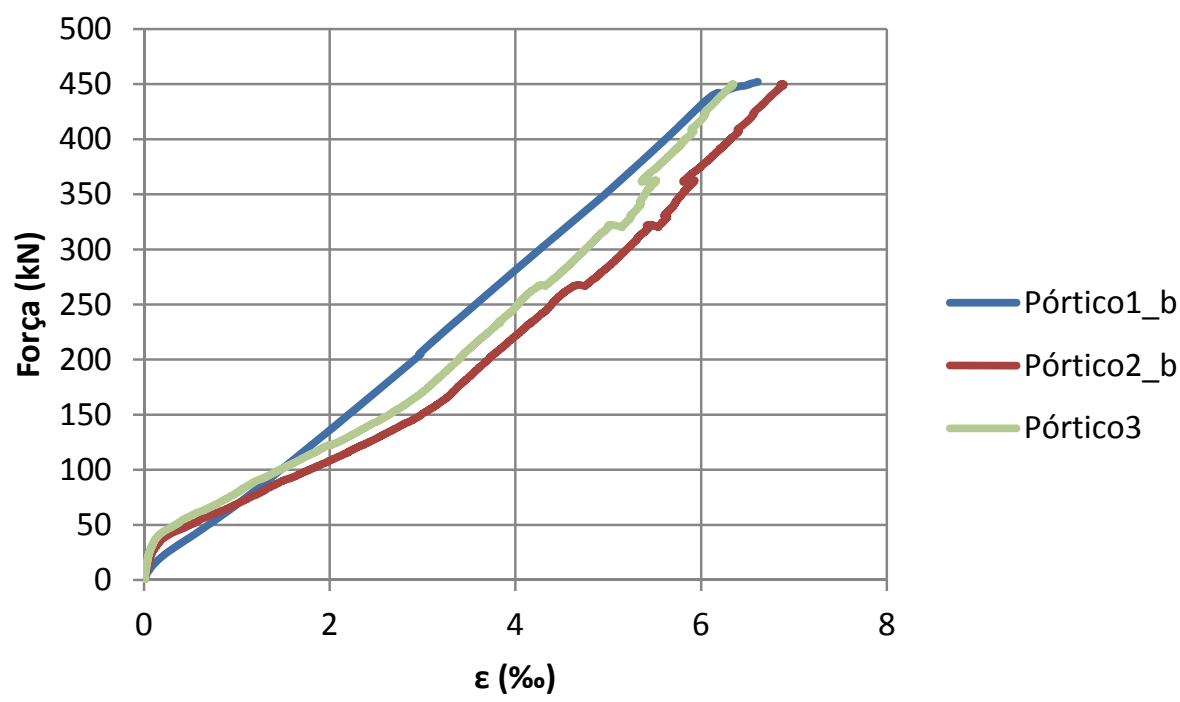

Figura 7.46 - Gráfico “Força x Deformação do Laminado1” (superior). 


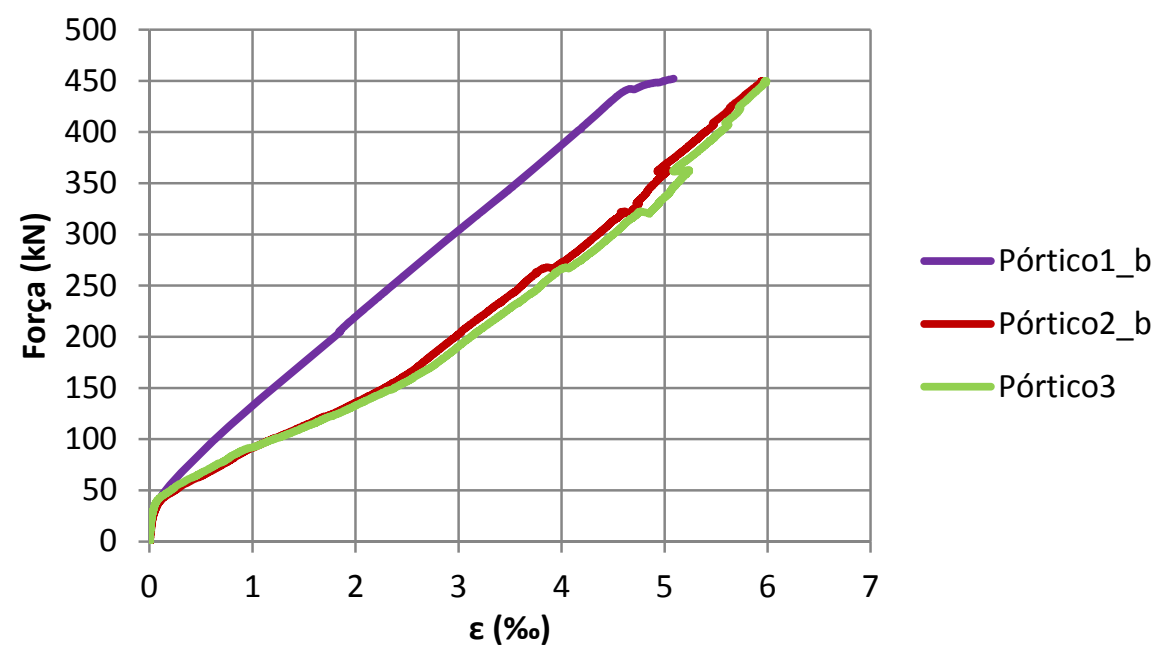

Figura 7.47 - Gráfico "Força x Deformação do Laminado2” (central).

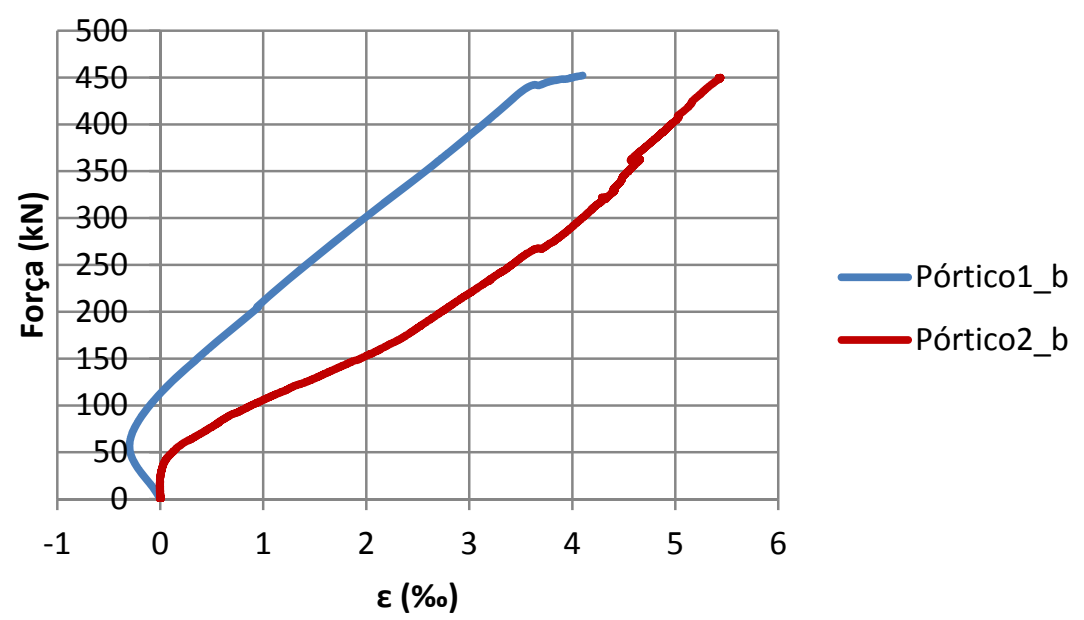

Figura 7.48 - Gráfico “Força x Deformação do Laminado3” (inferior).

$\mathrm{Na}$ Tabela 7.6, reúnem-se as deformações correspondentes às forças máximas apresentadas pelas armaduras instrumentadas. Destaca-se que as armaduras da viga do Pórtico3 apresentaram deformações superiores as dos outros modelos de pórtico. Os laminados apresentaram máxima deformação de 6,9 \%. A armadura que mais se deformou nos ensaios de pórticos foi a longitudinal inferior da viga que chegou a 5,3\%. No ensaio da viga, a armadura que apresentou maior deformação foi a do tirante do dente. O reforço promoveu a redução na solicitação de quase todas as armaduras instrumentadas. Excetuam-se as armaduras longitudinais da viga e do pilar (extensômetro superior) que apresentaram maiores deformação com o reforço, no entanto nenhuma delas apresentou escoamento. 
Tabela 7.6 - Resumo das máximas deformações apresentadas pelas armaduras instrumentadas.

\begin{tabular}{|c|c|c|c|c|c|}
\hline \multirow[b]{2}{*}{ Armadura } & \multicolumn{5}{|c|}{ Deformação (\%o) } \\
\hline & Viga & Pórtico1_a & Pórtico1_b & Pórtico2_b & Pórtico3 \\
\hline Suspensão & 4,132 & 0,723 & 1,781 & 1,013 & 2,390 \\
\hline Tirante do dente & 6,329 & 0,614 & 1,888 & 1,644 & 2,065 \\
\hline Tirante do consolo & - & 0,614 & 1,592 & 1,911 & 2,453 \\
\hline Longitudinal inferior (viga) & 2,287 & 0,809 & 4,199 & 3,861 & 5,257 \\
\hline Longitudinal superior (viga) & 0,024 & $-0,56$ & 1,387 & 1,242 & 1,260 \\
\hline Longitudinal superior (pilar) & - & 0,029 & 1,462 & 1,250 & 1,229 \\
\hline Longitudinal inferior (pilar) & - & $-0,059$ & $-0,231$ & $-0,431$ & $-0,625$ \\
\hline Laminado1 (superior) & - & - & 6,611 & 6,91 & 6,348 \\
\hline Laminado2 (central) & - & - & 5,087 & 5,962 & 5,988 \\
\hline Laminado3 (inferior) & - & - & 4,100 & 5,441 & - \\
\hline
\end{tabular}

\subsubsection{Rigidez das ligações}

Uma das desvantagens de optar por um pórtico como modelo de ensaio para estudo da ligação é a dificuldade na determinação do momento atuante na ligação e consequentemente na determinação da sua rigidez. Numa viga bi-apoiada com o carregamento aplicado como no ensaio (Figura 7.49), o momento no meio do vão pode ser calculado pela Equação 21.

$$
M_{\text {vão }}=\frac{F \cdot a}{2}
$$

Com os dados obtidos no ensaio da viga traçou-se a curva "Momento x Deformação da armadura longitudinal" apresentado na Figura 7.50. A curva tem comportamento aproximadamente bi-linear, deste modo, determinaram-se duas equações para relacionar momento e deformação: uma para momento até aproximadamente 20 kN.m e outra para momentos superiores a esse.

$$
\begin{aligned}
& M_{v \text { ão }}=199,76 \cdot \varepsilon_{l i} \\
& M_{v \text { ão }}=68,544 . \varepsilon_{l i}+11,262
\end{aligned}
$$




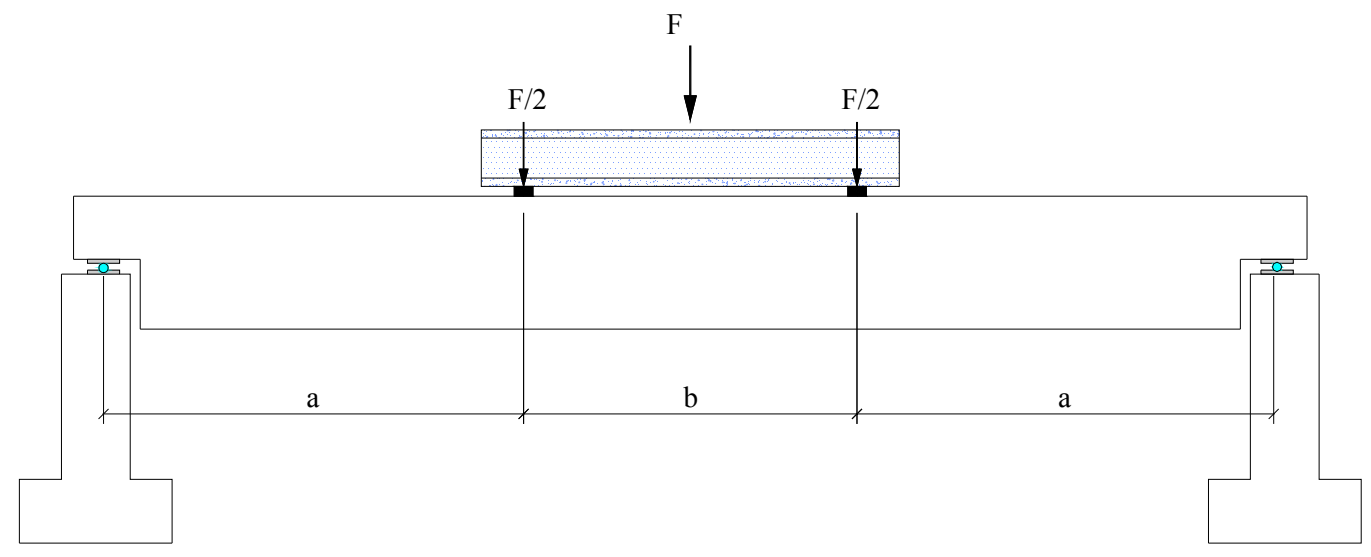

Figura 7.49 - Esquema estático do ensaio da Viga.

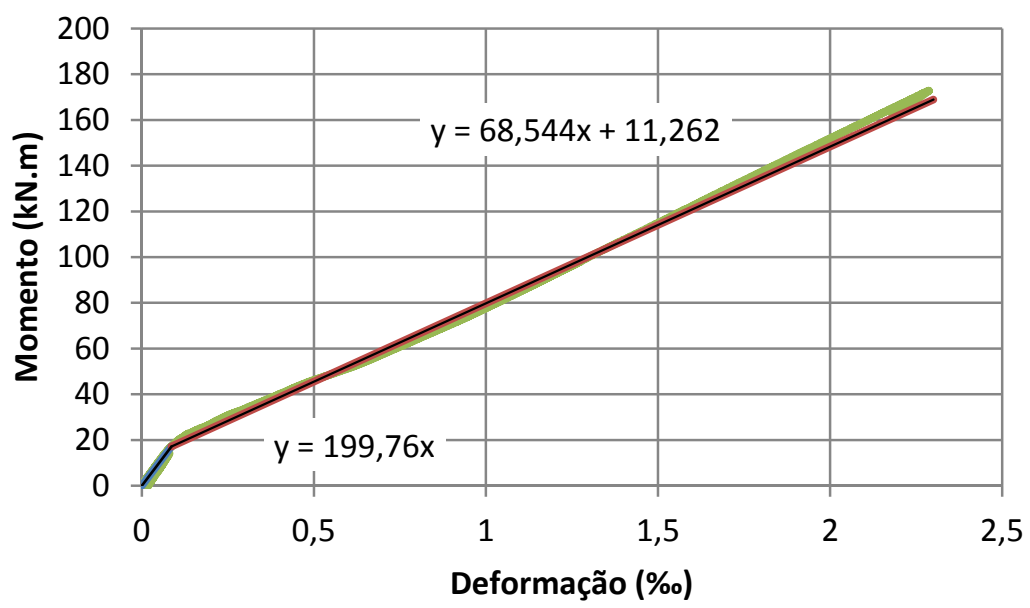

Figura 7.50 - Curva "Momento x deformação da armadura longitudinal da viga" e aproximação bi-linear.

Analisemos agora o pórtico da Figura 7.51 submetido a duas forças P/2. Independente das rigidezes da base e das ligações viga pilar (considerando simetria do problema) o diagrama de esforço cortante se apresentará como o da Figura 7.52 e o valor de H poderá variar, mas não o de $\mathrm{V}$ que será sempre $\mathrm{P} / 2$. O diagrama de momento será como o da Figura 7.53, em que Ma, Mb, Mc e Md irão variar conforme variem as rigidezes das bases e das ligações, mas a relação entre Md e Mc será mantida:

$$
M_{c}=M_{d}-V . c
$$

Com base no que foi exposto, determinou-se o momento a meio vão da viga dos pórticos usando as Equações 22 e 23 e o momento na ligação, pela equação 24 . 


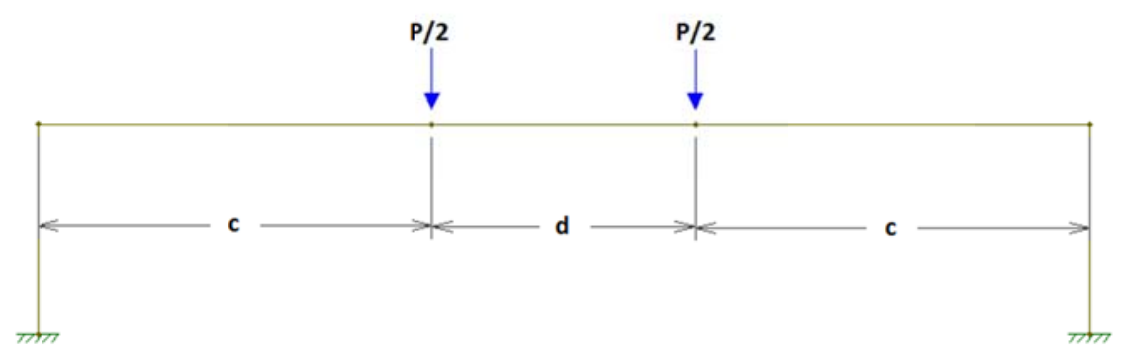

Figura 7.51 - Esquema estático do carregamento de um pórtico.

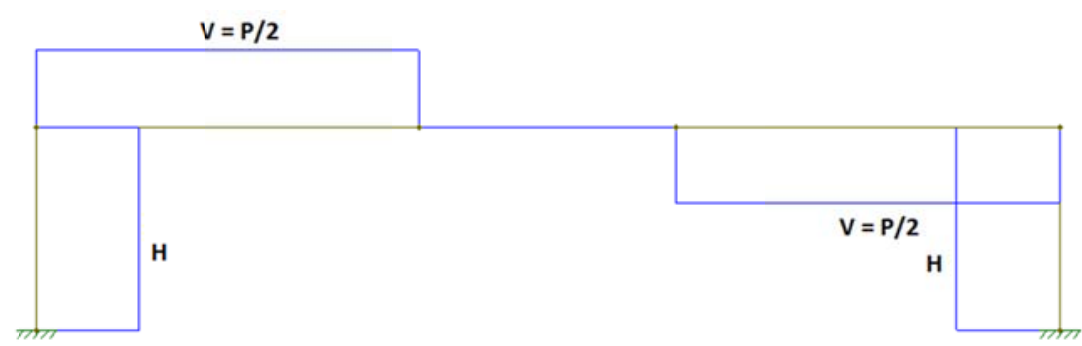

Figura 7.52 - Diagrama de esforço cortante correspondente ao pórtico da Figura 7.51.

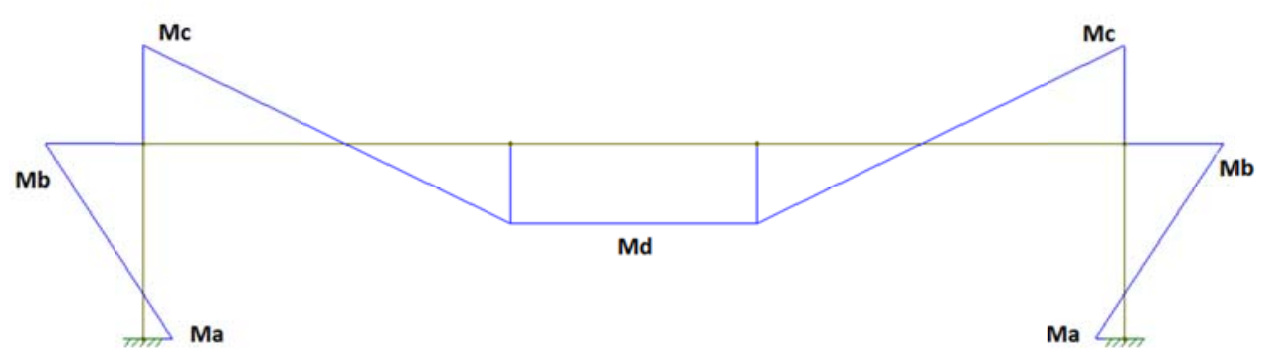

Figura 7.53 - Diagrama de momento correspondente ao pórtico da Figura 7.51.

Nos pórticos, a rotação na ligação foi determinada de duas maneiras distintas: pelo deslocamento relativo vertical entre dente e consolo (rotação em relação ao eixo horizontal, $\left.\phi_{\mathrm{h}}\right)$ e pelo deslocamento horizontal relativo entre viga e pilar (rotação em relação ao eixo vertical, $\phi_{\mathrm{v}}$ ). Tanto a rotação horizontal quanto a vertical utilizadas para o traçado dos gráficos das Figura 7.54 a Figura 7.56 são valores médios das rotações da ligação à esquerda e da direita calculados por meio das equações 25 e 26 respectivamente.

$$
\begin{aligned}
& \phi_{h}=\left[\left(\frac{T D 2-T D 3}{100}\right)+\left(\frac{T D 6-T D 7}{100}\right)\right]: 2 \\
& \phi_{v}=\left[\left(\frac{T D 1-T D 4}{360}\right)+\left(\frac{T D 5-T D 8}{360}\right)\right]: 2
\end{aligned}
$$


As siglas TD1 a TD8 se referem aos transdutores de deslocamento cujo posicionamento está definido na Figura 7.24.

Na Figura 7.54, apresentam-se as curvas "Momento x Rotação horizontal” traçadas com base nos resultados dos ensaios dos pórticos. O Pórtico1_a apresentou, em suas ligações, rotações muito superiores aos demais. Para uma melhor comparação entre as curvas correspondentes aos pórticos com ligações reforçadas, apresenta-se o gráfico da Figura 7.55 sem a curva do Pórtico1_a. As curvas praticamente se superpõem. Ressalta-se que elas correspondem a apenas parte dos ensaios. Em todos os ensaios se observou um comportamento inconsistente dos transdutores de deslocamento a partir de determinado nível de carregamento, provavelmente em função de fissuração na região de sua fixação. Os valores das inclinações iniciais destas curvas, que representam as rigidezes das ligações, são apresentados na Tabela 7.7.

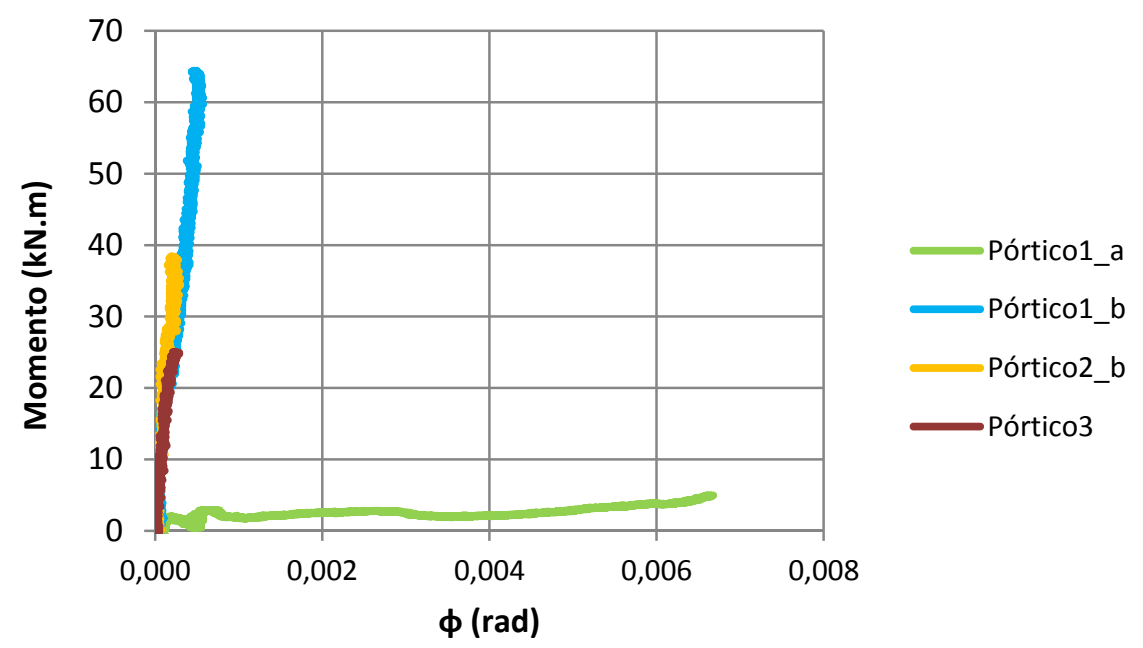

Figura 7.54 - Curvas "Momento x Rotação" calculada com base nos deslocamentos horizontais relativos na região da ligação. 


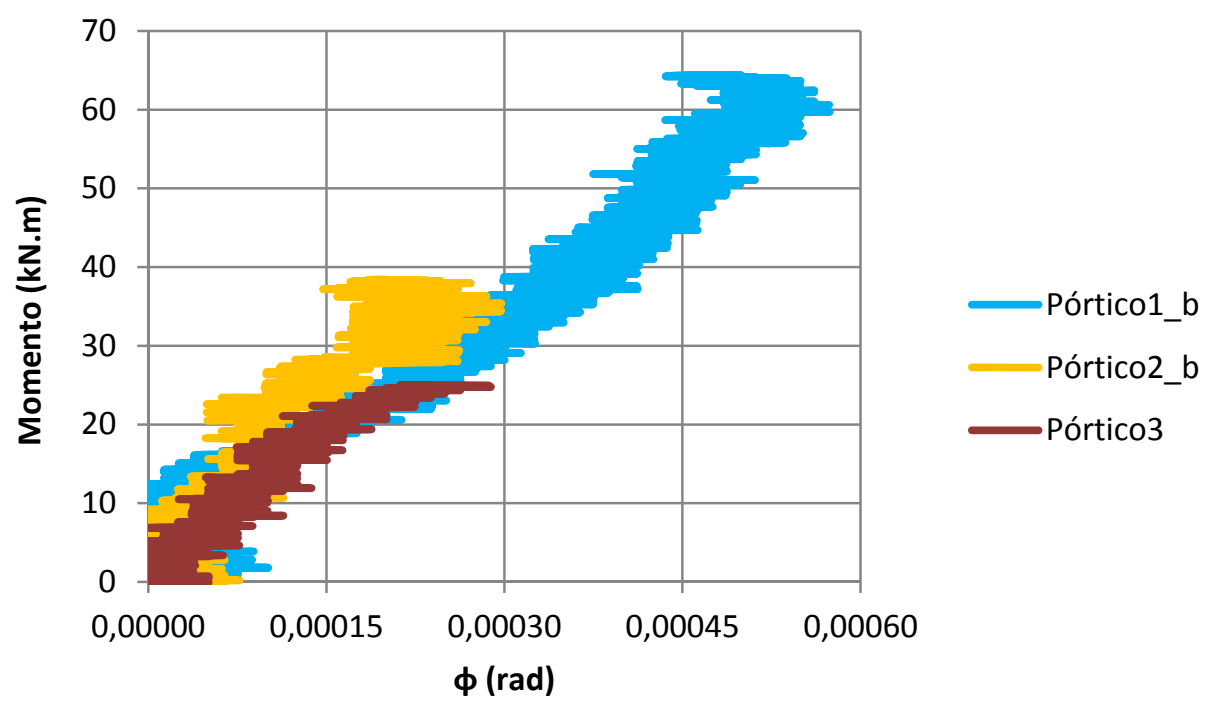

Figura 7.55 - Curvas "Momento x Rotação" calculada com base nos deslocamentos horizontais relativos na região da ligação somente para os pórticos com ligações reforçadas.

Na Figura 7.56 e Figura 7.57, apresentam-se as curvas "Momento x Rotação vertical” traçadas com base nos resultados dos ensaios dos pórticos. Justifica-se a apresentação da Figura 7.57 mais uma vez para facilitar a comparação das curvas correspondentes aos pórticos com ligações reforçadas que tiveram comportamento diferente do Pórticol_a. No gráfico da Figura 7.57, a curva correspondente ao Pórtico2_b tem inclinação inferior às demais, ao contrário do que se observa na Figura 7.55 em que a mesma curva parece ter uma inclinação maior. O valor da rigidez inicial da ligação do Pórtico2_b, calculado por regressão linear com limite da curva para o momento de 5 kN.m (Tabela 7.7), é cerca de um terço das demais. Analisando-se separadamente as curvas "Momento x Rotação vertical" das ligações do Pórtico2_b (Figura 7.58), nota-se que a ligação da direita é muito mais deformável que a da esquerda. Talvez tenha havido mau funcionamento dos transdutores com base nos quais foi calculada a rotação daquela ligação, ou tenha havido uma acomodação na ligação direita pela existência de alguma folga mal preenchida entre viga e pilar. A despeito da razão, considerase discutível o valor da rigidez de $62216 \mathrm{kN} . \mathrm{m} / \mathrm{rad}$. 


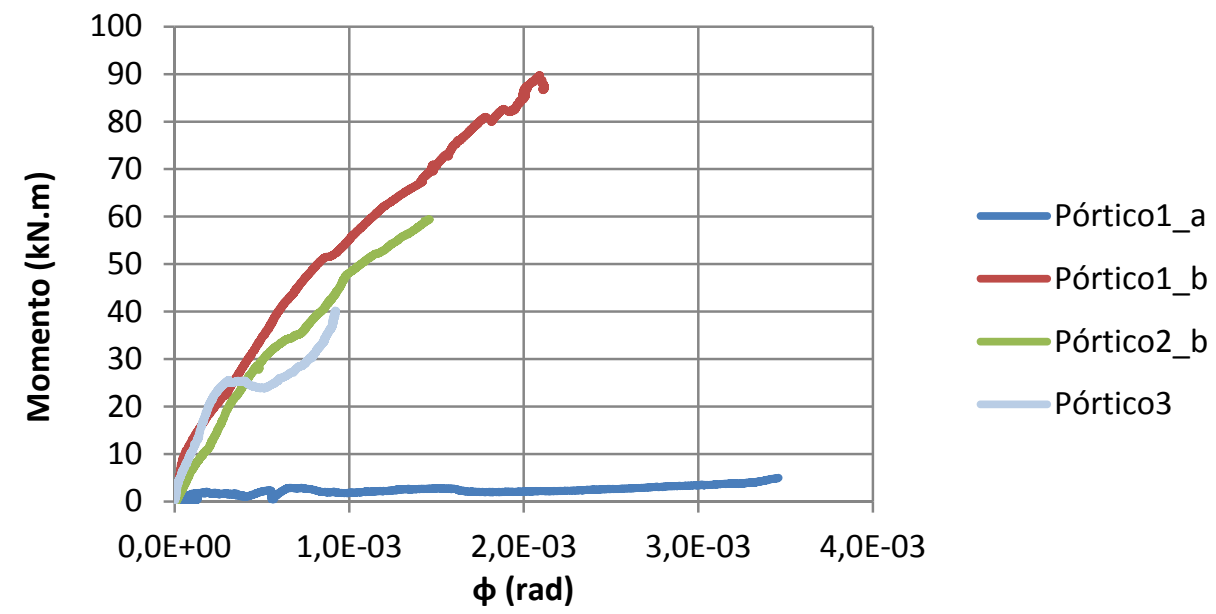

Figura 7.56 - Curvas "Momento x Rotação" calculada com base nos deslocamentos verticais relativos na região da ligação.

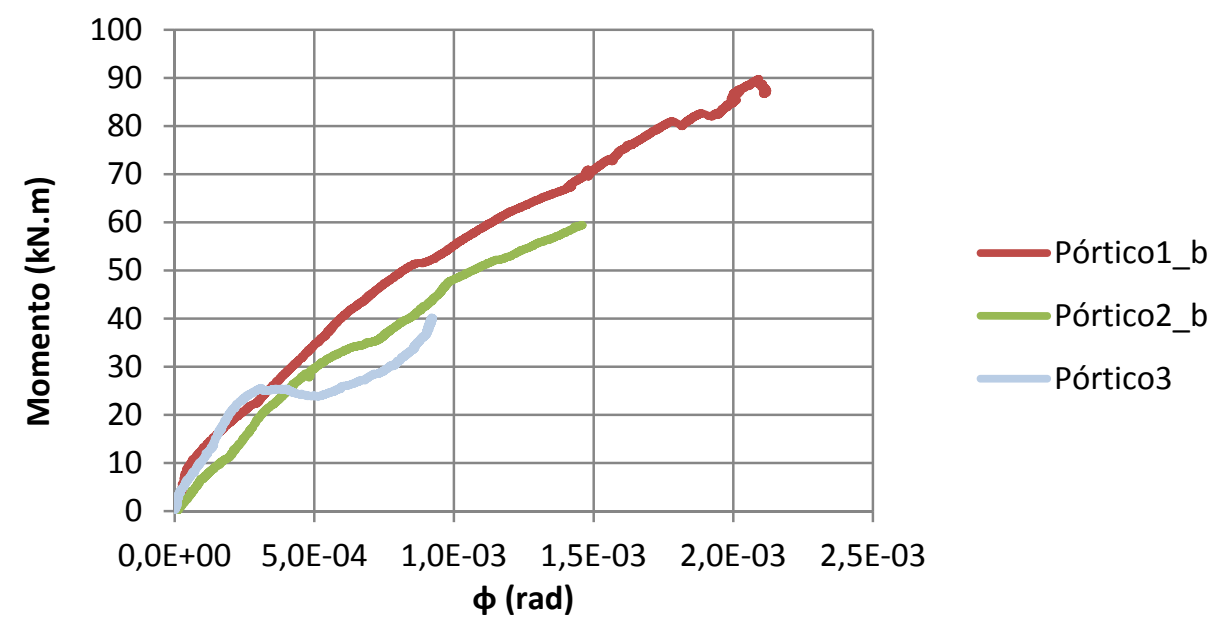

Figura 7.57 - Curvas "Momento x Rotação" calculada com base nos deslocamentos verticais relativos na região da ligação, somente dos pórticos com ligações reforçadas.
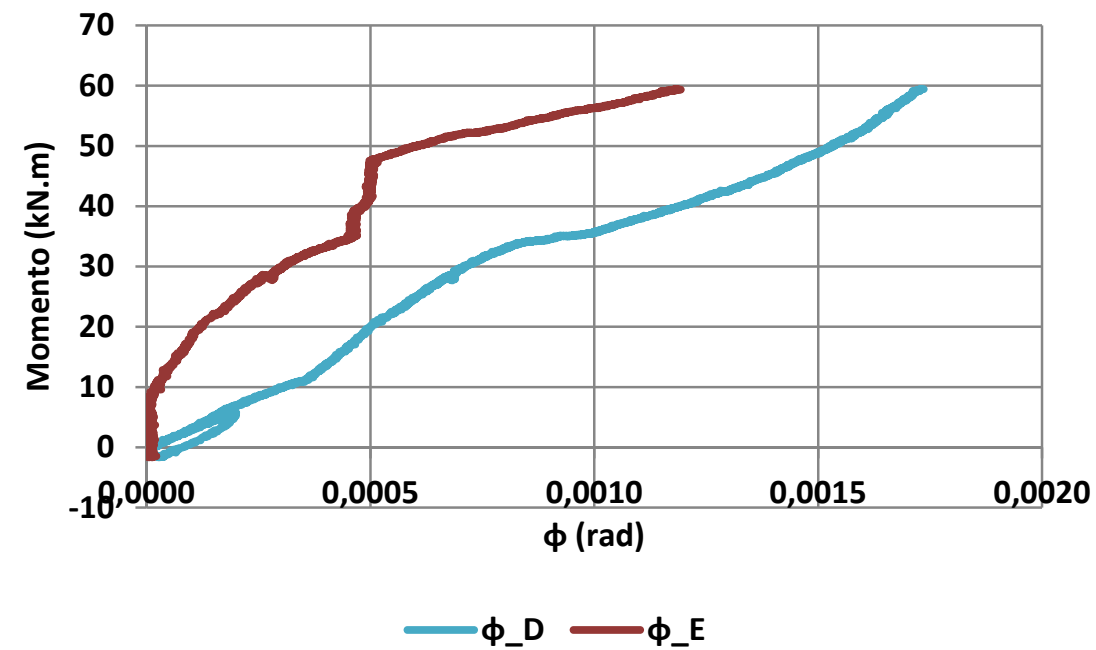

Figura 7.58 - Curvas "Momento x Rotação" calculada com base nos deslocamentos verticais relativos na região das ligações esquerda e direita, para Pórtico2_b. 
Apresenta-se na Figura 7.59 as curvas "Força x Deslocamento" a meio vão para todos os ensaios realizados. $\mathrm{Na}$ análise da rigidez a flexão de ligações, é mais usual e apropriada a avaliação de curvas "Momento x Rotação" como aquelas que discutimos, entretanto consideramos que a análise das curvas "Força x Deslocamento" é interessante para a avaliação da influência da rigidez da ligação no comportamento da estrutura, além de podermos incluir o resultado do ensaio da viga na comparação. Assim sendo, determinou-se a inclinação inicial das curvas apresentadas na Figura 7.59 que são apresentadas na Tabela 7.7.

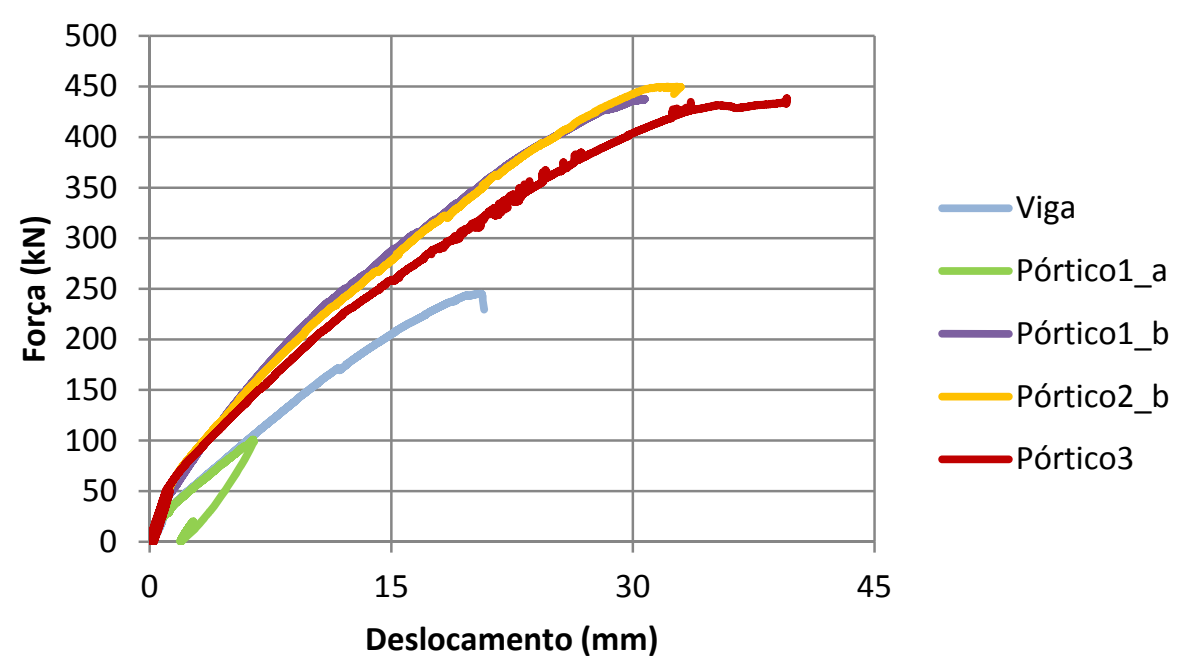

Figura 7.59 - Curvas "Força x Deslocamento".

O reforço das ligações promoveu o aumento da inclinação de $27 \%$, 49\% e $68 \%$. É natural que o aumento tenha sido menor para o Pórtico1_b que para os outros também reforçados uma vez que a viga fissurada apresentava menor rigidez o que obviamente influenciaria no deslocamento. Embora a rigidez da ligação tenha apresentado um incremento muito expressivo com o reforço, na relação "força x deslocamento" percebe-se uma alteração mais discreta. Há que se notar que o aumento da rigidez da ligação reflete o efeito do reforço na deformação daquela região especifica. Na curva "força x deslocamento" o deslocamento é função das deformações que ocorrem ao longo de toda a estrutura. 
Tabela 7.7 - Valores indicativos das rigidezes das ligações.

\begin{tabular}{cccccc} 
& \multicolumn{4}{c}{ Rigidez/inclinação inicial } \\
\hline Relação & Viga & Pórtico1_a & Pórtico1_b & Pórtico2_b & Pórtico3 \\
\hline Força x deslocamento $(\mathrm{kN} / \mathrm{mm})$ & 25,9 & 31,9 & 40,4 & 47,5 & 53,7 \\
Momento x $\phi \mathrm{h}(\mathrm{kN} . \mathrm{m} / \mathrm{rad})$ & - & 1140 & 270735 & 332936 & 256424 \\
Momento x $\phi \mathrm{v}(\mathrm{kN} . \mathrm{m} / \mathrm{rad})$ & - & 955 & 172968 & $\mathbf{6 2 2 1 6}$ & 176581 \\
\hline
\end{tabular}

\subsection{Simulação numérica do ensaio estático}

Os modelos numéricos para simulação dos ensaios principais foram gerados com base naquele utilizado para simulação do Ensaio-Piloto, descrito no Item 6.6. A simulação numérica foi realizada com uso do pacote computacional Diana. Adotaram-se modelos tridimensionais (Figura 7.60) nos quais se considerou a simetria em relação ao eixo longitudinal. Utilizaram-se nos mesmos elementos finitos para representação da viga, dos pilares e das interfaces (somente na simulação dos pórticos) e mesmos modelos constitutivos para os materiais. Armadura e laminados foram inseridos no modelo por meio do recurso Embedded Reinforcement. Não cabe discorrer novamente sobre o que já foi justificado anteriormente no Item 6.6 de modo que neste Item discutem-se apenas a alteração da restrição imposta nas bases dos pilares e os valores adotados para os parâmetros que são apresentados no Quadro 7.1, para o modelo numérico da viga, e no Quadro 7.2, para os modelos numéricos dos pórticos. Destaca-se que o recurso phased foi necessário somente para simulação do ensaio do Pórtico1 que foi o único realizado em duas fases.
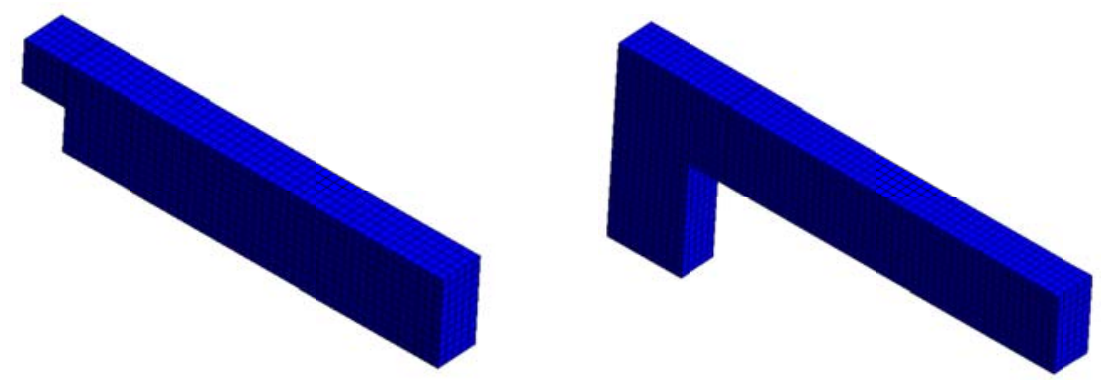

Figura 7.60 - Modelo tridimensional da viga (à esquerda) e do pórtico (à direita). 


\section{Módulo de elasticidade e energia de fratura}

A princípio, usou-se, na simulação numérica, o módulo de elasticidade obtido experimentalmente. No caso da viga, a média dos três ensaios realizados no dia 16/02/2012 (42 GPa) e para os pórticos a média dos demais ensaios apresentados na Tabela 7.2 (42 GPa). A energia de fratura foi determinada de acordo com a Equação 20 do CEB-FIP Model Code (1990). Na fase de avaliação do modelo numérico, buscava-se a proximidade entre as curvas "Força x Deslocamento" numérica e experimental. Assim como observado no caso da simulação do Ensaio-Piloto, o modelo numérico se apresentou mais rígido. A maior rigidez do modelo numérico foi observada em trabalhos como os de Canha (2004) e Pagnussat (2011) que adotaram reduções no módulo de elasticidade e na energia de fratura visando o ajuste do modelo numérico. Para determinar o percentual de redução nesses parâmetros que conduzisse ao ajuste do modelo numérico, decidiu-se realizar a simulação de um ensaio de fratura.

Nos ensaios experimentais de fratura, foram usados dois modelos com $500 \mathrm{~mm}$ de comprimento $150 \mathrm{~mm}$ de largura e $150 \mathrm{~mm}$ de altura. $O$ entalhe central tinha $4 \mathrm{~mm}$ de espessura e $30 \mathrm{~mm}$ de profundidade. $\mathrm{O}$ vão entre os apoios foi de $450 \mathrm{~mm}$. A força foi aplicada na seção central do modelo (Figura 7.61), sob controle da abertura do entalhe, a uma velocidade de $0,0001 \mathrm{~mm} / \mathrm{s}$. Na Figura 7.62, observam-se as curvas experimentais "Força $\mathrm{x}$ Abertura do entalhe". Na Figura 7.63, à esquerda, observam-se as curvas "Força x Abertura do entalhe" numérica e experimental. Ressalta-se que o modelo numérico foi elaborado com os mesmos parâmetros dos modelos dos pórticos. Nota-se na Figura 7.63, à esquerda, que também este modelo numérico se mostrou mais rígido que o experimental e como ele é constituído apenas de concreto justifica-se a necessidade de ajustar suas propriedades. $\mathrm{Na}$ Figura 7.63, à direita, apresentam-se as curvas "Força x Abertura do entalhe" experimental e numérica, neste caso com módulo de elasticidade e energia de fratura reduzidos a $78 \%$ dos valores experimentais, que conduziram a um bom resultado. 

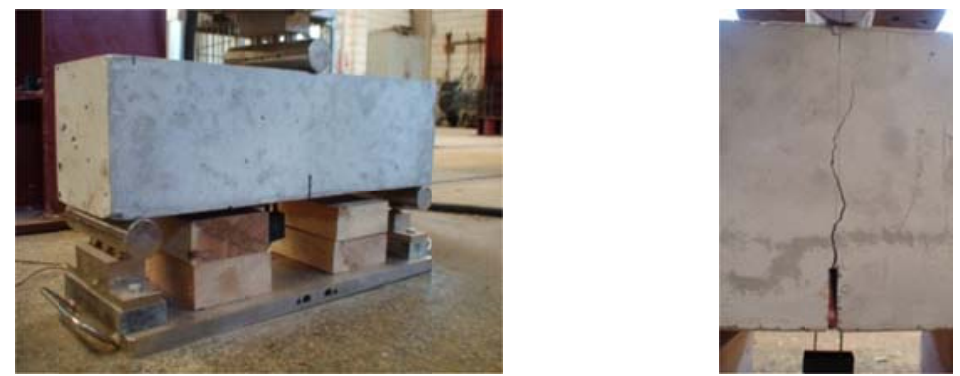

Figura 7.61 - Montagem do ensaio, à esquerda e abertura da fissura na iminência da ruptura do modelo, à direita.

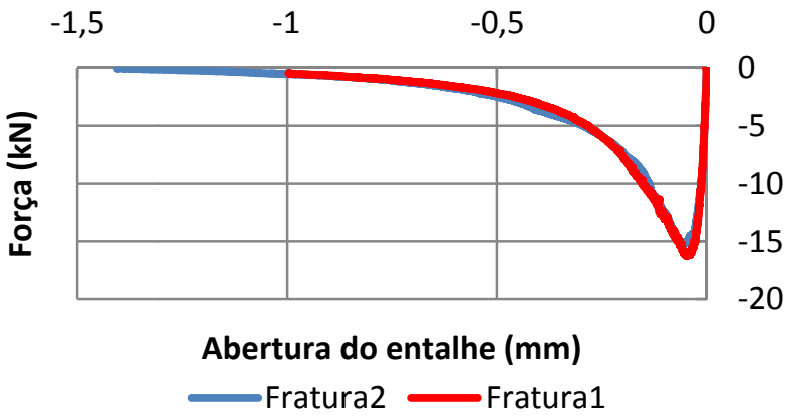

Figura 7.62 - Curvas "Força x Abertura do entalhe" experimentais, para os dois modelos ensaiados.
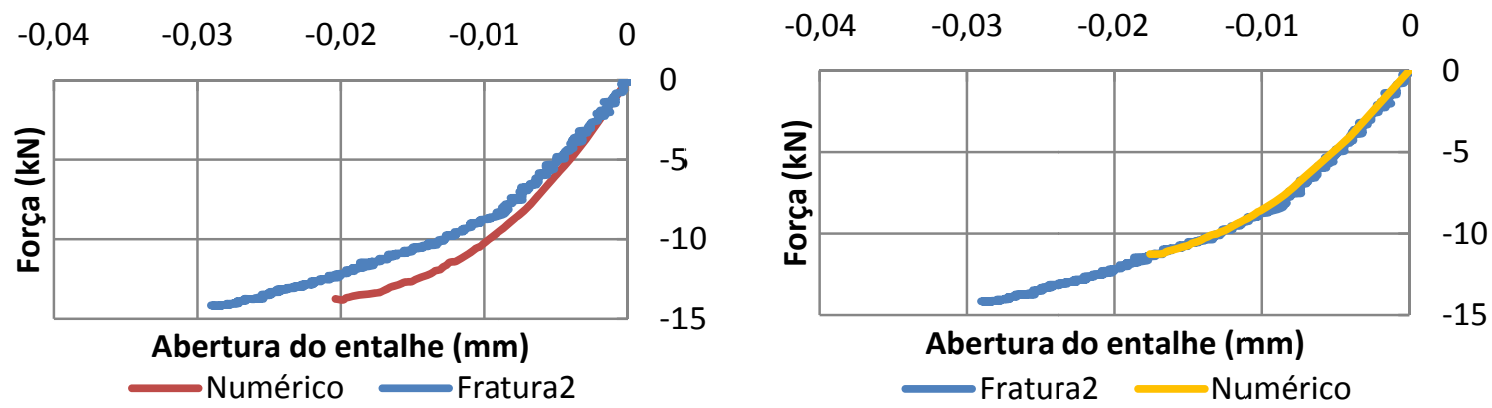

Figura 7.63 - Trecho inicial das curvas "Força x Abertura do entalhe", experimental e numérica antes dos ajustes das propriedades do concreto (à esquerda) e após os ajustes (á direita).

A redução a $78 \%$ do módulo de elasticidade e da energia de fratura foi empregada em novas simulações dos ensaios principais, contudo a aproximação entre os resultados experimentais e numéricos ainda não era satisfatória de modo que se decidiu alterar as restrições impostas ao modelo, o que se discute adiante.

\section{Apoios elásticos}

Como mencionado anteriormente, mesmo após a redução das propriedades do concreto, os modelos numéricos se mantinham mais rígidos que os experimentais. Isso e as análises dos ensaios dinâmicos apresentadas no Item 7.11 levaram a conclusão que as condições de apoio simples e engaste não representavam o que de fato ocorria nos ensaios 
experimentais da viga e dos pórticos. Sendo assim, ao invés de empregar restrições aos deslocamentos verticais no apoio da viga e aos deslocamentos verticais e horizontais nos nós da base do pilar, utilizaram-se apoios elásticos cujos valores são apresentados no Quadro 7.2 e Quadro 7.3. Esses valores foram aplicados a cada nó do apoio da viga e da base do pilar de modo que para obter as rigidezes vertical e horizontal resultantes é necessário multiplicar os coeficientes de molas dos Quadro 7.2 e Quadro 7.3 pelo número de nós que os compõem. Deste modo, a rigidez vertical do apoio da viga é $2200 \mathrm{~N} / \mathrm{mm}(=200 \times 11)$. A rigidez vertical resultante na base do pilar é $669700 \mathrm{~N} / \mathrm{mm}(=3700 \times 181)$ e a rigidez horizontal resultante é $9050 \mathrm{~N} / \mathrm{mm}$ (= $50 \times 181)$. O fato de utilizar apoios elásticos verticais implica em haver também a possibilidade de rotação na base do pilar.

\section{Rigidezes tangenciais e normais das interfaces}

Para as rigidezes tangenciais de todas as interfaces e normal da interface vertical superior foram adotados valores desprezíveis. Calculou-se a rigidez normal da interface horizontal dividindo-se o coeficiente angular da curva apresentada na Figura 7.8 (328450 $\mathrm{N} / \mathrm{mm}$ ) pela área da almofada de apoio $\left(145 \times 200 \mathrm{~mm}^{2}\right)$ o que resultou no valor de $11,3 \mathrm{~N} /$ $\mathrm{mm}^{3}$. A rigidez normal da interface vertical inferior foi calculada dividindo-se o módulo de elasticidade do graute $\left(29698 \mathrm{~N} / \mathrm{mm}^{2}\right.$ para os pórticos 1 e 2 e $28833 \mathrm{~N} / \mathrm{mm}^{2}$ para o pórtico 3) pela espessura da junta entre o consolo e a viga $(15 \mathrm{~mm})$.

\section{Demais parâmetros}

Para as armaduras, adotaram-se os valores de tensão de escoamento e módulo de elasticidade determinados experimentalmente, apresentados na Tabela 7.1. Para o laminado, adotou-se o módulo de elasticidade nominal (Tabela 6.7). Usaram-se as resistências do concreto à compressão e à tração determinadas experimentalmente. Para a viga, a média dos três ensaios realizados no dia 16/02/2012 e para os pórticos a média dos demais ensaios apresentados na Tabela 7.2. 
Quadro 7.2 - Resumo dos parâmetros utilizados na simulação numérica do modelo Viga.

\begin{tabular}{|c|c|c|c|}
\hline Parte estrutural & Material & Propriedade & Descrição \\
\hline \multirow{9}{*}{ Viga } & \multirow{9}{*}{ Concreto } & Modelo constitutivo & Maekawa fixed \\
\hline & & Módulo de elasticidade & $3,3 \mathrm{GPa}$ \\
\hline & & Coeficiente de Poison & 0,2 \\
\hline & & Fator de correção da plastificação (bfac) & 1 \\
\hline & & Resistência à compressão & $41,6 \mathrm{MPa}$ \\
\hline & & Resistência à tração & $3,58 \mathrm{MPa}$ \\
\hline & & Curva na tração & Exponencial \\
\hline & & Energia de fratura (GF1) & 0,064 \\
\hline & & Fator de retenção ao cisalhamento $(\beta)$ & 0,999999 \\
\hline \multirow{4}{*}{ Armadura } & \multirow{4}{*}{ Aço } & Módulo de elasticidade & Ver Tabela 7.1 \\
\hline & & Coeficiente de Poison & 0,3 \\
\hline & & Critério de resistência & Von Mises \\
\hline & & fy & Ver Tabela 7.1 \\
\hline Apoio & - & Coeficiente de mola vertical & $200 \mathrm{~N} / \mathrm{mm}$ \\
\hline
\end{tabular}

Quadro 7.3 - Resumo dos parâmetros utilizados na simulação numérica dos modelos de pórtico.

\begin{tabular}{|c|c|c|c|}
\hline Parte estrutural & Material & Propriedade & Descrição \\
\hline \multirow{9}{*}{ Pórtico 1 - 3} & \multirow{9}{*}{ Concreto } & Modelo constitutivo & Maekawa fixed \\
\hline & & Módulo de elasticidade & $3,3 \mathrm{GPa}$ \\
\hline & & Coeficiente de Poison & 0,2 \\
\hline & & Fator de correção da plastificação (bfac) & 1 \\
\hline & & Resistência à compressão & $49,8 \mathrm{MPa}$ \\
\hline & & Resistência à tração & $3,48 \mathrm{MPa}$ \\
\hline & & Curva na tração & Exponencial \\
\hline & & Energia de fratura (GF1) & 0,073 \\
\hline & & Fator de retenção ao cisalhamento $(\beta)$ & 0,999999 \\
\hline \multirow{2}{*}{ Apoio } & \multirow{2}{*}{-} & Coeficiente de mola vertical & $3700 \mathrm{~N} / \mathrm{mm}$ \\
\hline & & Coeficiente de mola horizontal & $50 \mathrm{~N} / \mathrm{mm}$ \\
\hline \multirow{4}{*}{ Armadura } & \multirow{4}{*}{ Aço } & Módulo de elasticidade & Ver Tabela 7.1 \\
\hline & & Coeficiente de Poison & 0,3 \\
\hline & & Critério de resistência & Ver Tabela 7.1 \\
\hline & & fy & $500 \mathrm{MPa}$ \\
\hline \multirow{2}{*}{ Interface vertical superior } & \multirow{2}{*}{-} & Rigidez normal & $1.10^{-9} \mathrm{~N} / \mathrm{mm}^{3}$ \\
\hline & & Rigidez tangencial & $1.10^{-10} \mathrm{~N} / \mathrm{mm}^{3}$ \\
\hline \multirow{2}{*}{ Interface vertical inferior } & \multirow[t]{2}{*}{-} & Rigidez normal & $\begin{array}{l}1,98 \cdot 10^{3} \mathrm{~N} / \mathrm{mm}^{3} \\
1,89 \cdot 10^{3} \mathrm{~N} / \mathrm{mm}^{3}\end{array}$ \\
\hline & & Rigidez tangencial & $1.10^{-10} \mathrm{~N} / \mathrm{mm}^{3}$ \\
\hline \multirow{2}{*}{ Interface horizontal } & \multirow{2}{*}{-} & Rigidez normal & $11,3 \mathrm{~N} / \mathrm{mm}^{3}$ \\
\hline & & Rigidez tangencial & $1.10^{-10} \mathrm{~N} / \mathrm{mm}^{3}$ \\
\hline \multirow{4}{*}{ Reforço } & \multirow{4}{*}{ Laminado } & Módulo de elasticidade & $131 \mathrm{GPa}$ \\
\hline & & Coeficiente de Poison & 0,3 \\
\hline & & Critério de resistência & Von Mises \\
\hline & & fy & $2000 \mathrm{MPa}$ \\
\hline
\end{tabular}




\section{Simulação do ensaio da viga}

Nas Figura 7.64 e Figura 7.68, apresentam-se as curvas numéricas e experimentais "força x deslocamento" e "força x deformação" na armadura longitudinal inferior da viga, de suspensão e tirante do dente. A força máxima alcançada pelo modelo numérico foi de $294 \mathrm{kN}$, $20 \%$ maior que o experimental e $14 \%$ inferior ao valor para o qual o modelo foi dimensionado (340 kN). As curvas "força x deslocamento" numérica e experimental (Figura 7.64) se superpõe até praticamente a ruptura. Na Figura 7.65, ilustra-se a deformada da viga no passo 83 da simulação, correspondente à força aplicada de $200 \mathrm{kN}$, que é coerente com o que se espera para uma viga bi-apoiada, submetida a flexão.

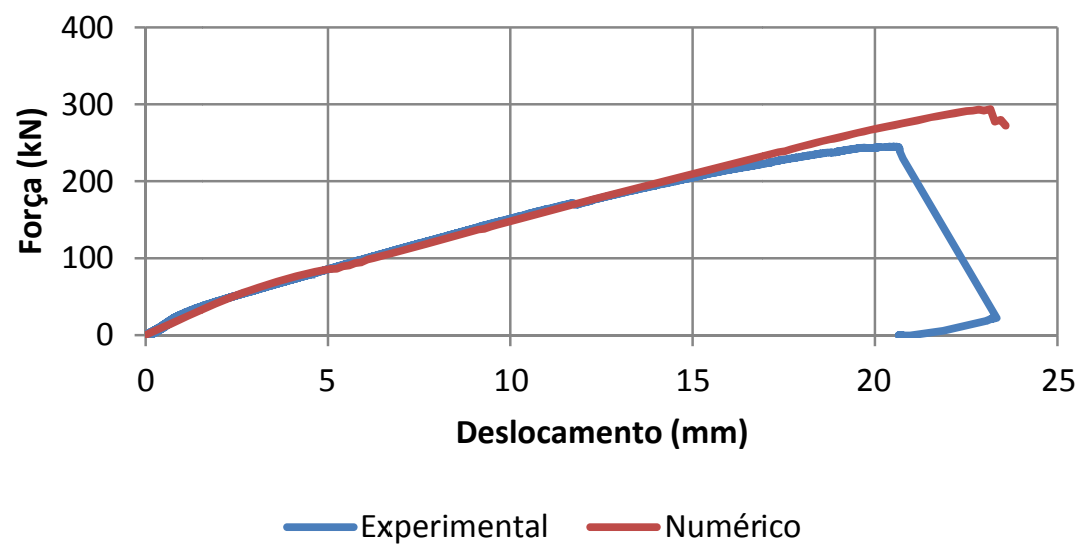

Figura 7.64 - Curvas “Força x Deslocamento" experimental e numérica - ensaio da viga.
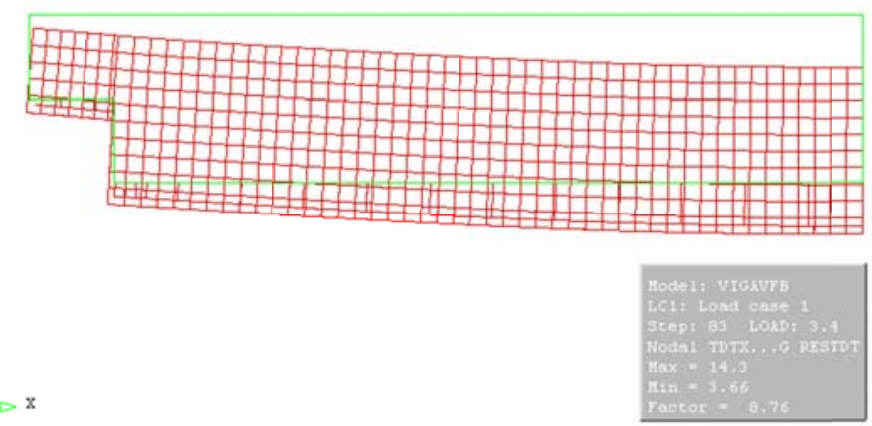

Figura 7.65 - Deformada da viga para o passo $83(200 \mathrm{kN})$. 
As curvas "Força x Deformação da armadura longitudinal inferior" experimental e numérica (Figura 7.66) apresentam a mesma rigidez inicial e se assemelham em forma. Ambas têm dois trechos aproximadamente lineares com inclinações diferentes e um trecho de transição entre eles. Na curva experimental, a transição ocorre para a força de $20 \mathrm{kN}$ e na experimental, $60 \mathrm{kN}$ e a inclinação do segundo trecho linear da curva numérica é superior a experimental. Em relação à máxima deformação, os dois modelos apresentaram valores bastante semelhantes: 2,3\%o, no experimental e 2,1\%o, no numérico.

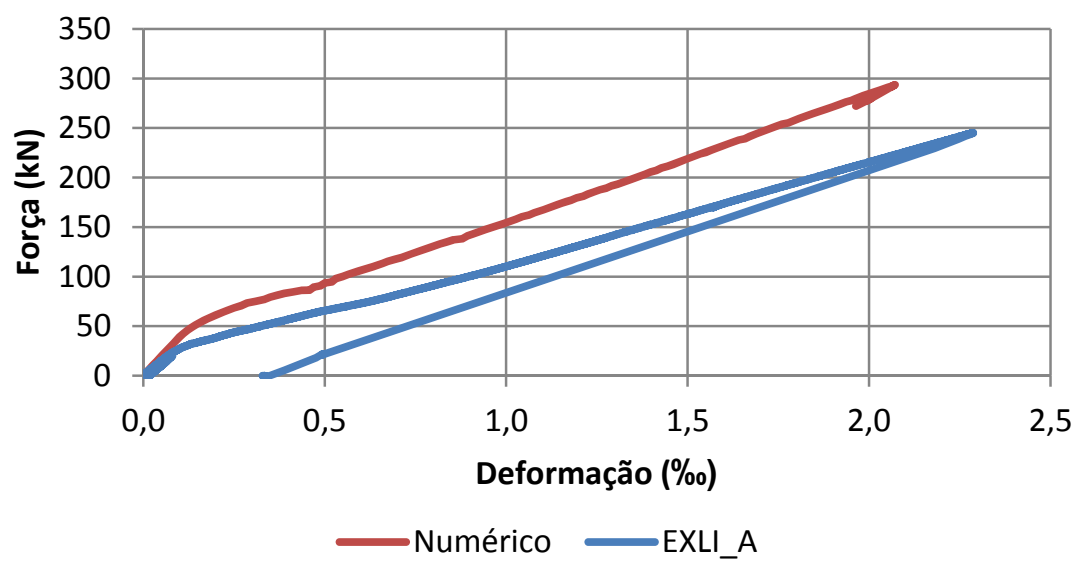

Figura 7.66 - "Força x Deformação da armadura longitudinal inferior" experimental e numérica - ensaio da viga.

Observa-se uma boa concordância entre a curva numérica e três das curvas experimentais "Força x Deformação do tirante do dente". Na Figura 7.67, percebe-se que uma das armaduras instrumentadas (EXTD_AD) apresenta deformação bastante superior às demais, escoa com força aplicada de $150 \mathrm{kN}$ e alcança deformação de $10 \%$ na ruptura. Isso indica que no apoio direito (onde ocorreu a ruptura) as tensões não se distribuíram igualmente o que justifica a ruptura com força aplicada inferior ao estimado analiticamente e numericamente. 


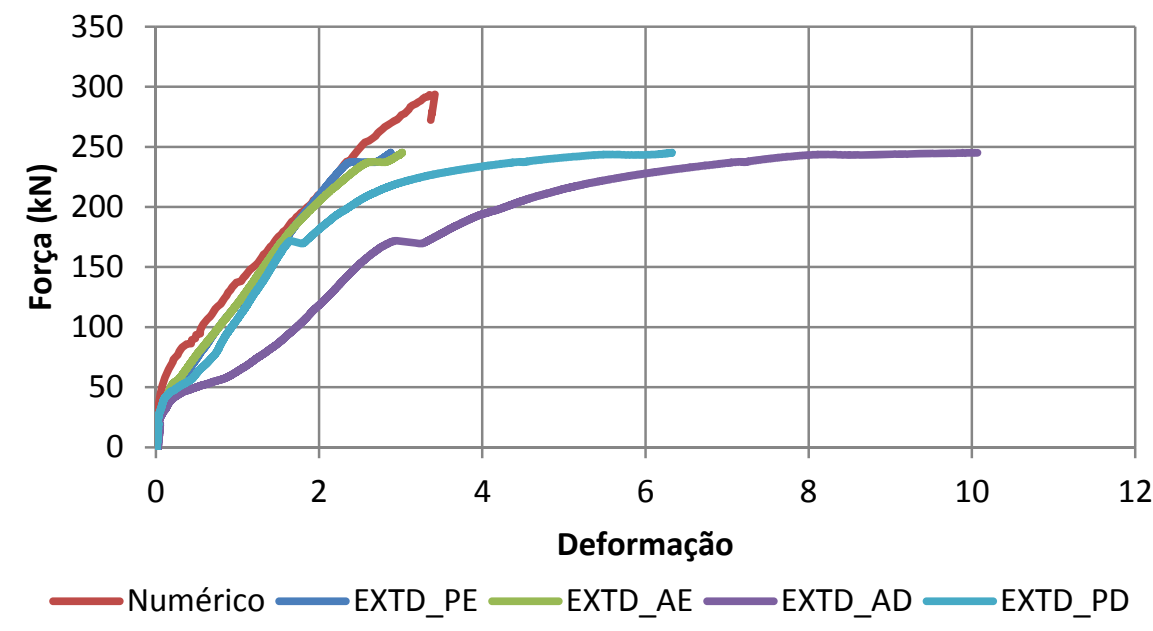

Figura 7.67 - Curvas "Força x Deformação do tirante do dente" experimental e numérica - ensaio da viga.

Há bastante semelhança na forma das Curvas "Força x Deformação da suspensão" experimental e numérica (Figura 7.68). A curva numérica apresenta maior deformação final em função de o modelo numérico ter rompido para uma força maior.

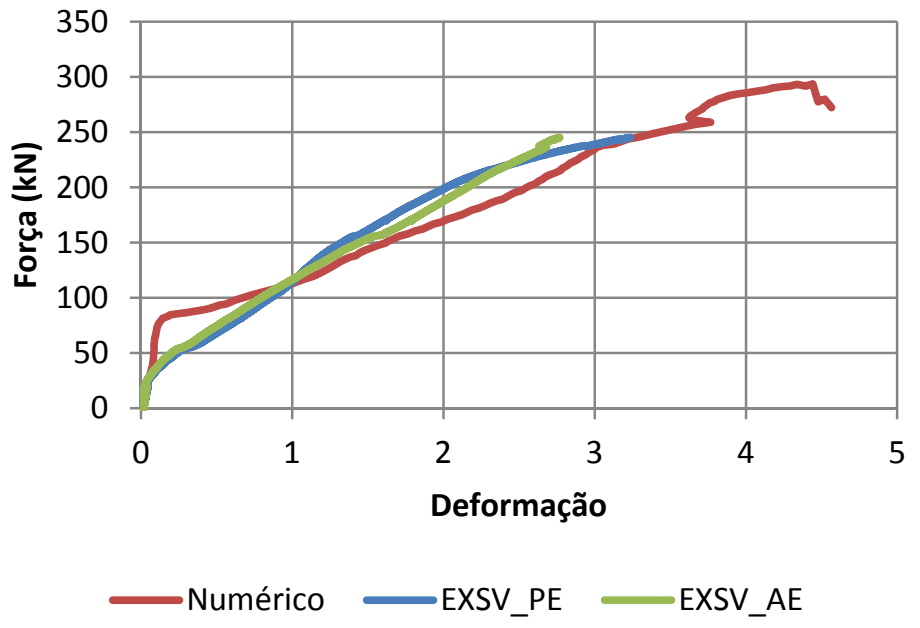

Figura 7.68 - Curvas "Força x Deformação da suspensão" experimental e numérica - ensaio da viga.

Na Figura 7.69, observa-se a distribuição das fissuras no modelo nos passos 7 (30 kN), $9(39$ kN), $31(90$ kN), $49(130$ kN), $83(200$ kN), $131(290$ kN) na simulação numérica. As primeiras fissuras surgiram no passo 7 no canto reentrante da viga. No passo 9, se observam fissuras no banzo inferior. Fissuras na região superior do modelo se iniciaram no 
passo 83. Na ruptura, há fissuras por praticamente toda a viga e ao longo de toda a altura do dente Gerber.

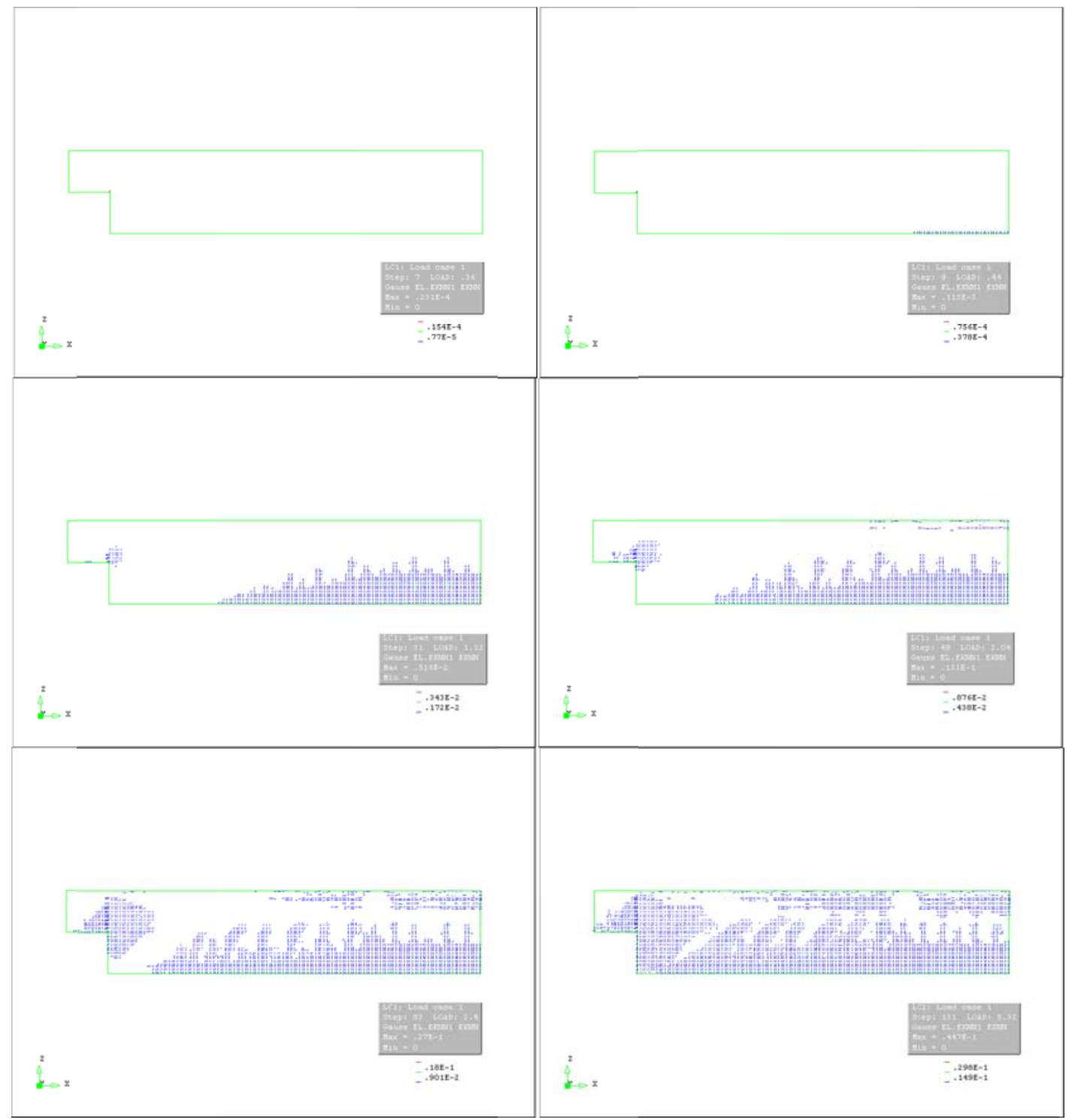

Figura 7.69 - Evolução da fissuração da viga.

As tensões principais mínimas no modelo nos passos $7(30 \mathrm{kN}), 9(39 \mathrm{kN}), 31(90$ kN), $49(130$ kN), $83(200$ kN), $131(290$ kN) são apresentadas em sequência na Figura 7.70. Até o passo 9, a biela que surge no processo de transferência da força do seu ponto de aplicação até o apoio é bem definida na região do dente e tem inclinação aproximada de $50^{\circ}$. No passo 31, começa a se perceber uma perturbação na distribuição inicial das tensões provavelmente relacionada à fissuração do modelo. 


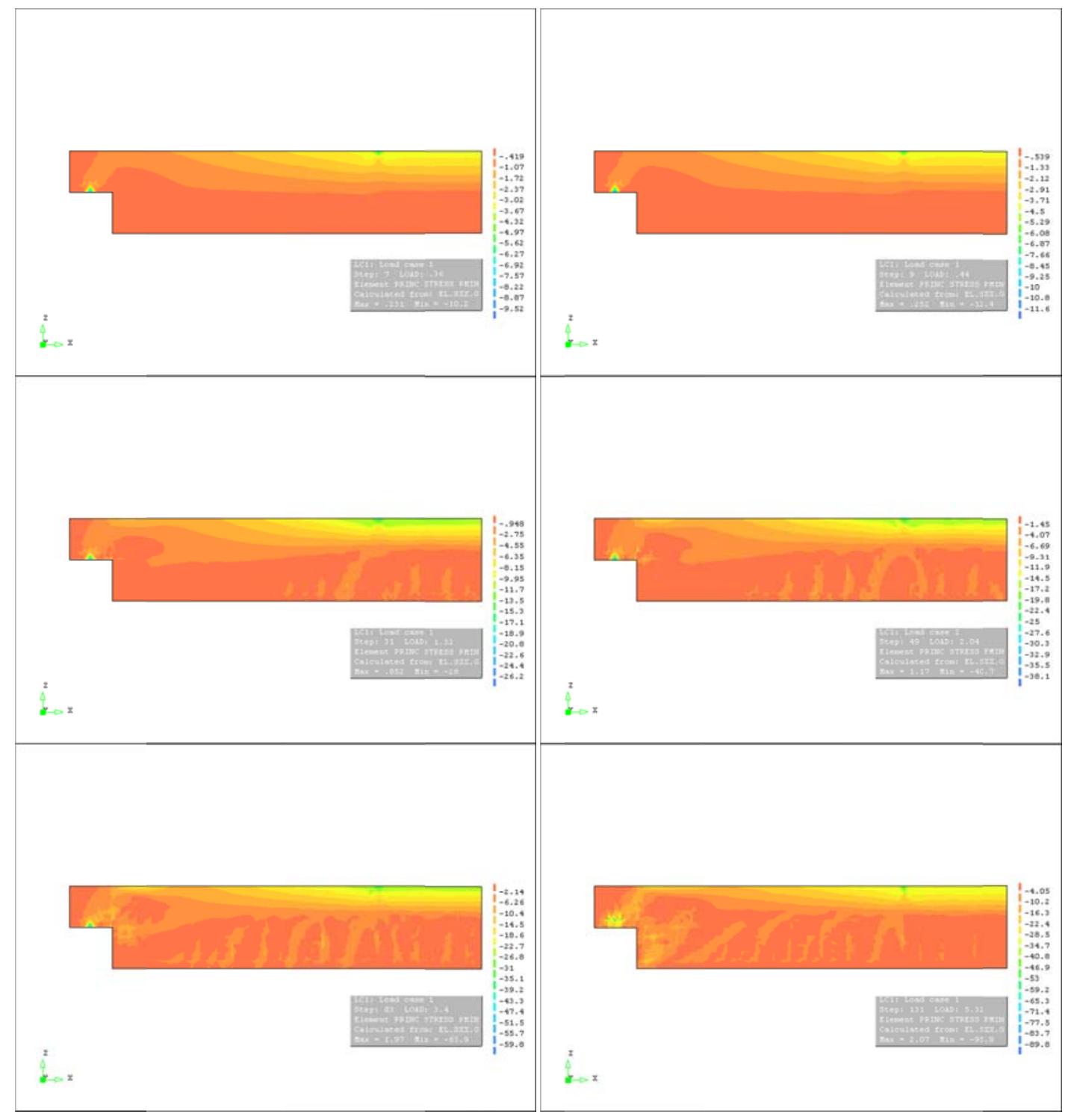

Figura 7.70 - Tensões principais mínimas ao longo do ensaio da viga.

\section{Simulação do ensaio do Pórtico1}

Na Figura 7.71, apresentam-se as curvas "Força x Deslocamento" experimental e numérica para a primeira fase do ensaio do Pórtico1 (Pórtico1_a). As curvas têm forma parecida e mesma inclinação inicial, mas para forças superiores a $30 \mathrm{kN}$ o modelo numérico é mais rígido que o experimental. Optou-se por limitar a primeira fase da simulação numérica pelo deslocamento experimental, de modo que a máxima força aplicada ao Pórtico1_a experimental foi de $100 \mathrm{kN}$ e no modelo numérico de $131 \mathrm{kN}$. Com a retirada da força, observa-se um deslocamento residual nas duas curvas, maior para a curva experimental. Uma 
justificativa para isso é o fato de supormos elástico o comportamento de partes do modelo que podem exibir plasticidade, como a interface horizontal que representa a almofada de apoio e as molas que foram empregadas para representar a deformabilidade da base. Nas demais curvas relativas ao ensaio do Pórtico1 (Figura 7.72, Figura 7.74 e Figura 7.75), os resultados da primeira e segunda fase de ensaio são apresentados conjuntamente.

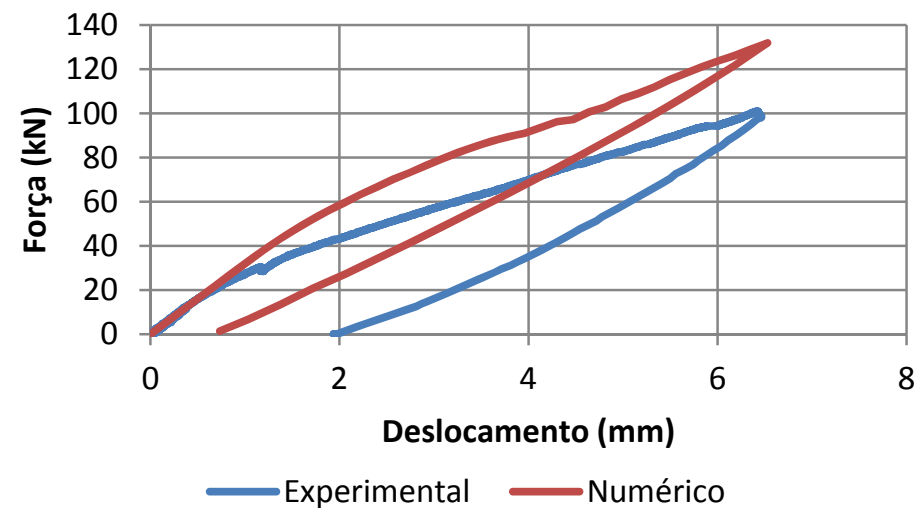

Figura 7.71 - Curvas “Força x Deslocamento” experimental e numérica - ensaio do Pórtico1_a.

Na Figura 7.72, observa-se que embora a deformação residual da primeira fase seja menor e o modelo numérico seja mais rígido a partir da forca de $30 \mathrm{kN}$, na ruptura, a diferença da força numérica e experimental é de $6 \%$ e o deslocamento numérico é $25 \%$ menor que o experimental.

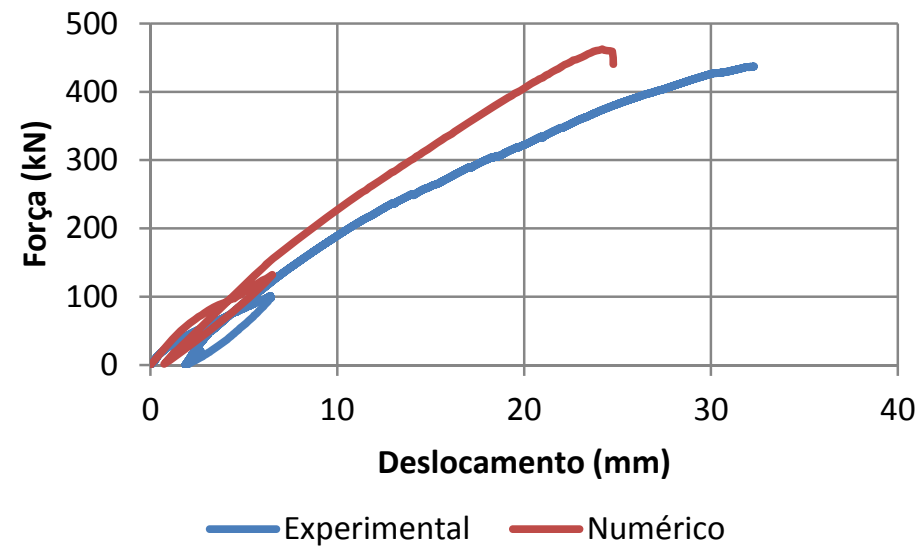

Figura 7.72 - Curvas "Força x Deslocamento" experimental e numérica ao longo das duas fases do ensaio do Pórtico1. 
A Figura 7.73, à esquerda, ilustra a deformada do Pórtico1 na primeira fase do ensaio. Nota-se a penetração das malhas do pilar e da viga, na região das interfaces verticais, coerente com o fato de elas não estarem ativas nesta fase. Na deformada da segunda fase do ensaio (Figura 7.73, à direita), ocorre uma menor rotação na região da ligação e não há mais a penetração das malhas, como tinha que ser, já que as interfaces verticais estão ativas.

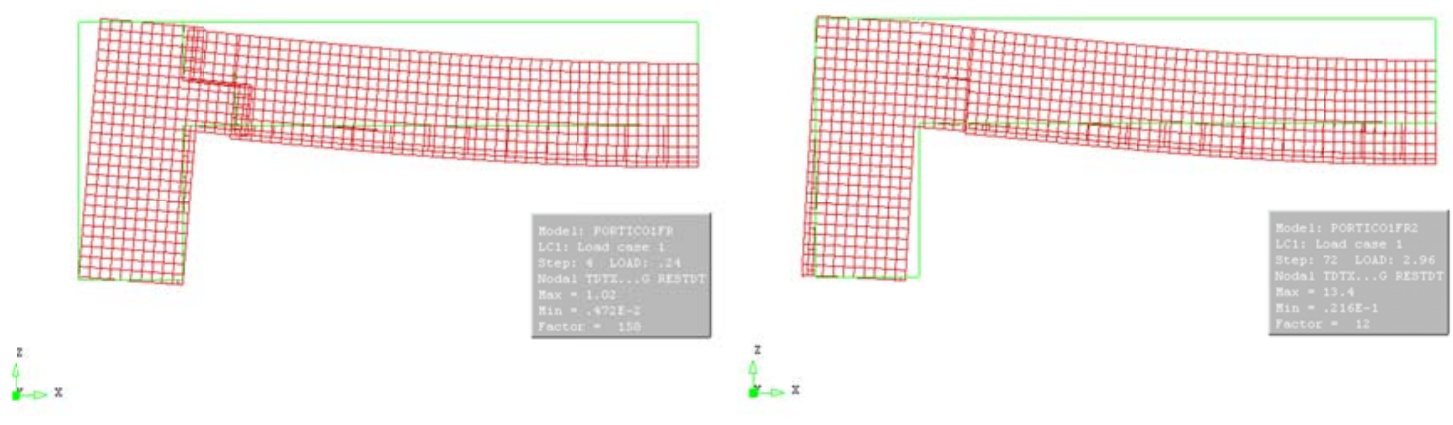

Figura 7.73 - Deformadas do Pórtico1, na primeira fase do ensaio (à esquerda) e na segunda fase (à direita).

As deformações da armadura longitudinal inferior e do tirante dlo dente numéricas são menores que as experimentais. A diferença é de 35\% no caso da armadura longitudinal inferior e de $60 \%$ no caso do tirante do dente, cujo comportamento não foi bem representado numericamente. A deformação da armadura de suspensão (Figura 7.75) também não foi bem representada, mas, neste caso, as maiores deformações foram observadas para o modelo numérico.

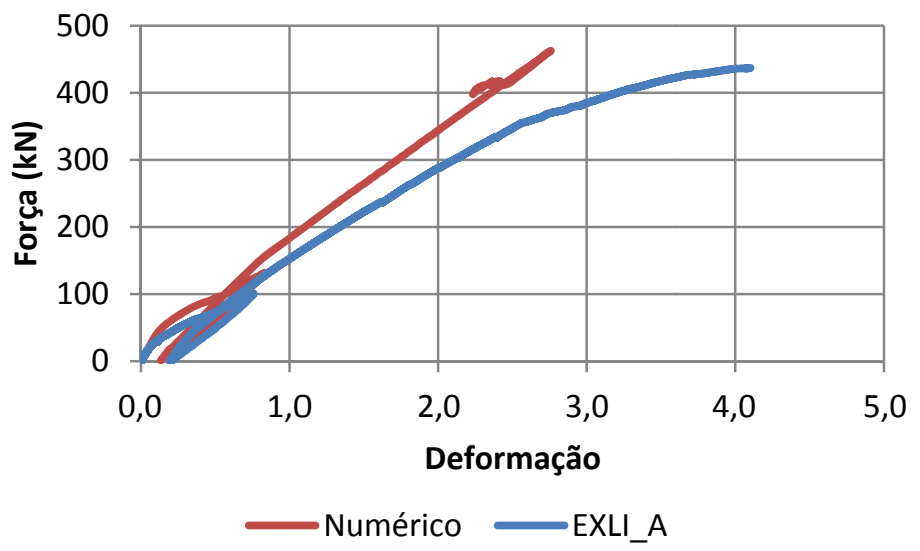

Figura 7.74 - Curvas “Força x Deformação da armadura longitudinal inferior” experimental e numérica - ensaio do Pórticol. 


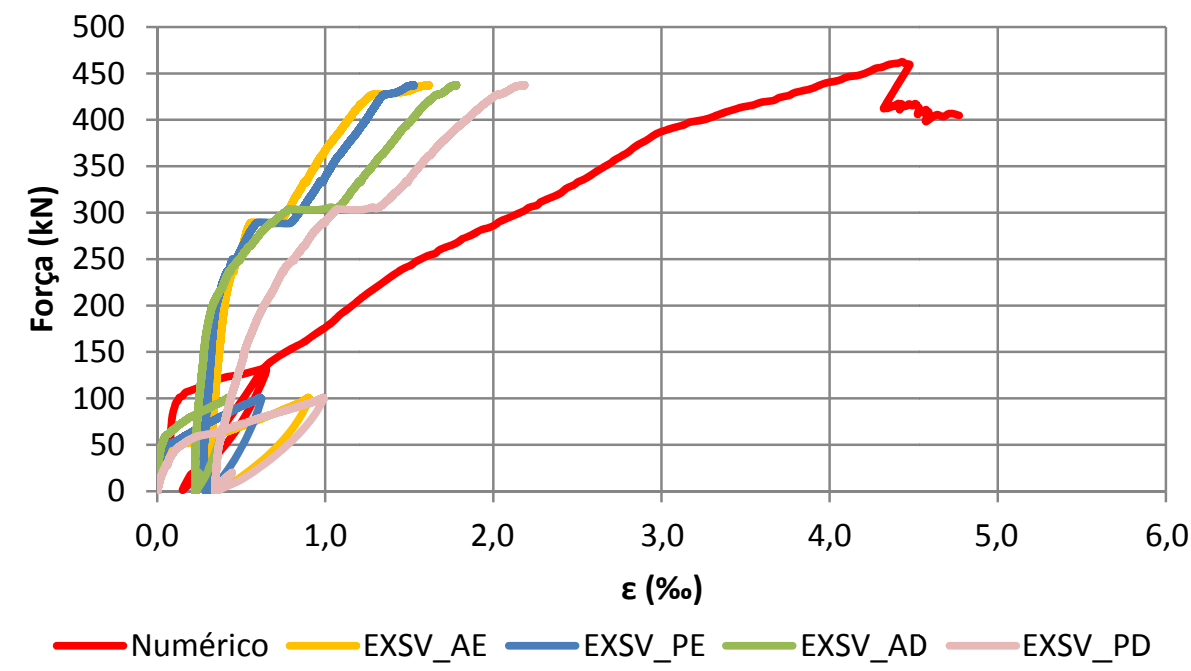

Figura 7.75 - Curvas “Força x Deformação da suspensão" experimental e numérica - ensaio do Pórtico1.

A Figura 7.76 ilustra a fissuração do modelo nos passos $4(32 \mathrm{kN}), 5(39 \mathrm{kN}), 21(90$ $\mathrm{kN})$ e $35(130 \mathrm{kN})$. A fissuração se iniciou no canto reentrante do dente no passo 4. Surgiram fissuras no banzo tracionado da viga no passo 5 e na base do pilar no passo 21. Com a aplicação da força máxima da primeira fase do ensaio, se observou um predomínio de fissuras na região tracionada da viga e no canto reentrante do dente.

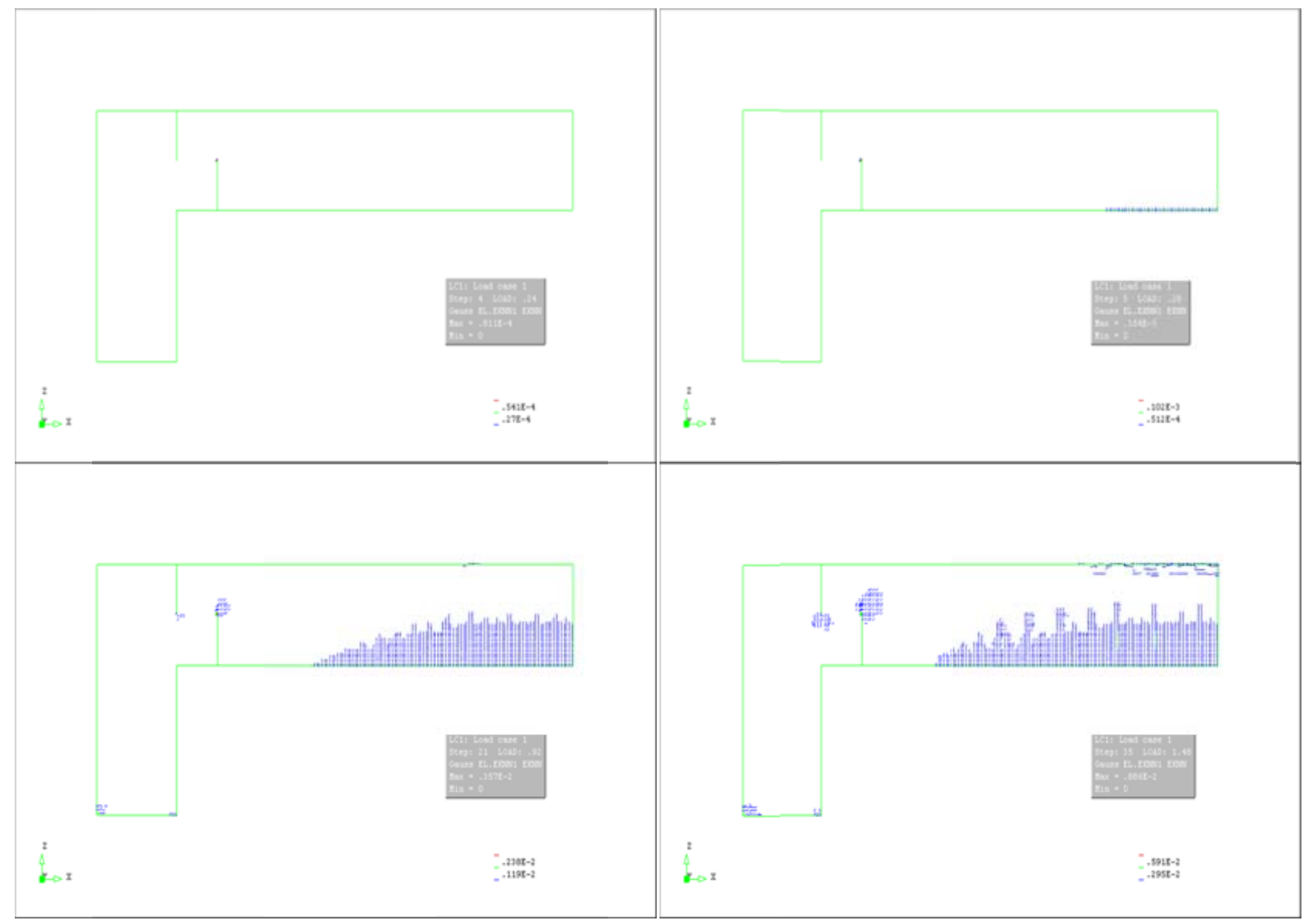

Figura 7.76 - Evolução da fissuração do modelo do Pórtico1_a. 
Na Figura 7.77 ilustra-se a fissuração do modelo nos passos $4(32 \mathrm{kN}), 6(39 \mathrm{kN}), 39$ $(180 \mathrm{kN}), 44(200 \mathrm{kN}), 116(415 \mathrm{kN})$ e $192(466 \mathrm{kN})$ da segunda fase do ensaio do Pórtico1. No passo 4, surgem fissuras na altura dos laminados na vizinhança da interface vertical superior. Até o passo 44, o aumento da força promove o surgimento de novas fissuras na região da ligação e no pilar sem evolução das fissuras do banzo tracionado e com aumento discreto da fissuração na região comprimida da viga. Nos passos 116 e 192, se observa fissuração distribuída ao longo de todo o modelo.

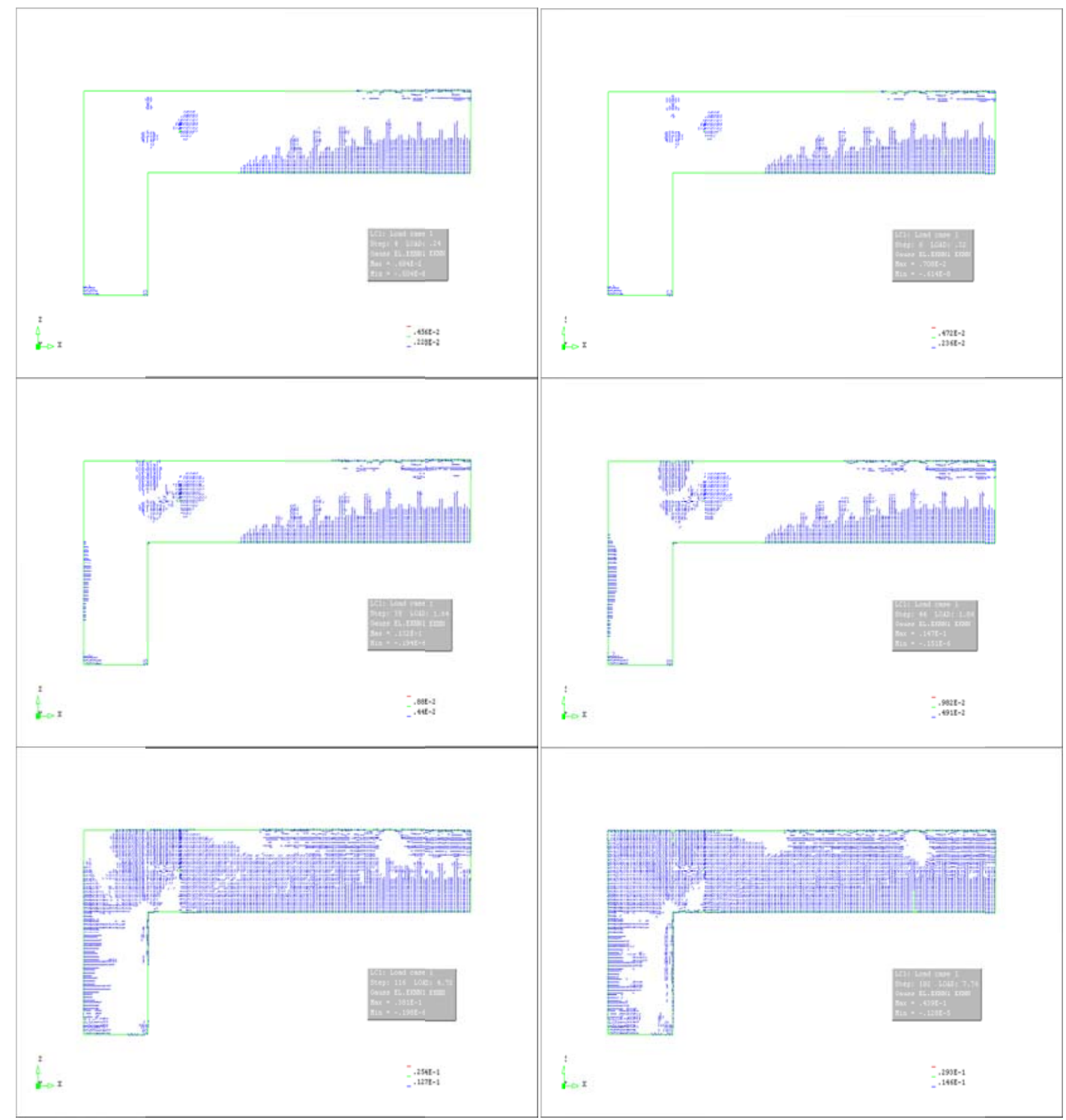

Figura 7.77 - Evolução da fissuração do modelo do Pórtico1_b. 
A Figura 7.76 ilustra as tensões principais mínimas nos passos $4(32 \mathrm{kN}), 5(39 \mathrm{kN})$, $21(90 \mathrm{kN})$ e $35(130 \mathrm{kN})$. Nota-se, nos passos 4 e 5, uma biela de compressão bem definida e com inclinação elevada na região do dente. Não há transferência de esforços pelas interfaces verticais que nesta fase do ensaio ainda não estão ativadas.

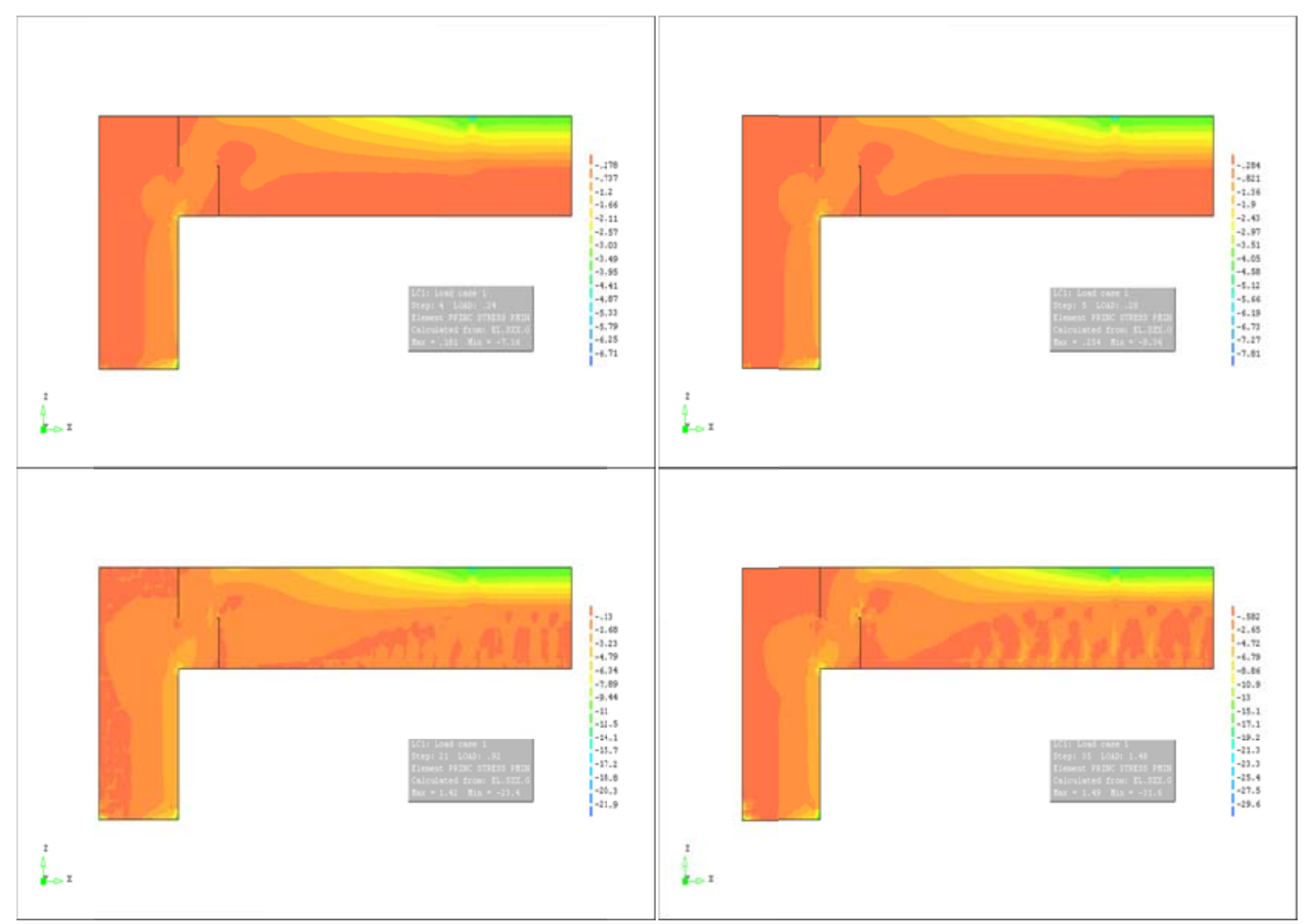

Figura 7.78 - Tensões principais mínimas ao longo do ensaio do Pórtico1_a.

Com a ativação das interfaces verticais, os esforços passam a ser transferidos também por elas, embora, nos passos iniciais (passos 4, 6 e 39 na Figura 7.79), ainda se observe uma biela principal (maiores tensões) atravessando a interface horizontal. No passo 44, aparentemente uma maior parte dos esforços migra para o pilar por meio da interface vertical inferior o que intensifica a concentração de tensões no canto inferior entre consolo e pilar. A distribuição de tensões no passo 192 sugere a ruptura por esmagamento do concreto na região de aplicação da força. 


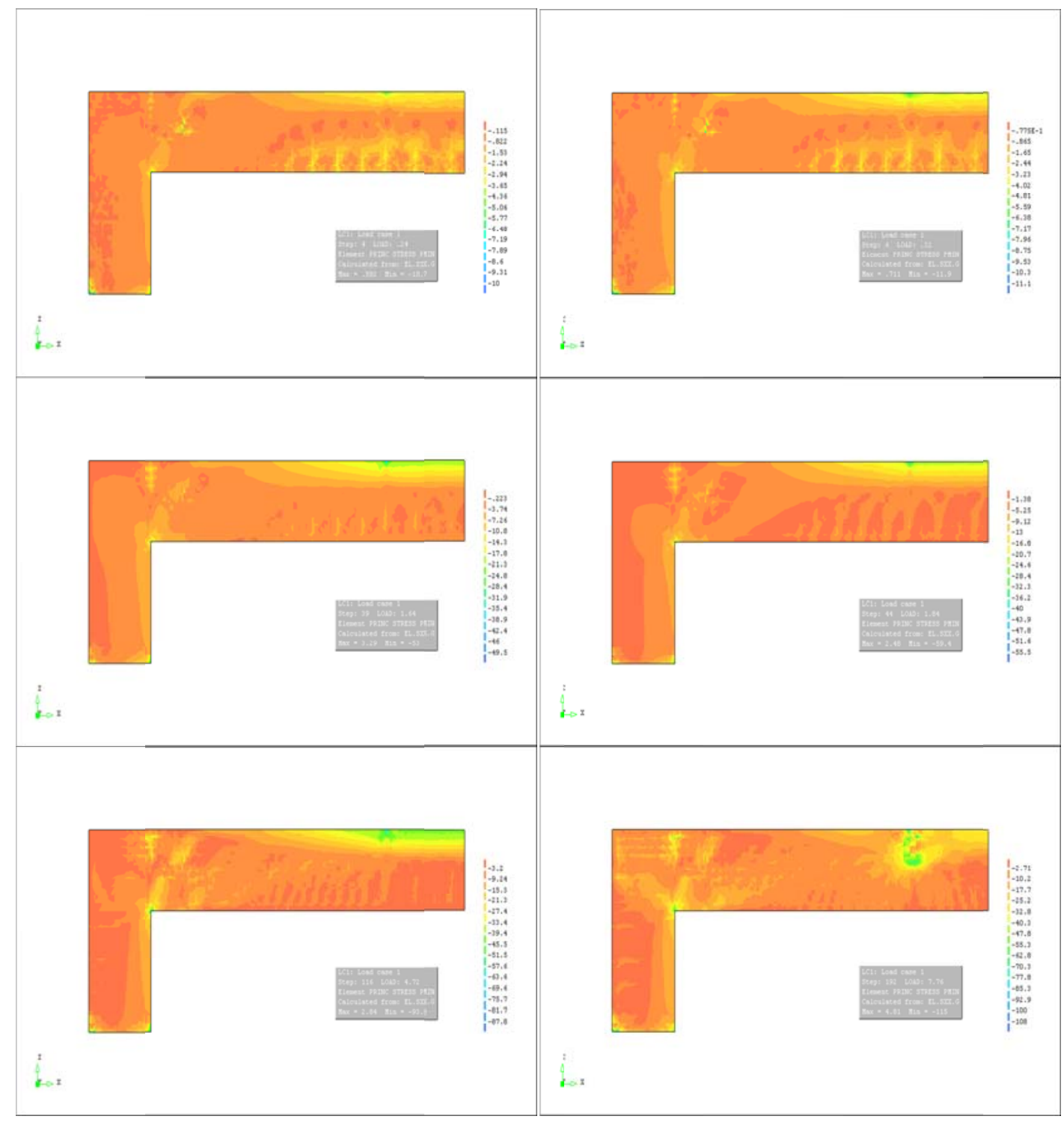

Figura 7.79 - Tensões principais mínimas ao longo do ensaio do Pórtico1_b.

\section{Simulação do ensaio do Pórtico2}

$\mathrm{Na}$ Figura 7.80, apresentam-se as curvas "Força x Deslocamento" experimental e numérica para o ensaio do Pórtico2_b. Nota-se que se alcançou no modelo numérico uma boa aproximação para a força máxima (apenas $2 \%$ de diferença) e para a inclinação inicial em relação à curva experimental. O deslocamento numérico máximo foi $30 \%$ menor que o experimental. A deformada do Pórtico2_b para o passo 3 é apresentada na Figura 7.81. 


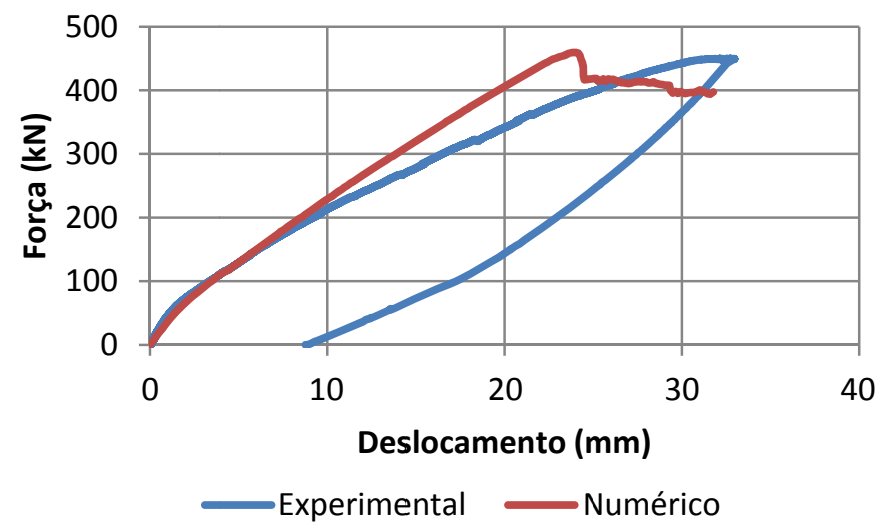

Figura 7.80 - Curvas "Força x Deslocamento" experimental e numérica - ensaio do Pórtico2_b.

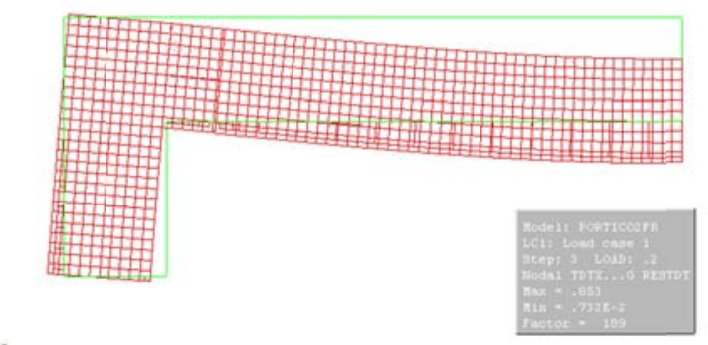

Figura 7.81 - Deformada do Pórtico2_b correspondente ao passo 3.

Na Figura 7.82, observam-se as curvas "Força x Deformação da armadura longitudinal inferior" experimental e numérica. A curva numérica é bastante semelhante à experimental até que se atinge a força de aproximadamente $370 \mathrm{kN}$, quando, na curva experimental, ocorre uma diminuição brusca na inclinação que não se verificou numericamente. Em virtude disso, a deformação máxima numérica é 30\% inferior à experimental.

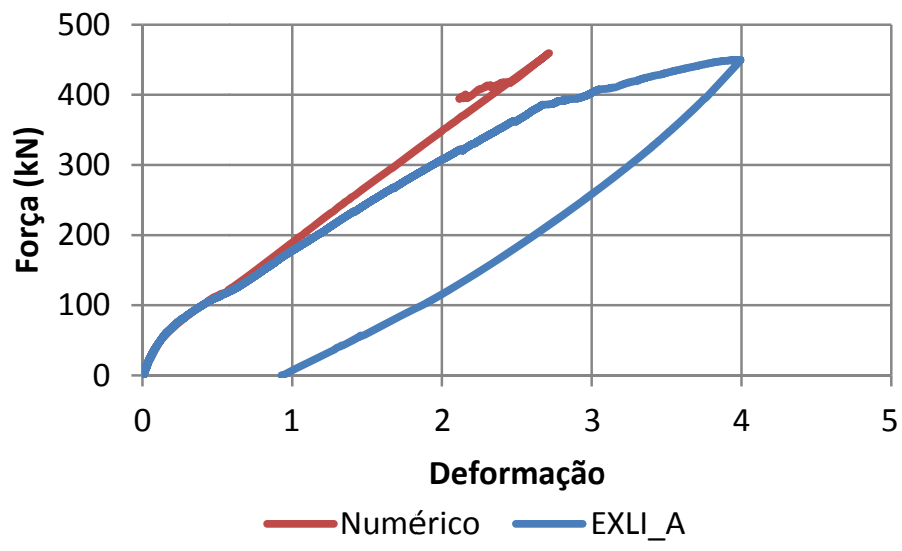

Figura 7.82 - Curvas "Força x Deformação da armadura longitudinal inferior" experimental e numérica - ensaio do Pórtico2_b. 
A curva "Força x Deformação do tirante do dente" apresenta bastante semelhança com a experimental (Figura 7.83). A deformação correspondente à força máxima do modelo numérico foi apenas 3\% inferior em relação à experimental.

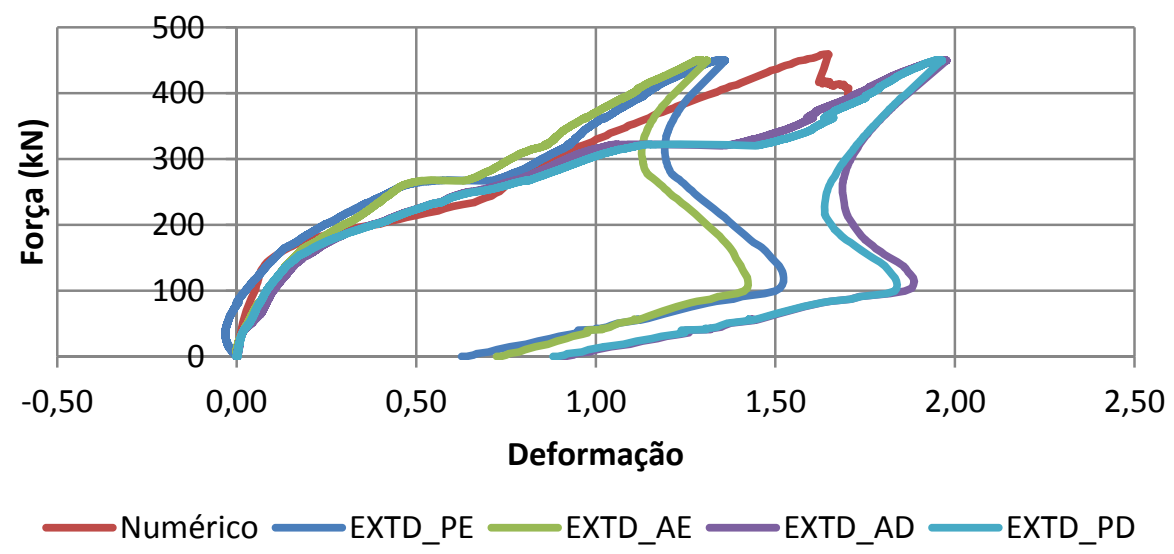

Figura 7.83 - Curvas "Força x Deformação do tirante do dente" experimental e numérica - ensaio do Pórtico2_b.

O comportamento da armadura de suspensão não foi bem representado numericamente. Para força aplicada inferior a $260 \mathrm{kN}$, as deformações na armadura de suspensão numérica e experimental apresentaram sinais diferentes e a deformação máxima numérica foi $60 \%$ inferior à experimental.

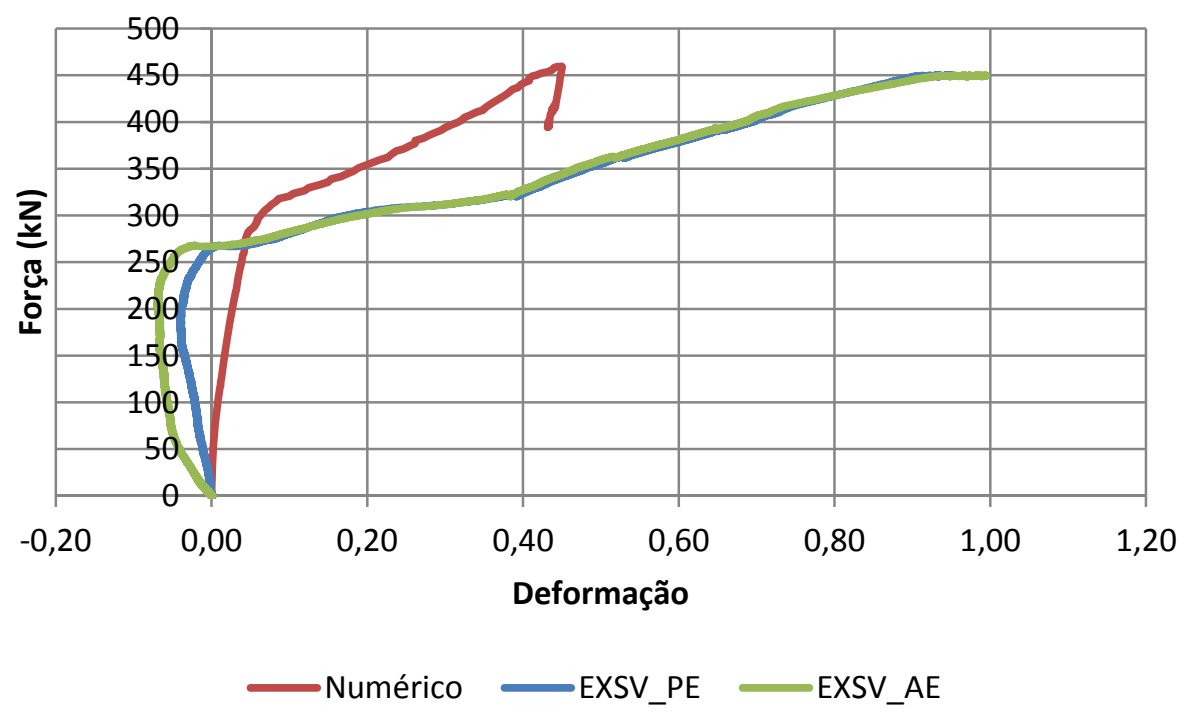

Figura 7.84 - Curvas “Força x Deformação da suspensão" experimental e numérica - ensaio do Pórtico2_b. 
Na Figura 7.85, ilustra-se a fissuração do Pórtico2_b nos passos 3 (32 kN), 15 (90 $\mathrm{kN}), 27(130 \mathrm{kN}), 42(180 \mathrm{kN}), 101(365 \mathrm{kN})$ e 161 (415 kN após a ruptura). No passo 3 surgem fissuras na altura do laminado e no canto reentrante do dente. No passo 15 , surgem fissuras na região inferior e superior da viga e na base do pilar.

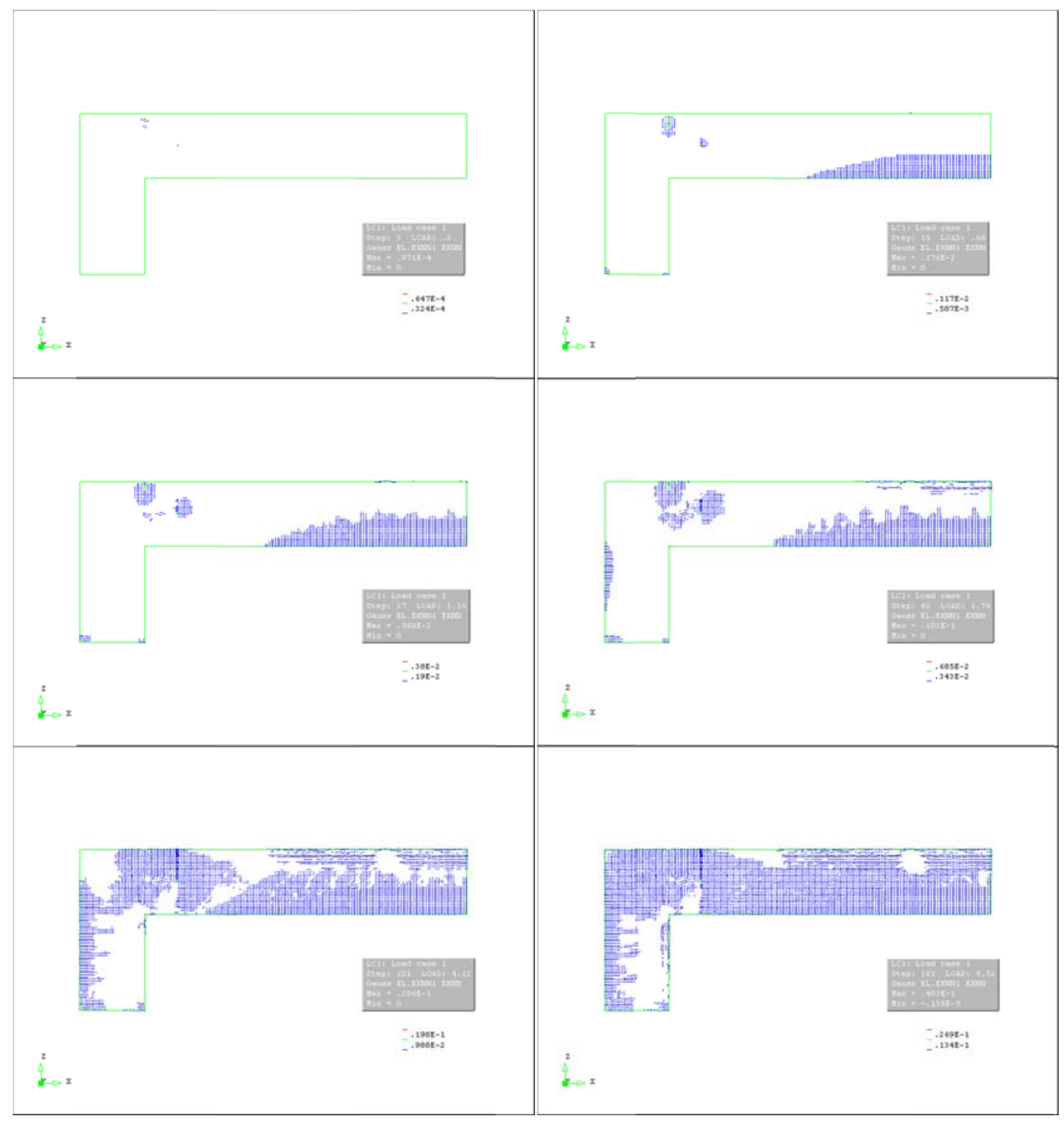

Figura 7.85 - Evolução da fissuração do ensaio do Pórtico2_b.

As tensões principais mínimas nos passos $3(32 \mathrm{kN}), 15(90 \mathrm{kN}), 27(130 \mathrm{kN}), 42(180$ kN), 101 (365 kN) e 161 (415 kN após a ruptura) são apresentadas na Figura 7.86. No passo 15, identificam-se duas bielas na região do dente, uma com inclinação elevada que atravessa a interface horizontal e uma com baixa inclinação que atravessa a interface vertical inferior. A 
distribuição das tensões se altera com o aumento da força e evolução da fissuração observando-se sempre maiores concentrações de tensão na região da aplicação da força, no canto inferior entre o consolo e o pilar e na base do pilar. A distribuição de tensões no passo 161 sugere ruptura por esmagamento do concreto na região de aplicação da força.

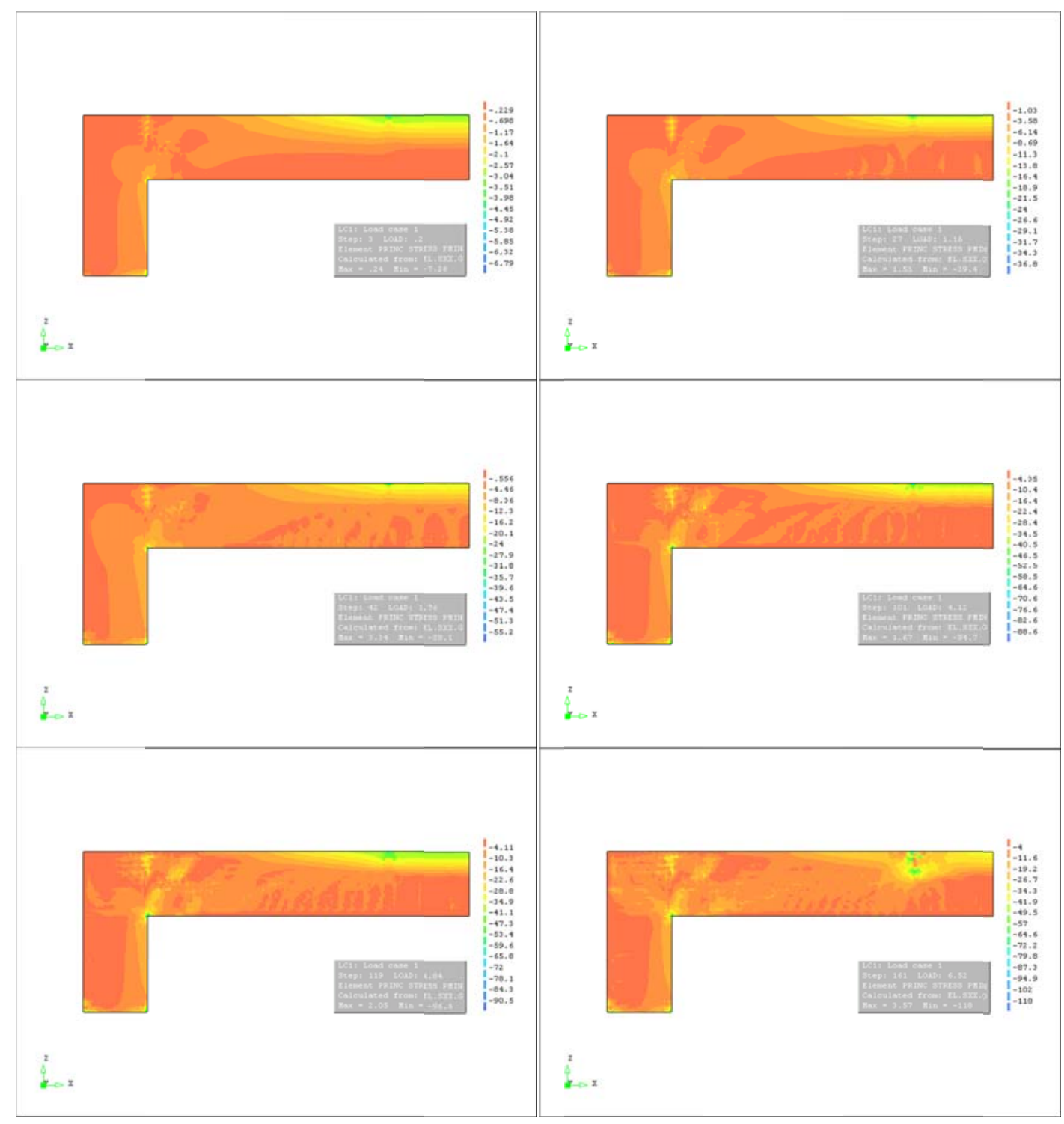

Figura 7.86 - Tensões principais mínimas ao longo do ensaio do Pórtico2_b.

\section{Simulação do ensaio do Pórtico3}

Obteve-se, no modelo numérico, uma boa aproximação para a força máxima ( $5 \%$ de diferença) e para a inclinação inicial em relação à curva experimental "força x deslocamento". O deslocamento numérico máximo foi $40 \%$ menor que o experimental. 


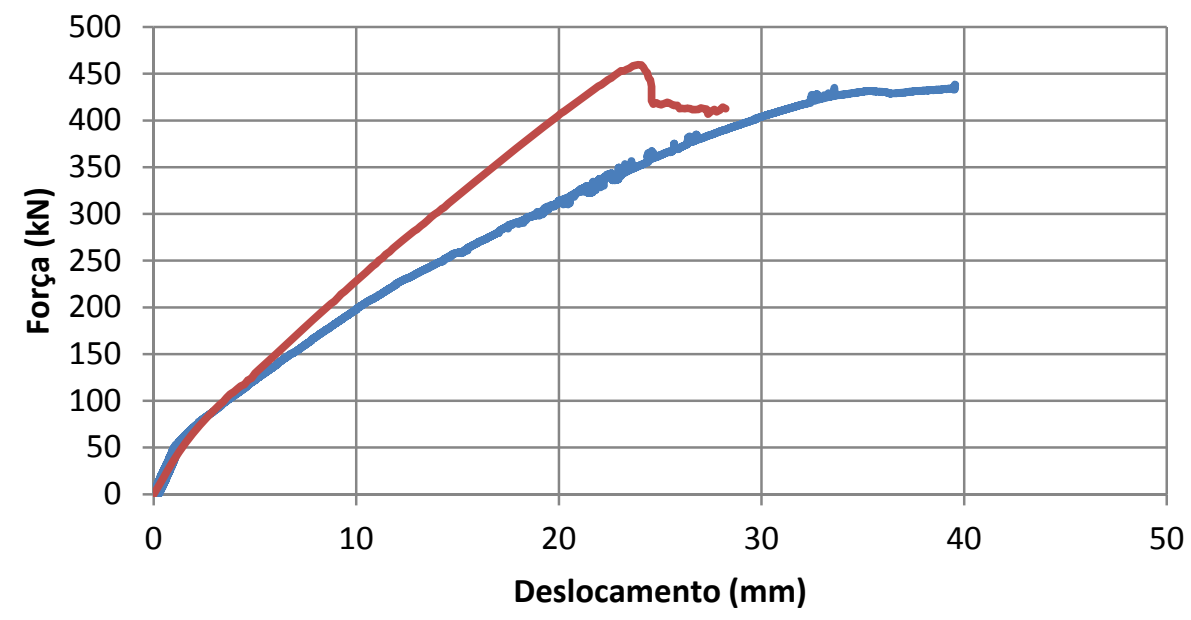

Experimental — Numérico

Figura 7.87 - Curvas "Força x Deslocamento" experimental e numérica - ensaio do Pórtico3.

A curva numérica "força x deformação da armadura longitudinal inferior" numérica semelhante à experimental até que se atinge a força de aproximadamente $350 \mathrm{kN}$, quando na curva experimental ocorre uma diminuição brusca na inclinação que não se verificou numericamente. A deformação máxima numérica é 60\% inferior à experimental.

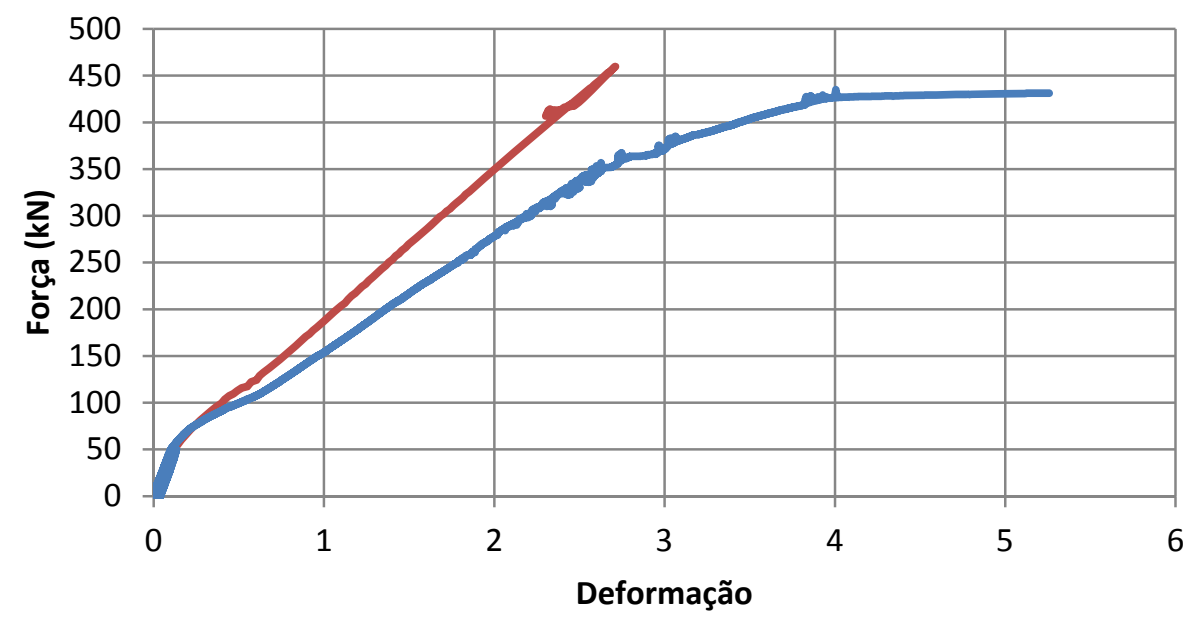

Numérico EXLI_A

Figura 7.88 - Curvas “Força x Deformação da armadura longitudinal inferior” experimental e numérica - ensaio do Pórtico3. 
As curvas "Força x Deformação do tirante do dente" experimental e numérica (Figura 7.89) são bastante semelhantes. A deformação máxima numérica é $30 \%$ inferior à experimental.

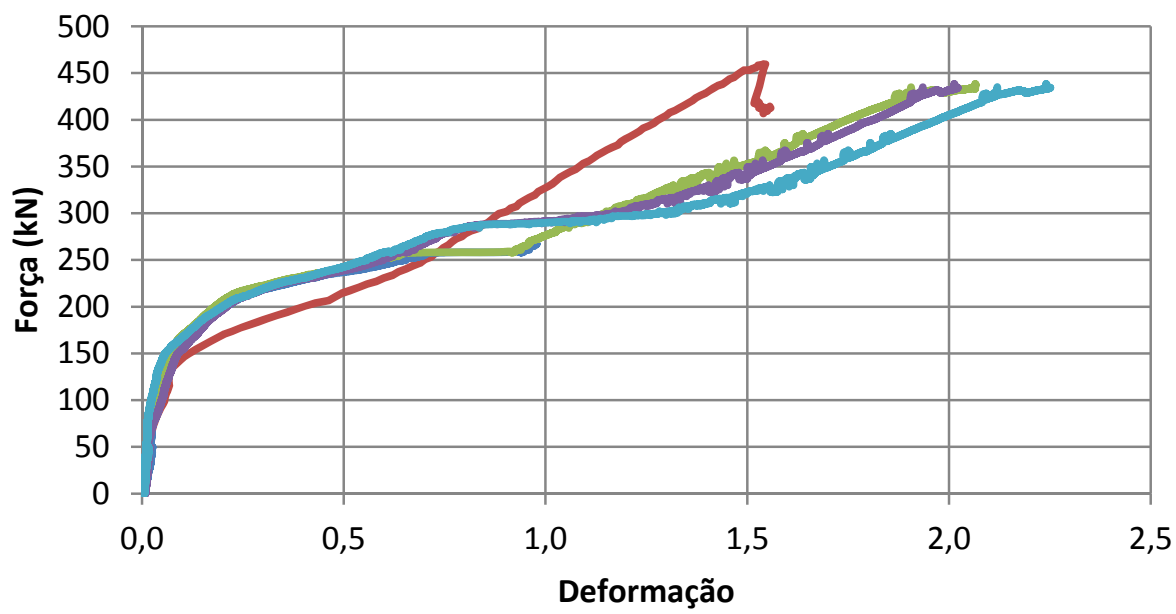

Numérico $\longrightarrow$ EXTD_PE EXTD_AE EXTD_AD EXTD_PD

Figura 7.89 - Curvas "Força x Deformação do tirante do dente” experimental e numérica - ensaio do Pórtico3.

As curvas "Força x Deformação da suspensão" experimentais (Figura 7.90) não tiveram seu comportamento bem representado numericamente. A deformação máxima numérica é apenas $20 \%$ da experimental.

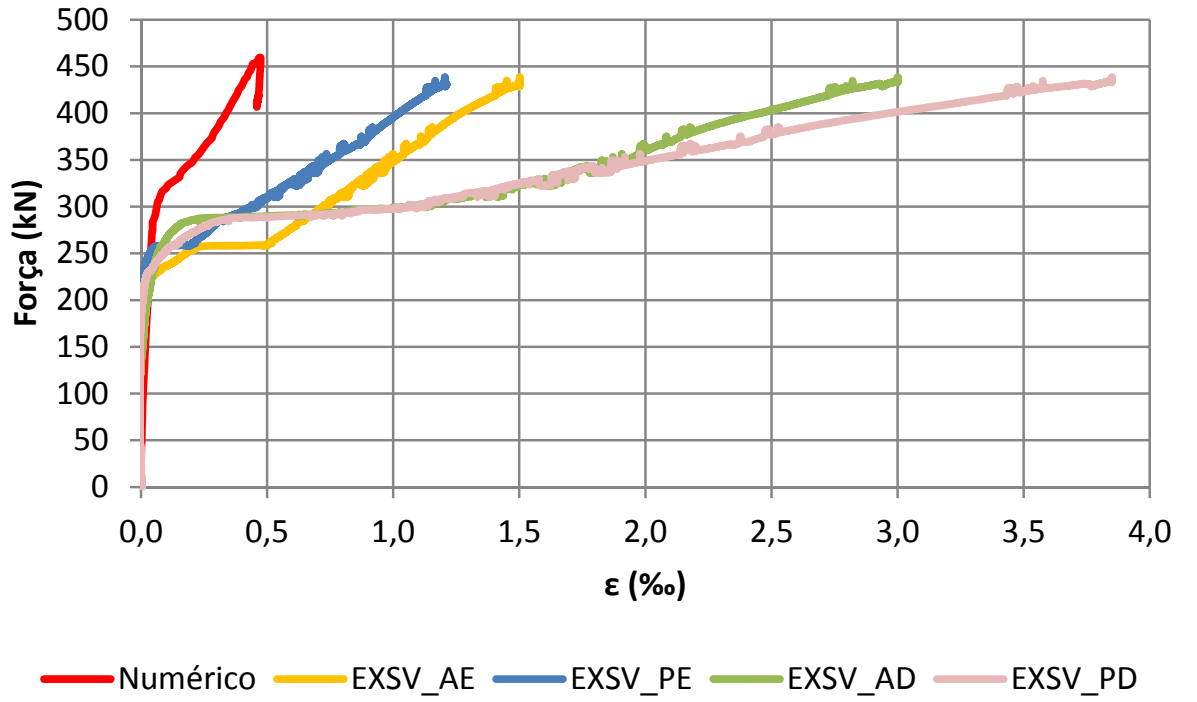

Figura 7.90 - Curvas “Força x Deformação da suspensão" experimental e numérica - ensaio do Pórtico3. 
Os resultados do modelo numérico correspondente Pórtico3_b em relação à fissuração e às tensões principais não apresentam diferenças relevantes de Pórtico2_b e ao modo que não se julga necessário repetir as considerações feitas. Apresentam-se a Figura 7.91 e a Figura 7.92 que comparadas à Figura 7.85 e à Figura 7.86, respectivamente, justificam issı.

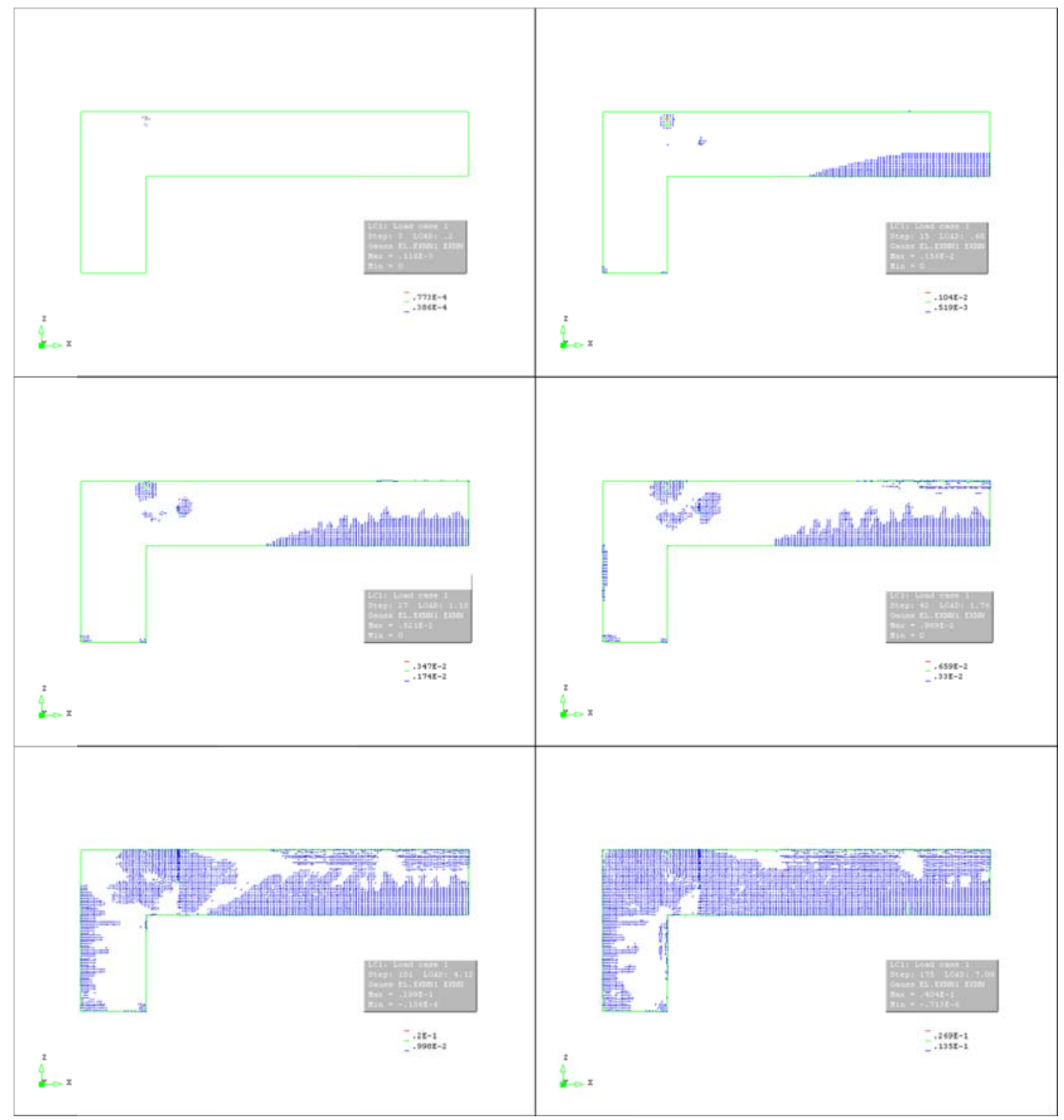

Figura 7.91 - Evolução da fissuração do ensaio do Pórtico3. 


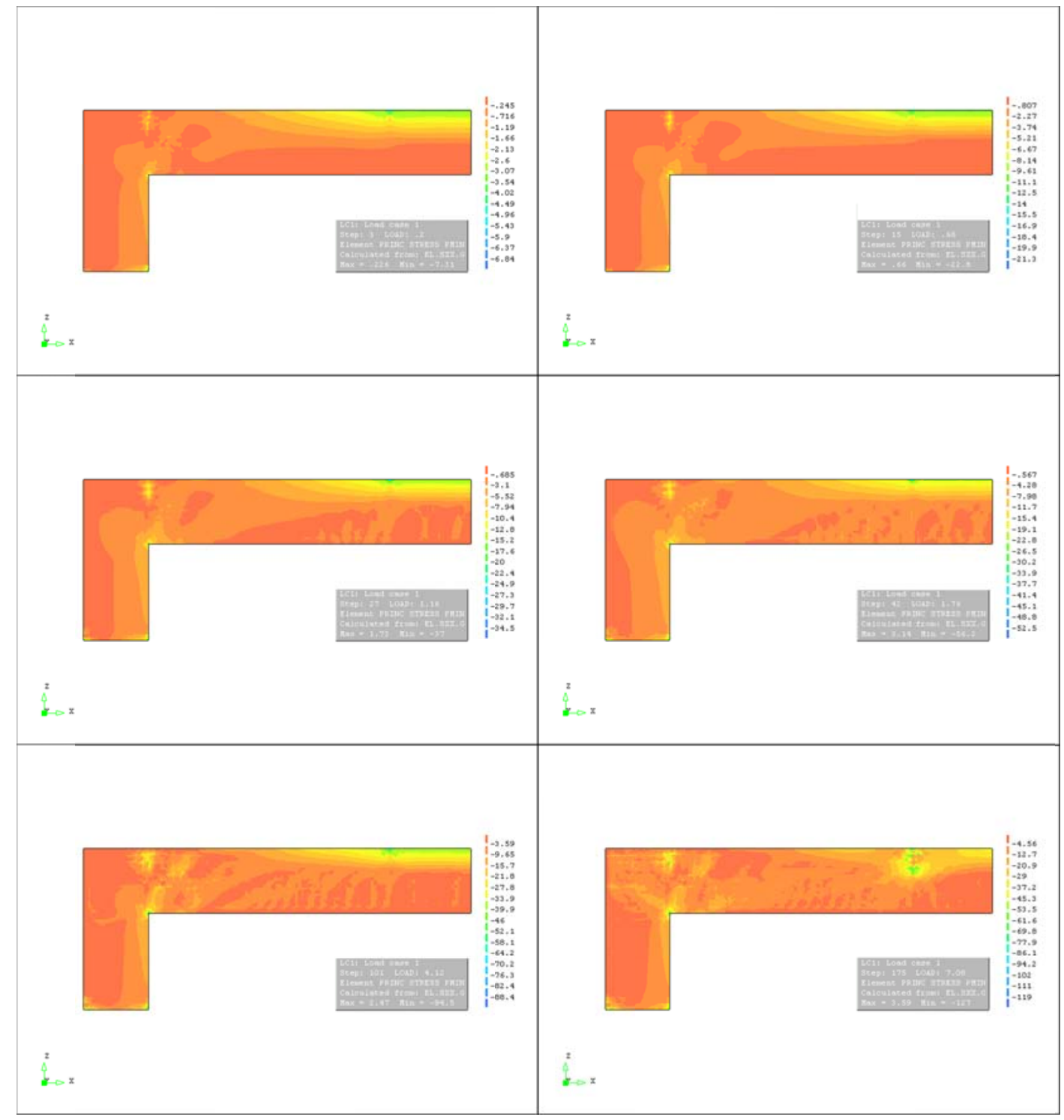

Figura 7.92 - Tensões principais ao longo do ensaio do Pórticio3.

\subsection{Execução do ensaio dinâmico}

O ensaio dinâmico foi planejado de modo a permitir a determinação experimental das frequências naturais e dos modos de vibrar a elas relacionados. Utilizaram-se neste ensaio dois acelerômetros piezelétricos da marca ENDEVCO $®$, modelo 7254A, sistema de aquisição de dados System 6000 e martelo com ponta emborrachada (Figura 7.94). A seguir, descrevese o procedimento de ensaio. 
a. Definição dos pontos de medição. Na viga, os pontos de medição fixados foram 2, 3, 5, 7 e 8 (Figura 7.93), cujas posições se aproximam daquelas em que teríamos os picos do $1^{\circ}, 2^{\circ}$ e $3^{\circ}$ modos para o caso de viga bi-apoiada. Os pontos de medição no ensaio do Pórtico1_a foram de 2 a 8 e para os demais ensaios, de 1 a 9;

b. Colagem de chapas metálicas nos pontos definidos $(2,3,5,7$ e 8 , para o ensaio da Viga e 1-9, para os demais);

c. Definição do ponto referencia (posição 8);

d. Posicionamento de um acelerômetro fixo no ponto de referência;

e. Posicionamento do acelerômetro móvel um ponto de medição;

f. Imposição de excitação transiente do modelo por 10 impactos com martelo, e no ponto de excitação distante $10 \mathrm{~cm}$ de um dos pontos de medição;

g. As etapas "e" e " $\mathrm{f}$ " foram repetidas variando-se o posicionamento do acelerômetro móvel, mantendo-se o ponto de excitação, até que se varreram todos os pontos de medição.

h. Repetiram-se as etapas de "e" a "g" para pelo menos 1 novo ponto de excitação.

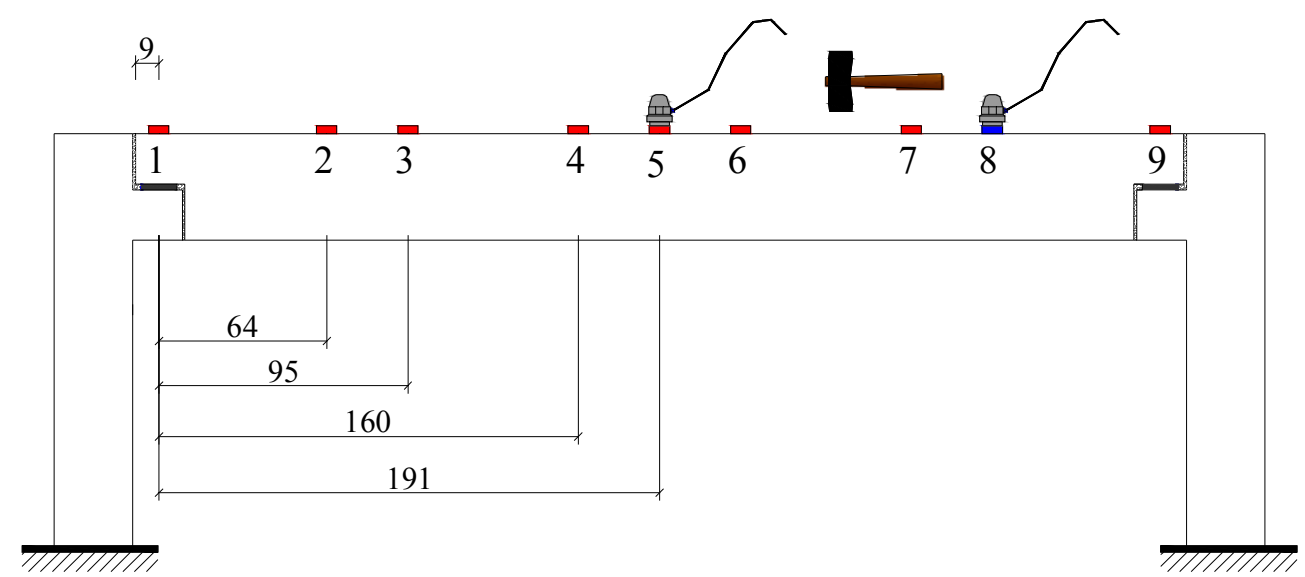

Figura 7.93 - Configuração esquemática do ensaio dinâmico (medidas em centímetros). 


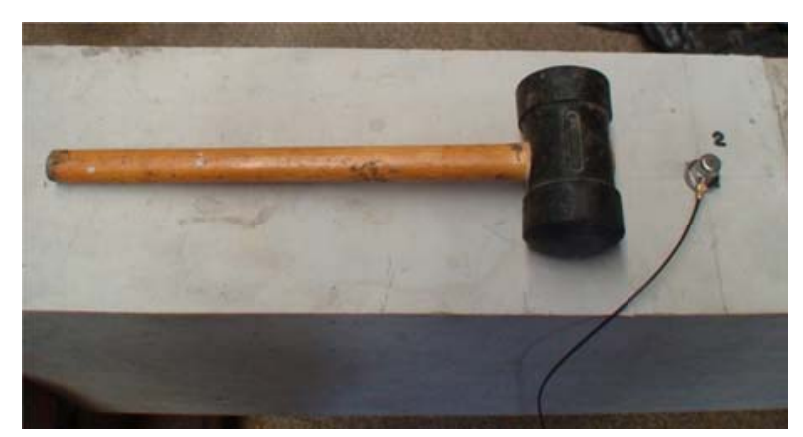

Figura 7.94 - Martelo usado para excitação dos modelos e acelerômetro fixado à viga.

Realizou-se um ensaio experimental dinâmico em um pilar isolado. A execução do ensaio no pilar obedeceu à mesma sequência do ensaio dinâmico dos demais modelos. Os pontos de medição no ensaio do pilar foram de 1-5 e o ponto de referência o 1 (Figura 7.95). A excitação foi imposta com martelo de ponta emborrachada em impactos na direção horizontal.
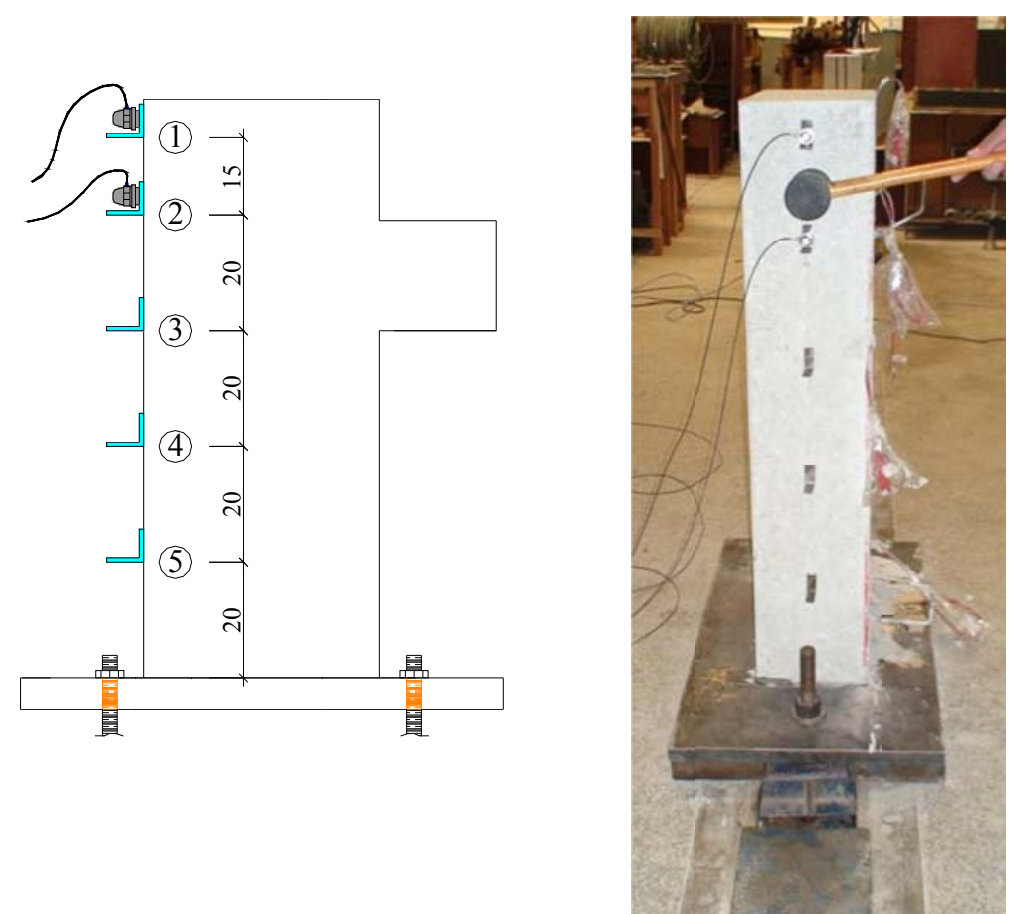

Figura 7.95 - Ensaio dinâmico do pilar: desenho esquemático destacando o posicionamento dos pontos de medição, à esquerda; foto, à direita. 


\subsection{Resultados e discussões do ensaio dinâmico}

As análises dos resultados dos ensaios dinâmicos foram feitas com uso de uma rotina desenvolvida no software scilab. O desenvolvimento desta rotina foi baseado na teoria dos métodos de ensaio por vibração ambiental documentados em Felber (1993). A Figura 7.96 ilustra os sinais obtidos nos acelerômetros fixo e móvel no domínio do tempo. Por meio da transformada rápida de Fourier (FFT de Fast Fourier Transform), esses sinais foram convertidos para o domínio da frequência resultando nos gráficos da Figura 7.97. Os picos nestes gráficos ocorrem aproximadamente para as frequências naturais da estrutura. Na Figura 7.98, apresenta-se o gráfico de transmissibilidade para uma determinada configuração de ensaio: posicionamentos específicos de excitação e dos acelerômetros fixo e móvel. A ordenada, neste gráfico, para uma dada frequência natural de interesse, nos fornece a razão entre o deslocamento modal do ponto em que está posicionado o acelerômetro móvel e do ponto em que está posicionado o acelerômetro fixo. Isso feito para todas as configurações empregadas nos ensaios nos permitiu uma boa estimativa dos modos de vibrar dos modelos.

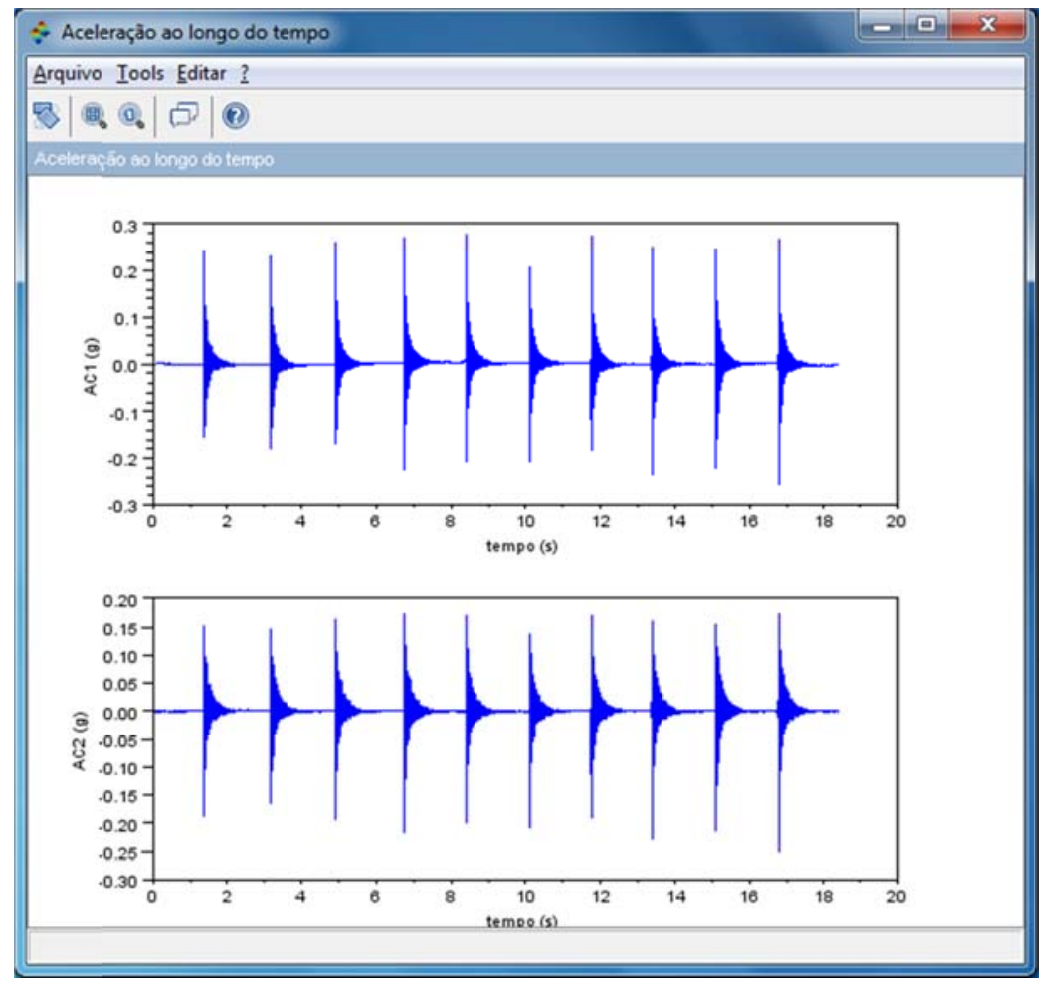

Figura 7.96 - Sinais dos acelerômetros fixo e móvel no domínio do tempo. 


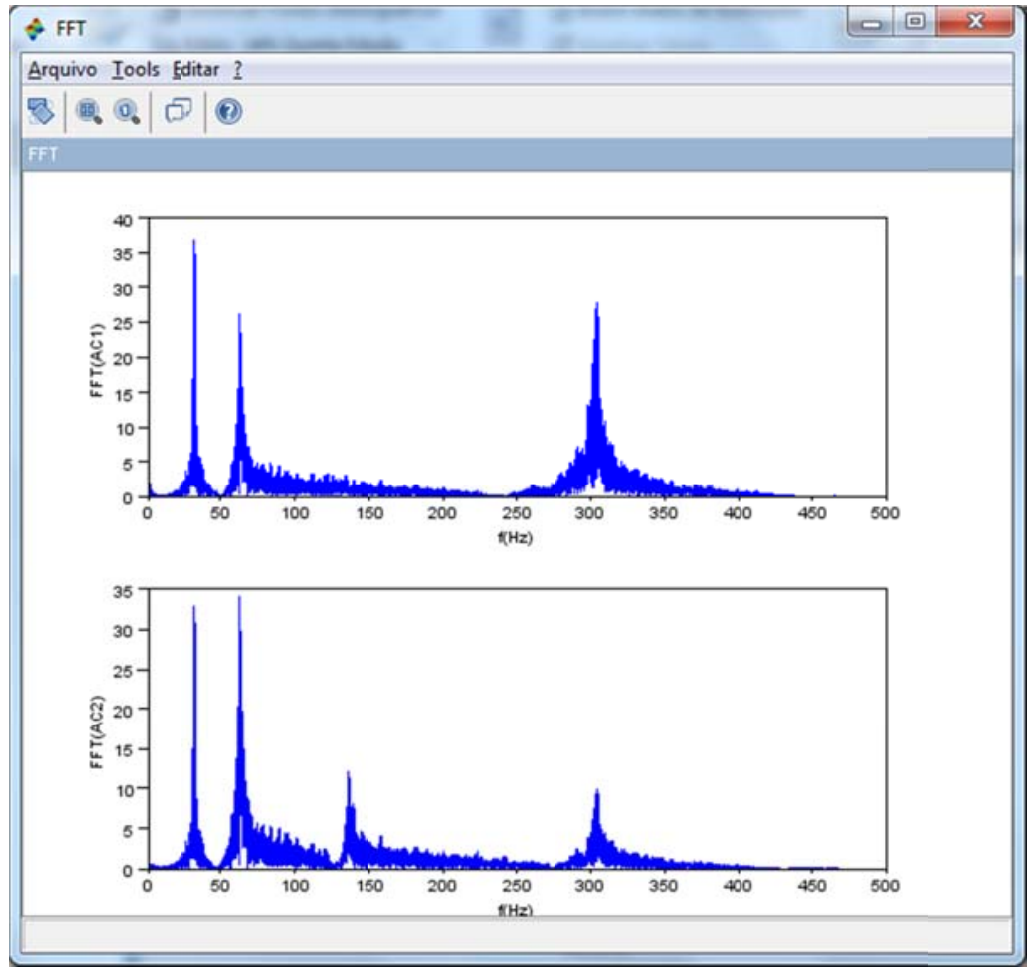

Figura 7.97 - Sinais dos acelerômetros fixo e móvel no domínio da frequência.

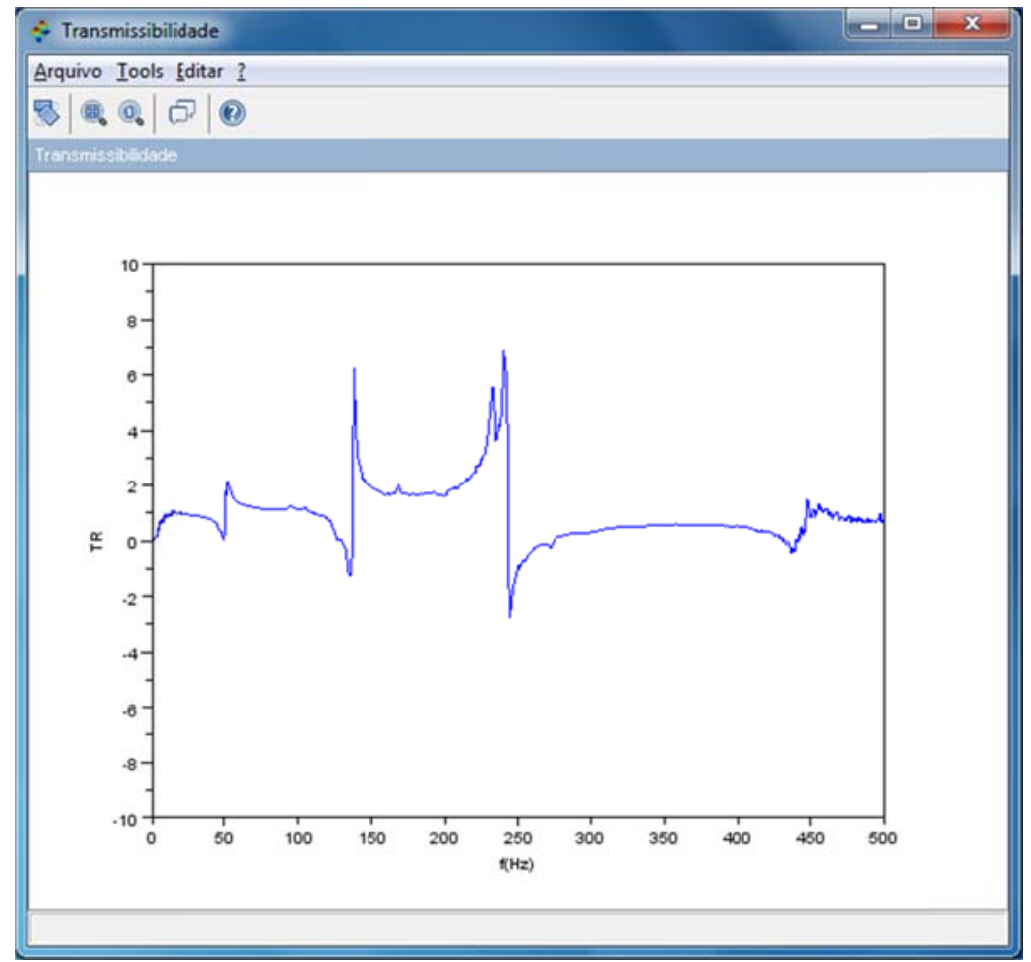

Figura 7.98 - Gráfico de transmissibilidade.

Na Figura 7.99, apresenta-se a FFT referente ao ensaio do pilar em que somente se consegue identificar uma frequência natural de $65 \mathrm{~Hz}$. As frequências identificadas nos 
ensaios dos pórticos estão reunidas na Tabela 7.8 que apresenta também a comparação das frequências antes e depois do reforço para os pórticos 1 e 2. Observa-se que o reforço promoveu um aumento da primeira frequência identificada de $13 \%$ no caso do Pórticol (em que o reforço foi executado em estrutura danificada) e de $43 \%$ no caso do Pórtico2 (em que se reforçou a estrutura íntegra).

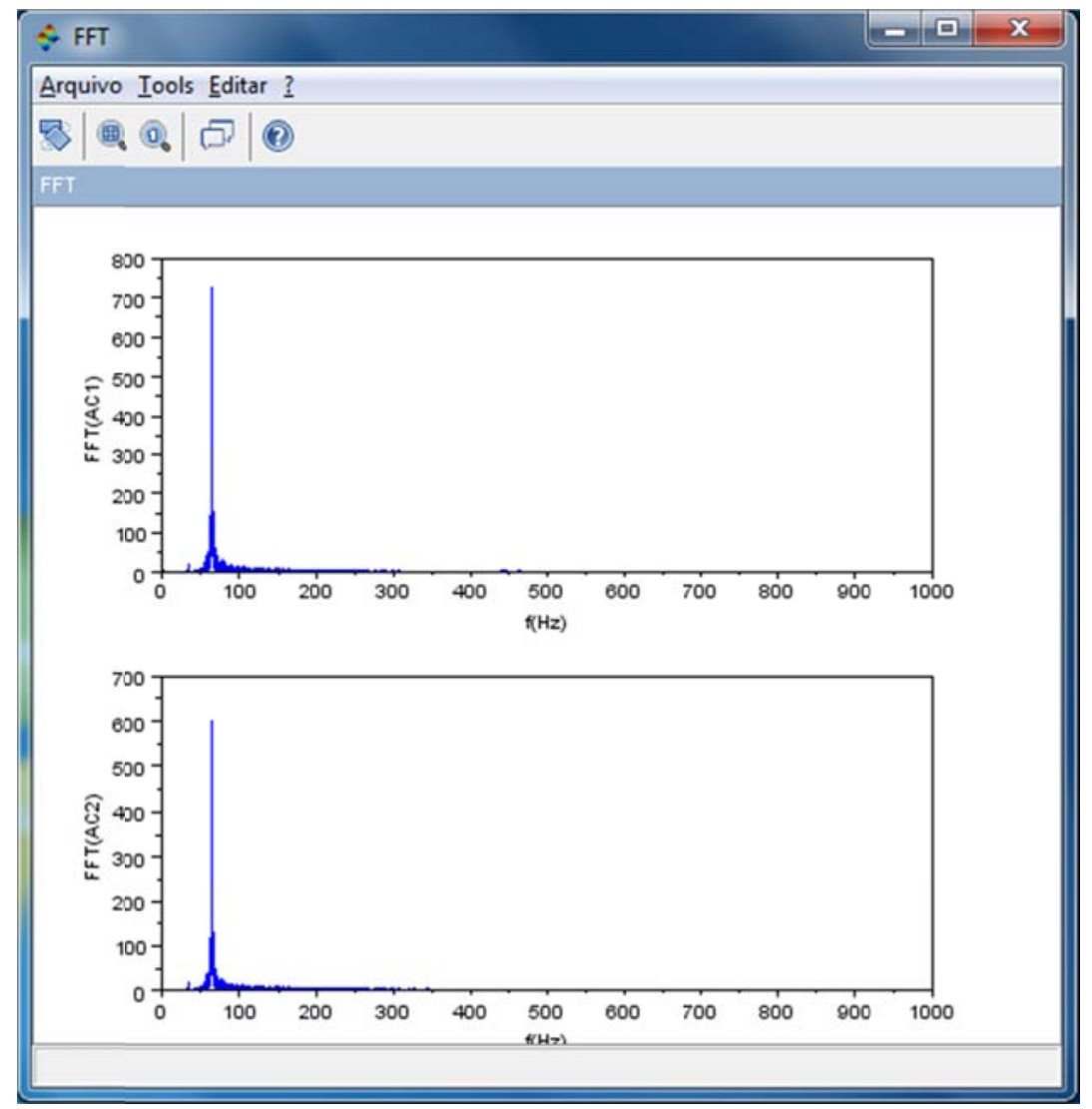

Figura 7.99 - FFTs referentes ao ensaio do pilar.

Tabela 7.8 - Frequências naturais identificadas experimentalmente.

\begin{tabular}{|c|c|c|c|c|c|c|c|}
\hline \multirow[b]{2}{*}{ Modo } & \multicolumn{7}{|c|}{ Frequência $(\mathrm{Hz})$} \\
\hline & Pórtico1_a & Pórtico1_b & $\Delta(\%)$ & Pórtico2_a & Pórtico2_b & $\Delta(\%)$ & Pórtico3 \\
\hline 1 & 46 & 52 & 13 & 41 & 58 & 43 & 58 \\
\hline 2 & 113 & 117 & 4 & 103 & 115 & 12 & 115 \\
\hline 3 & 145 & 159 & 10 & 150 & 158 & 5 & 180 \\
\hline 4 & 218 & 228 & 5 & 202 & 231 & 15 & 244 \\
\hline 5 & 289 & 341 & 20 & 235 & 367 & 56 & 343 \\
\hline
\end{tabular}


As Figura 7.100, Figura 7.101 e Figura 7.102 ilustram os deslocamentos modais dos pontos de medição para os três primeiros modos identificados no ensaio da viga. O primeiro modo se caracteriza por um ventre com deslocamento máximo próximo ao meio vão da viga. O segundo modo sugere um movimento com nó central e deslocamentos máximos nas extremidades. No terceiro modo, há aparentemente dois nós e o deslocamento máximo ocorre a meio vão da viga. A análise dos modos de vibrar relacionados às frequências identificadas foi feita para todos os ensaios. Seus resultados são apresentados e discutidos no Item 7.11, que trata da simulação numérica dos ensaios dinâmicos.

\section{Modo 1}

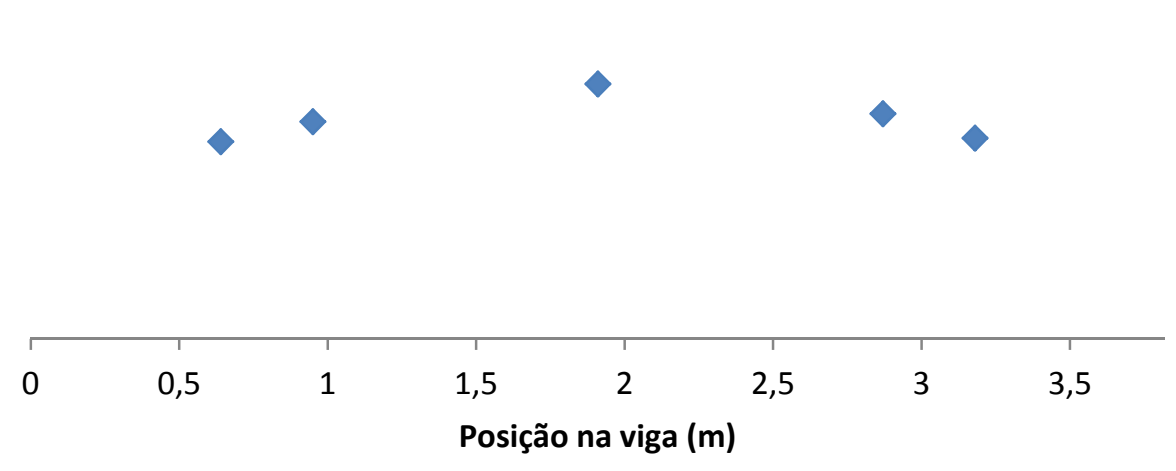

Figura 7.100 - Modo correspondente à primeira frequência natural identificada.

\section{Modo 2}

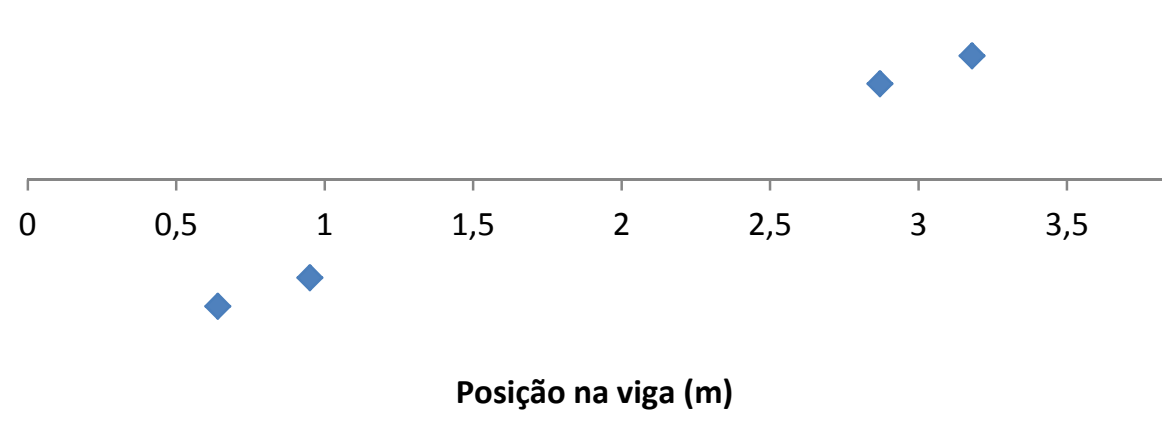

Figura 7.101 - Modo correspondente à segunda frequência natural identificada. 


\section{Modo 3}

\begin{tabular}{lllllll}
\hline 0,5 & 1 & 1,5 & 2 & 2,5 & 3 & 3,5 \\
& \\
& Posição na viga (m)
\end{tabular}

Figura 7.102 - Modo correspondente à terceira frequência natural identificada.

\subsection{Simulação numérica do ensaio dinâmico}

Realizaram-se simulações dos ensaios dinâmicos com uso do programa SAP2000. O principal intuito das simulações foi obter de forma indireta as rigidezes da ligação como em Nobrega (2004). O primeiro ensaio que se buscou reproduzir foi o do pilar, pois determinando-se as rigidezes da base do pilar, diminuiriam as variáveis na simulação dos modelos de pórtico. O pilar foi representado por 10 elementos finitos de barra com $10 \mathrm{~cm}$ de comprimento cada. Na base, simularam-se apoios elásticos por meio do recurso spring (Figura 7.103). Adotou-se o peso específico de $25 \mathrm{kN} / \mathrm{m}^{3}$ para o concreto e para seu módulo de elasticidade dinâmico o valor determinado experimentalmente de 43,61 GPa. Variaram-se as rigidezes da base e executou-se análise modal até que se coincidiu a primeira frequência natural numérica com aquela obtida experimentalmente $(65 \mathrm{~Hz})$. Traçaram-se os modos de vibrar correspondentes à essa frequência, numérico e experimental, a fim de confirmar que o modelo numérico representava o modelo físico, o que de fato se se comprova na Figura 7.103. As rigidezes na base tangencial, normal e rotacional que conduziram ao melhor ajuste do modelo foram: $\mathrm{Kt}=175000 \mathrm{kN} / \mathrm{m} ; \mathrm{Kn}=369000 \mathrm{kN} / \mathrm{m}$ e K $\phi=18500 \mathrm{kN} . \mathrm{m} / \mathrm{rad}$. 


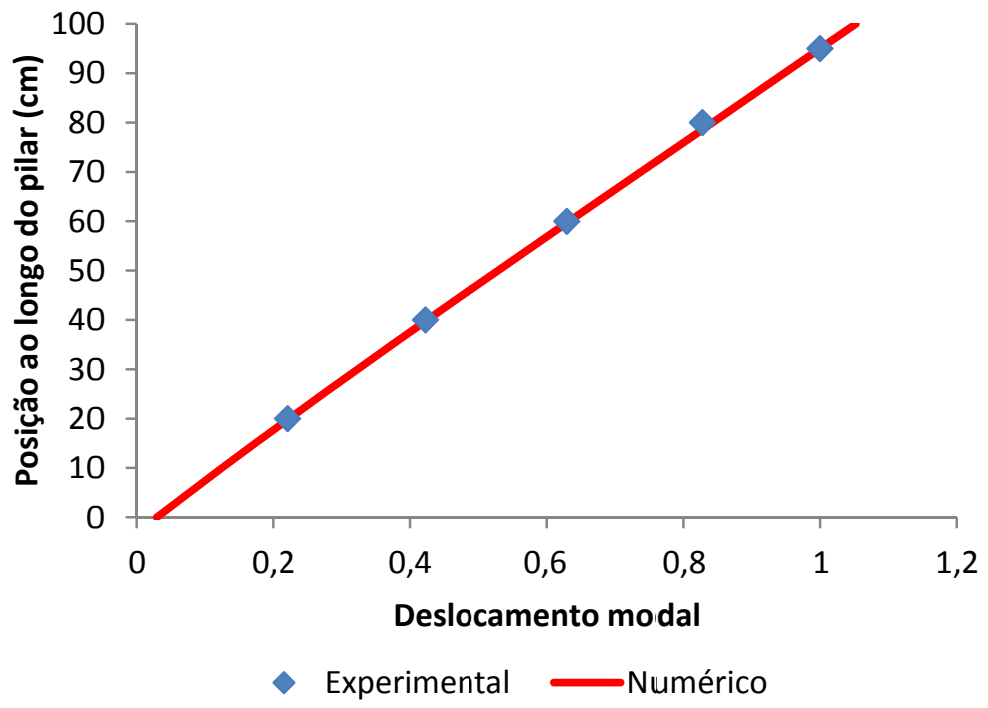

Figura 7.103 - Modelo numérico do pilar, à esquerda; modos de vibrar, numérico e experimental, correspondentes à primeira frequência natural identificada experimentalmente, à direita.

Na simulação do ensaio da viga, o modelo físico foi representado por um elemento de barra com 4 metros de comprimento dividido em 40 elementos finitos. Os apoios foram posicionados a 10 centímetros de cada extremidade (Figura 7.104). Num primeiro momento, admitiu-se uma condição ideal de apoios simples de modo que em um dos apoios restringiu-se os deslocamentos verticais e horizontais e no segundo apenas na direção vertical. Não se obteve uma boa correlação entre o ensaio experimental e numérico para essa condição assim decidiu-se adotar apoios elásticos por meio do recurso spring. Variou-se a rigidez do apoio elástico até que se obteve uma boa aproximação para os três primeiros modos. Na Tabela 7.9, observam-se os valores das frequências naturais correspondentes aos três primeiros modos obtidos experimentalmente e numericamente. Na Figura 7.109, Figura 7.110 e Figura 7.111 percebe-se que os modos de vibrar foram bem representados. 
Tabela 7.9 - Comparação dos valores das frequências naturais obtidas experimentalmente e por simulação numérica.

\begin{tabular}{|c|c|c|c|}
\hline \multirow{2}{*}{ Modo } & \multicolumn{2}{|c|}{ Frequência (Hz) } & \multirow{2}{*}{$\begin{array}{c}\text { Diferença } \\
(\%)\end{array}$} \\
\hline & Experimental & Numérico & \\
\hline 1 & 32,5 & 32,6 & 0,3 \\
\hline 2 & 64 & 64,2 & 0,2 \\
\hline 3 & 136,5 & 127,9 & 6,7 \\
\hline
\end{tabular}

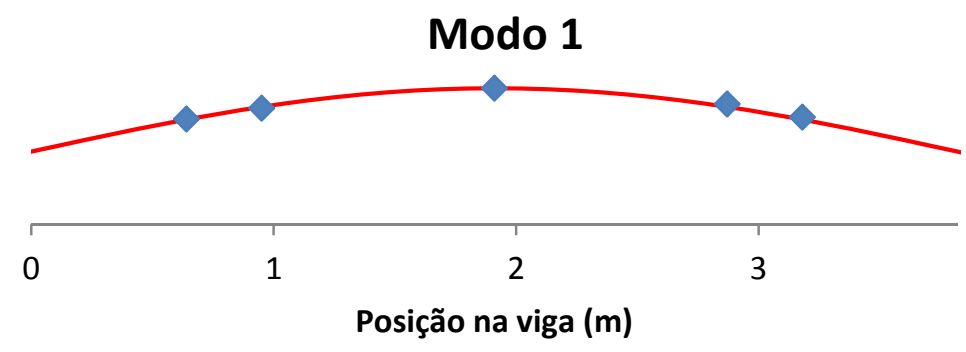

$\rightarrow$ Experimental — Numérico

Figura 7.105 - Modos experimental e numérico correspondentes à primeira frequência natural identificada.

\section{Modo 2}

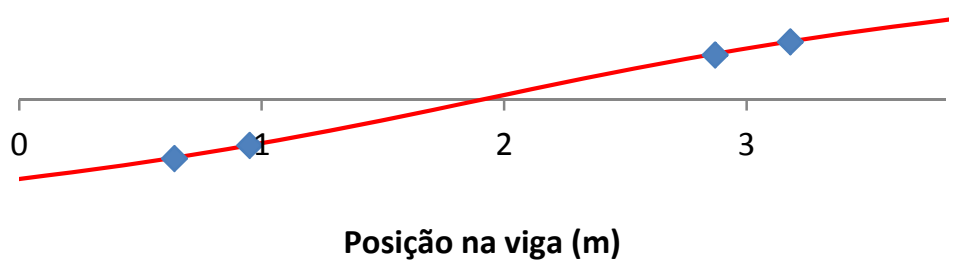

$\rightarrow$ Experimental — Numérico

Figura 7.106 - Modos experimental e numérico correspondentes à segunda frequência natural identificada.

\section{Modo 3}

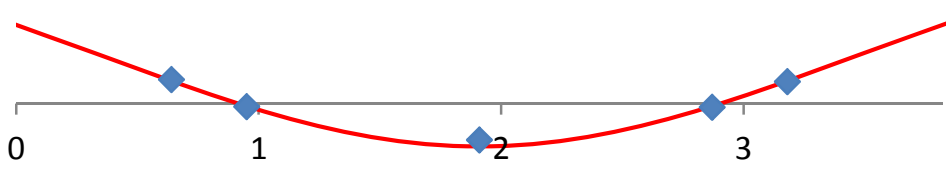

Posição na viga (m)

Experimental — Numérico

Figura 7.107 - Modos experimental e numérico correspondentes à terceira frequência natural identificada. 
$\mathrm{Na}$ simulação dos pórticos, viga e pilar foram representados por elementos de barra com comprimento de $80 \mathrm{~cm}$ e $400 \mathrm{~cm}$, respectivamente, divididos em elementos de $10 \mathrm{~cm}$ de comprimento. O consolo foi representado por uma barra com $20 \mathrm{~cm}$ de comprimento. No nó final do primeiro elemento da viga e no nó inicial do último elemento da viga, simularam-se ligações semirrígidas por meio do recurso release partial fixity. Adotaram-se para as rigidezes das bases dos pilares os valores obtidos por meio da simulação do ensaio do pilar e variaramse as rigidezes nas ligações buscando-se reproduzir o que foi observado experimentalmente. Os valores das rigidezes para os quais se obtiveram as melhores aproximações das frequências dos primeiros 5 modos identificados experimentalmente são apresentados na Tabela 7.10

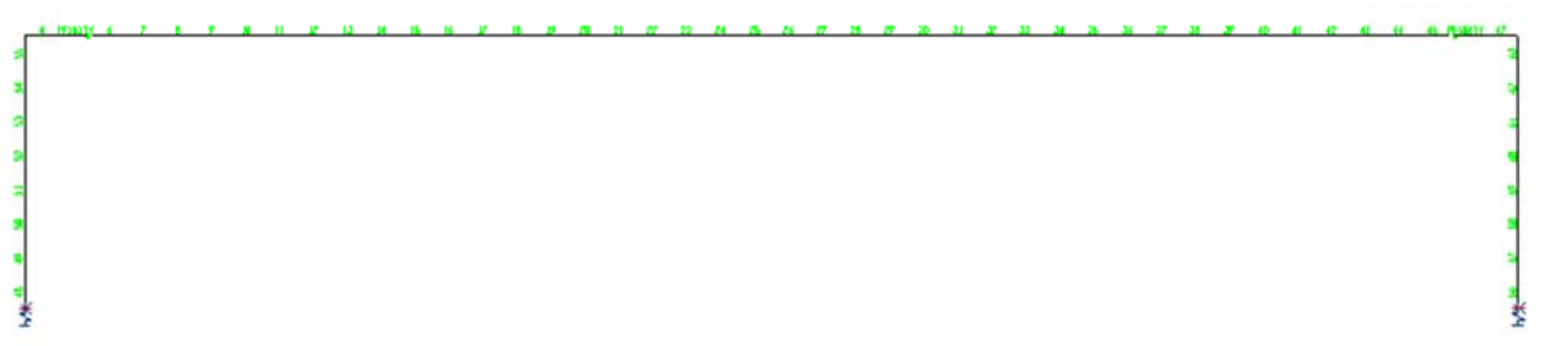

Figura 7.108 - Modelo numérico de pórtico.

Tabela 7.10 - Rigidezes de base e na ligação empregadas nos modelos numéricos.

\begin{tabular}{|c|c|c|c|c|c|}
\hline \multirow{2}{*}{ Modelo } & \multicolumn{3}{|c|}{ Rigidezes na base } & \multicolumn{2}{|c|}{ Rigidezes na ligação } \\
\hline & $\begin{array}{c}\text { Normal } \\
(\mathrm{kN} / \mathrm{m})\end{array}$ & $\begin{array}{c}\text { Tangencial } \\
(\mathrm{kN} / \mathrm{m})\end{array}$ & $\begin{array}{c}\text { Rotação } \\
(k N . m / r a d)\end{array}$ & $\begin{array}{l}\text { Normal } \\
(\mathrm{kN} / \mathrm{m})\end{array}$ & $\begin{array}{c}\text { Rotaçãoo } \\
(k N . m / r a d)\end{array}$ \\
\hline Viga & 26000 & Livre & Livre & - & - \\
\hline Pórtico1_a & 369000 & 175000 & 18500 & 165000 & 42 \\
\hline Pórtico2_a & 369000 & 175000 & 18500 & 165000 & 42 \\
\hline Pórtico2_b & 369000 & 175000 & 18500 & 500000 & 250000 \\
\hline Pórtico3 & 369000 & 175000 & 18500 & 500000 & 250000 \\
\hline
\end{tabular}

$\mathrm{Na}$ Tabela 7.11, reúnem-se os valores das frequências naturais determinadas experimentalmente e por meio de simulação numérica. A validade do modelo numérico é comprovada pela boa aproximação das formas modais apresentadas pela viga para os cinco 
primeiros modos no ensaio do Pórtico2_a (Figura 7.109 a Figura 7.113) e Pórtico2_b (Figura

\subsection{4 a Figura 7.118).}

Tabela 7.11 - Comparação entre as frequências naturais dos cinco primeiros modos determinadas de forma experimental e por simulação numérica

\begin{tabular}{|c|c|c|c|c|c|c|c|c|c|c|c|c|}
\hline \multirow[b]{2}{*}{ Modo } & \multicolumn{3}{|c|}{ Pórtico1_a } & \multicolumn{3}{|c|}{ Pórtico2_a } & \multicolumn{3}{|c|}{ Pórtico2_b } & \multicolumn{3}{|c|}{ Pórtico3 } \\
\hline & Exp. & Num. & $\begin{array}{c}\Delta \\
(\%)\end{array}$ & Exp. & Num. & $\begin{array}{c}\Delta \\
(\%)\end{array}$ & Exp. & Num. & $\begin{array}{c}\Delta \\
(\%)\end{array}$ & Exp. & Num. & $\begin{array}{c}\Delta \\
(\%)\end{array}$ \\
\hline 1 & 46 & 41 & -11 & 41 & 41 & -1 & 58 & 53 & -10 & 58 & 53 & -9 \\
\hline 2 & 113 & 110 & -3 & 103 & 110 & 6 & 115 & 125 & 9 & 115 & 125 & 9 \\
\hline 3 & 145 & 163 & 13 & 150 & 163 & 9 & 158 & 185 & 17 & 180 & 185 & 3 \\
\hline 4 & 217 & 234 & 8 & 202 & 234 & 16 & 231 & 243 & 5 & 244 & 243 & -1 \\
\hline 5 & 284 & 266 & -6 & 235 & 266 & 13 & 367 & 303 & -18 & 343 & 303 & -12 \\
\hline
\end{tabular}

\section{Modo 1}

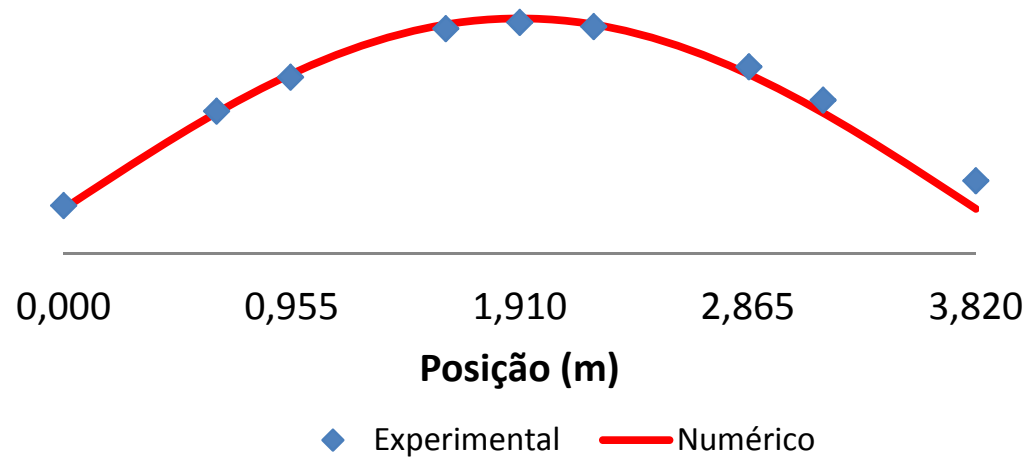

Figura 7.109 - Modos experimental e numérico correspondentes à primeira frequência natural identificada experimentalmente no ensaio do Pórtico2_a.

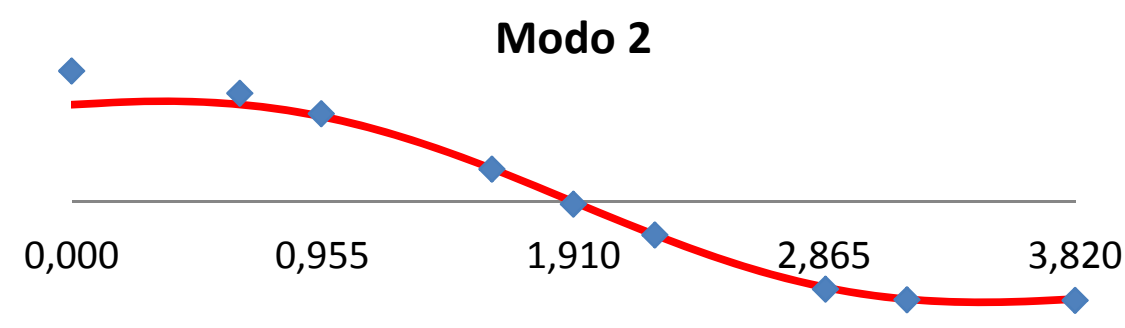

\section{Posição (m)}

$\rightarrow$ Experimental $\longrightarrow$ Numérico

Figura 7.110 - Modos experimental e numérico correspondentes à segunda frequência natural identificada experimentalmente no ensaio do Pórtico2_a. 


\section{Modo 3}

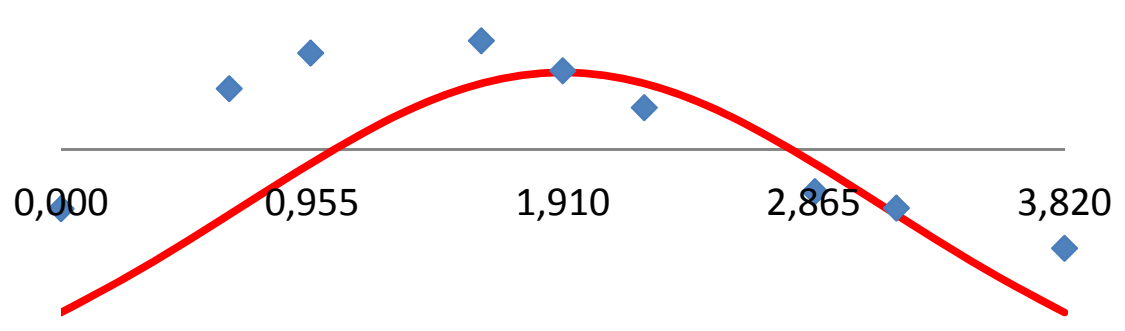

Posição (m)

Experimental — Numérico

Figura 7.111 - Modos experimental e numérico correspondentes à terceira frequência natural identificada experimentalmente no ensaio do Pórtico2_a.

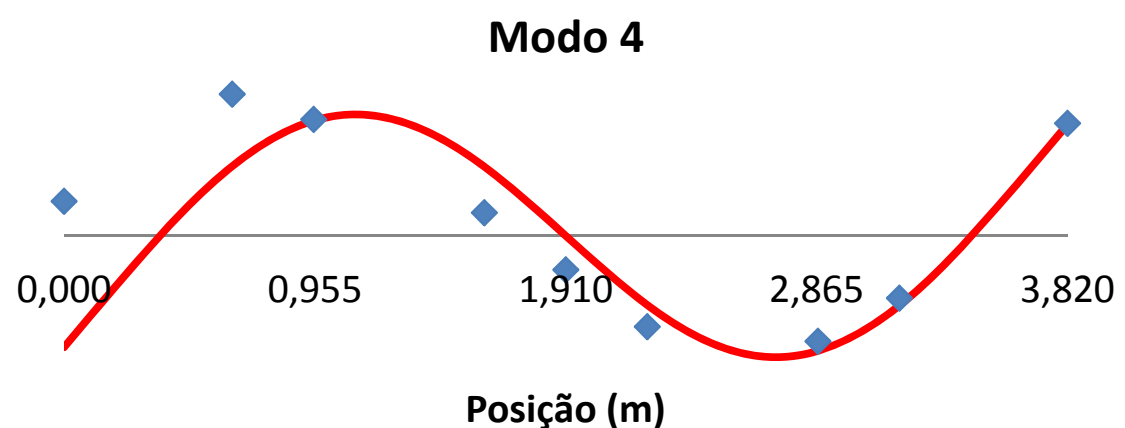

- Experimental — Numérico

Figura 7.112 - Modos experimental e numérico correspondentes à quarta frequência natural identificada experimentalmente no ensaio do Pórtico2_a.

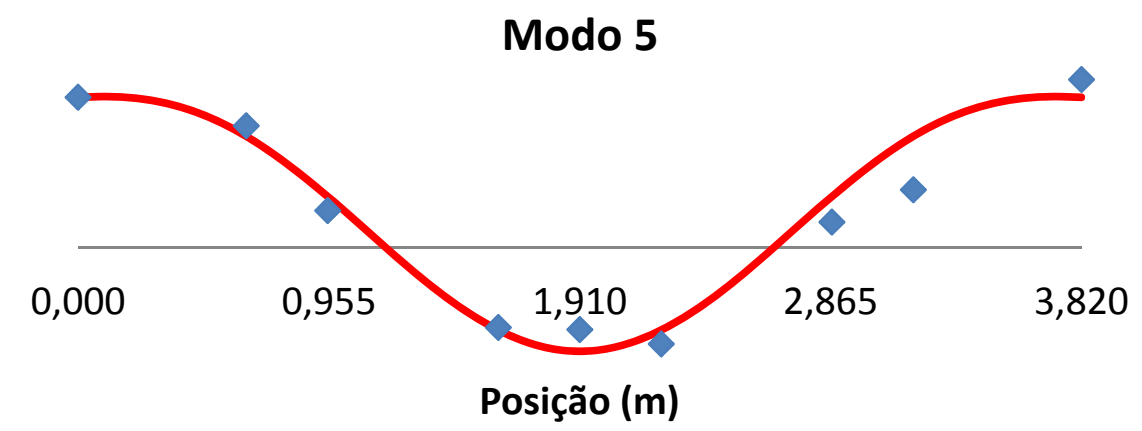

$\checkmark$ Experimental $\longrightarrow$ Numérico

Figura 7.113 - Modos experimental e numérico correspondentes à quinta frequência natural identificada experimentalmente no ensaio do Pórtico2_a. 


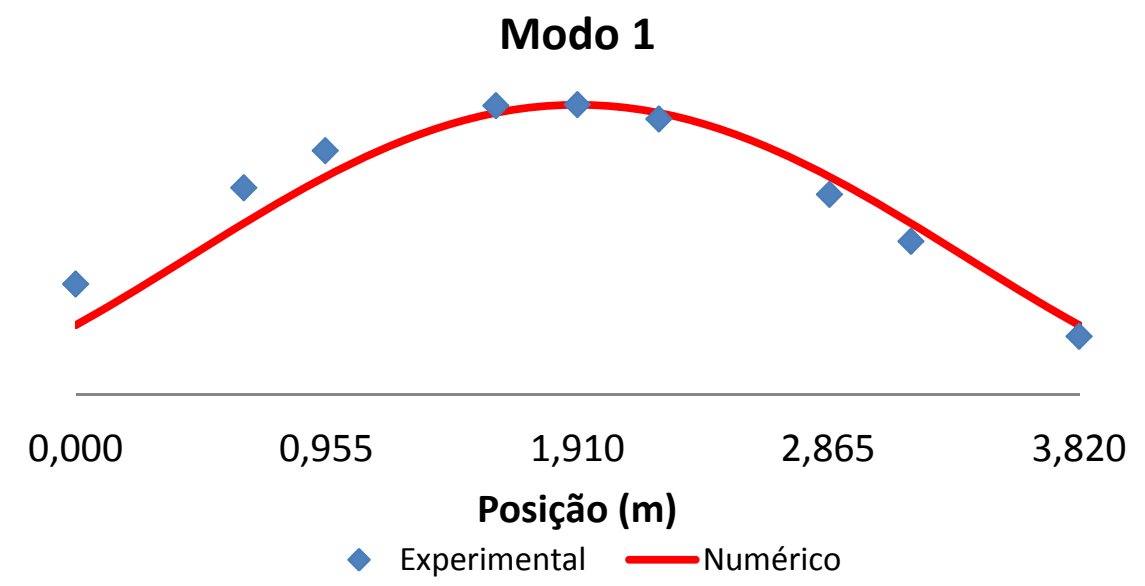

Figura 7.114 - Modos experimental e numérico correspondentes à primeira frequência natural identificada experimentalmente no ensaio do Pórtico2_b.

Modo 2

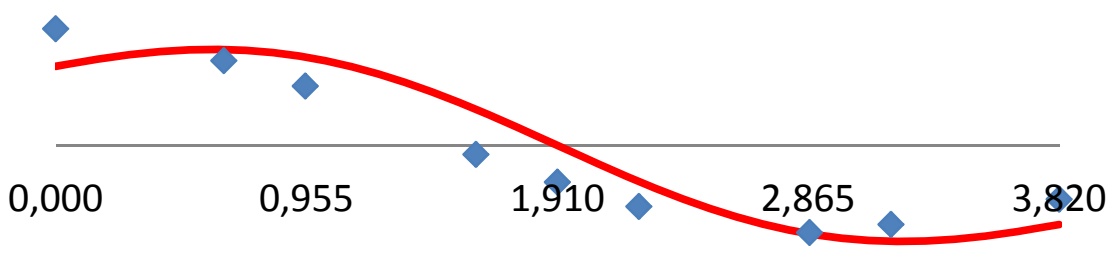

Posição (m)

Experimental $\longrightarrow$ Numérico

Figura 7.115 - Modos experimental e numérico correspondentes à segunda frequência natural identificada experimentalmente no ensaio do Pórtico2_b.

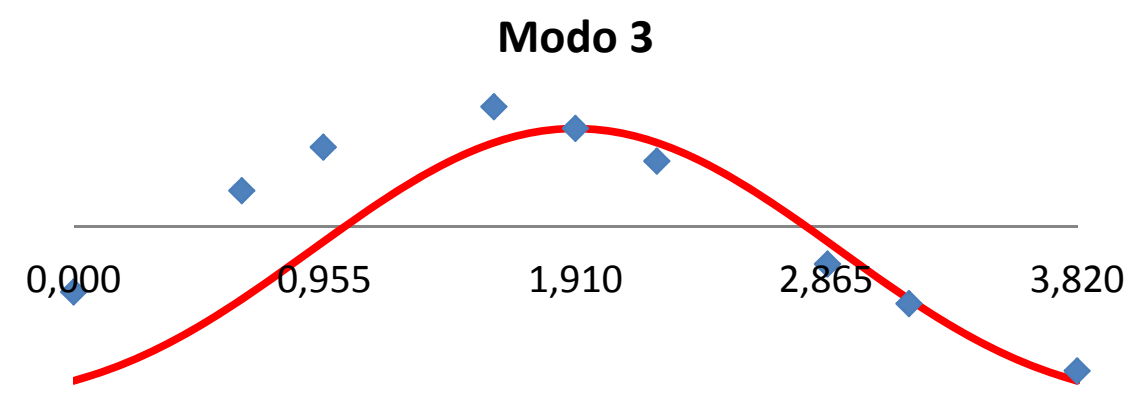

Posição (m)

$\rightarrow$ Experimental $\longrightarrow$ Numérico

Figura 7.116 - Modos experimental e numérico correspondentes à terceira frequência natural identificada experimentalmente no ensaio do Pórtico2_b. 


\section{Modo 4}

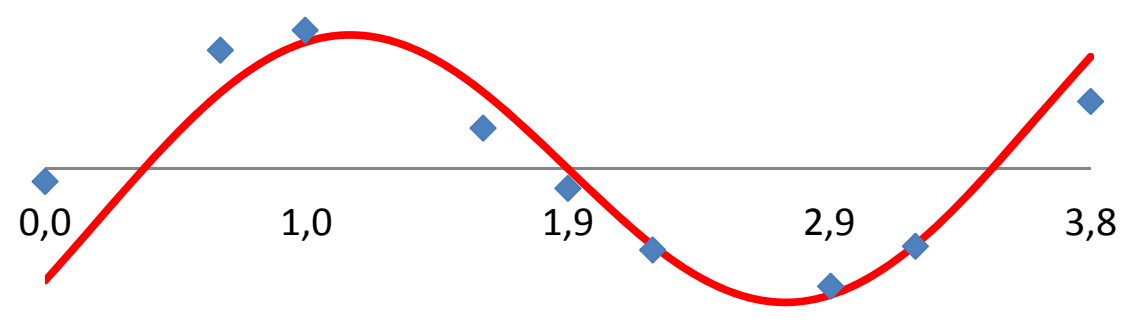

Posição (m)

Experimental $\longrightarrow$ Numérico

Figura 7.117 - Modos experimental e numérico correspondentes à quarta frequência natural identificada experimentalmente no ensaio do Pórtico2_b.

\section{Modo 5}

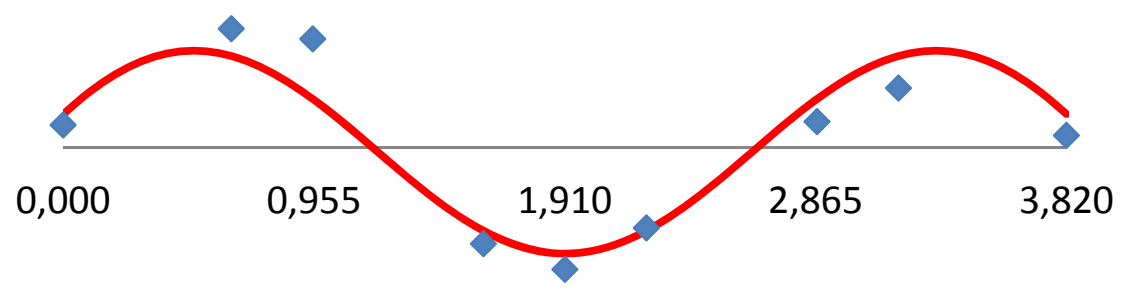

Posição (m)

$\rightarrow$ Experimental $\longrightarrow$ Numérico

Figura 7.118 - Modos experimental e numérico correspondentes à quinta frequência natural identificada experimentalmente no ensaio do Pórtico2_b.

\subsection{Conclusões}

Executaram-se ensaios experimentais em quatro modelos: uma viga e três pórticos que foram levados à ruptura. Na ruptura da viga verificou-se escoamento da armadura do tirante do dente e da suspensão. A força máxima suportada por este modelo foi inferior à estimada analiticamente. Supõe-se que imperfeições geométricas tenham ocasionado a concentração dos esforços em um dos lados de um dos apoios conduzindo à ruptura prematura. No Pórtico1, o modo de ruptura não ficou bem definido e o ensaio foi interrompido porque a imposição de deslocamento não resultava em aumento de força. No Pórtico2, observou-se o 
destacamento de uma porção de concreto no topo do pilar que continha os laminados inseridos, na região da ligação. Identificou-se o destacamento de uma parte do consolo em corte diagonal na ruptura do Pórtico3. A fissuração na região das ligações é um ponto negativo do reforço.

O reforço promoveu redução da solicitação das armaduras principais do dente e do consolo e o aumento da solicitação das armaduras do pilar e longitudinal superior da viga. A máxima deformação nos laminados foi de 6,9 \%o. Nos modelos reforçados, houve um melhor aproveitamento da capacidade resistente da viga e em todos os ensaios se identificou escoamento da armadura longitudinal da viga.

Pôde-se estimar a rigidez das ligações reforçadas por meio da análise da curva "momento x rotação" traçada com base nos resultados dos ensaios estáticos e indiretamente na simulação numérica dos ensaios dinâmicos. As rigidezes são apresentadas na Tabela 7.12 e embora elas não sejam idênticas considera-se satisfatório que elas tenham mesma ordem de grandeza.

Tabela 7.12 - Rigidezes a rotação obtidas no ensaio experimental e estático e na simulação do ensaio dinâmico.

\begin{tabular}{lcccc}
\hline \multirow{2}{*}{ Ensaio } & \multicolumn{4}{c}{ Rigidez_a rotação $(\boldsymbol{k N}$.m/rad) } \\
\cline { 2 - 5 } & Pórtico1_a & Pórtico2_a & Pórtico2_b & Pórtico3 \\
\hline Experimental estático & 955 & - & 62216 & 176581 \\
Numérico dinâmico & 42 & 42 & 250000 & 250000 \\
\hline
\end{tabular}

As simulações numéricas do ensaio dinâmico (com uso do SAP2000) e do ensaio estático (com uso do DIANA) demonstraram a necessidade de considerar a flexibilidade dos apoios para uma boa representação dos ensaios experimentais.

Elaborou-se um modelo numérico que representou satisfatoriamente o ensaio experimental estático principalmente em relação à resistência dos modelos físicos (Tabela 7.13). Apenas para a viga há maior diferença entre valores experimental e numérico, contudo julga-se que este modelo apresentou ruptura prematura como comentado anteriormente. Os 
resultados obtidos na simulação permitiram uma melhor visualização do processo de fissuração e um melhor entendimento da distribuição de tensões.

Tabela 7.13 - Força máxima nos ensaios experimentais e numéricos.

\begin{tabular}{lcccccccc}
\hline Modelo & \multicolumn{2}{c}{ Viga } & \multicolumn{2}{c}{ Pórtico1 } & \multicolumn{2}{c}{ Pórtico2 } & \multicolumn{2}{c}{ Pórtico3 } \\
\hline Ensaio & Exp. & Num. & Exp. & Num. & Exp. & Num. & Exp. & Num. \\
\hline Fmáx (kN) & 244 & 294 & 438 & 462 & 450 & 460 & 438 & 460 \\
\hline
\end{tabular}

No ajuste do modelo numérico, buscou-se reproduzir as mesmas frequências e modos observados experimentalmente. $\mathrm{O}$ reforço promoveu aumento na primeira frequência natural identificada experimentalmente de $13 \%$ para o Pórtico1 (previamente fissurado) e de $43 \%$ para o Pórtico2. 


\section{CAPÍTULO 8}

\section{CONCLUSÕES FINAIS}

Em relação à avaliação das resinas, conclui-se que os três tipos comparados apresentaram diferenças na trabalhabilidade, no modo de ruptura, na mobilização da capacidade resistente do laminado, no acabamento superficial e na homogeneidade do reforço.

Considerando-se o gráfico "tensão máxima de aderência x comprimento de ancoragem", verificou-se que uma diferença considerável na resistência de aderência foi observada apenas para os menores comprimentos aderidos. Para maiores comprimentos aderidos pode-se inferir um desempenho semelhante para os três tipos de resina utilizados.

A resina Sikadur ${ }^{\circledR}$ 330, embora não seja específica para colagem de laminados, apresentou desempenho quase tão bom quanto a Sikadur ${ }^{\circledR}$ 30. Para aplicação na colagem de entalhes no concreto de cobrimento lateral ou no banzo superior de peças estruturais, como utilizado nessa pesquisa, apresentou uma maior facilidade de emprego em função da sua consistência.

Em relação aos modelos reforçados, da ligação semirrígida e dos pórticos, conclui-se que o reforço foi eficiente no aumento de rigidez da ligação, promoveu redução nos deslocamentos verticais e aumento na resistência. 
Nos ensaios em pórticos pôde-se detectar que reforço promoveu redução da solicitação das armaduras principais do dente e do consolo e o aumento da solicitação das armaduras do pilar e longitudinal superior da viga. Nos modelos reforçados, houve um melhor aproveitamento da capacidade resistente da viga e em todos os ensaios dos houve escoamento da armadura longitudinal da viga. Contudo, há também o aspecto negativo da maior fissuração na região da ligação.

A análise numérica do ensaio-piloto foi útil na definição de diversos aspectos do modelo posteriormente usado para simulação dos ensaios principais como elementos finitos, tipo de análise e modelos constitutivos. O modelo constitutivo adotado para o concreto, Maekawa, permitiu a simulação do efeito da perda de rigidez do concreto com os ciclos de carregamento, que era fundamental para a representação do ensaio do Pórticol como foi realizado. A análise phased proporcionou que as deformações plásticas e a rigidez reduzida fossem consideradas como condições iniciais na fase 2 .

$\mathrm{Na}$ análise dos ensaios principais, as simulações numéricas do ensaio dinâmico (com uso do SAP2000) e do ensaio estático (com uso do DIANA) demonstraram a necessidade de considerar a flexibilidade dos apoios para uma boa representação dos ensaios experimentais. Elaborou-se um modelo numérico que representou satisfatoriamente o ensaio experimental estático principalmente em relação à resistência dos modelos físicos. A análise numérica confirmou a mudança na distribuição das tensões e permitiu uma maior compreensão de como essa alteração ocorre além de uma melhor visualização do processo de fissuração.

Nos ensaios principais, pôde-se estimar as rigidezes das ligações reforçadas por meio da análise da curva "momento x rotação" traçada com base nos resultados dos ensaios estáticos e indiretamente na simulação numérica dos ensaios dinâmicos. As rigidezes determinada pelos dois métodos apresentaram mesma ordem de grandeza. 
O reforço promoveu aumento na primeira frequência natural identificada experimentalmente de 13\% para o Pórtico1 (previamente fissurado) e de 43\% para o Pórtico2.

\subsection{Sugestão para trabalhos futuros}

- Avaliação das ligações reforçadas submetidas a ensaios cíclicos com inversão de momento.

- Estudo de dispositivos de ancoragem mecânica do laminado e do uso de protensão.

- Avaliação da combinação desta proposta de reforço com outras que minimizem a fissuração na região da ligação. 


\section{REFERÊNCIAS BIBLIOGRÁFICAS}

AMERICAN SOCIETY FOR TESTING AND MATERIALS. D 3039/D 3039M-08:

Standard test method for tensile properties of polymer matrix composite materials. West Conshohocken, PA, 2008.

ASSOCIAÇÃO BRASILEIRA DE NORMAS TÉCNICAS. NBR 5739: Concreto - Ensaio á compressão de corpos-de-prova cilíndricos. Rio de Janeiro, 1994.

ASSOCIAÇÃO BRASILEIRA DE NORMAS TÉCNICAS. NBR 6118: Projeto e execução de obras em concreto, Rio de Janeiro, 2003.

ASSOCIAÇÃO BRASILEIRA DE NORMAS TÉCNICAS. NBR 6152: Materiais metálicos Determinação das propriedades mecânicas à tração. Rio de Janeiro, 1992.

ASSOCIAÇÃO BRASILEIRA DE NORMAS TÉCNICAS. NBR 7222: Argamassas e concreto - Determinação da resistência à tração por compressão diametral de corpos-de-prova cilíndricos, Rio de Janeiro, 1994.

ASSOCIAÇÃO BRASILEIRA DE NORMAS TÉCNICAS. NBR 8522: Concreto Determinação dos módulos estáticos de elasticidade e de deformação e da curva tensão deformação. Rio de Janeiro, 2003

ALMEIDA, S. F. Análise experimental estática e dinâmica da rigidez de ligações de elementos pré-moldados de concreto sujeitas a danificação progressiva. Relatório Científico n² - FAPESP - Bolsa de Doutorado, São Carlos, 2007.

ALMEIDA, S. F. Análise experimental estática e dinâmica da rigidez de ligações vigapilar de concreto pré-moldado. 2010. Tese (Doutorado) - Escola de Engenharia de São Carlos, Universidade de São Paulo, São Carlos, 2010.

ARQUEZ, A. P. Aplicação de laminado de polímero reforçado com fibras de carbono (PRFC) inserido em substrato de microconcreto com fibras de aço para reforço à flexão de vigas de concreto armado. 2010. Dissertação (Mestrado), Escola de Engenharia de São Carlos, Universidade de São Paulo, São Carlos, 2010. 
AMERICAN CONCRETE INSTITUTE COMMITTEE 440. ACI 440.2R-08: Guide for the design and construction of externally bonded FRP systems for strengthening concrete structures. 2008.

BALDISSERA, A. Estudo experimental de uma ligação viga-pilar de concreto prémoldado parcialmente resistente a momento fletor. 2006. Dissertação (Mestrado), Escola de engenharia de São Carlos, Universidade de São Paulo, São Carlos, 2006.

BALLARIN, A.W. Desempenho das ligações de elementos estruturais pré-moldados de concreto. 1993. Dissertação (Mestrado), Escola de Engenharia de São Carlos, Universidade de São Paulo, São Carlos, 1993.

BARBOZA, A. S. R. Comportamento de juntas de argamassa solicitadas à compressão na ligação entre elementos pré-moldados. 2001. Tese (Doutorado), Escola de Engenharia de São Carlos, Universidade de São Paulo, São Carlos, 2001.

BARROS, J. et al. Análise experimental de pilares de betão armado reforçados com laminados de carbono sob acções cíclicas, em: Sísmica 2001, Ed. M. R. Fragoso, Horta, p. 491-503, 2001.

BARROS, J.A.O.; FERREIRA, D. R. S. M.; LOURENÇO, P. B. Comportamento de pilares de betão armado reforçados com laminados de fibras de carbono. Encontro Nacional de Betão Estrutural, 2000, FEUP, p. 393-402, Novembro, 2000.

BELLUCIO, E. K. Influência da rugosidade superficial e o uso de novos tipos de fibras em almofadas de argamassa para ligações de concreto pré-moldado. 2010. 106f. Dissertação (Mestrado) - Escola de Engenharia de São Carlos, Universidade de São Paulo, São Carlos, 2010.

BLASCHKO, M. Bond behavior of CFRP strips glued into slits, Proc. of 6th Int. Symposium on FRP Reinforcement for Concrete Structures (FRPRCS-6), K. H. Tan, ed., World Scientific, Singapore, 2003, pp. 205-214.

BLASCHKO M.; ZILCH, K. Rehabilitation of Concrete Structures with PRFC Strips Glued into Slits. Proceedings of the Twelfth International Conference on Composite Materials, Paris, 1999.

CANHA, R. M. F. Estudo teórico-experimental da ligação pilar-fundação por meio de cálice em estruturas de concreto pré-moldado. 2004. Tese (Doutorado), Escola de Engenharia de São Carlos, Universidade de São Paulo, São Carlos, 2004.

CASTRO, E. K. Reforço em Vigas “T” de Concreto Armado com Vários Tipos de Compósitos em Entalhes no Cobrimento de Concreto (CEC). 2005. Tese (Doutorado), Universidade de Brasília, Distrito Federal, 2005. 
CATOIA, B. Comportamento de vigas protendidas pré-moldadas com ligações semirígidas. Dissertação (Mestrado) - Universidade Federal de São Carlos, 2007.

COMITE EURO-INTERNATIONAL DU BETON. CEB-FIP Model Code for Concrete Structures. Paris, 1990.

CRUZ, J. M. S. Reforço de estruturas com laminados de CFRP inseridos no betão de recobrimento. 2004. Tese (Doutorado), Universidade do Minho, Guimarães, 2004.

DAVID, D. L. Análise teórica e experimental de conectores de cisalhamento e vigas mistas constituídas por perfis de aço formados a frio e laje de vigotas pré-moldadas. 2007. Tese (Doutorado), Escola de Engenharia de São Carlos, Universidade de São Paulo, São Carlos, 2007.

DE LORENZIS, L.; NANNI, A. Bond Between Near Surface Mounted FRP Rods and Concrete in Structural Strengthening. ACI Structures Journal, Vol. 99, No. 2, March-April 2002, pp. 123-133.

DE LORENZIS, L.; RIZZO, A.; AND LA TEGOLA, A. A modified pull-out test for bond of near-surface mounted FRP bars in concrete. Composites Part B: Engineering, Elsevier, V 33, No.8.

DE LORENZIS, L.; TENG, J. G. Near-surface mounted FRP reinforcement: An emerging technique for strengthening structures. Composites: Part B, 38, Available online 18 October 2006. Www.sciencedirect.com/locate/compositesb

DIANA. Finite Element Analysis: Users Manual release 9 - Element Library. Delft, Netherlands: TNO DIANA, 2005.

EBELING, E. B. Análise da base de pilares pré-moldados na ligação com cálice de fundação. 2006. Dissertação (Mestrado), Escola de Engenharia de São Carlos, Universidade de São Paulo, São Carlos, 2006.

EL DEBS, M. K. Concreto pré-moldado: fundamentos e aplicações. Escola de Engenharia de São Carlos, Universidade de São Paulo, São Carlos, 2000.

EUROCODE 3. Design of steel structures, part 1.8: design of joints. European committee for standardization, Brussels, 2003.

FARIAS, R. S. Estudo teórico-experimental do efeito da laje na transferência de forças em ligações viga-pilar misto preenchido. 2008. Dissertação (Mestrado), Escola de Engenharia de São Carlos, Universidade de São Paulo, São Carlos, 2008.

FEDERATION INTERNATIONALE DU BETON. FIB: Externally bonded FRP reinforcement for RC structures - Design and use of externally bonded fibre reinforced 
polymer reinforcement (FRP EBR) for reinforced concrete structures. CEB-FIP-grupo 9.3, Stuttgart, 2001.

FELBER, A.J. (1993). Development of a hybrid bridge evaluation system, $\mathrm{PhD}$ Thesis, Univ. of British. Columbia, Canada.

FERREIRA, M. A. Deformabilidade de ligações viga-pilar de concreto pré-moldado. 1999. Tese (Doutorado), Escola de Engenharia de São Carlos, Universidade de São Paulo, São Carlos. 1999.

FERREIRA, M. A; EL DEBS, M. K.; ELLIOTT, K. S. Modelo teórico para projeto de ligações semi-rígidas em estruturas de concreto pré-moldado. In: Congresso Brasileiro do Concreto, 44, 2002, Belo Horizonte. Anais. CD ROM.

FERREIRA, M. A. Estudo de deformabilidades de ligações para análise linear em pórticos planos de elementos pré-moldados de concreto. 1993. Dissertação (Mestrado), Escola de Engenharia de São Carlos, Universidade de São Paulo, São Carlos, 1993.

FONSECA, T. C. C. S. Reforço e incremento da rigidez à flexão de ligações viga-pilar de estruturas de concreto pré-moldado com polímero reforçado com fibra de carbono (PRFC). 2007. Dissertação (Mestrado), Escola de Engenharia de São Carlos, Universidade de São Paulo, São Carlos, 2007.

FORTES, A. S. Estruturas de concreto submetidas à flexão reforçadas com laminados de CFRP colados em entalhes. 2004. Tese (Doutorado), Universidade Federal de Santa Catarina, Florianópolis, 2004.

HASSAN, T.; RIZKALLA, S. F. Investigation of Bond in Concrete Structures Strengthened with Near Surface Mounted Carbon Fiber Reinforced Polymer Strips. Journal of composites for construction, ASCE, august, 2003.

HELENE, P. R. L. Manual para Reparo, Reforço e Proteção de Estruturas de Concreto. PINI, São Paulo, 1992.

KANG, J. Y. et al. Analytical Evaluation of RC Beams Strengthened with Near Surface Mounted CFRP Laminates. In: 7th international symposium - Fiber-reinforced polymer reinforcement for concrete structures (FRPRCS - 7), p.779-794, Kansas City, 2005. Proceedings. CD ROM.

MARIN, M. C.; El Debs, M. K. Análise do limite do número de pavimentos em estruturas usuais de múltiplos pavimentos em concreto pré-moldado. In: $2^{\circ}$ Encontro Nacional de Pesquisa-Projeto-Produção em Concreto Pré-Moldado. 2009, São Carlos. Anais. CD ROM.

METHA, P. K.; MONTEIRO, P. J. M. Concreto: estrutura, propriedades e materiais. São Paulo, Pini, 1994. 
MIOTTO, A. M. Ligações viga-pilar de estruturas de concreto pré-moldado: análise com ênfase na deformabilidade ao momento fletor. 2002. Tese (Doutorado), Escola de Engenharia de São Carlos, Universidade de São Paulo, São Carlos. 2002.

MONTEDOR, L.C. (2004). Desenvolvimento de compósito a ser utilizado como almofada de apoio nas ligações entre elementos pré-moldados. 144p. Dissertação (Mestrado) Escola de Engenharia de São Carlos, Universidade de São Paulo, São Carlos, 2004.

NÓBREGA, P. G. B. Análise dinâmica de estruturas de concreto: estudo experimental e numérico das condições de contorno de estruturas pré-moldadas. 2004. Tese (Doutorado), Escola de Engenharia de São Carlos, Universidade de São Paulo, São Carlos, 2004.

PAGNUSSAT, R. (2011). Análise numérica do comportamento de blocos sobre quatro estacas com cálice parcialmente embutido - Estudos de casos reais. Dissertação (Mestrado) - Escola de Engenharia de São Carlos, Universidade de São Paulo, São Carlos.

PANTELIDES, C. P. et al. Seismic retrofit of precast concrete panel connections with carbon fiber reinforced polymer composites. PCI Journal, v. 48, n. 1, p. 92-104, Jan./Feb., 2003.

RILEM-FIP-CEB. Bond test for reinforcing steel: 1-Beam test (7-II-28 D). RILEM Journal Materials and Structures, v. 6, n. 32, Mar./Apr., p. 96-105, 1973.

RODRIGUES, L. F. Juntas em pavimentos de concreto: dispositivos de transferência de carga. 2008. Tese (Doutorado) - Escola de Engenharia de São Carlos, Universidade de São Paulo, São Carlos, 2008.

SHIELD, C. et al. The effect of adhesive type on the bond of NSM tape to concrete. In: 7th international symposium - Fiber-reinforced polymer reinforcement for concrete structures (FRPRCS - 7), p.355-372, Kansas City, 2005. Proceedings. CD ROM.

SILVA, K. C. Estudo experimental de uma emenda de barra para concreto armado com tubo de aço e graute. 2008. Dissertação (Mestrado), Escola de Engenharia de São Carlos, Universidade de São Paulo, São Carlos, 2008.

SIQUEIRA, G. H. Almofada de apoio de compósito de cimento para ligações em concreto pré-moldado. 2007. Dissertação (Mestrado), Escola de Engenharia de São Carlos, Universidade de São Paulo, São Carlos, 2007.

SOARES, A. M. M. Análise estrutural de pórticos planos de elementos pré-fabricados de concreto considerando a deformabilidade das ligações. 1998. Dissertação (Mestrado), Escola de Engenharia de São Carlos, Universidade de São Paulo, São Carlos. 1998. 